\title{
FORMAS QUÍMICAS NO SOLO E DISPONIBILIDADE DE MICRONUTRIENTES À SOJA EM SISTEMA DE SEMEADURA DIRETA
}

\author{
SILVINO GUIMARÃES MOREIRA \\ Engenheiro Agrônomo
}

\section{Orientador: Prof. Dr. LUÍS IGNÁCIO PROCHNOW}

Tese apresentada à Escola Superior de Agricultura "Luiz de Queiroz", Universidade de São Paulo, para obtenção do título de Doutor em Agronomia, Área de concentração: Solos e Nutrição de Plantas.

PIRACICABA

Estado de São Paulo - Brasil

Janeiro - 2003 


\section{Dados Internacionais de Catalogação na Publicação (CIP) DIVISÃO DE BIBLIOTECA E DOCUMENTAÇÃO - ESALQ/USP}

Moreira, Silvino Guimarazes

Formas químicas no solo e disponibilidade de micronutrientes à soja em sistema de semeadura direta / Silvino Guimaraes Moreira. - - Piracicaba, 2003.

$149 \mathrm{p}$.

Tese (doutorado) - Escola Superior de Agricultura Luiz de Queiroz, 2003. Bibliografia.

1. Cobre 2. Manganês 3. Matéria orgánica 4. Plantio direto 5. Química do solo 6. Sola 7. Zinco I. Título

$\operatorname{CDD} 633.34$

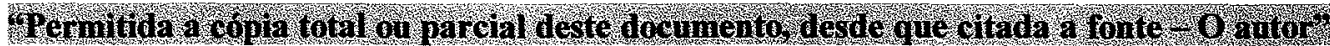


À minha mãe, Espedita, e ao meu pai, Antônio, pelo amor e carinho.

Às minhas irmãs, Edna, Claudia e Dayane, pelo carinho, apoio e confiança.

Ao meu irmão, Silvânio, pelo apoio constante e irrestrito à nossa família, quando estive ausente.

OFEREÇO.

À Minha namorada, Rosangela, pela presença, incentivo, paciência, carinho e compreensão, que possibilitaram nossa vitória em mais uma etapa. 


\section{AGRADECIMENTOS}

A Deus, por estar sempre presente na minha vida, em todos os momentos;

Aos Prof. Dr. Luís Ignácio Prochnow e Jorge de Castro Kiehl, pela amizade, confiança, orientação e apoio durante todo o tempo;

Ao Dr. Ladislau Martin Neto, da EMBRAPA-CNPDIA, pelas sugestões no plano de pesquisa e apoio na realização das análises por ressonância paramagnética eletrônica;

Ao Pesquisador Volnei Pauletti, da Fundação ABC, pela amizade e ajuda em todas as etapas da realização dos trabalhos de campo;

Aos pesquisadores da EMBRAPA-CNPDIA, Marcelo Luiz Simões e Wilson Tadeu Lopes da Silva, pelo grande apoio na realização e interpretação das análises por ressonância paramagnética eletrônica;

Ao Prof. Dr. Arquimedes Lavorenti, por ceder gentilmente seus laboratórios para execução das análises químicas;

Ao Prof. Dr. Quirino A. C. Carmello, pela colaboração na quantificação de metais por Espectroscopia de plasma;

Ao Prof. Dr. José Eduardo Corrente, pela ajuda na execução e interpretação das análises estatísticas; 
Às bibliotecárias Eliana M. Garcia e Silvia Zinsly pela correção das referências bibliográficas e normas da tese;

Ao Químico Luís Silva Júnior, do Departamento de Solos e Nutrição de Plantas da ESALQ/USP, pela colaboração na quantificação de metais em Espectroscopia de Absorção Atômica;

À Fundação $\mathrm{ABC}$ e todos os seus funcionários e estagiários, pela ajuda na execução do trabalho, em especial ao Técnico Agrícola Luís Carlos Costa, pela presteza e dedicação na execução dos trabalhos de campo;

Aos meus pais, Antônio Moreira e Espedita Luiz Moreira, ao meu irmão Silvânio e às minhas irmãs Edna, Cláudia e Dayane, pelo carinho e compreensão;

Ao grande amigo Eduardo Milton Albuquerque e à toda sua família, pela ajuda e incentivo durante toda a vida;

Aos companheiros do Curso de Pós Graduação em Solos e Nutrição de Plantas da ESALQ/USP, em especial a Edna Bertoncini, Thiago, Márcia Simonete, Cláudia Teixeira, Aderbal Rocha, Cristiano Andrade, Marcelo Alves, Ricardo Espíndola e Aline, pelos excelentes momentos compartilhados.

Aos amigos de república Jorge A. Guimarães e Miguel, pela boa convivência durante esses anos;

Aos grandes amigos Charles, Marina, Teresinha, Ranyse, pelos excelentes momentos compartilhados durante nossa estadia em Piracicaba;

À Coordenação do Curso de pós-graduação em Solos e Nutrição de Plantas e aos seus professores do curso, pelo apoio e à Fundação de Amparo à Pesquisa do Estado de São Paulo, pela concessão da bolsa de estudos. 


\section{LISTA DE ABREVIAÇÕES}

$\begin{array}{ll}\text { A } & \text { Interação hiperfina } \\ \text { AF } & \text { Ácido fúlvico } \\ \text { AH } & \text { Ácido húmico } \\ \text { CTC } & \text { Capacidade de troca de cátions } \\ \text { DTPA - TEA } & \text { Ácido dietileno-triamino-pentacético - trietanolamina } \\ \text { RPE } & \text { Ressonância paramagnética eletrônica } \\ \text { MO } & \text { Matéria orgânica } \\ \text { mT } & \text { mili Tesla } \\ \text { PM } & \text { Preparo mínimo } \\ \text { RMN } & \text { Ressonância magnética nuclear } \\ \text { SB } & \text { Soma de bases } \\ \text { SH } & \text { Substâncias húmicas } \\ \text { SSD } & \text { Sistema de semeadura direta } \\ \text { SSC } & \text { Sistema de semeadura convencional } \\ \text { V\% } & \text { Saturação por bases }\end{array}$


LISTA DE ABREVIATURAS ................................................................ ix

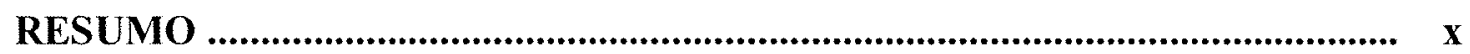

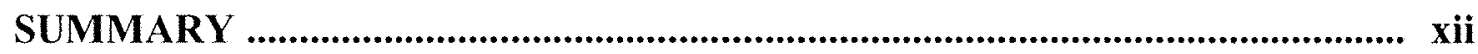

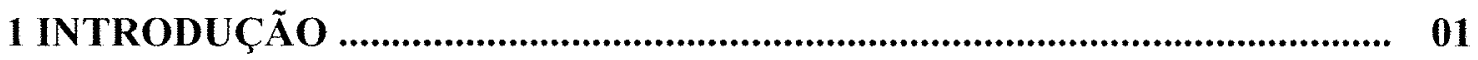

2 REVISÃO DE LITERATURA …................................................................ 04

2.1 Disponibilidade de micronutrientes ............................................................... 04

2.2 Avaliação da disponibilidade de micronutrientes com extratores

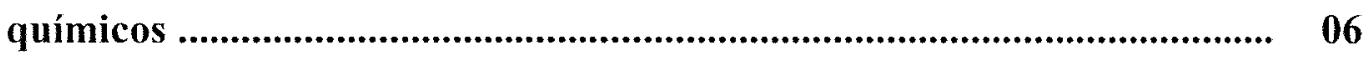

2.3 Fracionamento químico de micronutrientes............................................... 12

2.4 Matéria orgânica do solo .......................................................................... 17

2.5 Avaliação das substâncias húmicas e de micronutrientes do solo através de técnicas espectroscópicas ....................................................................... 19

3 MATERIAL E MÉTODOS ...................................................................... 22

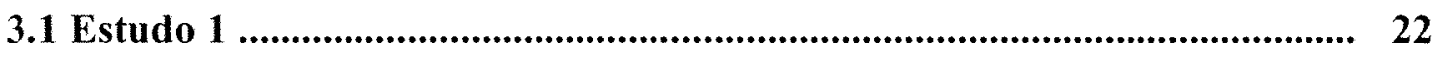

3.1.1 Hipóteses ....................................................................................................... 22

3.1.2 Caracterização da área experimental ............................................... 22

3.1.3 Delineamento experimental e características das parcelas ................ 25

3.1.4 Condução do experimento no campo ...................................................... 26

3.1.5 Coleta e preparo das amostras de terra e folha ..................................... 27

3.1.6 Digestão e quantificação de nutrientes nas folhas ................................ 28

3.1.7 Análises químicas de terra ...................................................................... 28

3.1.8 Extração e purificação dos ácidos húmicos dos solos .......................... 31

3.1.9 Análises espectroscópicas ........................................................................... 33 


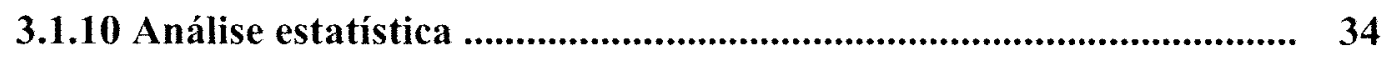

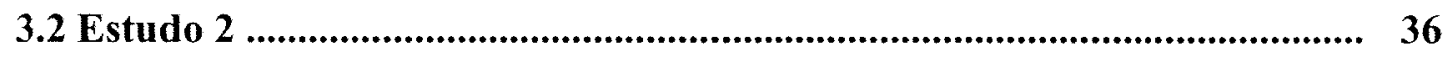

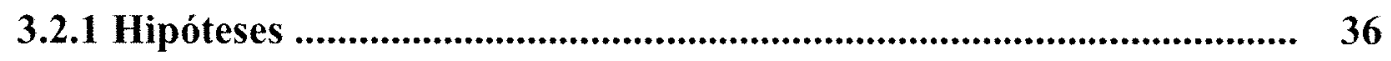

3.2.2 Caracterização da área experimental ............................................ 36

3.2.3 Condução do experimento no campo ................................................. 39

3.2.4 Coleta e preparo das amostras de terra e folha .................................. 41

3.2.5 Análise estatistica............................................................................ 42

4 RESULTADOS E DISCUSSÃO................................................................... 43

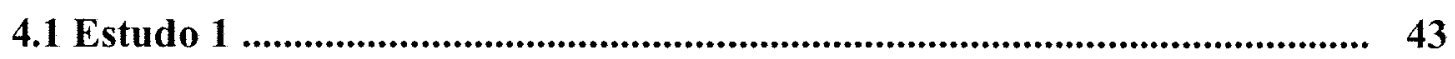

4.1.1 Atributos químicos do solo ..................................................................... 43

4.1.2 Substâncias húmicas no solo .............................................................. 49

4.1.3 Micronutrientes no solo ....................................................................... 51

4.1.3.1 Cobre no solo ........................................................................... 51

4.1.3.2 Ferro no solo ......................................................................... 56

4.1.3.3 Zinco no solo ............................................................................... 59

4.1.3.4 Manganês no solo ......................................................................... 64

4.1.4 Avaliação dos micronutrientes no solo por ressonância paramagnética eletrônica .......................................................................... $\quad 70$

4.1.5 Concentração de nutrientes nas folhas e quantidade acumulada na parte aérea das plantas ......................................................................... 77

4.1.6 Estudo de correlação para micronutrientes ........................................ 82

4.1.7 Produtividade de grãos de soja ....................................................... 89

4.1.8 Conclusões do Estudo 1 ..................................................................... 90

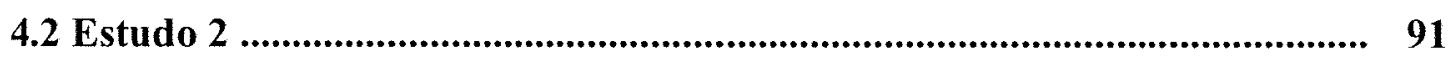

4.2.1 Extração seqüencial de micronutrientes nas amostras originais ...... 91

4.2.2 Teores e formas de Mn no solo, em função de doses de Mn no solo

4.2.3 Avaliação dos micronutrientes do solo por ressonância paramagnética eletrônica

4.2.4 Concentração e acúmulo de Mn na parte aérea das plantas, em 
função da aplicação de doses de Mn no solo ........................................ 112

4.2.5 Estudo de correlação para manganês ................................................... 114

4.2.6 Produtividade de soja, em função da aplicação de doses de Mn

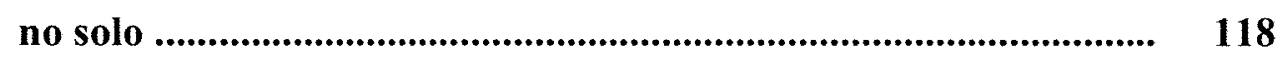

4.2.7 Conclusões do Estudo 2 2........................................................... 120

5 CONCLUS ÕES .................................................................................... 121

REFERÊNCIAS BIBLIOGRÁFICAS ...................................................... 122

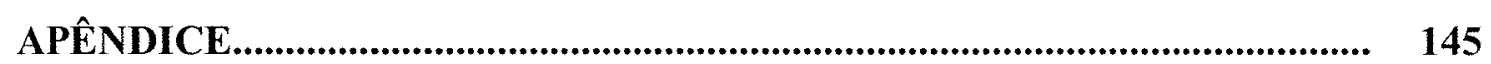




\title{
FORMAS QUÍMICAS NO SOLO E DISPONIBILIDADE DE MICRONUTRIENTES À SOJA EM SISTEMA DE SEMEADURA DIRETA
}

\author{
Autor: SILVINO GUIMARÃES MOREIRA \\ Orientador: Prof. Dr. LUÍS IGNÁCIO PROCHNOW
}

\section{RESUMO}

Com o objetivo principal de avaliar a disponibilidade de micronutrientes em solos cultivados sob sistema de semeadura direta (SSD) desenvolveram-se dois estudos ( 1 e 2), em condições de campo. O primeiro foi conduzido sobre um LATOSSOLO VERMELHO Distrófico de Ponta Grossa, PR, submetido há 12 anos sob diferentes métodos de preparo (SSD, sistema de semeadura convencional - SSC, preparo mínimo PM e SSD/escarificação a cada 3 anos). Desenvolveu-se o estudo 2, utilizando-se nove locais com e sem constatações de deficiências de Mn em soja, nos municípios de Tibagi, Ponta Grossa e Castro, PR. Em quatro locais, aplicaram-se doses de Mn, variando-se de 0 a $48 \mathrm{~kg} \mathrm{ha}^{-1}$. Nos dois estudos, avaliaram-se as disponibilidades de micronutrientes pelos extratores Mehlich I e III, $\mathrm{HCl} 0,1 \mathrm{~mol} \mathrm{~L}^{-1}$, DTPA-TEA a pH 7,3 e pela extração seqüencial de micronutrientes (formas trocável, orgânica, óxidos e residual), em amostras das camadas de 0,00-0,05, 0,05-0,10 e 0,10-0,20 m no caso do estudo 1 , e de 0,00-0,10 m, no estudo 2. Nas amostras das camadas de 0,00-0,05, 0,05-0,10 $\mathrm{m}$ do estudo 1 e de $0,00-0,10 \mathrm{~m}$ do estudo 2 foram extraídos os ácidos húmicos (AH), para se estudar as interações dos metais com os $\mathrm{AH}$, utilizando-se a ressonância paramagnética eletrônica (RPE). Nas amostras de folhas (estudo 1) e parte aérea das plantas (estudos 1 
e 2) determinaram-se os teores de macro e micronutrientes. No caso do estudo 1, os teores de Mn da camada de 0,00-0,05 m, extraídos por todos extratores, e das camadas de $0,05-0,10$ e $0,00-0,20 \mathrm{~m}$ (média dos extratores) do solo sob SSD foram maiores do que os do solo sob SSC. Fato semelhante foi observado para os teores de Zn da camada superficial (média dos extratores). A percentagem de Mn da fração orgânica (camada superficial) foi maior no SSD e SSD/preparo em relação ao SSC. A obtenção dos sinais de $\mathrm{Cu}$ e $\mathrm{Mn}$ nas amostras de $\mathrm{AH}$ foi impedida pelos altos teores de óxidos de Fe, mesmo após centrifugações em alta rotação para retirada dos óxidos de Fe. A produtividade de soja não foi modificada pelos métodos de preparo. No caso do estudo 2 , as doses de Mn geralmente elevaram os teores de Mn trocáveis dos solos, mas a concentração e a quantidade de Mn acumulada pelas plantas foram pouco afetadas. As formas de Mn trocável, orgânico e óxido aumentaram com as doses de Mn, em local com constatações de deficiência do nutriente. No caso da fração orgânica, os teores aumentaram de $5,4 \mathrm{mg}$ $\mathrm{kg}^{-1}$ na testemunha, para $35,1 \mathrm{mg} \mathrm{kg}{ }^{-1}$, com a maior dose. Nas amostras sólidas de $\mathrm{AH}$ (pH 3,0) não detectou-se Mn por RPE. A quantificação de Mn nessas amostras, após digestão nitro-perclórica, juntamente com a observação de sinais de Mn por RPE em AH em solução (pH 2,4), confirmou a hipótese de que o Mn estava ligado fortemente aos grupos funcionais do $\mathrm{AH}$. A produtividade da soja não variou com as doses de $\mathrm{Mn}$. $\mathrm{O}$ DTPA foi o extrator mais adequado na avaliação da disponibilidade de Mn à soja. 


\title{
CHEMICAL FRACTIONATION IN SOILS AND BIOAVAILABILITY OF MICRONUTRIENTS TO SOYBEAN UNDER NO TILLAGE
}

\author{
Author: SILVINO GUIMARÃES MOREIRA \\ Adviser: Prof. Dr. LUÍS IGNÁCIO PROCHNOW
}

\section{SUMMARY}

With the objective of evaluating the bioavailability of micronutrients in soils cultivated with soybean under no tillage (NT), two studies ( 1 and 2) were conducted at field conditions. Study 1 was carried out under an Oxisol located in Ponta Grossa, PR, which was submitted 12 years to four different tillage treatments (NT, conventional tillage - CT, minimum tillage - MT and NT/scarification each 3 years). Study 2 was carried out in nine sites of Tibagi, Ponta Grossa and Castro, PR, with and without previous Mn deficiency in soybean. In four sites was applied Mn rates, varying of 0 to $48 \mathrm{~kg} \mathrm{ha}^{-1}$. In both studies, the availability of soil micronutrients was studied by extractants Mehlich I and III, $\mathrm{HCl} 0.1 \mathrm{~mol} \mathrm{~L}^{-1}$, DTPA-TEA pH 7.3 and by the sequential extraction (exchangeable, organic, oxides and residual). The soil samples were collected from the layers of $0.00-0.05,0.05-0.10$ and $0.10-0.20 \mathrm{~m}$ (study 1) and $0.00-0.10 \mathrm{~m}$ (study 2). In the soil samples from the 0.00-0.05 and 0.05-0.10 m (study 1) and 0.00$0.10 \mathrm{~m}$ (study 2) was extracted humic acid (HA) in order to study the interaction of metals and HA, using the electronic paramagnetic resonance (EPR). Leave samples (study 1) and representative top plants (study 1 and 2) were collected and contents of 
macro and micronutrients analytically determined. In the study 1 , extractable soil $\mathrm{Mn}$ determined by all extractants in the soil layer of $0.00-0.05$, and in the average of all extractants in the soil layers of $0.05-0.10$ and $0.00-0.20 \mathrm{~m}$, were higher in the NT as compared to the CT. The same effect was obtained for $\mathrm{Zn}$ in the layer of 0.00-0.05 $\mathrm{m}$ in the average of all extractants. The percentage of $\mathrm{Mn}$ in the organic form in the $0.00-0.05$ $m$ soil layer was higher in the NT and NT with scarification as compared to the CT. The high amounts of $\mathrm{Fe}$ oxides in the HA samples did not make possible to obtain signals for $\mathrm{Cu}$ and $\mathrm{Mn}$, even after long high speed centrifugation of samples. Soybean yield was not affected by tillage systems. In the case of study 2, manganese rates applied affected directly the extractable soil Mn, but not the leave concentration or the uptake of Mn by the plants. Exchangeable, organic and oxide forms of $\mathrm{Mn}$ increased with rates applied in soils with previous Mn deficiency for soybean, with the highest increase for the organic fraction (5.4 to $35.1 \mathrm{mg} \mathrm{kg}^{-1}$ of $\mathrm{Mn}$ from the control to the highest rate of Mn applied, i.e., $48 \mathrm{~kg} \mathrm{ha}^{-1}$ ). Manganese was not detected by EPR in the solid samples of $\mathrm{AH}-\mathrm{pH}$ 3.0. Manganese quantification in the same samples, after nitric percloric digestion, plus clear signs for $\mathrm{Mn}$ by EPR in samples of $\mathrm{AH}-\mathrm{pH} 2.4$, lead to the idea that $\mathrm{Mn}$ was strongly linked to the functional groups of AH. Soybean yield was not affected by manganese rates. The DTPA-TEA was the most reliable extractor for the element in order to evaluate Mn bioavailability to soybean under NT. 


\section{INTRODUÇÃO}

Em muitos casos, as deficiências de micronutrientes são atribuídas apenas ao aumento de $\mathrm{pH}$ do solo, causado pela calagem excessiva, especialmente devido à má incorporação e/ou aplicação de doses de calcário acima da recomendada nos solos cultivados sob sistema de semeadura convencional (SSC). Em locais sob sistema de semeadura direta (SSD) existem alguns relatos de "manchas" de deficiências de Mn, causadas pela má distribuição do corretivo aplicado superficialmente. Contudo, essas explicações nem sempre procedem para muitos solos sob SSD, que embora apresentem teores adequados ou elevados de $\mathrm{Mn}$ e $\mathrm{Zn}$, de acordo com a metodologia oficial, vem apresentando deficiências de Mn em soja e Zn em milho.

Essas constatações levaram aos seguintes questionamentos: a eficiência dos extratores utilizados para solos cultivados sob SSC é a mesma para os solos sob SSD? Qual a influência do sistema de preparo do solo na disponibilidade de micronutrientes às plantas?

A tendência de os teores de $\mathrm{Mn}$ e $\mathrm{Zn}$ "trocáveis" serem mais elevados em solos sob SSD, em relação ao SSC, não pode ser explicada apenas através dos valores de $\mathrm{pH}$ do solo. No SSD, a aplicação superficial de calcário resulta em valores de $\mathrm{pH}$ mais elevados em superfície, o que em conseqüência deveria diminuir e não aumentar os teores desses nutrientes. Vários autores têm atribuído as maiores quantidades de $\mathrm{Mn}$ e Zn "trocáveis" no SSD aos teores mais elevados de MO existentes nos solos submetidos a esse sistema de cultivo.

Em solos norte-americanos e africanos, a aplicação de elevadas doses de fertilizantes nitrogenados em locais com predomínio de gramíneas nas rotações de 
culturas e/ou monocultivos de milho tem causado diminuição dos valores de $\mathrm{pH}$ e aumentos dos teores de $\mathrm{Mn}$ e $\mathrm{Zn}$ da camada superficial e, consequentemente, elevação da concentração foliar. No entanto, em condições brasileiras, os valores de $\mathrm{pH}$ da camada superficial dos solos sob SSD são elevados, principalmente devido à calagem superficial e ao emprego de rotações/sucessões que utilizam leguminosas e evitam a monocultura de milho.

A ocorrência de deficiências de Mn e Zn em plantas cultivadas em solos que apresentam "altos" teores desses micronutrientes sugere que os teores extraídos do solo não estejam disponíveis às plantas. Desse modo, os extratores desenvolvidos para solos sob SSC parece não possuírem a capacidade de discriminar a quantidade disponível em solos sob SSD.

O fracionamento químico ou a extração seqüencial de micronutrientes (formas solúvel + trocável, orgânica, óxido e residual), e posterior estudo de correlação entre os teores de micronutrientes distribuídos nessas formas com a quantidade absorvida pela planta pode auxiliar nos estudos de seleção de extratores químicos mais adequados na avaliação da disponibilidade de micronutrientes.

Ainda é pouco conhecido o efeito de métodos de preparo no grau de humificação das substâncias húmicas (SH) e na forma pela qual os micronutrientes são complexados pela MO. Utilizando-se a ressonância paramagnética eletrônica (RPE) é possível caracterizar o grau de humificação das SH e, em alguns casos, estudar a forma pela qual os metais estão complexados organicamente.

Com os objetivos de estudar o efeito de diferentes métodos de preparo na disponibilidade de micronutrientes, avaliada por diversos extratores químicos, e nas formas desses elementos no solo, obtidas por extração seqüencial; e avaliar o efeito dos métodos de preparo no grau de humificação das SH, através de RPE, desenvolveu-se o estudo (1) em um LATOSSOlO VERMELhO Distrófico de Ponta Grossa, PR.

Outro estudo (2) foi desenvolvido com os seguintes objetivos: 1- testar, entre vários extratores de micronutrientes do solo, qual é o mais adequado para avaliar a disponibilidade de Mn em solos sob SSD; 2- estudar, com o auxílio da RPE, o grau de humificação e a interação do Mn com os ácidos húmicos dos solos de locais com e sem 
constatações de deficiência desse elemento; e 3- avaliar em quais das frações do solo (trocável, orgânica, óxidos e residual) estava ligado o Mn, após sua aplicação no solo. 


\section{REVISÃO DE LITERATURA}

\subsection{Disponibilidade de micronutrientes às plantas}

A disponibilidade de micronutrientes às plantas é afetada por diversos atributos do solo, entre eles, $\mathrm{pH}$, teores de matéria orgânica $(\mathrm{MO})$ e $\mathrm{P}$, potencial redox do solo, temperatura e umidade do solo, além da atividade microbiana. Em solos sob sistema de semeadura direta (SSD), resultados de pesquisas de longa duração em diversas localidades têm demonstrado aumento na camada superficial (0,00-0,05 m) dos teores de MO (Bayer et al., 2002a; Bayer et al., 2002b; Motta et al., 2002; Paiva et al., 1997; Rhoton, 2000) e dos teores de P (Kitur et al., 1994; Motta et al., 2002; Rhoton, 2000; Selles et al., 1997), além de maior umidade e temperaturas mais amenas no solo devido à não incidência direta dos raios solares (Hungria et al., 1997; Voss \& Sidiras, 1985). Nos solos sob SSD, a calagem superficial também eleva seus valores de pH (Caires et al., 1999; Moreira et al., 2001). Essas características tornam a disponibilidade de micronutrientes no SSD diferente daquela em que o solo é constantemente revolvido.

Até o início dos anos sessenta, quando a agricultura brasileira começou sua expansão tecnológica, não havia grande preocupação relacionada à deficiência de micronutrientes no Brasil, uma vez que a maior parte da área cultivada era formada por solos originados de rochas eruptivas básicas, ricas em micronutrientes (Borkert et al., 2001). Assim, principalmente para o $\mathrm{Mn}$, havia maior preocupação no controle da toxicidade do que da deficiência (Martini et al., 1974). 
Com a incorporação de solos com teores naturalmente baixos ao sistema produtivo, esgotamento dos solos férteis, acelerado pelo aumento de produtividade, aliado à má incorporação do calcário e/ou aplicação na camada de 0,00-0,10 m de quantidades recomendadas para 0,00-0,20 m (Sanzonowicz, 1995; Tanaka et al., 1993), os problemas de deficiências de micronutrientes começaram a aumentar (Abreu et al., 1997).

Atualmente, com o grande crescimento das áreas sob SSD, os relatos de deficiências têm aumentado. Isto se deve em muitos casos à utilização inadequada do calcário, causando elevação acentuada do $\mathrm{pH}$. Assim é freqüente o aparecimento das chamadas "manchas de deficiência", locais com pH elevado e com presença de sintomas típicos de defíciência de Mn e outros nutrientes, devido à deposição do corretivo na lavoura (Motta \& Prevedello, 1995). Entretanto, as deficiências de micronutrientes nos solos sob SSD não podem ser atribuídas apenas ao aumento do $\mathrm{pH}$, como vinha sendo feito para o sistema de semeadura convencional (SSC), uma vez que muitos solos sob SSD que vem apresentando deficiências principalmente de Mn em soja (Pauletti, 1998) e Zn em milho (Motta \& Prevedello, 1995) possuem teores adequados ou elevados desses nutrientes de acordo com a metodologia oficial de São Paulo (Raij et al., 1997).

Aumentos dos teores "trocáveis" de Mn e Zn nas camadas superficiais de solos sob SSD têm sido constantemente observados (Castro et al., 1992; Edwards et al., 1992; Follett \& Peterson, 1988; Grove \& Blevins, 1988; Motta \& Prevedello, 1995; Motta et al., 2002; Rhoton, 2000). Em muitos trabalhos realizados fora do Brasil, os aumentos ocorridos, principalmente para o $\mathrm{Mn}$, são atribuídos à diminuição do $\mathrm{pH}$, provocada pela aplicação de elevadas doses de fertilizantes nitrogenados, em locais com monocultivos de milho e/ou rotações com predomínio de gramíneas (Bowman \& Halvorson, 1998; Follett \& Peterson, 1988; Grove \& Blevins, 1988; Juo et al., 1995).

A explicação citada anteriormente, entretanto, não se aplica à maioria das situações brasileiras porque a camada superficial é a que apresenta os maiores valores de pH, devido à calagem em superficie (Caires et al., 1999; Caires et al., 2000; Moreira et al., 2001). Além disso, com a rotação de cultura, utilizada em praticamente todas as áreas sob SSD no Brasil, a monocultura de milho é evitada e, consequentemente, 
diminui a utilização de nitrogenados. Deste modo, altos teores de alguns micronutrientes na superfície do solo são atribuídos à alta quantidade de resíduos culturais na superfície, que aumentam o conteúdo de MO (Castro et al., 1992; Edwards et al., 1992; Hargrove et al., 1982; Rhoton, 2000).

A ocorrência de deficiências de Mn e $\mathrm{Zn}$ em plantas cultivadas em solos sob SSD e que apresentam "altos" teores desses nutrientes sugere que os extratores desenvolvidos para solos sob SSC não têm a mesma eficiência, quando utilizados em solos sob outros métodos de cultivo. Pode ser que os micronutrientes extraídos por estes extratores não estejam prontamente disponíveis às plantas, sugerindo a necessidade de estudos no sentido de se definir um extrator que possa avaliar adequadamente a quantidade disponível.

Existem na literatura diversos levantamentos em que se compara a fertilidade dos solos sob SSD com a de solos sob outros sistemas de cultivo (Castro et al., 1992; Edwards et al., 1992; Follett \& Peterson, 1988; Grove \& Blevins, 1988; Motta et al., 2002; Rhoton, 2000). No entanto, são poucos os estudos que relacionam os teores dos nutrientes no solo com as concentrações foliares e com as produtividades das culturas.

Utilizando-se um LATOSSOLO VERMELHO submetido a três, seis e nove anos sob SSD e diferentes doses de calcário, Moreira (1999) encontrou correlações baixas e/ou não significativas entre os teores de $\mathrm{Cu}$ no solo, extraídos com DTPA TEA pH 7,3 e o $\mathrm{Cu}$ nas folhas de soja. Para o Fe, as correlações foram inversas, e para o $\mathrm{Mn}$ e $\mathrm{Zn}$, foram significativas, mas baixas. Aliado a isso, Estes (1972) encontrou menores concentrações de nutrientes nas folhas e maior produção de milho no SSD em relação ao SSC. O autor sugere que a mudança do sistema de cultivo possa levar a alterações nos níveis críticos dos nutrientes.

\subsection{Avaliação da disponibilidade de micronutrientes com extratores químicos}

Os métodos de extração de micronutrientes catiônicos mais estudados têm sido as soluções quelantes, as ácidas diluídas e as salinas (Abreu et al., 1997). No caso das 
primeiras, o método proposto originalmente por Lindsay \& Norvell (1978), empregando-se o DTPA TEA a pH 7,3 é o mais difundido, embora tenha sido inicialmente desenvolvido para solos calcários do sudoeste dos Estados Unidos da América do Norte (Abreu et al., 1997; O`Connor, 1988). Para solos ácidos, Norvell (1984) propôs a utilização do DTPA + ácido acético $+\mathrm{NH}_{4} \mathrm{OH}+\mathrm{CaCl}_{2}$ a $\mathrm{pH} 5,3$. Contudo, apesar de estar mais próximo das condições brasileiras, este método não tem sido incluído em estudos de seleção de extratores para avaliar a disponibilidade de micronutrientes (Abreu et al., 1997). A razão para esse fato talvez seja a de que a maior estabilidade dos complexos do DTPA com $\mathrm{Cu}$, Mn e $\mathrm{Zn}$ ocorra acima de $\mathrm{pH}$ 7,0 (Norvell, 1991).

No Brasil, a solução ácida mais estudada é a chamada duplo ácido ou Mehlich I

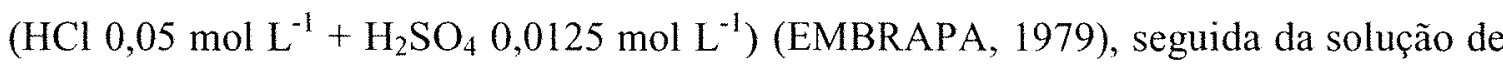
$\mathrm{HCl}$ 0,1 mol L ${ }^{-1}$ (Abreu et al., 2002). No entanto, em 1984 foi proposta a utilização do extrator Mehlich III para solos ácidos (Mehlich, 1984), em substituição ao Mehlich I. Este método, como o Mehlich I, possibilita redução de custos em laboratórios de análise de solo pela sua capacidade de extrair simultaneamente outros nutrientes (Abreu et al., 1998; Walworth et al., 1992).

O extrator Mehlich III apresenta em sua constituição o EDTA. No entanto, como a solução apresenta baixo valor de $\mathrm{pH}(2,4$ a 2,6), a estabilidade dos complexos formados (EDTA-Cu, EDTA-Mn, EDTA-Zn) é muita baixa. Além disso, há muita competição do Fe com os outros metais, uma vez que os complexos EDTA-Fe têm alta estabilidade em condições ácidas (Norvell, 1991). Contudo, Mehlich (1984) observou que a presença do EDTA $\left(0,001 \mathrm{~mol} \mathrm{~L}^{-1}\right)$ no Mehlich III aumentou as extrações de Mn e $\mathrm{Cu}$, em relação às soluções sem EDTA.

O princípio de extração das soluções ácidas baseia-se na dissolução dos minerais de argilas, o que dificulta a definição das formas extraídas. As soluções concentradas de ácidos fortes têm sido evitadas porque geralmente extraem metais não-lábeis da fase sólida. De modo geral, as soluções diluídas de ácidos fortes removem os metais dos sítios de troca e parte daqueles complexados ou adsorvidos (Abreu et al., 2002). 
Desde que esses extratores foram propostos, muitos trabalhos foram desenvolvidos no sentido de selecionar as melhores metodologias para serem utilizadas em laboratórios de rotina. No Brasil, a maioria dos trabalhos iniciais teve como objetivo avaliar a disponibilidade de Zn (Bataglia \& Raij, 1989; Lantamann \& Meurer, 1982; Muraoka et al., 1983b; Ribeiro \& Tucunango-Sarabia, 1984), uma vez que muitos solos brasileiros possuem baixa disponibilidade desse nutriente. De acordo com Fontes (1997), do total dos trabalhos de fertilidade do solo com micronutrientes, publicados na Revista Brasileira de Ciência do Solo no período de janeiro a dezembro de 1996, 44\% tratavam do $\mathrm{Zn}$. Mas; faltam trabalhos que avaliem a disponibilidade de $\mathrm{Zn}$ em solos sob SSD.

Existem oficialmente no Brasil pelo menos quatro extratores em utilização nas diversas regiões brasileiras: DTPA TEA pH 7,0 no Estado de São Paulo; Mehlich I, principalmente em Minas Gerais e na Região Centro Oeste; $\mathrm{HCl} 0,1 \mathrm{~mol} \mathrm{~L}^{-1}$ na Região Sul e Mehlich III, que tem sido utilizado principalmente para amostras de solos de locais que receberam aplicação de lodo de esgoto.

Essa estratificação regional na utilização dos extratores ocorreu principalmente porque os grupos de pesquisa das diversas regiões brasileiras desenvolveram mais pesquisas com determinados extratores químicos, causando acúmulo de informações para esses extratores nos locais em que foram estudados. Desse modo, existem resultados na literatura brasileira que justificam a utilização desses extratores em cada uma dessas regiões, como será discutido a seguir. No entanto, estudos são necessários para os solos sob SSD.

No caso da avaliação da disponibilidade de $\mathrm{Zn}$, existem inúmeros trabalhos realizados no Brasil e exterior mostrando a superioridade do DTPA, mas há também vários outros que mostram não haver diferença entre o DTPA, Mehlich I, III, $\mathrm{HCl} \mathrm{0,1}$ mol L ${ }^{-1}$ e EDTA, ou que os últimos foram mais eficientes. Além disso, é difícil concluir sobre qual é o melhor extrator, uma vez que, quando os coeficientes de correlação são significativos, seus valores são muitos próximos (Abreu et al., 2002). Desse modo, a aceitação de alguns deles ocorreu em certos casos por serem considerados multinutrientes, fato que diminui custos e aumenta a praticidade dentro dos laboratórios de rotina. 
Em solos agrícolas, os extratores DTPA TEA pH 7,0, $\mathrm{HCl} 0,1 \mathrm{~mol} \mathrm{~L}^{-1}$ e Mehlich I foram igualmente eficientes (Buzetti, 1992; Couto et al., 1992; Warman, 1992) ou o DTPA foi superior (Davis et al., 1995; Shangs \& Bates, 1987) na avaliação da disponibilidade de $\mathrm{Zn}$. Para alguns locais que receberam a aplicação de lodo de esgoto (Mulchi et al., 1987 e 1991; Oliveira \& Mattiazzo, 2001) e em solo calcário (Rashid et al., 1997), o Mehlich III foi tão eficiente quanto o DTPA TEA pH 7,0. Apesar de o Mehlich III ser muito utilizado, em laboratórios de rotina, para avaliação da disponibilidade de micronutrientes de solos que receberam aplicação de lodo, em alguns casos não tem sido tão eficiente, quanto o DTPA (Bataglia \& Raij, 1989; King \& Hajjar, 1990).

Em trabalhos realizados no Estado de São Paulo, o DTPA foi mais eficiente do que os extratores $\mathrm{HCl}$ 0,1 mol L $\mathrm{L}^{-1}$ e Mehlich I (Abreu \& Raij, 1996; Bataglia \& Raij, 1994) e Mehlich III (Bataglia \& Raij, 1989) na avaliação do Zn disponível. Entretanto, em estudos desenvolvidos no Rio Grande do Sul (Lantmann \& Meurer, 1982), em Minas Gerais (Ribeiro \& Tucunango-Sarabia, 1984) e na Venezuela (Arriechi \& Ramirez, 1997), a disponibilidade de Zn foi mais bem avaliada pela solução Na-EDTA 0,1 mol $\mathrm{L}^{-1}$, comparada às soluções ácidas $\left(\mathrm{HCl} 0,1 \mathrm{~mol} \mathrm{~L}^{-1}\right.$ e Mehlich I). Por sua vez, o Mehlich I foi mais adequado para estimar a disponibilidade de $\mathrm{Zn}$ em solos de Minas Gerais do que o $\mathrm{Na}_{2}$-EDTA e o DTPA, nos estudos de Amaral Sobrinho et al. (1993) e Paula et al. (1991), respectivamente.

A maioria dos trabalhos realizados para avaliar a disponibilidade de micronutrientes foi conduzida em condições de casa de vegetação (Abreu et al., 1994a,b; Abreu et al., 1996; Abreu \& Raij, 1996; Couto et al., 1992; Rosolem et al., 1992), necessitando de comprovação dos resultados em condições de campo. A ocorrência de deficiências de Mn e Zn em plantas cultivadas em solos sob SSD que apresentam "altos" teores trocáveis desses nutrientes sugere que os extratores atuais não são adequados para o SSD ou que os níveis críticos devem ser alterados com a mudança do sistema de cultivo.

$\mathrm{Na}$ literatura nacional e estrangeira não foram encontrados estudos visando avaliar a eficiência de extratores químicos para solos sob SSD. Recentemente foram 
obtidas em solos norte-americanos, cultivados sob SSD, correlações negativas entre os teores de Mn e Zn, extraídos com Mehlich I, com a concentração desses nutrientes nas folhas de milho (Shuman \& McCracken, 1999a). No entanto, os autores utilizaram apenas o extrator Mehlich I.

No caso do Mn, a complexidade da análise é aumentada porque a disponibilidade desse elemento é grandemente influenciada por reações de oxirredução no solo (Abreu et al., 2002). Desse modo, cuidados adicionais devem ser tomados no preparo do solo para análise, uma vez que a secagem das amostras de terra em temperaturas superiores a $40{ }^{\circ} \mathrm{C}$, armazenamento por longo período (Miyazawa et al., 1996a), acidificação, congelamento ou qualquer prática que estimule a doação de elétrons, conduz à redução das formas oxidadas e aumenta a quantidade extraída (Abreu et al., 2002).

Em solos norte-americanos, que receberam aplicação de lodo de esgoto, o DTPA TEA pH 7,0 foi o extrator mais eficiente na avaliação da disponibilidade de Mn (Brown et al., 1997; Mulchi et al., 1987 e 1991). Eficiência similar do DTPA ocorreu em alguns estudos desenvolvidos no Estado de São Paulo, sem aplicação de lodo (Camargo et al., 1982; Rosolem et al., 1992). No entanto, em outras situações as soluções ácidas foram melhores do que o DTPA (Alva, 1992; Anjos \& Mattiazzo, 2001; Bataglia \& Raij, 1989), ou não se conseguiram correlações significativas entre o Mn extraído do solo com DTPA e o Mn absorvido pela planta (Abreu et al., 1994a,b). Sims (1985) encontrou altas correlações entre o Mn absorvido pelas plantas e o extraído por Mehlich I e III.

No caso das soluções salinas, a mais estudada para extração de micronutrientes é o acetato de amônio $1 \mathrm{~mol} \mathrm{~L}^{-1}$ a pH 7,0, que extrai $\mathrm{Cu}, \mathrm{Mn}$ e $\mathrm{Zn}$, sendo mais eficiente na avaliação da disponibilidade de Mn (Miyazawa et al., 1996a). Muraoka et al. (1983a) encontraram valores de correlação entre $\mathrm{Mn}$-solo e Mn-planta de 0,78 $\left(\mathrm{NH}_{4} \mathrm{OAc}\right), 0,48$ (DTPA) e 0,39 (EDTA). Abreu et al. (1994a,b) constataram que a solução de $\mathrm{CaCl}_{2} \mathbf{0 , 1}$ mol $\mathrm{L}^{-1}$ estava entre os métodos que melhor estimaram o Mn disponível, mesmo com elevação do $\mathrm{pH}$ pela calagem (Abreu et al., 1994b), fato que não ocorreu com os extratores ácidos e o DTPA, provavelmente porque os primeiros solubilizaram e o último quelatizou o Mn não-lábil. No entanto, todos os resultados mencionados para o 
Mn foram obtidos em solos cultivados sob SSC, evidenciando a necessidade de estudos para solos sob SSD.

No caso do $\mathrm{Cu}$, embora existam relatos na literatura de situações em que os teores das camadas superficiais são menores no SSD, comparado ao SSC (Franzluebbers \& Hons 1996; Rhoton, 2000; Shuman \& McCracken, 1999b), devido aos maiores teores de MO no SSD (Motta et al., 2002; Paiva et al., 1997) e à forte tendência do Cu de ser complexado organicamente (Basta \& Tabatabai, 1992; Shuman, 1988; Sims, 1986), não existe no Brasil registro de deficiência, causada pela adoção do SSD. No entanto, é importante a seleção de extratores adequados para o monitoramento da disponibilidade de $\mathrm{Cu}$, uma vez que há grande discordância na literatura em relação à avaliação da disponibilidade deste nutriente, mesmo para solos cultivados convencionalmente.

As soluções ácidas (Mehlich I e III) e DTPA TEA pH 7,3 foram igualmente eficientes na avaliação da disponibilidade de Cu nos estudos de Mulchi et al. (1991). Em estudo realizado com solo orgânico do cerrado, os extratores Mehlich III e DTPA foram adequados na avaliação da disponibilidade de $\mathrm{Cu}$, e o Mehlich I, ineficiente (Galrão \& Sousa, 1985). Resultados similares foram observados por Abreu et al. (1996), utilizandose 31 amostras de diversos solos do Estado de São Paulo.

A solução de DTPA TEA pH 7,3 foi a mais eficiente na avaliação da disponibilidade de $\mathrm{Cu}$ em vários casos (Bataglia \& Raij, 1989; Camargo et al., 1982; Gimenez et al., 1992; King \& Hajjar, 1990; Mulchi et al., 1987). Por outro lado, foi ineficiente nos trabalhos de Faust \& Christians (1999). Em outros estudos, a solução de Melhich III tem se mostrado adequada (Anjos \& Mattiazzo, 2001; Mulchi et al., 1992).

Em decorrência dos altos teores de Fe encontrados em solos brasileiros, problemas relacionados à toxicidade são mais comuns do que aqueles com deficiência. Portanto, para o Fe é importante analisar o comportamento dos extratores em amostras com teores elevados, faixa de maior interesse agronômico. Assim, geralmente aproveita-se o extrato utilizado para determinar $\mathrm{Cu}, \mathrm{Mn}$ e $\mathrm{Zn}$ disponível e quantifica-se o Fe (Abreu et al., 1997; Abreu et al., 2002).

Nos estudos de Camargo et al. (1982), o DTPA TEA pH 7,0 foi o extrator mais adequado na avaliação da disponibilidade do Fe. Entretanto, Bataglia \& Raij (1989) não 
observaram correlação entre $\mathrm{Fe}$ absorvido por plantas de sorgo e os teores no solo, extraídos com diversos extratores. Resultados similares foram observados por Mulchi et al. $(1987,1991$ e 1992).

Outra metodologia rápida e de baixo custo que vem sendo estudada na tentativa de selecionar os melhores extratores, consiste em utilizar amostras de terra enviadas por técnicos e fazendeiros aos laboratórios de rotina (Abreu et al., 1998; Raij et al., 1998; Vocasek \& Friedericks, 1994). Nesses trabalhos, os teores obtidos por um método considerado padrão de uma dada região são correlacionados com os teores extraídos com outros potenciais extratores (Schmisek et al., 1998; Walworth et al., 1992), sem utilização de planta.

Em alguns casos tem sido encontradas correlações significativas entre os teores de micronutrientes extraídos pelo DTPA, Mehlich III e outros extratores (Abreu et al., 1998; Rashid et al., 1997; Schmisek et al., 1998; Walworth et al., 1992). Entretanto, geralmente não existe correlação quando os teores de micronutrientes são baixos. Como essa geralmente é a faixa de maior interesse agronômico, mesmo que os resultados das correlações sejam promissores, devem ser realizados estudos com planta (Abreu et al., 1998), como propõe o presente trabalho.

\subsection{Fracionamento químico de micronutrientes do solo}

No fracionamento ou extração seqüencial de micronutrientes, a mesma amostra é tratada sucessivamente com diferentes reagentes, de forma a caracterizar as concentrações de metais nas diferentes formas químicas (Amaral Sobrinho et al., 1997). Diversos métodos de fracionamento de metais têm sido propostos e utilizados (Ahnstrom \& Parker, 1999; Gibson \& Farmer, 1986; Ma \& Uren, 1995; Miller et al., 1986; Saviozzi et al., 1997; Shuman, 1985; Tessier et al., 1979). Embora existam diversas metodologias, o princípio da extração seqüencial é similar em qualquer uma delas, ou seja, consiste em extrair de uma mesma amostra de terra elementos cada vez mais imóveis, com reagentes cada vez mais fortes. 
Em qualquer uma das metodologias empregadas nas extrações seqüenciais de micronutrientes catiônicos, os metais são geralmente separados em formas trocável + solúvel em água, orgânica, adsorvido aos óxidos de $\mathrm{Fe} / \mathrm{Mn} / \mathrm{Al}$ e residual. Em certos casos, alguns autores têm separado os micronutrientes ligados à fração óxidos em metais ligados aos óxidos de Fe cristalinos e metais ligados aos óxidos mal cristalizados (Chao, 1984; Shuman, 1985). No entanto, essa separação aparenta não ser importante no presente estudo, uma vez que as maiores modificações são esperadas na fração orgânica, devido às variações no teor de MO provocadas pelos métodos de preparo.

$\mathrm{Na}$ extração das formas trocável + solúvel um dos extratores mais utilizados atualmente tem sido o $\mathrm{Sr}\left(\mathrm{NO}_{3}\right)_{2}$, uma vez que o $\mathrm{Sr}$ é um cátion pouco comum nos solos (Ahnstrom \& Parker, 1999; Bertoncini, 2002). Outros extratores, como $\mathrm{CaCl}_{2}, \mathrm{MgCl}_{2}$ e $\mathrm{Mg}\left(\mathrm{NO}_{3}\right)_{2}$, têm sido utilizados (Chao, 1984). Soluções com $\mathrm{Cl}^{-}\left(\mathrm{CaCl}_{2}, \mathrm{MgCl}_{2}\right)$ apresentam a vantagem de não causar mudança apreciável no $\mathrm{pH}$ do meio, mas o $\mathrm{Cl}^{-}$é um ânion complexante mais forte do que o $\mathrm{NO}_{3}^{-}$(Abreu et al., 2002), podendo complexar os metais do solo durante a extração (Shuman, 1985).

Para a oxidação da MO e liberação dos metais, o hipoclorito de sódio tem sido um dos mais utilizados (Ahnstrom \& Parker, 1999; Bertoncini, 2002; Shuman, 1985). As principais vantagens do hipoclorito em relação a outros extratores (peróxido de hidrogênio, pirofosfato de sódio) são a maior seletividade e eficiência na extração. Segundo Chao (1984), com três extrações sucessivas com o hipoclorito é possível oxidar 98\% do carbono orgânico. Uma das únicas desvantagens do hipoclorito é a possibilidade de provocar o entupimento do queimador do espectrofotômetro de absorção atômica, no momento das leituras, uma vez que a solução apresenta alto teor de $\mathrm{Na}$ (Bertoncini, 2002). No entanto, o problema pode ser contornado, em alguns casos, por meio da diluição da solução.

O pirofosfato de sódio apresenta baixa eficiência na extração (Ahnstrom \& Parker, 1999; Shuman, 1985); além disso, em alguns casos, pode superestimar os teores de metais na fração orgânica, uma vez que existem relatos de que o extrator pode solubilizar os óxidos de Fe amorfos (Shuman, 1985) e sulfetos (Chao, 1984). O peróxido de hidrogênio pode superestimar os teores de metais na fração orgânica, pois dissolve os 
óxidos de Mn (Ahnstrom \& Parker, 1999; Shuman, 1985) e provoca dissolução de sulfetos, além da formação de oxalatos que atacam os óxidos de Fe (Abreu et al., 2002).

Os metais ligados aos óxidos são liberados por meio da dissolução dos óxidos por agentes redutores. Nesse tipo de extração, um dos extratores mais utilizados era o ditionito. No entanto, este redutor apresenta a grande desvantagem de ser geralmente contaminado com Zn (Abreu et al., 2002; Bertoncini, 2002), em concentrações de até $400 \mathrm{mg} \mathrm{kg}^{-1}$ (Chao, 1984), além de provocar o entupimento do queimador do espectrofotômetro de absorção atômica (Bertoncini, 2002; Chao, 1984). A solução extratora mais utilizada atualmente para extração dos metais ligados aos óxidos de Fe/Mn tem sido a associação do ácido oxálico + oxalato de amônio + ácido ascórbico (Bertoncini, 2002). Outras vantagens e falhas de alguns métodos são discutidas com mais detalhes por Abreu et al. (2002) e Bertoncini (2002).

As aplicações práticas dessas metodologias geralmente têm-se restringido a estudos ambientais. A maioria dos estudos de fracionamento visa avaliar ambientes contaminados com metais pesados e/ou locais que receberam aplicação de resíduos industriais, agro-industriais ou de lodo de esgoto, cuja preocupação principal é estudar a contaminação do meio e os perigos à saúde, além dos problemas de fitotoxicidade, que esses metais podem causar (Amaral Sobrinho et al., 1997; Bertoncini, 2002; King, 1998; Ma \& Rao, 1997; Wang et al., 1997; Zalidis et al., 1999). Pouca ou nenhuma atenção tem sido dada à possibilidade de utilização dessa técnica para caracterizar as formas de micronutrientes (solúvel, trocável, orgânica, óxidos de $\mathrm{Fe} / \mathrm{Mn} / \mathrm{Al}$, residual e outras) de solos agrícolas em função de sistemas de cultivos, como propõe este estudo.

A distribuição dos micronutrientes no solo nas diferentes formas sofre mudanças com a introdução do SSD, mas faltam informações sobre o que determina o acréscimo ou decréscimo de determinado elemento em cada fração, com a mudança do sistema de cultivo (Motta \& Prevedello, 1995). Através do fracionamento é possível conhecer o conteúdo de micronutrientes presentes nas diferentes frações, e com posterior estudo de correlação, saber qual está mais correlacionada com a quantidade absorvida pela planta (Shuman, 1986). Assim, esses trabalhos podem auxiliar nos estudos de 
seleção dos extratores químicos que melhor avaliem a disponibilidade de micronutrientes às plantas.

Além dos teores prontamente disponiveis às plantas é importante conhecer o conteúdo de micronutrientes nas outras formas, uma vez que grande parte dos metais pode estar retida na superfície da MO, em solos arenosos (Sims, 1986) e nos óxidos de Fe e Mn, nos solos argilosos (Miller et al., 1986; Shuman, 1988). No caso de solos cultivados sob SSD, o estudo da distribuição dos micronutrientes nas diversas formas torna-se ainda mais importante do que para solos cultivados convencionalmente, uma vez que o SSD aumenta os teores de MO (Motta et al., 2002; Paiva et al., 1997) e os teores de P (Kitur et al., 1994; Rhoton, 2000; Selles et al., 1997), além de influenciar os valores de $\mathrm{pH}$ da camada superficial, que são os principais fatores que modificam a disponibilidade de micronutrientes.

Os teores de Mn e Zn "trocáveis" encontrados em solos sob SSD são maiores que os observados em solos sob SSC (Castro et al., 1992; Edwards et al., 1992; Follett \& Peterson, 1988; Grove \& Blevins, 1988; Motta et al., 2002). Assim, um dos fatores que podem explicar as deficiências de Mn na soja (Pauletti, 1998) e de Zn no milho (Motta \& Prevedello, 1995) nesses locais é a complexação desses metais pela MO. Edwards et al. (1992) e Motta et al. (2002) obtiveram em Ultissolos americanos correlações diretas entre o teor de $\mathrm{MO}$ e os teores de $\mathrm{Mn}$ e $\mathrm{Zn}$ extraídos por Mehlich 1, mas não investigaram a correlação com a quantidade absorvida pela planta.

Em solos com elevados teores de $\mathrm{MO}$ a retenção de $\mathrm{Mn}$ no solo decresceu com a profundidade do perfil, o que foi atribuído às diminuições dos valores de $\mathrm{pH}$ e dos teores de MO (Pavanasasivam, 1973). Zhang et al. (1997a,b) também observaram que os maiores teores de Mn na fração orgânica foram observados na camada superficial, devido ao seu maior teor de MO.

Em solos brasileiros, Castro et al. (1992) também obtiveram correlações diretas entre a MO e os teores de Mn e Zn, extraídos por DTPA. Motta et al. (2002) obtiveram fortes relações entre o $\mathrm{pH}$ e carbono orgânico com o teor de $\mathrm{Zn}$ de dois Ultissolos do Alabama, cultivados há 17 anos sob diferentes sistemas de preparo. No entanto, o teor de Mn estava correlacionado apenas com o carbono orgânico. Em experimento de casa de 
vegetação, Sims (1986) obteve correlações inversas entre o Mn da fração orgânica e o Mn absorvido pelo trigo, mas faltam informações em condições de campo para os solos cultivados sob SSD do Brasil.

Os maiores valores de $\mathrm{pH}$ encontrados na camada superficial dos solos sob SSD devido à calagem podem influenciar negativamente a disponibilidade de $\mathrm{Cu}, \mathrm{Fe}, \mathrm{Mn}$ e $\mathrm{Zn}$ às plantas. Nos estudos de Shuman (1986), o aumento do $\mathrm{pH}$ diminuiu as formas trocáveis de $\mathrm{Zn}$ e Fe, e elevou as formas de Fe, Mn e Zn na fração orgânica. Sims (1986) observou em solos arenosos que a maior parte do Mn e Zn estavam na fração trocável até pH (água) 5,2, mas acima deste valor, estavam complexados organicamente e ligados aos óxidos de Fe. A diminuição da disponibilidade de Mn nestes solos pode ser devida à formação de compostos orgânicos insolúveis (Tisdale et al., 1985), que é favorecida pelo aumento de $\mathrm{pH}$.

Com a elevação do $\mathrm{pH}$ aumenta a ionização dos grupos $\mathrm{COOH}$ presentes nos ácidos húmicos $(\mathrm{AH})$ e fúlvicos $(\mathrm{AF})$ e, consequentemente, sua habilidade em se ligar aos íons metálicos ( $\mathrm{Cu}, \mathrm{Mn}$ e $\mathrm{Zn}$ ) (Stevenson, 1994). Resultados de diversos autores levantados por Stevenson (1994) para Cu e Zn e por Nifant'eva et al. (2001) para o Zn, indicam que as constantes de estabilidade com os AF e AH aumentam com a elevação do $\mathrm{pH}$, uma vez que a desprotonação dos grupos dos $\mathrm{AH}$ e AF que complexam os metais é maior (Fernández et al., 1999). Deve ser ressaltado que as constantes de estabilidades dos metais com AH geralmente são maiores do que com os AF (Nifant'eva et al., 2001; Stevenson, 1994).

Com a elevação do $\mathrm{pH}$, a atividade dos microorganismos que oxidam o $\mathrm{Mn}^{2+}$ em complexos estáveis com a MO também é elevada (Tisdale et al., 1985). O $\mathrm{Mn}^{2+}$ adsorvido pela $\mathrm{MO}$ em baixos valores de $\mathrm{pH}$, provavelmente está presente nos solos na forma de complexos de esfera externa, enquanto grande parte pode estar como complexo de esfera interna, com o aumento do $\mathrm{pH}$ e temperatura (Senesi, 1990).

A distribuição de micronutrientes em diferentes frações, em função de diversas condições de redução e de pH, foi estudada por Sims \& Patrick (1978) em solos aluviais situados ao longo do Rio Mississipi, nos Estados Unidos da América do Norte. O aumento das condições redutoras, bem como a diminuição do pH, elevaram os teores de 
$\mathrm{Cu}, \mathrm{Fe}, \mathrm{Mn}$ e $\mathrm{Zn}$ nas frações trocável e orgânica. Acredita-se que a diminuição do potencial redox e do $\mathrm{pH}$ tenham aumentado a solubilização dos micronutrientes precipitados e oclusos nos óxidos e hidróxidos. McDaniel \& Buol (1991) observaram que as formas de $\mathrm{Fe}$ e $\mathrm{Mn}$ estavam mais associadas à posição dos solos na paisagem, devido às condições de redução e de acidez, do que ao material de origem.

Em solo norte-americano, cultivado há oito anos sob diferentes métodos de preparo, Shuman \& Hargrove (1985) observaram que o SSD diminuiu os teores de Mn da fração trocável em relação ao solo sob preparo mínimo, mas aumentou o Mn na orgânica do SSD, comparado ao SSC. No entanto, essa observação restringiu-se apenas à camada de 0,00-0,02 $\mathrm{m}$, tendo pouca importância prática. Estudos em condições brasileiras devem ser conduzidos utilizando-se as camadas mais inferiores dos solos.

\subsection{Matéria orgânica do solo}

A caracterização da $\mathrm{MO}$ dos solos tropicais torna-se importante porque a maior parte da capacidade de troca de cátions (CTC) desses solos depende das cargas negativas geradas a partir da dissociação de grupos químicos da $\mathrm{MO}$, principalmente carboxílicos (Franchini et al., 2002). Outro papel vital da MO está na complexação de metais, dentre os quais alguns são micronutrientes (Martin-Neto et al., 1991). Na complexação de metais, tanto as substâncias húmicas (SH) de alto peso molecular (AH e AF), como as de baixo peso molecular são envolvidas. A diferença é que os metais envolvidos nos complexos orgânicos com os AH e AF são imóveis e indisponíveis às plantas, enquanto os envolvidos nos complexos com substâncias de baixo peso molecular são móveis e disponíveis (Lobartini \& Orioli, 1996; Stevenson, 1994).

Para simplificar o estudo da MO do solo, sempre se aceitou o conceito de que a MO é dividida em dois grandes grupos, denominados de substâncias não húmicas e o das SH (Stevenson, 1994). Segundo essa linha, o primeiro grupo é formado de substâncias de baixo peso molecular, facilmente degradáveis por microorganismos, incluindo polissacarídeos, carboidratos, proteínas, gorduras e graxas, ácidos nucléicos, 
dentre outros. Por sua vez, as SH seriam constituídas de uma mistura complexa de macromoléculas, não inteiramente identificáveis quimicamente, sintetizadas no próprio solo e resistentes à degradação química e ao ataque microbiano (Bertocini, 2002; Stevenson, 1994). Os principais constituintes das $\mathrm{SH}$ seriam os $\mathrm{AH}, \mathrm{AF}$ e huminas.

As SH sempre foram apresentadas como substâncias de alto peso molecular, de natureza aromática e alifática e de coloração amarela a negra, amorfa e coloidal (Senesi \& Loffredo, 1999). No entanto, esse conceito está sendo questionado (Novotny, 2002).

A partir da observação de que existem grandes discrepâncias entre os valores dos pesos moleculares dos AH apresentados na literatura, se iniciaram suspeitas de que muitos dos valores não correspondiam à realidade. Um exemplo clássico citado por Piccolo (2001) foi o trabalho de Cameron et al. (1972). Nesse estudo, os autores encontraram valores que variavam de 2.600 a 1.360 .000 daltons para $\mathrm{AH}$ de mesma origem. Piccolo (2001) acredita que os autores devem ter medido associações de pequenas moléculas agregadas ao acaso por diferentes forças durante o fracionamento químico. Em trabalhos de sua autoria e de outros autores foi observado que, quando os AH são redissolvidos e ocorre adição de ácidos orgânicos para baixar seu pH, após medições por cromatografia de exclusão por tamanho, verifica-se drástica redução nos valores de seu peso molecular.

A partir principalmente dessas evidências, Piccolo (2001) sugeriu um novo conceito para as SH. Segundo a nova definição, as SH seriam associações supramoleculares de moléculas pequenas e heterogêneas de baixo peso molecular, unidas por forças fracas, tais como interações hidrofóbicas dispersivas, ao contrário das ligações covalentes que sempre se imaginou.

Pelo novo conceito, os AH são considerados associações de pequenas moléculas predominantemente hidrófobicas, estabilizadas em meio neutro por forças dispersivas (Van der Waals), e em meio ácido, por pontes de hidrogênio. Por sua vez, os AF seriam associações de pequenas moléculas hidrofilicas, as quais possuem suficientes grupos ácidos funcionais capazes de mantê-los dispersos em qualquer valor de $\mathrm{pH}$.

Apesar da controvérsia sobre a definição conceitual da $\mathrm{MO}$, na maioria dos laboratórios em que ela vem sendo estudada ainda se aplica o "antigo" conceito da 
solubilidade química (Stevenson, 1994). Desse modo, para seu estudo, a MO é separada por métodos químicos em $\mathrm{AF}, \mathrm{AH}$ e humina. Inicialmente procede-se a extração das $\mathrm{SH}$ com solução alcalina e, em seguida, são separados os AF, AH e a humina, em função de suas solubilidades em ácido, alcali e alcali a quente, respectivamente (Guerra \& Santos, 1999; Lobartini \& Orioli, 1996). Após o fracionamento químico, os AF e AH estão aptos a serem analisados por técnicas espectroscópicas, como ressonância magnética nuclear (RMN) e ressonância paramagnética eletrônica (RPE), dentre outras.

O fracionamento físico da MO também pode ser realizado e, para isto, existem dois métodos principais: o primeiro baseia-se na diferença de densidade e, o segundo, no tamanho dos constituintes implicados no complexo organo-mineral e de outras partículas do solo (granulométrico) (Guerra \& Santos, 1999). Contudo, a aplicação de técnicas espectroscópicas em frações físicas ou em solo intacto é mais complexa. O principal problema está relacionado aos óxidos de ferro, uma vez que o carbono associado a esse metal paramagnético $\left(\mathrm{Fe}^{3+}\right.$ ) pode não ser detectado pela RMN. Em RPE, o $\mathrm{Fe}^{3+}$ pode causar o alargamento do sinal, sobrepondo-se aos sinais dos radicais semiquinonas e de outros metais, que em casos extremos não são quantificados (Ceretta et al., 1999).

\subsection{Avaliação de substâncias húmicas e de micronutrientes do solo através de técnicas espectroscópicas}

Uma das principais informações a respeito das SH (AF e AH) é a medida do grau de humificação (Bayer et al., 2000; Martin-Neto et al., 1994), que é diretamente proporcional ao número de radicais livres semiquinona, obtido por RPE (Ceretta et al., 1999; Martin-Neto et al., 1991). A concentração desses radicais aumenta com o avanço da humificação (Bayer et al., 2000). A técnica utilizada para detectar e quantificar os radicais livres semiquinona é bem estabelecida (Martin-Neto et al., 1994; Martin-Neto et al., 1991; Martin-Neto et al., 1998).

Utilizando-se a RPE, Bayer et al. (1996) avaliaram os AH extraídos da camada de 0,00-0,025 m de um ARGISSOLO VERMELHO, submetido a diferentes rotações de 
culturas, em SSD. Nos locais com maior adição de resíduos, os AH apresentaram menor concentração de radicais livres semiquinonas, o que caracteriza uma MO menos humificada. Resultados similares foram observados por Bayer et al. (2000) em agregados organo-minerais e em amostras de $\mathrm{AH}$ de um solo com 12 anos de cultivo sob SSD, com diferentes sistemas de culturas.

Recentemente, Bayer et al. (2002c) avaliaram o efeito de rotações de cultura, sob SSD e SSC, em solo do Rio Grande do Sul, após diferentes tempos de cultivo. Após nove anos de cultivo houve aumento no número de radicais livres semiquinonas no SSC, e diminuição, no SSD, o que caracteriza uma MO menos humificada no SSD. Nos locais com maior adição de resíduos, os $\mathrm{AH}$ apresentaram menor concentração de radicais livres semiquinonas, o que caracteriza a introdução de $\mathrm{C}$ mais jovem nas estruturas dos $\mathrm{AH}$. A maior taxa de decomposição de $\mathrm{MO}$ e de introdução de $\mathrm{C}$ nas SH do solo sob SSC possibilitou maior acúmulo de AH mais aromáticos, comparado ao SSD. Resultados similares foram observados por Bayer et al. (2002b) em agregados organominerais de amostras de um solo do Rio Grande do Sul com 15 anos sob SSD e SSC.

É comum observar alta correlação entre a concentração de radicais livres dos AH, determinada por RPE, e o grau de aromaticidade determinado por RMN-C ${ }^{13}$ (Bayer et al., 2000; Martin-Neto et al., 1998; Saab, 1999), indicando que a semiquinona é um bom indicador da aromaticidade das SH (Martin-Neto et al., 1998).

Com a RPE também é possível em alguns casos identificar e determinar a concentração de um dado elemento, além do seu estado de valência e simetria. Em algumas situações, pode-se identificar os grupos das $\mathrm{SH}$ ligantes envolvidos nos complexos com metais. Vale destacar que a RPE aplica-se apenas para as moléculas e/ou íons que têm elétrons desemparelhados como $\mathrm{Cu}^{2+}, \mathrm{Fe}^{3+}$ e $\mathrm{Mn}^{2+}$ (Ceretta et al., 1999), não sendo aplicada no caso do $\mathrm{Zn}^{2+}$. Detalhes sobre os princípios básicos da $\mathrm{RPE}$ podem ser obtidos em Ceretta et al. (1999), Saab (1999) e Novotny (2002).

Diversos estudos envolvendo os complexos $\mathrm{SH}$ com metais foram realizados para o Cu (Martin-Neto et al., 1991; Schnitzer \& Ghosh, 1982; Senesi et al., 1985a,b; Senesi \& Sposito, 1984), o qual geralmente encontra-se ligado às SH de forma covalente (Senesi, 1990). No entanto, Martin-Neto (1991) identificaram em amostras de AH, 
extraídas de solos brasileiros, dois tipos de complexos do $\mathrm{Cu}$ com os $\mathrm{AH}$. Em um dos casos o metal era coordenado a átomos de oxigênio e no outro com o nitrogênio. $\mathrm{Na}$ primeira situação tratava-se de uma associação fraca e o Cu estava disponível às plantas; no entanto, no segundo caso, o $\mathrm{Cu}$ estava fortemente retido aos $\mathrm{AH}$.

No caso do Mn, em algumas situações é possivel determinar os valores da constante hiperfina (A), que varia com a força da ligação do $\mathrm{Mn}$ aos $\mathrm{AH}$, aumentando-se quase que linearmente com o caráter iônico das ligações. Os complexos de $\mathrm{Mn}^{2+}$ com as SH indicam coordenação a átomos de oxigênio em sítios octaédricos (Novotny, 2002), sendo que valores de A entre 9,3 a 9,6 mT são relacionados aos complexos de esfera externa (Lakatos et al., 1977). Nesse caso, o Mn mantém sua esfera de hidratação, ou seja, o $\mathrm{Mn}^{2+}$ estar solvatado - $\left(\mathrm{Mn}\left(\mathrm{H}_{2} \mathrm{O}\right)_{6}\right)^{2+}$, sendo adsorvido principalmente por atração eletrostática. Valores de A entre 8,4 a $8,8 \mathrm{mT}$ indicam complexos de esfera interna (Novotny, 2002), e os grupos funcionais possivelmente envolvidos seriam o carboxílico, as hidroxilas fenólicas e alcoólica, a carbonila e a metoxila (Schnitzer \& Khan, $1978^{1}$, citados por Novotny, 2002).

Nas medidas de RPE em complexos de Mn com ácidos monocarboxílicos e policarboxílicos (AH e AF) com ligações muito estáveis (esfera interna), ocorre perda de sinal do Mn devido ao grande alargamento de linha (McBride, 1982). Martin-Neto et al. (1988) também não observaram sinais de Mn em solução, extraído do solo com DTPA, mas intensos sinais de $\mathrm{Mn}$ foram observados, quando o metal foi retirado do solo com água ou pela solução Mehlich I. Nos estudos de McBride (1982), a estabilidade dos complexos do $\mathrm{Mn}$ com os ácidos monocarboxílicos e policarboxílicos aumentou com a elevação do $\mathrm{pH}$, pois à medida que houve aumento do $\mathrm{pH}$, diminuiu a intensidade do sinal. Assim, no presente estudo, se o Mn estiver associado à MO, na forma de ligações muito estáveis, pode não ser possível sua detecção por RPE.

\footnotetext{
' SCHNITZER, M.; KHAN, S.U. Soil Organic Matter. Amsterdam: Elsevier, 1978. 319p.
} 


\section{MATERIAL E MÉTODOS}

\subsection{Estudo 1}

\subsubsection{Hipóteses}

1) Os teores de Mn nos solos sob SSD, em condições subtropicais úmidas do Sul do Brasil, tendem a ser maiores do que nos solos cultivados sob SSC.

2) Ligações estáveis entre o Mn e a MO em SSD são responsáveis pela contradição verificada em condições de campo entre os elevados teores de Mn revelados pela análise de terra e as deficiências deste elemento apresentadas pela soja.

\subsubsection{Caracterização da área experimental}

A área experimental, pertencente à Fundação $\mathrm{ABC}$, situa-se no município de Ponta Grossa, PR, sobre um LATOSSOLO VERMELHO Distrófico típico A moderado, muito argiloso. O clima da região é subtropical úmido (cfb) mesotérmico, com verões frescos e geadas severas e freqüentes no inverno. A temperatura média do mês mais quente é de $22^{\circ} \mathrm{C}$, e do mais frio, $18^{\circ} \mathrm{C}$, sem estação seca. A altitude média varia de 840 a $980 \mathrm{~m}$ (Maack, $1968^{2}$, citado por Sá, 1993). No local do experimento o relevo é plano.

Antes da instalação do experimento, o solo foi cultivado durante muitos anos sob SSC com baixa utilização de insumos. No inverno de 1988 realizou-se a correção do solo com a aplicação de $7300 \mathrm{~kg} \mathrm{ha}^{-1}$ de calcário, o qual foi incorporado a $0,35 \mathrm{~m}$ de profundidade com arado de aiveca. Outras duas aplicações superficiais de calcário de

\footnotetext{
${ }^{2}$ MAACK, R. Classificação do Clima do Estado do Paraná. In: Geografia Física do Estado do Paraná. 2. ed., Rio de Janeiro: 1981.p. 175-189.
} 
de $2000 \mathrm{~kg} \mathrm{ha}^{-1}$ cada foram realizadas antes dos cultivos de inverno dos anos de $1992 \mathrm{e}$ 1994. As características químicas das amostras de terra coletadas em 1989, após a calagem de 1988, podem ser vistas na Tabela $1 \mathrm{e}$, as físicas, na Tabela 2.

O experimento de campo foi instalado no verão de 1990, com a adoção dos diferentes métodos de preparo: SSD - sistema de semeadura direta; SSC - sistema de semeadura convencional, constando de uma aração com arado de discos $(\cong 0,20 \mathrm{~m})$ e uma gradagem com grade niveladora $(\cong 0,10 \mathrm{~m})$, antes dos cultivos de verão e inverno de cada ano; PM - preparo mínimo, consistindo de uma gradagem com grade aradora $(\cong 0,17 \mathrm{~m})$ e duas com grade niveladora $(\cong 0,10 \mathrm{~m})$, antes dos cultivos de verão e inverno de cada ano; SSD/preparo - SSD com escarificação de cerca de $0,30 \mathrm{~m}$, aproximadamente a cada três anos (inverno). Realizaram-se as escarificações nos anos de 1990, 1992, 1995, 1999 e 2002.

O histórico da área experimental até os dias atuais consta na Tabela 3. Na Tabela 4 podem ser visualizados os resultados das análises químicas de terra coletadas em 1993 , em função dos métodos de preparo. Comparando-se esses dados com os da Tabela 1, nota-se que houve correção da acidez do solo e aumento da disponibilidade de nutrientes (P, K, Ca e Mg), independente do sistema de preparo.

Tabela 1. Propriedades químicas do LATOSSOLO VERMELHO, em diferentes profundidades, no ano de 1989, após a calagem (antes da instalação do experimento).

\begin{tabular}{|c|c|c|c|c|c|c|c|}
\hline Prof. & $\mathrm{pH}_{(\mathrm{CaCl})}$ & $\mathbf{P}$ & MO & $\bar{K}$ & $\mathrm{Ca}$ & Mg & $\mathrm{V}$ \\
\hline $\mathrm{m}$ & & $\mathrm{mg} \mathrm{dm}^{-3}$ & $-\mathrm{gdm}^{-3}$ & & $\mathrm{ol}_{\mathrm{c}} \mathrm{dn}$ & & $\%$ \\
\hline $0,00-0,10$ & 5,6 & 6 & 35 & 3,7 & 37,5 & 29,6 & 59,6 \\
\hline $0,10-0,20$ & 4,5 & 3 & 30 & 1,3 & 13,5 & 9,4 & 28,3 \\
\hline $0,20-0,30$ & 4,3 & 0 & 23 & 0,8 & 6,5 & 4,9 & 16,6 \\
\hline
\end{tabular}

Tabela 2. Conteúdos de areia, silte e argila totais do LATOSSOLO VERMELHO, em diferentes profundidades.

\begin{tabular}{ccrcc}
\hline Prof. & Areia & Silte & Argila & Classificação textural \\
\hline $\mathrm{m}$ & & $\mathrm{g} \mathrm{kg}^{-1}$ & & \\
$0,00-0,10$ & 300 & 70 & 630 & muito argilosa \\
$0,10-0,20$ & 340 & 20 & 640 & muito argilosa \\
$0,20-0,30$ & 300 & 70 & 630 & muito argilosa \\
\hline
\end{tabular}


Tabela 3. Histórico da área experimental de 1988 a 2002.

\begin{tabular}{|c|c|c|c|c|c|c|}
\hline \multirow[t]{3}{*}{ Ano } & \multicolumn{3}{|c|}{ Inverno } & \multicolumn{3}{|c|}{ Verão } \\
\hline & \multirow[t]{2}{*}{ Cultura } & \multicolumn{2}{|c|}{ Adubação } & \multirow[t]{2}{*}{ Cultura } & \multicolumn{2}{|c|}{ Adubação } \\
\hline & & Semeadura & Cobertura & & Semeadura & Cobertura \\
\hline & & $\mathrm{kgh}$ & & & $\mathrm{kg} \mathrm{ha}^{-1}$ & \\
\hline 1988 &.-- & - & - & soja & 200 de $02: 20: 20$ & - \\
\hline 1989 & trigo & 350 de $08: 30: 20$ & 67,5 de $\mathrm{N}^{(1)}$ & soja & 300 de $00: 20: 20^{(2)}$ & \\
\hline 1990 & tremoço azul & 150 de $00: 20: 20$ & - & milho & $\begin{array}{c}300 \mathrm{de} \\
08: 30: 20+1 \% \mathrm{Zn}\end{array}$ & 67,5 de $\mathrm{N}$ \\
\hline 1991 & aveia branca & 350 de $08: 30: 20$ & 45,0 de $\mathrm{N}$ & soja & 600 de $00: 20: 20$ & -...- \\
\hline 1992 & trigo & 300 de $10: 30: 16$ & 67,5 de $\mathrm{N}$ & soja & 200 de $00: 25: 25$ & (n)......... \\
\hline 1993 & ervilhaca & 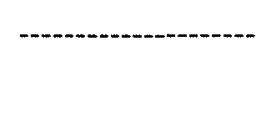 & & milho & $\begin{array}{lll}150 \text { de } 10: 30: 16 \\
+83 \text { de } & \mathrm{SS}^{*(3)}+43 \\
\text { de } \mathrm{KCl} & \end{array}$ & $67,5 \mathrm{de} \mathrm{N}$ \\
\hline 1994 & aveia branca & -....... & --------- & soja & 240 de $00: 25: 25$ & -..-- \\
\hline 1995 & trigo & 244 de $12: 24: 16$ & 30,0 de $\mathrm{N}$ & soja & 300 de $00: 20: 20$ & -..-1-n- \\
\hline 1996 & ervilhaca & - & -............... & milho & $\begin{array}{c}300 \mathrm{de} \\
10: 20: 20+1 \% \mathrm{Zn}\end{array}$ & 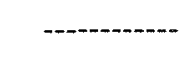 \\
\hline 1997 & aveia branca & -... & -........ & soja & 160 de $00: 25: 25$ & -..-n- \\
\hline 1998 & trigo & 200 de $10: 20: 20$ & 45,0 de $\mathrm{N}$ & soja & 156 de $00: 26: 26$ & -...-... \\
\hline 1999 & aveia preta & - & - & milho & 300 de $10: 20: 20$ & 67,5 de $\mathrm{N}$ \\
\hline 2000 & aveia branca & - & - & soja & 160 de $00: 25: 25$ & 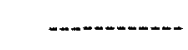 \\
\hline 2001 & trigo & 200 de $10: 20: 20$ & 45,0 de $\mathrm{N}$ & soja & 160 de $00: 25: 25$ & 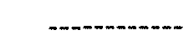 \\
\hline
\end{tabular}


Tabela 4. Propriedades químicas do LATOSSOLO VERMELHO, em diferentes profundidades, em função de métodos de preparo do solo em 1993.

\begin{tabular}{|c|c|c|c|c|c|c|c|}
\hline Prof. & $\mathrm{pH}_{(\mathrm{CaCl})}$ & $\mathbf{P}$ & MO & $\mathbf{K}$ & $\mathbf{C a}$ & $\mathbf{M g}$ & $\mathbf{V}$ \\
\hline $\mathrm{m}$ & & $\mathrm{mg} \mathrm{dm^{-3 }}$ & $-\mathrm{gdm} \mathrm{m}^{-3}-$ & & nol $_{c} \mathrm{dn}$ & & $\%$ \\
\hline \multicolumn{8}{|c|}{ SSD $^{1}$} \\
\hline $0,00-0,10$ & 6,0 & 19 & 38 & 5,3 & 50,4 & 35,4 & 71 \\
\hline $0,10-0,20$ & 6,0 & 6 & 34 & 3,6 & 47,3 & 34,1 & 71 \\
\hline $0,20-0,30$ & 5,4 & 1 & 29 & 2,7 & 28,9 & 25,3 & 54 \\
\hline \multicolumn{8}{|c|}{ SSC } \\
\hline $0,00-0,10$ & 5,9 & 12 & 36 & 4,1 & 48,8 & 37,4 & 72 \\
\hline $0,10-0,20$ & 6,0 & 8 & 36 & 4,3 & 52,4 & 52,3 & 76 \\
\hline $0,20-0,30$ & 5,5 & 3 & 32 & 2,3 & 36,3 & 30,8 & 60 \\
\hline \multicolumn{8}{|c|}{ PM } \\
\hline $0,00-0,10$ & 6,0 & 14 & 39 & 4,9 & 55,0 & 37,2 & 74 \\
\hline $0,10-0,20$ & 5,6 & 5 & 35 & 2,6 & 39,8 & 30,9 & 70 \\
\hline $0,20-0,30$ & 5,0 & 1 & 29 & 1,7 & 23,3 & 21,1 & 65 \\
\hline \multicolumn{8}{|c|}{ SSD/Preparo } \\
\hline $0,00-0,10$ & 5,9 & 19 & 38 & 5,2 & 49,9 & 35,6 & 70 \\
\hline $0,10-0,20$ & 5,6 & 7 & 35 & 3,1 & 41,3 & 30,6 & 63 \\
\hline $0,20-0,30$ & 4,9 & 1 & 29 & 2,1 & 22,5 & 19,3 & 43 \\
\hline
\end{tabular}

") SSD: sistema de semeadura direta; SSC: sistema de semeadura convencional - uma aração com arado de discos $(\cong 0,20 \mathrm{~m})$ e uma gradagem com grade niveladora $(\cong 0,10 \mathrm{~m})$, antes dos cultivos de verão e inverno a cada ano; PM: preparo mínimo - uma gradagem com grade aradora $(\cong 0,17 \mathrm{~m})$ e duas com grade niveladora $(\cong 0,10 \mathrm{~m})$, antes dos cultivos de verão e inverno de cada ano; SSD/Preparo: SSD com escarificação $(\cong 0,30 \mathrm{~m})$ a cada três anos (inverno).

\subsubsection{Delineamento experimental e características das parcelas}

O delineamento experimental foi o de blocos ao acaso (três blocos), com parcelas subdivididas. Os tratamentos principais consistiram dos quatro métodos de preparo do solo (SSD, SSC, PM e SSD/preparo), e os secundários, de três profundidades de amostragens $(0,00-0,05,0,05-0,10$ e $0,10-0,20 \mathrm{~m})$. O tamanho das parcelas correspondeu a $8 \mathrm{~m} \times 25 \mathrm{~m}\left(200 \mathrm{~m}^{2}\right)$. Cada parcela constituiu-se de aproximadamente 20 linhas, espaçadas de $0,40 \mathrm{~m}$ ( 16 plantas por metro), com área útil de 10 linhas centrais de $4 \mathrm{~m}$ de comprimento. 


\subsubsection{Condução do experimento no campo}

Apesar de o experimento ter se iniciado em 1990, serão fornecidos detalhes específicos sobre a condução da lavoura apenas para as duas últimas safras (2000/2001 e 2001/2002), uma vez que serão apresentados na tese somente as produções de soja obtidas nos dois últimos cultivos.

Para cobertura do solo antes da implantação da cultura de soja, safras de 2000/2001 e 2001/2002, utilizaram-se aveia branca e trigo (var. CD 105), respectivamente, semeados nos meses de maio de cada ano. A semeadura da aveia foi realizada mecanicamente através de semeadora de parcelas com o espaçamento de aproximadamente $0,17 \mathrm{~m}$ entrelinhas, regulada para distribuir $70 \mathrm{~kg} \mathrm{ha}^{-1}$ de sementes, sem aplicação de adubo. Na semeadura do trigo utilizou-se a mesma semeadora e espaçamento, porém, aplicou-se $200 \mathrm{~kg} \mathrm{ha}^{-1}$ da fórmula 10:20:20 na semeadura e $45 \mathrm{~kg}$ $\mathrm{ha}^{-1}$ de $\mathrm{N}$ em cobertura.

$\mathrm{Na}$ Figura 1 são apresentadas as precipitações pluviais médias mensais registradas nos últimos dois anos (2000 e 2001). Do período de semeadura da soja até a colheita choveu $567 \mathrm{~mm}$ durante a safra $2000 / 2001 \mathrm{e}, 702 \mathrm{~mm}$, durante a safra 2001/2002. A necessidade de água durante todo o ciclo da cultura da soja, varia de 450 a $800 \mathrm{~mm}$, dependendo das condições climáticas, do manejo da cultura e da duração do ciclo (EMBRAPA, 1998).

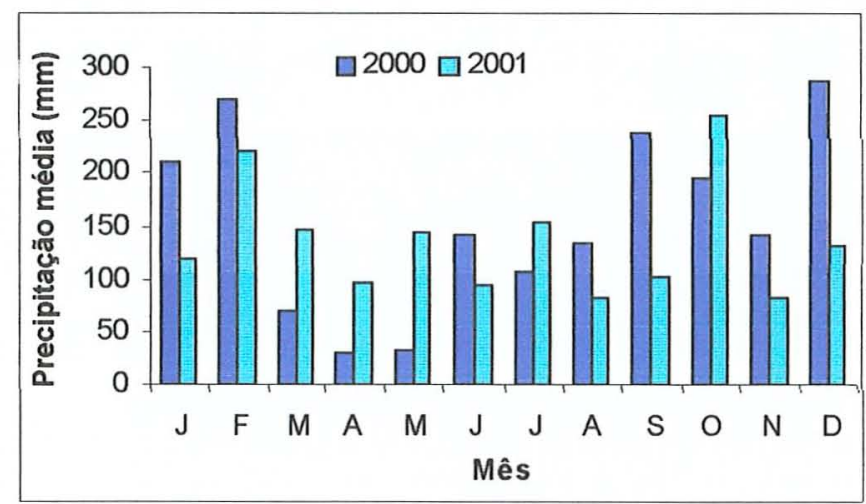

Figura 1 - Precipitações pluviais médias mensais ocorridas durante os anos de 2000 e 2001 em Ponta Grossa, PR. 
Antes das semeaduras da soja (cv. BRS 133), em cada cultivo, efetuaram-se a dessecação das plantas daninhas com 1,2 $\mathrm{L} \mathrm{ha}^{-1}$ da mistura comercial de fluazifop-p-butil $\left(125 \mathrm{~g} \mathrm{~L}^{-1}\right)+$ fomesafen $\left(125 \mathrm{~g} \mathrm{~L}^{-1}\right)+0,7 \mathrm{~L} \mathrm{ha}^{-1}$ de bentazon $\left(600 \mathrm{~g} \mathrm{~L}^{-1}\right)$. As semeaduras da primeira e segunda safras foram efetuadas nos dias 29/12/00 e 01/11/01, respectivamente, utilizando-se o espaçamento de $0,40 \mathrm{~m}$ entre linhas com 16 plantas por metro linear.

Nas adubações de plantio de cada ano (2000 e 2001) utilizaram-se $40 \mathrm{~kg} \mathrm{ha}^{-1} \mathrm{de}$ $\mathrm{K}_{2} \mathrm{O}$ e $40 \mathrm{~kg} \mathrm{ha}^{-1}$ de $\mathrm{P}_{2} \mathrm{O}_{5}$, empregando-se $160 \mathrm{~kg} \mathrm{ha}^{-1}$ da fórmula 0-25-25, de acordo com as recomendações da Fundação ABC. As sementes de soja foram inoculadas com estirpes selecionadas de Bradyrhizobium em meio líquido, sendo $150 \mathrm{~mL}$ para cada 50 $\mathrm{kg}$ de semente. As sementes da primeira safra foram tratadas com $60 \mathrm{~mL}$ de benomil e $100 \mathrm{~g}$ de tolylfluanid para cada $50 \mathrm{~kg}$, e as da segunda, com $60 \mathrm{~mL}$ de carbendazin (500 $\left.\mathrm{g} \mathrm{L}^{-1}\right)$ e $140 \mathrm{~g}$ de thiram $\left(700 \mathrm{~g} \mathrm{~kg}^{-1}\right)$ para cada $100 \mathrm{~kg}$ de sementes.

Durante os cultivos da soja, efetuou-se o controle de lagartas utilizando-se $100 \mathrm{~g}$ $\mathrm{ha}^{-1}$ de diflubenzuron (250 $\mathrm{g} \mathrm{kg}^{-1}$ ); do bicudo da soja com 0,4 $\mathrm{L} \mathrm{ha}^{-1}$ de monocrotophos (400 $\left.\mathrm{g} \mathrm{L}^{-1}\right)$; e de percevejos, aplicando-se $50 \mathrm{~mL} \mathrm{ha}^{-1}$ de permetrin $\left(250 \mathrm{~g} \mathrm{~L}^{-1}\right)$. Para controle de plantas daninhas de folhas largas e estreitas, realizaram-se aplicações de 0,6 $\mathrm{L} \mathrm{ha}^{-1}$ de fomesafen $\left(250 \mathrm{~g} \mathrm{~L}^{-1}\right)$ e $0,3 \mathrm{~kg} \mathrm{ha}^{-1}$ de butroxydim $\left(250 \mathrm{~g} \mathrm{~kg}^{-1}\right)$, respectivamente.

As colheitas da soja das safras de 2000/2001 e 2001/2002 foram realizadas manualmente nos meses de abril de 2001 e 2002, respectivamente. As trilhagens foram realizadas mecanicamente, utilizando-se debulhadora de grãos estacionária, peneirandose logo em seguida, pesando-se os grãos e lendo-se a umidade. Para os cálculos das produtividades, considerou-se um teor de umidade nos grãos de $13 \%$.

\subsubsection{Coleta e preparo das amostras de terra e folha}

As amostras de terra foram coletadas no mês de outubro de 2001 , e as folhas e plantas inteiras, em fevereiro de 2001 (soja em pleno florescimento - estádio R2 a R3) e janeiro de 2002, quando a soja estava no início do florescimento (estádio R1 a R2). As amostras de terra foram coletadas com trado calador nas profundidades de $0,00-0,05$, 
0,05-0,10 e 0,10-0,20 m, em número de 20 amostras simples por parcela. Estas amostras foram secas em estufa a $40^{\circ} \mathrm{C}$, destorroadas, moídas e passadas em peneira de $0,002 \mathrm{~m}$.

Para avaliação da concentração de nutrientes nas folhas, coletaram-se 20 trifólios por parcela, retirando-se a terceira folha a partir do ápice das plantas. Para a avaliação da quantidade de nutrientes acumulada, coletaram-se duas amostras de plantas (parte aérea) por parcela de duas linhas de $0,5 \mathrm{~m}$ de comprimento cada. Após a coleta, as amostras de folha foram lavadas e colocadas para secar em estufa a $65^{\circ} \mathrm{C}$ até atingir massa constante e moídas. As amostras das plantas inteiras também foram secas, pesadas e moídas.

\subsubsection{Digestão e quantificação de nutrientes nas folhas}

As amostras de folhas e plantas foram submetidas às digestões nitro-perclórica, para as extrações de P, K, S, Ca, Mg, Cu, Fe, Mn e Zn; sulfúrica, para extração de N; e à incineração em mufla até $550^{\circ} \mathrm{C}$ para extração do $\mathrm{B}$, conforme métodos descritos por Malavolta et al. (1997). Realizaram-se as quantificações de N por titulação; as de B e P por colorimetria; $\mathrm{S}$ por turbidimetria com $\mathrm{BaCl}_{2}$; e as demais em espectrofotômetro de absorção atômica.

\subsubsection{Análises químicas de terra}

Nas amostras de terra, determinaram-se os valores de $\mathrm{pH}$ e os teores de $\mathrm{MO}, \mathrm{P}$, $\mathrm{K}, \mathrm{Ca}, \mathrm{Mg}$, conforme metodologias propostas por Raij et al. (1987), sendo calculados os valores de saturação por bases (V\%) e CTC. Os teores de carbono total também foram quantificados por combustão via seca, utilizando-se aparelho determinador de $\mathrm{C}$ e $\mathrm{N}$, tipo Leco CN 2000. As demais análises serão descritas nos itens apresentados a seguir.

\section{Extração dos micronutrientes do solo}

$\mathrm{Na}$ extração dos micronutrientes ( $\mathrm{Cu}, \mathrm{Fe}, \mathrm{Mn}$ e Zn trocáveis) das amostras de terra utilizaram-se quatro extratores, e a quantificação foi efetuada em espectrofotômetro de absorção atômica. As soluções extratoras foram: 
1- Ácido dietileno-triamino-pentacético (DTPA) $0,005 \mathrm{~mol} \mathrm{~L}^{-1}+$ trietanolamina (TEA) $0,1 \mathrm{~mol} \mathrm{~L}^{-1}+\mathrm{CaCl}_{2} 0,01 \mathrm{~mol} \mathrm{~L}^{-1}$ a pH 7,0. Adicionaram-se 10 gramas de terra em 20 $\mathrm{mL}$ de solução, a qual foi agitada por duas horas e filtrada (Lindsay \& Norvell, 1978);

2- Mehlich I ( $\left.\mathrm{HCl} 0,05 \mathrm{~mol} \mathrm{~L}^{-1}+\mathrm{H}_{2} \mathrm{SO}_{4} 0,0125 \mathrm{~mol} \mathrm{~L}^{-1}\right)$. Adicionaram-se cinco gramas de terra em $25 \mathrm{~mL}$ de solução, a qual foi agitada por 10 minutos e filtrada (EMBRAPA, 1979);

3- Mehlich III ( $\mathrm{CH}_{3} \mathrm{COOH} \mathrm{0,2} \mathrm{mol} \mathrm{L}^{-1}+\mathrm{NH}_{4} \mathrm{NO}_{3} 0,25 \mathrm{~mol} \mathrm{~L}^{-1}+\mathrm{NH}_{4} \mathrm{~F} 0,015 \mathrm{~mol} \mathrm{~L}^{-1}+$ $\mathrm{HNO}_{3}$ 0,013 $\mathrm{mol} \mathrm{L}^{-1}+$ EDTA $0,001 \mathrm{~mol} \mathrm{~L}^{-1}$ ). Adicionaram-se 2,5 gramas de terra em $25 \mathrm{~mL}$ de solução, a qual foi agitada por cinco minutos e filtrada (Mehlich, 1984);

4- Solução de $\mathrm{HCl} 0,1 \mathrm{~mol} \mathrm{~L}^{-1}$. Adicionaram-se 2,5 gramas de terra em $25 \mathrm{~mL}$ de solução, a qual foi agitada por 30 minutos e filltrada (Wear \& Sommer, 1948).

\section{Extração seqüencial de micronutrientes do solo}

A metodologia empregada na extração seqüencial de $\mathrm{Cu}, \mathrm{Fe}, \mathrm{Mn}$ e $\mathrm{Zn}$ foi adaptada de Chang et al. (1984), Shuman (1985) e Ahnstrom \& Parker (1999), como será discutido a seguir. Os micronutrientes catiônicos foram separados em quatro frações (formas trocável + solúvel em água, orgânica, óxido de $\mathrm{Fe} / \mathrm{Mn} / \mathrm{Al}$ e residual), além da fração total.

As formas trocável + solúvel foram extraídas com $\operatorname{Sr}\left(\mathrm{NO}_{3}\right)_{2}$. Para a oxidação da MO e liberação dos metais utilizou-se o hipoclorito de sódio. Os metais ligados aos óxidos foram liberados por meio da dissolução dos óxidos por agentes redutores (ácido oxálico + oxalato de amônio + ácido ascórbico). Os metais presentes nas formas residual e total foram extraídos pela completa digestão dos materiais com ácidos concentrados em forno de microondas. O processo de extração seqüencial iniciou-se com uma mesma amostra de terra (2,5 gramas), em três repetições de laboratório, que foi tratada seqüencialmente com os seguintes extratores:

1- Solução de $\operatorname{Sr}\left(\mathrm{NO}_{3}\right)_{2}$ 0,1 mol L $\mathrm{L}^{-1}$ (fração trocável + solúvel): Realizaram-se duas extrações, adicionando-se em cada uma $10 \mathrm{~mL}$ da solução extratora às amostras de terra. Em cada uma das extrações, agitaram-se as misturas terra/solução por duas 
horas a baixa velocidade. Em seguida, realizaram-se centrifugações a $15000 \mathrm{rpm}$ por 10 minutos. O sobrenadante de ambas as extrações foi filtrado e transferido para frasco pré pesado. Após a segunda extração, lavaram-se as amostras de terra com 5 $\mathrm{mL}$ de $\mathrm{NaCl} 0,1 \mathrm{~mol} \mathrm{~L}^{-1}$, com o objetivo de remover os metais extraídos e a solução extratora utilizada. Após a lavagem, as amostras foram centrifugadas e filtradas. O sobrenadante foi misturado ao da fase anterior. Nesse material foi adicionado $\mathrm{HNO}_{3}$ concentrado para se obter uma solução $1 \%$, com o objetivo de evitar o aparecimento de microorganismos.

2- Solução de $\mathrm{NaOCl}$ a $5 \%, \mathrm{com} \mathrm{pH}$ ajustado a 8,5 (micronutrientes ligados à fração orgânica): foram adicionados $5 \mathrm{~mL}$ da solução extratora aos tubos contendo a mesma amostra de terra utilizada na extração anterior, os quais foram colocados em banhomaria $\left(90-95^{\circ} \mathrm{C}\right)$, com agitação por 30 minutos. As amostras foram centrifugadas a 15000 rpm por 10 minutos, e os sobrenadantes recolhidos em frascos pré pesados. $\mathrm{O}$ procedimento foi repetido quatro vezes até a completa oxidação da MO, que ocorre quando cessa a formação de espuma. Após a última extração, lavaram-se as amostras com $5 \mathrm{~mL}$ de $\mathrm{NaCl} 0,1 \mathrm{~mol} \mathrm{~L}^{-1}$, para remover os metais extraídos e a solução extratora utilizada. As amostras foram centrifugadas e o sobrenadante misturado ao das extrações com $\mathrm{NaOCl}$, adicionando-se $\mathrm{HNO}_{3}$ concentrado, na mesma proporção e com o mesmo objetivo da fase anterior. Antes de passar para a próxima etapa, as amostras de terra foram secas em estufa e trituradas.

3- Soluções de ácido oxálico $0,2 \mathrm{~mol} \mathrm{~L}^{-1}+$ oxalato de amônio $0,2 \mathrm{~mol} \mathrm{~L}^{-1}+$ ácido ascórbico 0,1 mol L ${ }^{-1}$, ajustada a pH 3,0 (fração ligada aos óxidos de $\mathrm{Fe}$, Al e $\mathrm{Mn}$ ): adicionaram-se $20 \mathrm{~mL}$ da solução extratora a cada amostra de terra (dois gramas), agitando-se em banho-maria $\left(90-95^{\circ} \mathrm{C}\right)$ por 30 minutos e centrifugando-se a 10000 rpm por 10 minutos. Recolheram-se os sobrenadantes em frascos pré pesados, após filtragem. Repetiu-se o procedimento quatro vezes para que houvesse completa redução dos óxidos de $\mathrm{Fe}$, verificada pelo desaparecimento da coloração vermelha. Antes de passar para a próxima fase, lavaram-se as amostras de terra com $5 \mathrm{~mL}$ de $\mathrm{NaCl} 0,1 \mathrm{~mol} \mathrm{~L}^{-1}$. Novamente, as amostras foram secas em estufa e trituradas. 
4- Digestão ácida em microondas (micronutrientes fração residual). Após avaliar diversas misturas de ácidos, condições de pressão e tempo de irradiação das amostras, a metodologia descrita a seguir foi a que permitiu a completa digestão do material: transferiu-se 0,5 grama do material de coloração cinza obtido na fase anterior para tubos de microondas. Nos tubos, adicionaram-se $4 \mathrm{~mL}$ de $\mathrm{HCl}, 3 \mathrm{~mL}$ de $\mathrm{HNO}_{3}$ e 5 $\mathrm{mL}$ de HF concentrados. Os tubos foram fechados e colocados em microondas, sob pressão de 170 psi, com 100\% de potência $(630 \mathrm{~W})$, durante 50 minutos. Após esse período, foram esfriados, adicionando-se na sequiência $5 \mathrm{~mL}$ de $\mathrm{H}_{3} \mathrm{BO}_{3} 3 \%$ para evitar a complexação dos metais pelo flúor, além de possíveis danos aos equipamentos no momento das leituras. Os tubos foram novamente colocados no microondas por aproximadamente 15 minutos sob pressão de 170 psi.

5- Teores totais de micronutrientes: Para cada amostra utilizaram-se 0,5 grama de terra, em três repetições de laboratório, utilizando-se os mesmos extratores e procedimentos para a fração residual. No entanto, aumentou-se a quantidade de $\mathrm{HNO}_{3}$ de 3 para $4 \mathrm{~mL}$ devido ao maior teor de MO nas amostras de terra (teor total) em relação ao material da fração residual (extração seqüencial), e diminuiu-se o $\mathrm{HCl}$ de 4 para $3 \mathrm{~mL}$. Deve ser ressaltado que a somatória dos teores de metais extraídos das diferentes frações deve corresponder aos valores encontrados para os teores totais. As determinações dos teores de micronutrientes nas diferentes frações, com exceção dos teores de $\mathrm{Cu}, \mathrm{Fe}$ e $\mathrm{Zn}$, da fração trocável (espectrofotometria de plasma), foram efetuadas em espectrofotômetro de absorção atômica. Todas as diluições foram realizadas com base em massa (massa da solução/massa da amostra de terra).

\subsubsection{Extração e purificação dos ácidos húmicos dos solos}

Os AH foram isolados de acordo com a técnica de extração, fracionamento e purificação recomendada pela "International Humic Substances Society" (IHSS) (Schnitzer, 1982), sem a utilização do $\mathrm{NaP}_{2} \mathrm{O} 70,1 \mathrm{~mol} \mathrm{~L} \mathrm{~L}^{-1}$, uma vez que sua recomendação é restrita aos solos com elevados teores de Ca (Alexandrova, 1960). 
Para a extração das SH de cada amostra de terra utilizaram-se dois recipientes com capacidade de $1 \mathrm{~L}$. Em cada recipiente foram colocados 100 gramas de TFSE e $500 \mathrm{~mL}$ da solução extratora $\mathrm{NaOH} 0,5 \mathrm{~mol} \mathrm{~L}^{-1}$, os quais foram agitados durante 24 horas em agitador circular. Após este período, realizou-se a centrifugação das amostras a 6000 rpm por 20 minutos. Após a centrifugação, o sobrenadante foi filtrado sob vácuo, e conservado em bequer sob atmosfera de $\mathrm{N}_{2}$, para evitar a oxidação das SH. Realizaramse ainda mais duas extrações, com relação sólido-extrator 1:2, sendo que na segunda extração o tempo de agitação foi de 12 horas e, na terceira, de 6 horas.

Os filtrados das outras duas extrações foram juntados ao primeiro e sempre conservados sob atmosfera de $\mathrm{N}_{2}$. Eliminou-se a fase sólida (humina) e a solução alcalina contendo as $\mathrm{SH}$ foi acidificada com $\mathrm{HCl} 50 \%$ até pH 1,0-1,5, ficando em repouso durante 12 horas para floculação e precipitação dos AH. Realizou-se centrifugação a $6000 \mathrm{rpm}$ durante 20 minutos para separação dos AH e AF.

Para eliminar as impurezas presentes nos $\mathrm{AH}$, cada amostra foi redissolvida em $100 \mathrm{~mL}$ da solução extratora $(\mathrm{NaOH})$, seguido de três centrifugações (6000 rpm durante 20 minutos). Após cada centrifugação, o material precipitado (impurezas) era descartado e o sobrenadante recolhido para nova centrifugação. Após as centrifugações, o sobrenadante foi acidificado até $\mathrm{pH}$ 1,0 e deixado em repouso por 12 horas para nova precipitação dos AH.

Após a precipitação dos $\mathrm{AH}$, realizou-se a centrifugação para separação do sobrenadante. Foram, então realizadas três lavagens com $30 \mathrm{~mL}$ de água bidestilada,

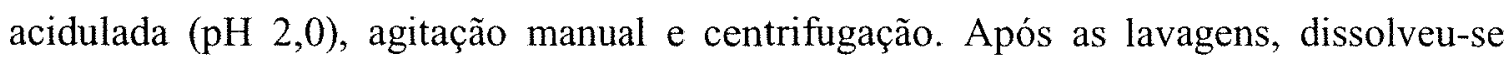
cada amostra de AH em $100 \mathrm{~mL}$ de água bidestilada, a qual foi agitada por duas horas e transferida para membrana semi-permeável (6-8000 daltons), seguindo-se a diálise por cinco dias, com o propósito de eliminar as moléculas de baixo peso molecular e íns. Após a diálise, os $\mathrm{AH}$ foram congelados e liofilizados.

Através de estudos preliminares por RPE, detectaram-se a presença de altos teores de Fe em todas as amostras, que impediam a observação dos picos dos outros metais. Assim, utilizaram-se os procedimentos recomendados pela EMBRAPA/CNPDIA 
(Barreiro, 2002 ${ }^{3}$ ) para eliminação do Fe das amostras de AH. Segundo Novotny (2002), esse $\mathrm{Fe}$, responsável pelo alargamento do sinal de RPE, encontra-se nas formas de óxido e hidróxido. Para sua eliminação, as amostras sólidas de $\mathrm{AH}$ foram redissolvidas em 100 $\mathrm{mL}$ de $\mathrm{KOH} 0,1 \mathrm{~mol} \mathrm{~L}^{-1}$, completando-se a solução com $\mathrm{KCl}$ até atingir $0,3 \mathrm{~mol} \mathrm{~L}^{-1}$ de $\mathrm{K}^{+}$

Depois de redissolvidas, as amostras foram centrifugadas por um periodo de três horas em alta rotação $(12500 \mathrm{rpm})$, eliminando-se o precipitado (impurezas) do fundo dos tubos. O sobrenadante foi recolhido e acidificado até $\mathrm{pH} 1,0$ e deixado em repouso por 12 horas para nova precipitação dos $\mathrm{AH}$. Após a precipitação dos $\mathrm{AH}$, realizou-se a centrifugação para separação do sobrenadante. Foram, então realizadas novamente lavagens com água bidestilada, diálise e liofilização das amostras, como descrito anteriormente.

\subsubsection{Análises espectroscópicas}

As análises por RPE das amostras de AH foram realizadas no Laboratório de Espectroscopia da EMBRAPA/CNPDIA de São Carlos, utilizando-se espectrômetro de

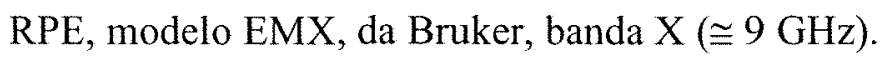

Para quantificação dos radicais livres tipo semiquinona foi utilizado o método do padrão secundário (Singer, 1959), com um cristal de rubi $\left(\mathrm{Al}_{2} \mathrm{O}_{3}\right)$ contendo $0,5 \%$ de $\mathrm{Cr}^{+3}$ por peso. Seu fator $g$ é de 1,263 e, portanto, não interfere no sinal do radical livre, cujo valor de $g$ está em torno de 2,003 (Martin-Neto et al., 1998). Os parâmetros experimentais foram $0,2 \mathrm{~mW}$ de potência, determinada pelo experimento de saturação de potência (Figura 2), com amplitude de modulação de 2 Gauss pico a pico. $O$ experimento de saturação de potência é realizado para obter a maior intensidade do sinal (I), sem provocar sua saturação. Em todas as amostras de AH foram quantificados os teores de $\mathrm{C}$ total para normalização dos resultados em número de spins/ $\mathrm{g}$ de $\mathrm{C}$.

\footnotetext{
${ }^{3}$ BARREIRO, J.C. (EMBRAPA. Centro de Instrumentação Agropecuária, São Carlos). Comunicação pessoal, 2002
} 


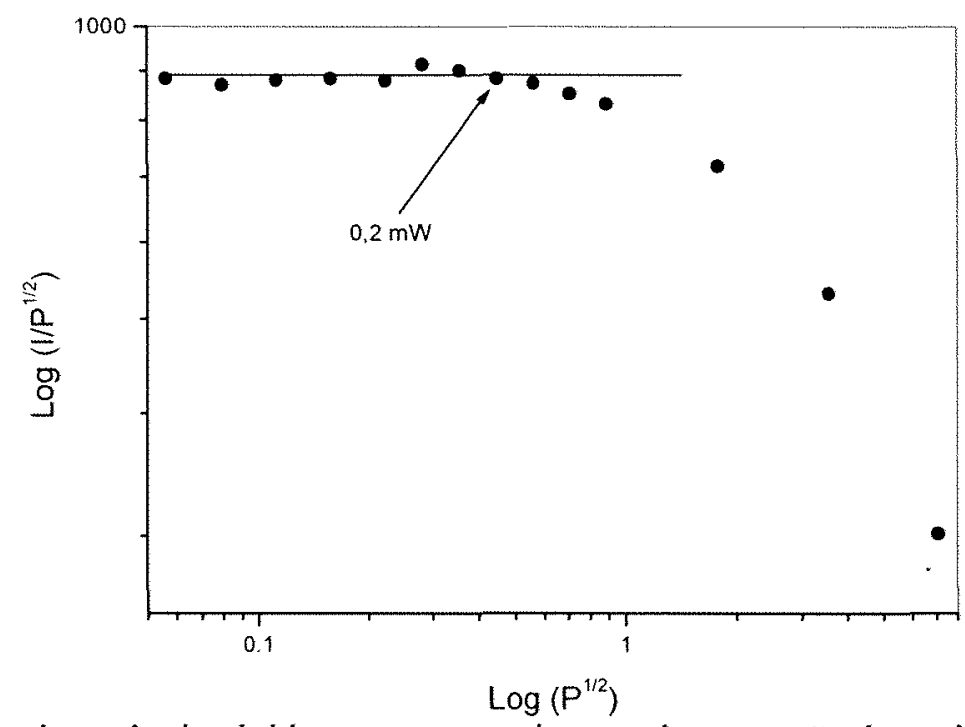

Figura 2 - Valores de potência obtidos com o experimento de saturação de potência.

Através da RPE, também foram obtidas as informações estruturais sobre a complexação dos micronutrientes com as SH, utilizando-se metodologias propostas por Senesi \& Sposito (1984) e Martin-Neto et al. (1991). As leituras foram realizadas, utilizando-se amostras de $\mathrm{AH}$ sólidas e em solução ( $\mathrm{pH}$ 3,0 e 2,5). Os parâmetros experimentais foram $50 \mathrm{~mW}$ de potência, com amplitude de modulação de 10 Gauss pico a pico. Também quantificaram-se os teores $\mathrm{Cu}$, Fe, $\mathrm{Mn}$ e $\mathrm{Zn}$ nas amostras de $\mathrm{AH}$ sólidas, as quais foram digeridas por ataque nitro-perclórico.

\subsubsection{Análise estatística}

Para avaliação dos teores de macronutrientes no solo, os resultados foram submetidos à análise de variância (teste F), e as médias comparadas pelo teste de Tukey a $5 \%$. Considerou-se um delineamento em blocos, com parcelas subdivididas, sendo os sistemas de preparo os tratamentos principais e as profundidades, as subparcelas.

A análise estatística para avaliar o efeito dos sistemas de preparo nos teores de micronutrientes, extraídos por diversos métodos, foi realizada separadamente para cada profundidade $(0,00-0,05,0,05-0,10,0,10-0,20$ e $0,00-20 \mathrm{~m})$, através de um fatorial métodos de preparo (quatro) x extratores (quatro), com três blocos. Para avaliar o efeito 
dos métodos de preparo nas formas dos micronutrientes no solo, a análise foi idêntica à anterior, através de um fatorial métodos de preparo (quatro) $\mathrm{x}$ frações (quatro). Os teores dos metais das diferentes frações foram transformados em percentagem da somatória do teor total (trocável + orgânica + óxido + residual).

Deve ser ressaltado que para obtenção dos teores médios dos atributos químicos $(\mathrm{pH}, \mathrm{MO}, \mathrm{V} \%, \mathrm{CTC}$, teores de macro e micronutrientes) da camada de 0,00-0,20 m, foram calculadas médias ponderadas das camadas de 0,00-0,05, 0,05-0,10 e 0,10-0,20 m.

Para a escolha do melhor extrator para micronutrientes foram realizados estudos de correlação linear simples entre o teor no solo e a concentração na folha-índice (terceiro par de folhas a partir do ápice). Estudos de correlação também foram realizados entre o teor no solo e a quantidade acumulada na parte aérea. Esses parâmetros da planta também foram correlacionados com os teores das formas trocável $\left(\operatorname{Sr}\left(\mathrm{NO}_{3}\right)_{2} 0,1 \mathrm{~mol} \mathrm{~L}^{-1}\right)$ e orgânica.

Para avaliação da concentração de nutrientes nas folhas, acúmulo na parte aérea, produtividade de grãos e dos atributos da camada de $0,00-0,20 \mathrm{~m}$ do solo $(\mathrm{pH}$, MO, C, P, K, Ca, Mg, CTC e V\%), os resultados foram submetidos ao teste de Friedman, uma vez que o grau de liberdade do resíduo era baixo, o que comprometeria a análise de variância pelo teste $\mathrm{F}$ (gl. total $=11$, gl. tratamentos $=3$, gl. blocos $=2$ e gl. residuo=6). 


\subsection{Estudo 2}

\subsubsection{Hipóteses}

1) Ligações estáveis entre a $M O$ e o Mn em SSD são responsáveis pela contradição entre teores extraídos em processos analíticos e quantidades acumuladas pelas plantas.

2) Os extratores desenvolvidos para avaliar a disponibilidade de Mn em solos sob SSC não são eficientes quando utilizados em solos cultivados em SSD.

\subsubsection{Caracterização da área experimental}

No estudo 2, procurou-se selecionar solos sob SSD com ampla variação nos teores de Mn, uma vez que os resultados obtidos no estudo 1 indicaram que uma das causas da ausência de correlação entre os teores de Mn no solo (DTPA, Mehlich I e III, $\mathrm{HCl} 0,1 \mathrm{~mol} \mathrm{~L}^{-1}$ ) e a concentração na planta poderia ser a pequena amplitude dos dados. Outro aspecto considerado na escolha dos locais foi a seleção de solos em que já haviam sido constatadas deficiências de Mn em soja e locais em que as deficiências ainda não foram observadas.

Nove locais foram selecionados para o estudo, sendo que em seis deles já houve constatação de deficiência de Mn em soja (locais I, II, V, VI, VIII e IX), e três locais em que ainda não foram constatadas deficiências (locais III, IV e VII). Na Tabela 5 são apresentadas as características dos diferentes locais e, na Tabela 6, o histórico de cultivo. Os teores de areia, silte e argila totais estão na Tabela 7. 
Tabela 5. Propriedades químicas dos solos na camada de 0,00-0,10 m.

\begin{tabular}{|c|c|c|c|c|c|c|c|c|c|c|c|c|c|}
\hline $\begin{array}{l}\text { Locais/ } \\
\text { Def. de } \mathrm{Mn}^{1}\end{array}$ & $\begin{array}{l}\mathrm{pH} \\
\mathrm{CaCl}_{2}\end{array}$ & $\mathbf{P}$ & $\mathbf{S}$ & MO & $\mathbf{K}$ & $\mathrm{Ca}$ & $\mathrm{Mg}$ & $\mathbf{V}$ & B & $\mathrm{Cu}$ & $\mathrm{Fe}$ & Mn & $\mathbf{Z n}$ \\
\hline & \multicolumn{2}{|c|}{$\mathrm{mg} \mathrm{dm^{-3 }}$} & \multicolumn{2}{|c|}{$\mathrm{g} \mathrm{dm}^{-3}$} & \multicolumn{3}{|c|}{$\mathrm{mmol}_{\mathrm{c}} \mathrm{dm}^{-3}$} & $\%$ & \multicolumn{5}{|c|}{$\mathrm{mg} \mathrm{dm}^{-3}$} \\
\hline 1- Con & 5,2 & 38 & 11 & 47 & 3,8 & 41 & 23 & 62 & 0,19 & 1,0 & 98 & 1,2 & 1,5 \\
\hline II- Col & 5,5 & 24 & 14 & 41 & 3,4 & 56 & 24 & 75 & 0,14 & 2,0 & 103 & 1,4 & 0,5 \\
\hline III- & 5, & 34 & 11 & 2 & 3,6 & 66 & 12 & 74 & 0,12 & 1, & 47 & 3,5 & 1,7 \\
\hline IV-S & 5,8 & 133 & 9 & 53 & 4,2 & 77 & 30 & 82 & nd & 2,2 & 42 & 3,9 & 8,2 \\
\hline V-Cor & 5 , & 21 & 14 & 6 & 2,5 & 63 & 35 & 71 & 0,16 & 0,5 & 166 & ,2 & 0,3 \\
\hline VI-Con & 5 & 67 & 7 & 2 & 3,0 & 40 & 15 & 76 & nd & 0,6 & 49 & 1,1 & 0,3 \\
\hline VII-S & 4,8 & 34 & 9 & 40 & 2,6 & 47 & 18 & 59 & 0,20 & 2,2 & 92 & 1,4 & 6,2 \\
\hline VIII-Com Def. & 5,7 & 32 & 13 & 38 & 3,6 & 58 & 28 & 80 & 0,12 & 1,0 & 49 & 0,9 & 2,1 \\
\hline IX-Com Def. & 5,4 & 26 & 11 & 71 & 4,7 & 92 & 43 & 79 & 0,23 & 1,5 & 98 & 1,5 & 8,0 \\
\hline
\end{tabular}

(1) Local I: Faz. Santa Rosa; Locais II e III: Faz. Novo Horizonte; Local IV: Campo Experimental da Fundação ABC; Locais V e VI: Faz. Capão da Onça; Local VII: Faz. Curralinho; Local VIII: Faz. Boa Vista e Local IX: Faz. São Daniel. Com Def.: local com constatação de defíciência de Mn em soja; Sem Def.: local onde não é constatada deficiência. Os locais I, II, III e VIII estão localizados no município de Tibagi; os locais V e VI em Ponta Grossa e os locais IV, VII e IX em Castro, PR. nd: teor não detectado.

As amostras de terra de todos os locais, antes da aplicação das doses de Mn, foram submetidas à extração seqüencial de micronutrientes e à extração e fracionamento das SH (metodologia apresentada nos itens 3.1 .7 e 3.1.8). As análises dos AH sólidos e em solução ( $\mathrm{pH} 3,0$ e 2,5) por RPE foram realizadas na EMBRAPA/CNPDIA, conforme descrito no item 3.1.9. Os AH foram digeridos (digestão nitro-perclórica) para obtenção dos teores de $\mathrm{Cu}$, Fe, $\mathrm{Mn}$ e $\mathrm{Zn}$. 
Tabela 6. Histórico de cultivo dos locais selecionados para o estudo 2.

\begin{tabular}{cl}
\hline Locais & \multicolumn{1}{c}{ Características } \\
\hline Faz. Santa & Área de integração agricultura/pecuária, sendo dois anos consecutivos de soja, \\
Rosa & seguido de um ano de milho no verão. No inverno é semeado a lanço sementes de \\
(Local I) & azevém $\left(30 \mathrm{~kg} \mathrm{ha}^{-1}\right)$, misturado com aveia preta $\left(50 \mathrm{~kg} \mathrm{~h}^{-1}\right)$ para pastejo de gado. \\
& O solo (CAMBISSOLO HÚMICO Distrófico típico textura média) é cultivado em \\
& SSD por mais de oito anos e tem sido constatadas constantes deficiências de Mn \\
& em soja. Realizou-se a última calagem no inverno de 1999, empregando-se 2000 \\
& $\mathrm{~kg} \mathrm{ha}^{-1}$ superficialmente.
\end{tabular}

Faz. Novo Área com rotação soja e milho, sendo dois anos consecutivos de soja e um ano de Horizonte milho. No inverno é utilizada aveia preta para produção de massa, com exceção do (Locais ano de 2001, que foi utilizado trigo. Os dois locais (II e III) são cultivados em II e III) SSD por cinco anos. O solo do local II é classificado como CAMBISSOLO HÁPLICO Tb Distrófico típico A proeminente textura média e tem sido observadas constantes deficiências de Mn em soja nos últimos anos. O solo do local III é um CAMBISSOLO HÚMICO Distrófico típico textura média e no local não são observadas deficiências de $\mathrm{Mn}$. No inverno de 2000 foi realizada a última calagem, empregando-se $2000 \mathrm{~kg} \mathrm{ha}^{-1}$ superficialmente.

Campo Área com rotação milho e soja no verão, e aveia preta, no inverno. Local cultivado Experimental sob SSD desde de 1998 e sem constatação de deficiência de Mn em soja. O solo é (Local IV) um LATOSSOLO BRUNO Distrófico típico A proeminente textura muito argilosa. A última calagem foi realizada no inverno de 1997, empregando-se 2000 $\mathrm{kg} \mathrm{ha}^{-1}$ superficialmente.

Faz. Capão Local V: Área com rotação milho e soja no verão, e trigo, no inverno. Local da Onça cultivado em SSD por oito anos e com problemas constantes de deficiência de $\mathrm{Mn}$ (Locais em soja. Local VI: Área de integração agricultura/pecuária, sendo quatro anos Ve VI) consecutivos de soja, seguido de um ano de milho no verão. No inverno é semeado a lanço sementes de azevém, misturado com aveia para pastejo. Local cultivado em SSD por oito anos e com problemas constantes de deficiência de Mn em soja.

Faz. Área com rotação milho e soja no verão, sendo dois anos consecutivos de soja, Curralinho seguido de um ano de milho no verão. Quando a cultura de verão é a soja, no (Local VII) inverno cultiva-se aveia preta, e quando milho, cultiva-se trigo no inverno. Local com mais de oito anos de cultivo em SSD e sem problemas de deficiência de Mn em soja.

Faz. Boa Área com rotação milho e soja no verão, e aveia preta, no inverno. Local com Vista mais de oito anos de cultivo em SSD e com problemas constantes de deficiência (Local VIII) de Mn em soja.

Faz. São Área com rotação milho e soja no verão, e azevém, no inverno, para semente. Daniel Local cultivado em SSD por três anos e com problemas de deficiência de Mn em (Local IX) soja. 
Tabela 7. Conteúdos de areia, silte e argila totais, na camada de $0-0,10 \mathrm{~m}$.

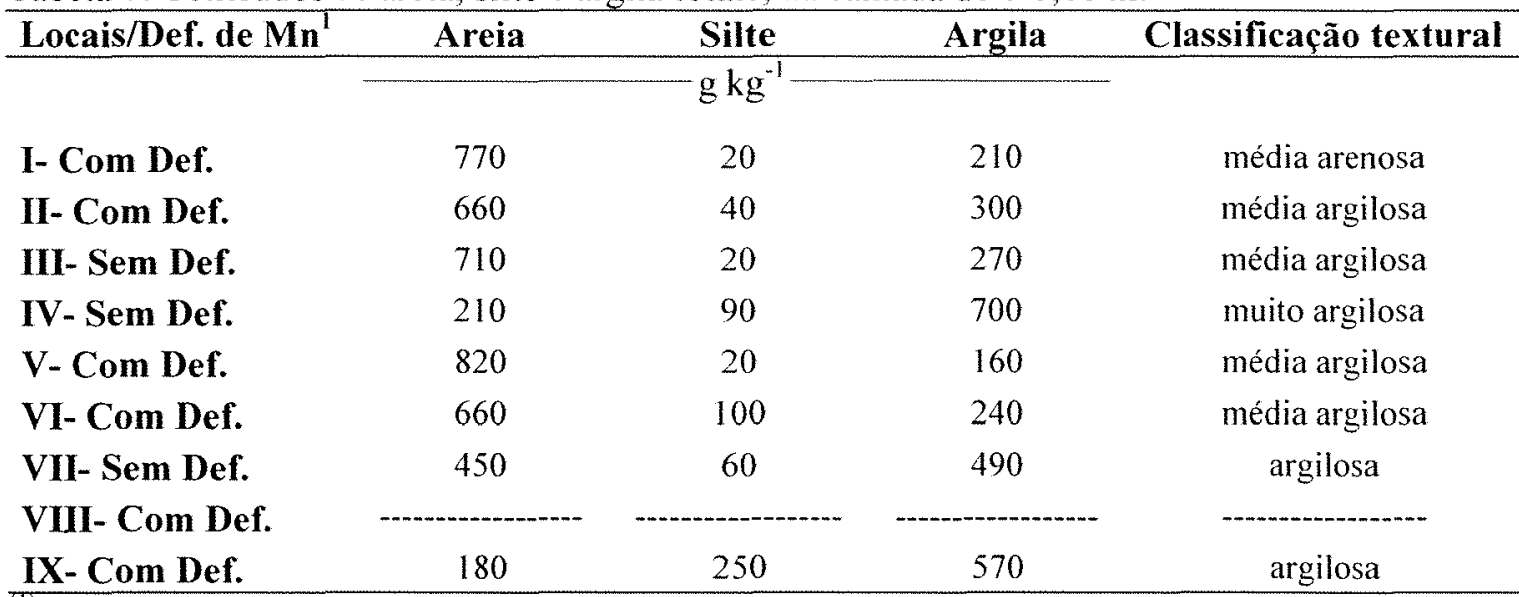

(1) Local I: Faz. Santa Rosa; Locais II e III: Faz. Novo Horizonte; Local IV: Campo Experimental da Fundação ABC; Locais V e VI: Faz. Capão da Onça; Local VII: Faz. Curralinho; Local VIII: Faz. Boa Vista e Local IX: Faz. São Daniel. Com Def.: local com constatação de deficiência de Mn em soja; Sem Def.: local onde não é constatada deficiência. Os locais I, II, III e VIII estão localizados no município de Tibagi; os locais V e VI em Ponta Grossa e os locais IV, VII e IX em Castro, PR. -.-: teor não medido.

\subsubsection{Condução do experimento no campo}

Dos nove locais, quatro foram selecionados para cultivo de soja e obtenção de curvas de resposta ao Mn, sendo dois locais com constatação de deficiência de Mn (I e II) e dois com teores considerados adequados e sem constatação de defíciência em campo (III e IV).

Para obtenção da amplitude desejada dos teores de Mn no solo e na planta, utilizaram-se sete doses de $\mathrm{Mn}\left(0 ; 1,5 ; 3 ; 6 ; 12 ; 24\right.$ e $\left.48 \mathrm{~kg} \mathrm{ha}{ }^{-1}\right)$, na forma de $\mathrm{MnSO}_{4}$ ( $31 \%$ de Mn), aplicadas manualmente, a lanço, no dia 23/10/2001, antes da semeadura da soja. Para equalização do $\mathrm{S}$ aplicado na forma de $\mathrm{MnSO}_{4}$, utilizou-se $\mathrm{S}$ na forma elementar. Devido aos baixos teores de B, em todos os locais aplicaram-se $2 \mathrm{~kg} \mathrm{ha}^{-1}$ do nutriente a lanço, na forma de ácido bórico (17\% de B). Pela mesma razão, foi aplicado no Local II $5 \mathrm{~kg} \mathrm{ha}^{-1}$ de $\mathrm{Zn}$, a lanço, na forma se sulfato de zinco heptahidratado (20\% de $\mathrm{Zn}$ ).

$\mathrm{O}$ delineamento experimental foi o de blocos ao acaso (quatro blocos). $\mathrm{O}$ tamanho das parcelas correspondeu a $2,8 \mathrm{~m} \times 8 \mathrm{~m}$ de comprimento $\left(22,4 \mathrm{~m}^{2}\right)$. Antes da semeadura da soja, efetuou-se a dessecação das plantas daninhas utilizando-se $1 \mathrm{~kg} \mathrm{ha}^{-1}$ 
de glyphosate (720 $\mathrm{g} \mathrm{kg}^{-1}$ ) nos locais I, II e III. No Local IV, utilizou-se $1 \mathrm{~L} \mathrm{ha}^{-1}$ de glyphosate $\left(360 \mathrm{~g} \mathrm{~L}^{-1}\right)$.

A semeadura da soja (cv. BRS 133) foi efetuada no dia 23/10/2001 nos locais II e III; no dia 31/10/2001 no Local I; e em 01/11/2001 no Local IV. Nos locais I e IV utilizaram-se o espaçamento de $0,40 \mathrm{~m}$ entre linhas, e nos demais, $0,45 \mathrm{~m}$. Na adubação de plantio dos locais I, II e III utilizaram-se $250 \mathrm{~kg} \mathrm{ha}^{-1}$ da fórmula $0-25-25$ devido à menor fertilidade dos solos nesses locais; e no Local IV, empregaram-se $100 \mathrm{~kg} \mathrm{ha}^{-1} \mathrm{da}$ fórmula 0-26-26. A adubação foi baseada nas recomendações técnicas da Fundação $\mathrm{ABC}$.

As sementes de soja foram inoculadas em meio líquido com $150 \mathrm{~mL}$ de inoculante por $50 \mathrm{~kg}$ de sementes. No tratamento das sementes utilizadas nos locais I e $\mathrm{IV}$, utilizaram-se $60 \mathrm{~mL}$ de carbendazin $\left(500 \mathrm{~g} \mathrm{~L}^{-1}\right)$ e $140 \mathrm{~g}$ de thiram $\left(700 \mathrm{~g} \mathrm{~kg}^{-1}\right)$ para cada $100 \mathrm{~kg}$ de sementes. Nos locais II e III, empregaram-se $160 \mathrm{~g}$ de captan $\left(750 \mathrm{~g} \mathrm{~kg}^{-1}\right)$ para $100 \mathrm{~kg}$ de sementes.

No Local I, o controle de plantas daninhas de folhas largas foi realizado utilizando-se $40 \mathrm{~g} \mathrm{ha}^{-1}$ de chlorimuron-ethyl $\left(250 \mathrm{~g} \mathrm{~kg}^{-1}\right)+0,25 \mathrm{~L} \mathrm{ha}^{-1}$ de lactofen $(240 \mathrm{~g}$ $\left.\mathrm{L}^{-1}\right)$ e o controle das gramíneas, com $0,25 \mathrm{~L} \mathrm{ha}^{-1}$ de clothodim $\left(240 \mathrm{~g} \mathrm{~L}^{-1}\right)$. Efetuou-se o controle de lagartas utilizando-se $100 \mathrm{~g} \mathrm{ha}^{-1}$ de diflubenzuron $\left(250 \mathrm{~g} \mathrm{~kg}^{-1}\right)$ e o de percevejos, aplicando-se $125 \mathrm{~mL} \mathrm{ha}^{-1}$ de permetrin $\left(250 \mathrm{~g} \mathrm{~L}^{-1}\right)$. Para controle de doenças fúngicas de final de ciclo realizou-se uma aplicação de $0,2 \mathrm{~L} \mathrm{ha}^{-1}$ de difenoconazole $\left(250 \mathrm{~g} \mathrm{~L}^{-1}\right)$.

Nos locais II e III, o controle de plantas daninhas de folhas largas foi realizado utilizando-se $0,9 \mathrm{~L} \mathrm{ha}^{-1}$ do herbicida de pré-emergência, flumetsulam $\left(120 \mathrm{~g} \mathrm{~L}^{-1}\right)$, aplicado junto com dessecante glyphosate e o controle das gramíneas, com $0,25 \mathrm{~L} \mathrm{ha}^{-1}$ de clothodim $\left(240 \mathrm{~g} \mathrm{~L}^{-1}\right)$. Efetuaram-se o controle de lagartas utilizando-se $100 \mathrm{~g} \mathrm{ha}^{-1} \mathrm{de}$ diflubenzuron $\left(250 \mathrm{~g} \mathrm{~kg}^{-1}\right)$ e de percevejos, aplicando-se $120 \mathrm{~mL} \mathrm{ha}^{-1}$ de lambdacyhalothrin $\left(50 \mathrm{~g} \mathrm{~L}^{-1}\right)$. Com esse último tratamento foi aplicado $0,5 \mathrm{~kg} \mathrm{ha}^{-1} \mathrm{de}$ fluquinconazole para controle de doenças fúngicas de final de ciclo. Com esse mesmo objetivo, realizou-se também uma aplicação de $0,2 \mathrm{~L} \mathrm{ha}^{-1}$ difenoconazole $\left(250 \mathrm{~g} \mathrm{~L}^{-1}\right)$. 
No Local IV, para o controle das plantas daninhas utilizaram-se $0,8 \mathrm{~L} \mathrm{ha}^{-1}$ da mistura comercial de fluazifop-p-butil $\left(125 \mathrm{~g} \mathrm{~L}^{-1}\right)+$ fomesafen $\left(125 \mathrm{~g} \mathrm{~L}^{-1}\right)$, além dos herbicidas fomesafen $\left(125 \mathrm{~g} \mathrm{~L}^{-1}\right)$ e clothodin $\left(240 \mathrm{~g} \mathrm{~L}^{-1}\right)$, nas dosagens de 0,6 e $0,4 \mathrm{~L}$ $\mathrm{ha}^{-1}$, respectivamente. Durante o cultivo da soja, efetuaram-se o controle de lagartas utilizando-se $0,12 \mathrm{~L} \mathrm{ha}^{-1}$ de beta-cyfluthrin $\left(50 \mathrm{~g} \mathrm{~L}^{-1}\right)$; do bicudo da soja com $0,2 \mathrm{~L} \mathrm{ha}^{-1}$ de alpha-cypermetrin $\left(100 \mathrm{~g} \mathrm{~L}^{-1}\right)$ e de percevejos, aplicando-se $0,4 \mathrm{~L} \mathrm{ha}^{-1}$ de monocrotophos $\left(400 \mathrm{~g} \mathrm{~L}^{-1}\right)$.

A precipitação pluvial da época de aplicação do Mn no solo até a coleta de solo e folha foi de aproximadamente $470 \mathrm{~mm}$ nos locais I, II e III, e cerca de $450 \mathrm{~mm}$, no Local IV. Se for considerada a precipitação até a colheita da soja, os valores foram de 731 e $712 \mathrm{~mm}$, na ordem citada acima. A necessidade de água durante todo o ciclo da cultura da soja, varia de 450 a $800 \mathrm{~mm}$, dependendo das condições climáticas, do manejo da cultura e da duração do ciclo (EMBRAPA, 1998). No entanto, vale ressaltar que houve um veranico entre os dias 19/10 a 09/11/02 em Tibagi, PR, que prejudicou germinação e o desenvolvimento inicial da soja semeada no dia 23/10/02 nos locais II e III, e daquela semeada no Local I, no dia 31/10/2002.

A colheita da soja foi realizada manualmente nos dias 15 e 16 de abril de 2002 , e a trilhagem foi realizada mecanicamente, utilizando-se debulhadora de grãos estacionária, peneirando-se logo em seguida, pesando-se os grãos e lendo-se a umidade. Para os cálculos da produtividade, considerou-se um teor de umidade nos grãos de $13 \%$.

\subsubsection{Coleta e preparo das amostras de terra e folha}

As amostras de terra e de plantas foram coletadas no dia 23/01/2002, quando a soja dos locais II, III e IV encontrava-se no início do florescimento (estádio - R2) e a soja do Local I, no estádio imediatamente anterior ao estádio reprodutivo, R1. As amostras de terra foram retiradas com trado calador na profundidade de $0,00-0,10 \mathrm{~m}$, em número de 20 amostras simples por parcela. Estas amostras foram secas em estufa a $40^{\circ} \mathrm{C}$, destorroadas, moídas e passadas em peneira de $0,002 \mathrm{~m}$. Nessas amostras foram 
determinados os teores de Mn com quatro extratores (DTPA-TEA, pH 7,3; Mehlich I, Mehlich III e $\mathrm{HCl} 0,1 \mathrm{~mol} \mathrm{~L}^{-1}$ ), conforme metodologias descritas no estudo 1.

Nas amostras dos tratamentos 0,12 e $48 \mathrm{~kg} \mathrm{ha}^{-1}$ de Mn do Local I foi realizada a extração seqüencial de $\mathrm{Mn}$, conforme metodologia descrita no item 3.1.7. Amostras de $\mathrm{AH}$ dos locais I e II, das parcelas que receberam $48 \mathrm{~kg} \mathrm{ha}^{-1}$ de $\mathrm{Mn}$ foram extraídas, segundo metodologia apresentada no item 3.1.8. Nas amostras sólidas de AH foram quantificados os radicais orgânicos tipo semiquinona por RPE, e em amostras sólidas e em solução (pH 3,0 e 2,5) foram avaliadas por essa técnica as interações dos metais com os grupos funcionais dos $\mathrm{AH}$, conforme metodologia descrita no item 3.1.9.

No caso das amostras de plantas, coletaram-se duas amostras por parcela (parte aérea) com $0,5 \mathrm{~m}$ de comprimento cada. Após a coleta, as amostras foram lavadas em água desionizada, colocadas para secar em estufa a $65^{\circ} \mathrm{C}$ até atingir massa constante, pesadas e moídas. Nessas amostras foram analisadas as concentrações de Mn, conforme metodologias de Malavolta et al. (1997), descritas no estudo 1.

\subsubsection{Análise estatística}

Os resultados dos teores de $\mathrm{Mn}$ no solo, concentração e quantidade acumulada de $\mathrm{Cu}, \mathrm{Fe}, \mathrm{Mn}$ e $\mathrm{Zn}$ e produção de grãos foram submetidos à análise de variância (teste F), seguida de análise de regressão. Essa análise foi realizada separadamente para cada local (I, II, III e IV). O mesmo tipo de análise citado acima foi realizado para os resultados obtidos na extração seqüencial do Mn do Local I, após a aplicação do nutriente no solo (doses 0,12 e $48 \mathrm{~g} \mathrm{ha}^{-1}$ ).

Para a escolha do melhor extrator para Mn foram realizados estudos de correlação linear simples entre o teor do elemento no solo, avaliado pelos diversos extratores, com a concentração e a quantidade acumulada na parte aérea. Essa análise foi realizada para cada local e também utilizando-se os resultados de todos os locais em conjunto. 


\section{RESULTADOS E DISCUSSÃO}

\subsection{Estudo 1}

\subsubsection{Atributos químicos do solo}

Comparando-se os resultados obtidos após 12 anos de cultivo (Tabela 8) com os de 1993 (Tabela 4), nota-se que os teores de P e MO aumentaram em todos os tratamentos. As elevações dos teores de $\mathrm{P}$ podem ser atribuídas à adubação fosfatada realizada no período. Os aumentos dos teores de MO ocorreram devido ao aumento na utilização de insumos e da adoção de rotações de culturas, após o início do experimento (Tabela 3). A ausência de variabilidade no teor de $\mathrm{K}$ pode ser devida à elevação na quantidade exportada pelas culturas. Também não eram esperadas grandes variações nos teores de Ca e Mg, uma vez que a última calagem foi realizada em 1994.

Diferentemente de outros resultados obtidos fora do Brasil, em que os valores de pH da camada superficial são geralmente menores nos solos sob SSD em relação ao SSC, os valores de pH não foram modificados pelos sistemas de preparo (Tabelas 8 e 9).

A diminuição dos valores de $\mathrm{pH}$ em solos cultivados sob SSD é provocada pela aplicação de elevadas doses de fertilizantes nitrogenados, em locais com monocultivos de milho e/ou com rotações com predomínio de gramíneas (Bowman \& Halvorson, 1998; Follett \& Peterson, 1988; Grove \& Blevins, 1988; Juo et al., 1995). Nessa situação, a ausência de revolvimento da camada arável faz com que os íons $\mathrm{H}^{+}$ produzidos durante o processo de nitrificação e os ácidos orgânicos formados durante a mineralização da MO acumulem na superfície (Bowman \& Halvorson 1998). Desse modo, todo processo de acidificação limita-se a essa profundidade (Bowman \& Halvorson, 1998; Follett \& Peterson, 1988; Franzluebbers \& Hons, 1996). 
A acidificação da camada superficial dos solos cultivados sob SSD no Brasil é controlada pela calagem em superfície (Caires et al., 2000; Moreira, 1999; Sá, 1995a), além de ser evitada pela inclusão da soja na rotação em praticamente todas as áreas sob SSD, evitando-se a monocultura de milho. Em solo norte-americano, Edwards et al. (1992) observaram maior acidez nas camadas superficiais nos solos em que havia monocultivo de milho, comparado aos locais que o milho era cultivado em rotação com a soja, devido à menor utilização de nitrogenados no sistema. Em solo africano, Juo et al. (1995) observaram que o decréscimo no valor de $\mathrm{pH}$ causado pela adubação nitrogenada na rotação milho/caupi (Vigna unguiculata) foi $57 \%$ do valor causado pelo monocultivo de milho.

Tabela 8. Atributos químicos de um LATOSSOLO VERMELHO cultivado sob diferentes métodos de preparo por 12 anos consecutivos, em diferentes profundidades (médias de três repetições).

\begin{tabular}{|c|c|c|c|c|c|c|c|c|c|}
\hline $\begin{array}{l}\text { Método de } \\
\text { Preparo }^{1}\end{array}$ & $\underset{\mathrm{CaCl}_{2}}{\mathrm{pH}}$ & $\mathbf{P}$ & MO & $\mathbf{C}^{2}$ & $\mathbf{K}$ & $\mathrm{Ca}$ & $\mathbf{M g}$ & CTC & $\bar{V}$ \\
\hline
\end{tabular}

\begin{tabular}{|c|c|c|c|c|c|c|c|c|c|}
\hline \multicolumn{10}{|c|}{$0,00-0,05 \mathrm{~m}$} \\
\hline SSD & $5,6 \mathrm{Aa}^{3}$ & $83 \mathrm{Aa}$ & $58 \mathrm{Aa}$ & $37,2 \mathrm{Aa}$ & $4,4 \mathrm{Aa}$ & $71,3 \mathrm{Aa}$ & $28,3 \mathrm{Aa}$ & $136,7 \mathrm{Aa}$ & $75 \mathrm{Aa}$ \\
\hline SSC & $5,9 \mathrm{Aa}$ & $39 \mathrm{Ab}$ & $46 \mathrm{Ac}$ & $26,9 \mathrm{Ab}$ & $4,1 \mathrm{Aa}$ & $45,0 \mathrm{Aa}$ & $19,0 \mathrm{Aa}$ & $104,1 \mathrm{Aa}$ & $65 \mathrm{Aa}$ \\
\hline PM & $6,0 \mathrm{Aa}$ & $42 \mathrm{Aab}$ & $51 \mathrm{Abc}$ & $30,3 \mathrm{Ab}$ & $4,4 \mathrm{Aa}$ & $48,7 \mathrm{Aa}$ & $20,0 \mathrm{Aa}$ & $106,4 \mathrm{Aa}$ & $69 \mathrm{Aa}$ \\
\hline SSD/prep. & $5,5 \mathrm{Aa}$ & $60 \mathrm{Aab}$ & $56 \mathrm{Aab}$ & $36,2 \mathrm{Aa}$ & $4,0 \mathrm{Aa}$ & $50,0 \mathrm{Aa}$ & $22,3 \mathrm{Aa}$ & $115,0 \mathrm{Aa}$ & $66 \mathrm{Aa}$ \\
\hline \multicolumn{10}{|c|}{$0,05-0,10 \mathrm{~m}$} \\
\hline SSD & $5,5 \mathrm{Aa}$ & $78 \mathrm{Aa}$ & $44 \mathrm{Ba}$ & $26,5 \mathrm{Ba}$ & $3,2 \mathrm{Aa}$ & $54,7 \mathrm{Aa}$ & $21,7 \mathrm{Aa}$ & $114,2 \mathrm{Aa}$ & $70 \mathrm{Aa}$ \\
\hline SSC & $5,6 \mathrm{Aa}$ & $32 \mathrm{Ab}$ & $45 \mathrm{Aa}$ & $26,5 \mathrm{Aa}$ & $2,8 \mathrm{Aa}$ & $41,7 \mathrm{Aa}$ & 17,3 $\mathrm{Aa}$ & $99,2 \mathrm{Aa}$ & $62 \mathrm{Aa}$ \\
\hline PM & $6,0 \mathrm{Aa}$ & $40 \mathrm{ABab}$ & $49 \mathrm{Aa}$ & $28,9 \mathrm{Aa}$ & 3,0 Aa & $45,7 \mathrm{Aa}$ & $19,3 \mathrm{Aa}$ & $102,3 \mathrm{Aa}$ & $66 \mathrm{Aa}$ \\
\hline SSD/prep. & $5,5 \mathrm{Aa}$ & $44 \mathrm{Aab}$ & $43 \mathrm{Ba}$ & $27,9 \mathrm{Ba}$ & $2,6 \mathrm{Aa}$ & $46,7 \mathrm{Aa}$ & $19,0 \mathrm{Aa}$ & $102,9 \mathrm{Aa}$ & $66 \mathrm{Aa}$ \\
\hline \multicolumn{10}{|c|}{$0,10-0,20 \mathrm{~m}$} \\
\hline SSD & $5,9 \mathrm{Aa}$ & $37 \mathrm{Ba}$ & $40 \mathrm{Ba}$ & $22,7 \mathrm{Ca}$ & 2,9 Aa & $40,7 \mathrm{Aa}$ & $18,7 \mathrm{Aa}$ & $100,6 \mathrm{Aa}$ & $62 \mathrm{Aa}$ \\
\hline SSC & $5,8 \mathrm{Aa}$ & $29 \mathrm{Aa}$ & $44 \mathrm{Aa}$ & $24,2 \mathrm{Aa}$ & 2,7 Aa & $43,7 \mathrm{Aa}$ & $17,7 \mathrm{Aa}$ & $100,4 \mathrm{Aa}$ & $63 \mathrm{Aa}$ \\
\hline PM & 5,9 Aa & $22 \mathrm{Ba}$ & $39 \mathrm{Ba}$ & $22,9 \mathrm{Ba}$ & $2,7 \mathrm{Aa}$ & $40,0 \mathrm{Aa}$ & $18,0 \mathrm{Aa}$ & $94,4 \mathrm{Aa}$ & $64 \mathrm{Aa}$ \\
\hline SSD/prep. & $5,4 \mathrm{Aa}$ & $41 \mathrm{Aa}$ & $41 \mathrm{Ba}$ & $23,2 \mathrm{Ca}$ & $2,0 \mathrm{Aa}$ & $41,3 \mathrm{Aa}$ & $14,7 \mathrm{Aa}$ & $97,3 \mathrm{Aa}$ & $58 \mathrm{Aa}$ \\
\hline C.V & $6,7 \%$ & $20,3 \%$ & $6,2 \%$ & $4,9 \%$ & $7,7 \%$ & $18,2 \%$ & $12,6 \%$ & $9,6 \%$ & $7,6 \%$ \\
\hline
\end{tabular}

(1) SSD: sistema de semeadura direta; SSC: sistema de semeadura convencional - uma aração com arado de discos $(\cong 0,20 \mathrm{~m})$ e uma gradagem com grade niveladora $(\cong 0,10 \mathrm{~m})$, antes dos cultivos de verão e inverno a cada ano; PM: preparo mínimo - uma gradagem com grade aradora $(\cong 0,17 \mathrm{~m})$ e duas com grade niveladora $(\cong 0,10 \mathrm{~m})$, antes dos cultivos de verão e inverno de cada ano; SSD/prep.: SSD com escarificação ( $\cong 0,30$ $\mathrm{m})$ a cada três anos (inverno). ${ }^{(2)}$ carbono determinado por combustão via seca. ${ }^{(3)}$ Letras minúsculas comparam métodos de preparo dentro de cada profundidade e as maiúsculas comparam profundidades dentro de cada método de preparo, pelo teste de Tukey a $5 \%$. 
A ausência de variação nos valores de $\mathrm{pH}$, devido aos métodos de preparo (Tabelas 8 e 9), pode ser atribuída em grande parte à pequena quantidade de $\mathrm{N}$ utilizada, uma vez que a soja é a principal cultura na rotação. Além disso, as quantidades de $\mathrm{N}$ utilizadas nas culturas de milho e trigo são bem menores do que àquelas utilizadas em condições americanas (Tabela 3). Considerando-se os últimos três anos (1999 a 2001), foram aplicados na área de estudo $162,5 \mathrm{~kg} \mathrm{ha}^{-1}$ de $\mathrm{N}\left(97,5 \mathrm{e} 65 \mathrm{~kg} \mathrm{ha}^{-1}\right.$ nas culturas do milho em 1999 e no trigo em 2001, respectivamente), ou seja, cerca de $54 \mathrm{~kg} / \mathrm{ha} / \mathrm{ano}$. Durante um ano, Edwards et al. (1992) aplicaram o total de $280 \mathrm{~kg} \mathrm{ha}^{-1} \mathrm{de} \mathrm{N}$, nas culturas de trigo e milho. Rhoton (2000) utilizou, na mesma situação, $274 \mathrm{~kg} \mathrm{ha}^{-1} \mathrm{de} \mathrm{N}$. Vale destacar que Grove \& Blevins (1988) não observaram reduções nos valores de pH com doses anuais de até $168 \mathrm{~kg} \mathrm{ha}^{-1}$ na cultura do milho.

Tabela 9. Atributos químicos de um LATOSSOLO VERMELHO cultivado sob diferentes métodos de preparo por 12 anos consecutivos, na camada de 0,00-0,20 m (média ponderada das camadas de $0,00-0,05 ; 0,05-0,10$ e $0,10-0,20 \mathrm{~m}$ ).

\begin{tabular}{|c|c|c|c|c|c|c|c|c|c|}
\hline $\begin{array}{l}\text { Método de } \\
\text { Preparo }\end{array}$ & $\underset{\mathrm{CaCl}_{2}}{\mathbf{p H}}$ & $\mathbf{P}$ & MO & $\mathrm{C}^{2}$ & $\mathbf{K}$ & $\mathbf{C a}$ & $\mathrm{Mg}$ & CTC & $\mathbf{V}$ \\
\hline & & $\mathrm{mg} \mathrm{dm}^{-3}$ & \multicolumn{2}{|c|}{$\mathrm{g} \mathrm{dm}^{-3}$} & \multicolumn{4}{|c|}{$\mathrm{mmol}_{\mathrm{c}} \mathrm{dm}^{-3}$} & $\%$ \\
\hline SSD & $5,8 \mathrm{a}$ & $59 a$ & $46 \mathrm{a}$ & $27 \mathrm{a}$ & $3,4 \mathrm{a}$ & $52 a$ & $22 a$ & $113 a$ & $67 \mathrm{a}$ \\
\hline SSC & $5,8 \mathrm{a}$ & $32 b$ & $45 \mathrm{a}$ & $25 \mathrm{a}$ & $3,1 \mathrm{a}$ & $44 \mathrm{a}$ & $17 \mathrm{~b}$ & $101 \mathrm{a}$ & $64 \mathrm{a}$ \\
\hline $\mathbf{P M}$ & $5,9 \mathrm{a}$ & $31 \mathrm{~b}$ & $44 \mathrm{a}$ & $26 \mathrm{a}$ & $3,2 \mathrm{a}$ & $44 a$ & $19 \mathrm{ab}$ & $99 \mathrm{a}$ & $66 \mathrm{a}$ \\
\hline SSD/prep. & $5,4 \mathrm{a}$ & $47 \mathrm{ab}$ & $45 \mathrm{a}$ & $28 \mathrm{a}$ & $2,7 \mathrm{a}$ & $45 \mathrm{a}$ & $19 a b$ & $103 a$ & $52 \mathrm{a}$ \\
\hline
\end{tabular}

(1) SSD; sistema de semeadura direta; SSC: sistema de semeadura convencional - uma aração com arado de discos $(\cong 0,20 \mathrm{~m})$ e uma gradagem com grade niveladora $(\cong 0,10 \mathrm{~m})$, antes dos cultivos de verão e inverno a cada ano; PM: preparo mínimo - uma gradagem com grade aradora $(\cong 0,17 \mathrm{~m})$ e duas com grade niveladora $(\cong 0,10 \mathrm{~m})$, antes dos cultivos de verão e inverno de cada ano; SSD/prep.: SSD com escarificação $(\cong 0,30 \mathrm{~m})$ a cada três anos (inverno). ${ }^{(2)}$ carbono determinado por combustão via seca. ${ }^{(\hat{)})}$ Letras minúsculas comparam métodos de preparo, pelo teste de Friedman a $5 \%$.

Os teores de $\mathrm{P}$ das camadas superficiais foram inversamente proporcionais à intensidade do preparo do solo (Tabela 8). Os teores médios da camada de 0,00-0,20 m também foram maiores no SSD, comparado ao SSC (Tabela 9). Resultados similares foram observados por outros autores em condições norte-americanas (Kitur et al., 1994; Motta et al., 2002; Rhoton, 2000; Selles et al., 1997). 
No presente estudo, os resultados mencionados acima eram esperados pois à medida que aumenta-se a intensidade de preparo eleva-se o contato do $\mathrm{P}$ aplicado como fertilizante com as partículas do solo (Castro, 1995; Hargrove et al., 1982; Muzilli, 1985; Sidiras \& Pavan, 1985) e, consequentemente, a probabilidade de sua fixação aos colóides do solo. No SSD, a ausência de revolvimento do solo diminui a superficie de contato do $\mathrm{P}$ aplicado com os colóides e, desse modo, reduz as reações de fixação do $\mathrm{P}$, aumentando sua disponibilidade. Além disso, no SSD há aumento das formas de $\mathrm{P}$ orgânico causado pelo aumento da MO (Sá, 1995b).

Os teores de MO, obtidos por oxidação com dicromato de potássio, na presença de $\mathrm{H}_{2} \mathrm{SO}_{4}$ e quantificados por colorimetria (metodologia de rotina) apresentaram boa relação com os teores de $\mathrm{C}$ determinados por combustão via seca. Esse fato pode ser comprovado pela multiplicação dos teores de C obtidos por combustão por 1,72.

Os teores de $\mathrm{C}$ e $\mathrm{MO}$ da camada superficial foram inversamente proporcionais à intensidade do preparo do solo (Tabela 8). Ambos foram mais elevados no SSD em relação ao SSC. Resultados similares foram obtidos por Motta et al. (2002), em condições norte-americanas, e por Bayer et al. (2002a) e Bayer et al. (2002b), em solos do Rio Grande do Sul, em que as condições de umidade e temperatura são semelhantes às do local do estudo (Região Centro-Sul do Paraná).

Teores de MO mais elevados no solo sob SSD em relação ao SSC estão relacionados à decomposição mais lenta dos resíduos vegetais na superfície (Bayer et al., 2002 b,c; Franchini et al., 2002) em decorrência das menores temperaturas e aeração do solo, face ao não revolvimento no SSD, uma vez que a quantidade de material vegetal introduzida é a mesma em ambos os sistemas (Castro, 1995; Centurion, 1988).

No SSC, o revolvimento do solo acelera a decomposição da MO porque aumenta a aeração do solo e a atividade dos microorganismos (Bayer et al., 2002b,c; Franchini et al., 2002; Sidiras \& Pavan, 1985). Desse modo, diversos resultados de pesquisas em várias localidades têm demonstrado aumento na camada superficial dos teores de MO (Bayer et al., 2002a; Bayer et al., 2002b; Kitur et al., 1994; Motta et al., 2002; Paiva et al., 1997; Rhoton, 2000) nos solos sob SSD. 
A elevação dos teores de MO na superficie de solos sob SSD é mais rápida através da utilização de seqüências de cultivo com predominância de gramíneas, as quais produzem altas quantidades de resíduos (Havlin et al., 1990; Lal et al., 1990; Santos \& Siqueira, 1996).

Apesar de a variação nos teores de MO ter ocorrido apenas na camada superficial, a MO dessa camada tem importante papel na qualidade do solo. Bruce et al. (1995) observaram que a manutenção da MO nos primeiros centímetros foi essencial para aumentar a infilttração e a disponibilidade de água em Ultissolos degradados. Desse modo, a manutenção da MO em solos sob SSD reduz a erosão, melhorando a conservação do solo e água e diminuindo as perdas de nutrientes (Castro et al., 1986; Dedecek et al., 1986; Vieira et al., 1978).

Os teores de $\mathrm{K}$ não foram modificados pelos métodos de preparo (Tabelas 8 e 9). Os resultados quanto ao $\mathrm{K}$ encontrados na literatura tem sido contraditórios. Desse modo, alguns autores tem verificado maiores teores de $\mathrm{K}$ na camada superficial de solos cultivados sob SSD, comparado ao SSC (Motta et al., 2002; Sidiras \& Pavan, 1985) e, por sua vez, outros tem observado o inverso (Edwards et al., 1992; Hargrove et al., 1982; Rhoton, 2000). De acordo com Motta et al. (2002), diferenças na acumulação de resíduos, remoção de nutrientes pelas culturas, aplicação de fertilizantes e condições de lixiviação são fatores que contribuem para explicar as diferenças encontradas entre os sistemas de cultivo. Sidiras \& Pavan (1985) acreditam que no SSC ocorre maior mobilização do K através de lixiviação, erosão e utilização pelas plantas.

Quanto aos teores $\mathrm{Ca}$ e $\mathrm{Mg}$, somente os teores médios de $\mathrm{Mg}$ da camada de 0,00-0,20 m variaram com os métodos de preparo, sendo maiores no SSD, e menores no SSC (Tabela 9). Motta et al. (2002) observaram aumento dos teores de Ca e Mg apenas nas camadas superficiais de dois Ultissolos americanos. Os aumentos dos teores $\mathrm{Ca}$ e $\mathrm{Mg}$ dos solos sob SSD geralmente ocorrem após a calagem superficial (Caires et al., 1999; Moreira et al., 2001; Sá, 1995a). Os altos níveis de Ca e Mg em solos sob SSD foram atribuídos por Edwards et al. (1992) à elevação da CTC do solo devido ao aumento do teor de MO. No entanto, no presente estudo os valores da CTC não foram modificados pelos métodos de preparo. 
Os atributos químicos estudados modificaram-se pouco com a profundidade de coleta, sendo que as maiores variações ocorreram no SSD (Tabela 8). Nesse sistema de cultivo, os teores de $\mathrm{P}$ foram maiores nas camadas superficiais em relação à camada de 0,10-0,20 m, e os teores de $\mathrm{C}$ e $\mathrm{MO}$ foram maiores na camada superficial, comparada às inferiores. Esse fato ocorre porque sem o revolvimento do solo, a MO acumula-se na superfície. Além disso, a adubação e a calagem no SSD restringem-se à camada superficial, e o P é pouco móvel no solo. Moreira et al. (2001) obteve melhor uniformidade na distribuição de nutrientes no perfil em solo com nove anos de cultivo em SSD do que em solos com três e seis anos sob SSD. Com o aumento do tempo de cultivo sob SSD, a distribuição dos nutrientes no perfil do solo tende a ser mais homogênea (Crozier et al., 1999).

Apesar de o calcário ser um produto de baixa solubilidade, pode ocorrer sua movimentação por meio de poros e canais formados por organismos e pela decomposição de raizes (Oliveira \& Pavan, 1996), bem como por meio da formação de pares iônicos entre os produtos liberados pela decomposição dos restos culturais na

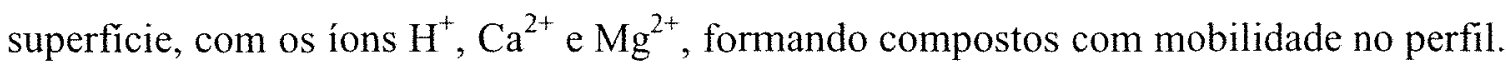
Com a lixiviação desses compostos, ocorre a reação dos pares iônicos com $\mathrm{H}^{+}$e $\mathrm{Al}^{3+}$ das camadas inferiores do solo, liberando $\mathrm{Ca}$ e $\mathrm{Mg}$ e, desta forma, aumentando o $\mathrm{pH}$ e os teores de $\mathrm{Ca}$ e $\mathrm{Mg}$, e diminuindo o Al tóxico em profundidade (Miyazawa et al., 1996b). Crozier et al. (1999), avaliando 59 solos norte-americanos sob SSD, observaram que os locais com mais de seis anos de cultivo apresentaram maior homogeneidade dos nutrientes no perfil, não mostrando diferenças entre as camadas de $0,00-0,10$ e $0,10-0,20$ $\mathrm{m}$, quanto aos valores de $\mathrm{pH}$ e aos teores de Ca. 


\subsubsection{Substâncias húmicas no solo}

$\mathrm{O}$ número de radicais orgânicos semiquinona dos $\mathrm{AH}$ extraídos da camada superficial foi diretamente proporcional à intensificação do preparo do solo (Figura 3). É consenso na literatura que quanto maior a quantidade de radicais livres semiquinonas obtidos por ressonância paramagnética eletrônica (RPE), maior é o grau de humificação das SH (Bayer et al., 2000; Martin-Neto et al., 1998). Deste modo, pode-se dizer que os $\mathrm{AH}$, extraídos da camada de 0,00-0,05 m, do solo sob SSC apresentaram-se mais humificados do que os AH do solo cultivado em SSD.

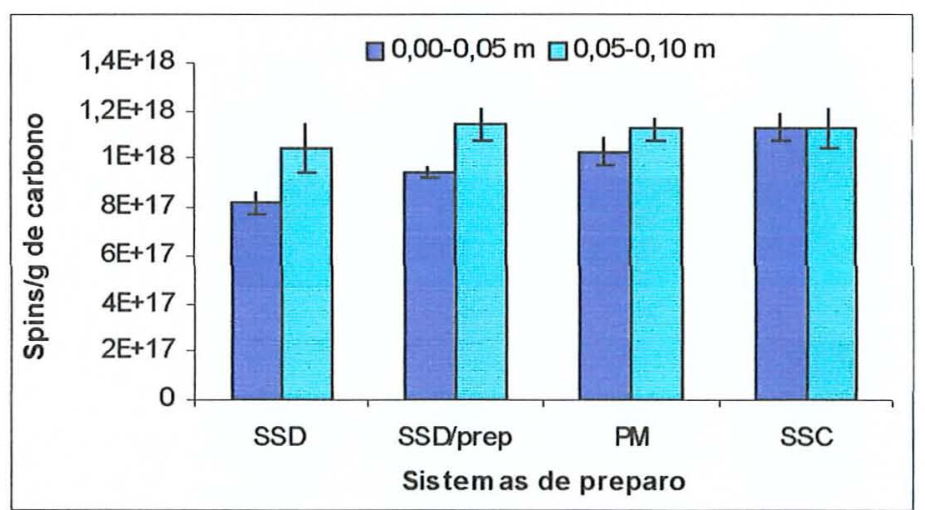

Figura 3 - Número de radicais livres semiquinona de amostras de AH, extraídas das camadas de 0,00-0,05 e 0,05-0,10 $\mathrm{m}$ do LATOSSOLO VERMELHO, submetido a diversos métodos de preparo (SSD: sistema de semeadura direta; SSC: sistema de semeadura convencional - uma aração com arado de discos $(\cong 0,20 \mathrm{~m})$ e uma gradagem com grade niveladora $(\cong 0,10 \mathrm{~m})$, antes dos cultivos de verão e inverno a cada ano; PM: preparo mínimo - uma gradagem com grade aradora $(\cong 0,17 \mathrm{~m})$ e duas com grade niveladora $(\cong 0,10 \mathrm{~m})$, antes dos cultivos de verão e inverno de cada ano; $\mathrm{SSD} /$ prep.: $\mathrm{SSD}$ com escarificação $(\cong 0,30 \mathrm{~m})$ a cada três anos (inverno)). As barras de erro representam o desvio padrão da média $(\mathrm{n}=2)$.

Os resultados obtidos no presente estudo são semelhantes a outros publicados na literatura, para solos do Rio Grande do Sul (Bayer et al., 2000; Bayer et al., 1996, Bayer et al., 2002b,c), em que as condições de umidade e temperatura são semelhantes às do local do estudo (Região Centro-Sul do Paraná).

Nos locais em que o solo é constantemente revolvido, o aumento das condições de aeração acelera a decomposição dos resíduos culturais, levando à formação de uma MO mais humificada (Bayer et al., 2002c). A menor taxa de decomposição da MO no 
SSD faz com que a MO recém adicionada tenha menor grau de humificação. Bayer et al. (2000) estudaram o efeito de 12 anos de cultivo sob SSD, com diferentes sistemas de culturas, sobre a quantidade de semiquinonas em amostras de AH. O incremento dos resíduos culturais decresceu o número de radicais livres porque a MO recém adicionada possui baixo grau de humificação, comparado ao das SH nativas do solo (Bayer et al., 2002b,c).

A rápida decomposição de restos culturais na superfície de solos sob SSC leva a síntese de polímeros (elevado peso molecular) estáveis no solo. Por sua vez, a decomposição em SSD é mais lenta, levando a coexistência de SH de vários tamanhos moleculares (baixo a elevado peso molecular) e composições (Evangelou \& Marsi, 2001). Estes autores observaram que as substâncias de menor peso molecular possuíam maior quantidade de grupos carboxílicos e fenólicos, as quais foram mais importantes na complexação de metais. No presente estudo observou-se tendência dos solos sob SSD apresentaram maior quantidade de radicais semiquinona (Figura 3) e portanto, menor síntese de polímeros estáveis no solo. Isto está em concordância com a hipótese de que em solos sob SSD pode estar ocorrendo maior grau de complexação de Mn pelos compostos de menor peso molecular. 


\subsubsection{Micronutrientes no solo}

\subsubsection{Cobre no solo}

Os teores de $\mathrm{Cu}$ extraídos pelos diferentes extratores não variaram com os métodos de preparo, em nenhuma das profundidades amostradas (Tabela 10). Resultados similares foram obtidos por outros autores (Edwards et al., 1992; Hargrove et al., 1982; Motta et al., 2002). No entanto, em solos cultivados sob SSD têm sido observados menores teores de $\mathrm{Cu}$ na camada de 0,00-0,05 $\mathrm{m}$ do que nas inferiores (Franzluebbers \& Hons 1996; Moreira, 1999; Motta \& Prevedello, 1995; Pauletti, 1998).

Em alguns casos, tem-se encontrado menores teores de $\mathrm{Cu}$ na camada superficial de solos sob SSD, comparado aos solos cultivados sob SSC (Franzluebbers \& Hons 1996; Rhoton, 2000; Shuman \& McCracken, 1999b). Essas variações vêm sendo atribuídas ao maior teor de MO da camada superficial dos solos sob SSD e à forte tendência do $\mathrm{Cu}$ em se ligar à MO (Basta \& Tabatabai, 1992; Franzluebbers \& Hons 1996; Sims, 1986). No presente estudo, houve correlação inversa e altamente significativa $(\mathrm{p}<0,01)$ entre o teor de $\mathrm{Cu}$ da camada superficial, extraído por $\mathrm{HCl} 0,1 \mathrm{~mol}$ $\mathrm{L}^{-1}$, e o teor de $\mathrm{MO}(\mathrm{r}=-0,84)$.

A ausência de variação nos teores de $\mathrm{Cu}$ observada no presente estudo (Tabela 10), pode ser atribuída à homogeneidade nos valores de $\mathrm{pH}$ do solo, em função dos tratamentos (Tabela 8). Edwards et al. (1992) observaram que os teores de $\mathrm{Cu}$ do solo não foram modificados pelos métodos de preparo, no entanto, quando utilizaram seqüências de culturas em que altas quantidades de $\mathrm{N}$ eram empregadas, houve abaixamento do $\mathrm{pH}$ e elevação da disponibilidade de $\mathrm{Cu}$. Em locais que foram empregadas altas doses de N, Follett \& Peterson (1988) também observaram maiores teores de Cu na camada superficial de solos sob SSD em relação aos cultivados sob SSC devido à redução do $\mathrm{pH}$ do solo sob SSD, causada pela adubação nitrogenada. 
Tabela 10. Teores de Cu obtidos por diferentes extratores em um LATOSSOLO VERMELHO cultivado sob diferentes métodos de preparo por 12 anos consecutivos, em diferentes profundidades (médias de três repetições).

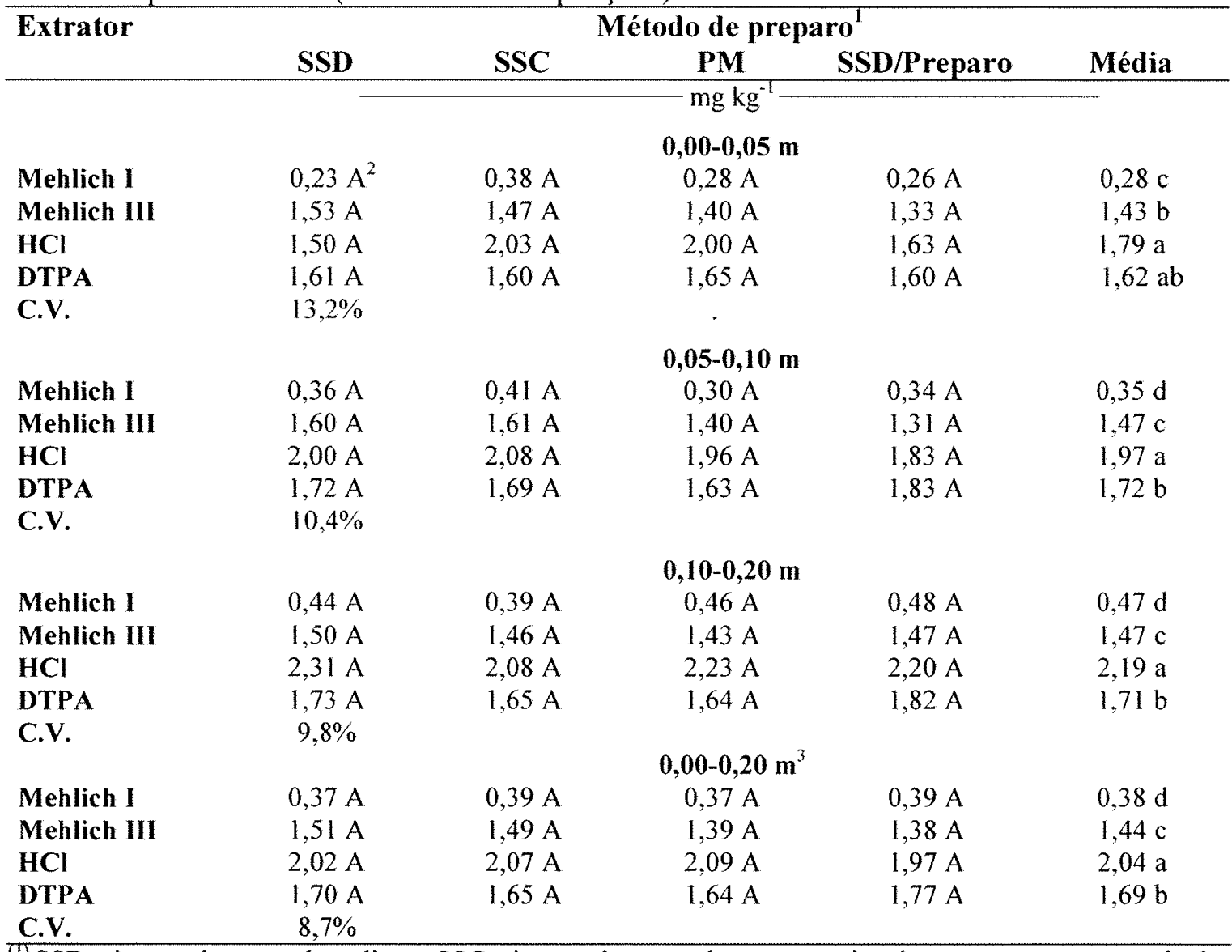

(1) SSD: sistema de semeadura direta; SSC: sistema de semeadura convencional - uma aração com arado de discos $(\cong 0,20 \mathrm{~m})$ e uma gradagem com grade niveladora $(\cong 0,10 \mathrm{~m})$, antes dos cultivos de verão e inverno a cada ano; PM: preparo mínimo - uma gradagem com grade aradora $(\cong 0,17 \mathrm{~m})$ e duas com grade niveladora $(\cong 0,10 \mathrm{~m})$, antes dos cultivos de verão e inverno de cada ano; SSD/Preparo: SSD com escarificação $(\cong 0,30 \mathrm{~m})$ a cada três anos (inverno). ${ }^{(2)}$ Letras maiúsculas comparam métodos de preparo e minúsculas comparam extratores dentro de cada profundidade, pelo teste de Tukey a $5 \% .{ }^{(3)}$ Os teores dessa camada são médias ponderadas dos teores das camadas de $0,00-0,05 ; 0,05-0,10$ e $0,10-0,20 \mathrm{~m}$.

A solução ácida Mehlich I extraiu os menores teores de $\mathrm{Cu}$ em todas as profundidades, e a solução de $\mathrm{HCl} 0,1 \mathrm{~mol} \mathrm{~L}^{-1}$, os maiores teores (Tabela 10). $\mathrm{O} \mathrm{HCl}$ extraiu maior quantidade de $\mathrm{Cu}$ do que os extratores Mehlich I e III porque possui menor valor de $\mathrm{pH}$ e, consequentemente, maior poder de solubilizar o $\mathrm{Cu}$ do solo. $\mathrm{O}$ fato de o DTPA TEA pH 7,3 ter extraído maior quantidade de $\mathrm{Cu}$ do que o Mehlich I e III pode ser atribuído à alta estabilidade do complexo DTPA-Cu, formado acima de $\mathrm{pH}$ 7,0 
(Tisdale et al., 1985). Apesar de o Mehlich III apresentar EDTA em sua constituição, a solução possui baixo valor de $\mathrm{pH}(\cong 2,4)$ e, de acordo com Norvell $(1991)$, a estabilidade do complexo formado entre EDTA (ou qualquer outro quelante) com o $\mathrm{Cu}$ é praticamente nula em meio ácido, devido à competição com o Fe. Além disso, a concentração do DTPA $\left(0,005 \mathrm{~mol} \mathrm{~L}^{-1}\right)$ na solução extratora é superior à do EDTA na solução Mehlich III $\left(0,001 \mathrm{~mol} \mathrm{~L}^{-1}\right)$.

As percentagens de $\mathrm{Cu}$ nas diferentes formas (trocável, orgânica, óxidos de $\mathrm{Fe} / \mathrm{Mn} / \mathrm{Al}$ e residual) não foram modificadas pelos métodos de preparo, com exceção da camada de 0,05-0,10 m (Tabela 11). Nessa camada, a percentagem de $\mathrm{Cu}$ na forma orgânica foi maior nos solos sob SSC e PM em relação ao solo sob SSD.

Por meio de espectroscopia de absorção atômica e de plasma não foi detectado $\mathrm{Cu}$ na forma trocável, em nenhum dos tratamentos (Tabela 11). Não se pode descartar a hipótese de que o extrator utilizado $\left(\operatorname{Sr}\left(\mathrm{NO}_{3}\right)_{2}\right)$ tenha sido ineficiente na extração do $\mathrm{Cu}$ trocável, mas é mais provável que os teores de $\mathrm{Cu}$ prontamente disponíveis às plantas sejam baixos no solo, devido aos valores de pH observados (Tabela 8). Cong-Tu \& Chen (2001) também não detectaram teores trocáveis de $\mathrm{Cu}$, extraídos com $\mathrm{Mg}\left(\mathrm{NO}_{3}\right)_{2} 0,05 \mathrm{~mol}$ $\mathrm{L}^{-1}$, em amostras de um Ferrossolo chinês $\left(\mathrm{pH}_{\text {agua }}=4,6\right)$, sem adição de fertilizantes.

Nos trabalhos de McLaren \& Crawford (1973), os teores de $\mathrm{Cu}$ solúveis + trocáveis de 16 solos, extraídos com $\mathrm{CaCl}_{2} 0,05 \mathrm{~mol} \mathrm{~L}^{-1}$, variaram de $0,1 \%\left(0,01 \mathrm{mg} \mathrm{kg}^{-1}\right)$ a $0,2 \%\left(0,5 \mathrm{mg} \mathrm{kg}^{-1}\right)$ do teor total. De acordo com Stevenson (1994), grande parte do $\mathrm{Cu}$ trocável ocorre em formas quelatadas, o que dificulta a extração com o sal utilizado no presente estudo $\left(\mathrm{Sr}\left(\mathrm{NO}_{3}\right)_{2} 0,1 \mathrm{~mol} \mathrm{~L}{ }^{-1}\right)$.

Acredita-se que os valores de $\mathrm{pH}$ em $\mathrm{CaCl}_{2}$, entre 5,4 a 6,0, associados aos altos teores de MO das camadas superficiais tenham influenciado negativamente a disponibilidade de Cu. Em condições controladas, Al-Sewailem et al. (1999) utilizaram partículas de areia cobertas com óxidos de $\mathrm{Fe}$ e verificaram que a maior adsorção do $\mathrm{Cu}$ aos óxidos ocorreu entre pH (água) 5,0 e 6,5. Bibak (1994) também demonstrou que a adsorção do $\mathrm{Cu}$ aos óxidos de $\mathrm{Al}$ e Fe (Ferrihidrita e goetita) e ao $\mathrm{AH}$ aumentou com a elevação do $\mathrm{pH}$. 
Tabela 11. Percentagem de $\mathrm{Cu}$ em diferentes frações e profundidades, em um LATOSSOLO VERMELHO, submetido a diferentes métodos de preparo do solo (médias de 12 repetições).

\begin{tabular}{|c|c|c|c|c|c|c|}
\hline \multirow{2}{*}{$\begin{array}{l}\text { Sistema de } \\
\text { preparo }\end{array}$} & \multicolumn{4}{|c|}{ Frações } & \multirow{2}{*}{$\begin{array}{c}\text { Soma das } \\
\text { frações }\end{array}$} & \multirow[t]{2}{*}{ Total } \\
\hline & Trocável & Orgânica & Óxidos & Residual & & \\
\hline & & & & & $\mathrm{mg} \mathrm{h}$ & + \\
\hline \multirow[b]{2}{*}{$\operatorname{SSD}^{I}$} & \multicolumn{6}{|c|}{$0,00-0,05 \mathrm{~m}$} \\
\hline & 0,0 & 7,1 & 21,7 & 71,2 & 27,4 & 28,5 \\
\hline SSD/prep. & 0,0 & 7,3 & 22,3 & 70,5 & 27,5 & 28,9 \\
\hline PM & 0,0 & 7,6 & 22,2 & 70,2 & 27,3 & 27,3 \\
\hline SSC & 0,0 & 6,2 & 23,6 & 70,2 & 26,9 & 27,2 \\
\hline Média & $0,0 \underline{D}^{2}$ & $7,0 \underline{\mathrm{C}}$ & $22,5 \underline{B}$ & $70,5 \underline{A}$ & & \\
\hline \multirow[t]{2}{*}{ C.V. } & 2,9 & & & & & \\
\hline & \multicolumn{6}{|c|}{$0,05-0,10 \mathrm{~m}$} \\
\hline SSD & $0,0 \mathrm{aD}$ & $5,1 \mathrm{bC}$ & $24,0 \mathrm{aB}$ & $71,0 \mathrm{aA}$ & 27,2 & 28,7 \\
\hline SSD/prep. & $0,0 \mathrm{aD}$ & $6,0 \mathrm{abc}$ & $23,8 \mathrm{aB}$ & $70,2 \mathrm{aA}$ & 27,5 & 28,3 \\
\hline PM & $0,0 \mathrm{aD}$ & $6,4 \mathrm{aC}$ & $22,7 \mathrm{aB}$ & $70,9 \mathrm{aA}$ & 27,1 & 27,9 \\
\hline SSC & $0,0 \mathrm{aD}$ & $6,5 \mathrm{aC}$ & $24,1 \mathrm{aB}$ & $69,4 \mathrm{aA}$ & 27,0 & 28,9 \\
\hline Média & 0,0 & 6,0 & 23,7 & 70,4 & & \\
\hline \multirow[t]{2}{*}{ C.V. } & 2,3 & & & & & \\
\hline & \multicolumn{6}{|c|}{$0,10-0,20 \mathrm{~m}$} \\
\hline SSD & 0,0 & 4,3 & 23,5 & 72,2 & 26,8 & 29,3 \\
\hline SSD/prep. & 0,0 & 4,5 & 23,8 & 71,7 & 27,5 & 29,9 \\
\hline PM & 0,0 & 5,1 & 23,1 & 71,8 & 27,6 & 28,1 \\
\hline SSC & 0,0 & 5,7 & 23,1 & 71,2 & 27,3 & 27,3 \\
\hline Média & $0,0 \underline{\mathrm{D}}$ & $4,9 \underline{C}$ & $23,4 \underline{\mathrm{B}}$ & $71,7 \underline{\mathrm{A}}$ & & \\
\hline \multirow[t]{2}{*}{ C.V. } & \multirow{2}{*}{\multicolumn{6}{|c|}{$0,00-0,20 \mathrm{~m}^{3}$}} \\
\hline & & & & & & \\
\hline $\begin{array}{l}\text { SSD } \\
\text { SSD/nren }\end{array}$ & 0,0 & 5,2 & 23,2 & 71,6 & 27,1 & 28,9 \\
\hline SSD/prep. & 0,0 & 5,6 & 23,4 & 71,0 & 27,5 & 29,3 \\
\hline PM & 0,0 & 6,1 & 22,8 & 71,2 & 27,4 & 27,9 \\
\hline SSC & 0,0 & 6,1 & 23,5 & 70,5 & 27,1 & 27,7 \\
\hline Média & $0,0 \underline{\mathrm{D}}$ & $5,7 \underline{\mathrm{C}}$ & 23,2 B & $71,1 \underline{\mathrm{A}}$ & & \\
\hline C.V. & 3,1 & & & & & \\
\hline
\end{tabular}

(1) SSD: sistema de semeadura direta; SSC: sistema de semeadura convencional - uma aração com arado de discos $(\cong 0,20 \mathrm{~m})$ e uma gradagem com grade niveladora $(\cong 0,10 \mathrm{~m})$, antes dos cultivos de verão e inverno a cada ano; PM: preparo mínimo - uma gradagem com grade aradora $(\cong 0,17 \mathrm{~m})$ e duas com grade niveladora $(\cong 0,10 \mathrm{~m})$, antes dos cultivos de verão e inverno de cada ano; SSD/prep.: SSD com escarificação $(\cong 0,30 \mathrm{~m})$ a cada três anos (inverno). ${ }^{(2)}$ Letras maiúsculas sublinhadas comparam frações dentro de profundidades; minúsculas comparam sistemas de preparos dentro de cada fração; e maiúsculas comparam frações dentro de métodos de preparo, pelo teste de Tukey a $5 \%$. Os dados originais apresentados foram transformados em arco seno $(\mathrm{X} / 100)^{1 / 2}$, para as análises estatísticas. ${ }^{(3)}$ Os teores dessa camada são médias ponderadas dos teores das camadas de 0,00-0,05; 0,05-0,10 e 0,10-0,20 m.

Nos solos argilosos, o Cu trocável diminui com o aumento do $\mathrm{pH}$ principalmente porque sua adsorção aos óxidos de Fe é aumentada (Sims, 1986). O aumento do pH diminui o excesso de cargas positivas da superficie dos óxidos, favorecendo a adsorção do $\mathrm{Cu}^{2+}$. Além disso, o aumento do $\mathrm{pH}$ eleva as formas $\mathrm{CuOH}^{+}$, que tem adsorção 
preferencial sobre $\mathrm{Cu}^{2+}$, devido sua menor energia de hidratação (Al-Sewailem et al., 1999). A elevação dos valores de pH também aumenta o número de sítios de ligação dos metais com a $\mathrm{MO}$ e, consequentemente, a quantidade adsorvida e a estabilidade da ligação (Sims \& Patrick, 1978).

A maior quantidade de $\mathrm{Cu}$ foi encontrada na fração residual, seguida da fração óxido e orgânica (Tabela 11). Resultados similares têm sido observados por outros autores em amostras de terra, sem adições de resíduos (Bertoncini, 2002) e fertilizantes (Ma \& Uren, 1998). Cong-Tu \& Chen (2001) encontraram 95\% da quantidade total de $\mathrm{Cu}$ na forma residual em amostras de um Ferrossolo chinês, não adubado. A grande retenção de $\mathrm{Cu}$ na forma residual pode ser atribuída à difusão do metal da superfície do mineral para dentro de microporos de óxidos de $\mathrm{Fe}$ cristalinos e minerais silicatados (Ma \& Uren, 1998)

Os maiores teores de Cu na fração óxido em relação à orgânica ocorreram devido aos elevados teores de argila do solo utilizado no estudo (Al-Sewailem et al., 1999; Shuman, 1988; Shuman, 1991). A quantidade de $\mathrm{Cu}$ adsorvida aos óxidos é diretamente proporcional à quantidade de argila do solo (Al-Sewailem et al., 1999) e ao aumento do pH (Bibak, 1994; Sims, 1986).

Apesar de a MO possuir grupos como os carboxílicos e fenólicos, que mantém fortes ligações com o Cu no solo (Manunza et al., 1995; Stevenson, 1994), os teores de Cu geralmente predominam na fração orgânica, apenas nos solos arenosos (Sims, 1986; Zhang et al., 1997a,b). Shuman (1988) observou aumento dos teores de Cu na fração orgânica, com a aplicação de palha de trigo triturada, somente em solos arenosos. Nos solos argilosos, a maior parte do $\mathrm{Cu}$ estava nas formas residual e óxidos, como observado no presente trabalho.

Vale ressaltar que para todos os micronutrientes a quantidade total, obtida pela digestão completa das amostras de terra em forno de microondas, ficou muito próxima da somatória das frações (trocável, orgânica, óxidos e residual) (Tabelas 11, 13, 15 e 17), o que indica coerência nos resultados. 


\subsubsection{Ferro no solo}

Em quaisquer das profundidades amostradas, os teores de $\mathrm{Fe}$ não foram alterados pelos métodos de preparo (Tabela 12). Resultados similares foram observados por outros autores (Castro et al., 1992; Motta et al., 2002). No entanto, em alguns casos, aplicações de elevadas doses de fertilizantes nitrogenados em solos sob SSD podem abaixar os valores de $\mathrm{pH}$ da camada superficial (Bowman \& Halvorson, 1998; Grove \& Blevins, 1988; Juo et al., 1995) e aumentar os teores de Fe (Follett \& Peterson, 1988). Por sua vez, Franzluebbers \& Hons (1996) e Rhoton (2000) observaram menores teores de Fe na camada superficial de solos sob SSD em relação ao SSC; os primeiros atribuíram o fato aos maiores teores de $\mathrm{P}$ dos solos sob SSD, que poderia diminuir a disponibilidade de Fe. Rhoton (2000) acredita que a complexação do Fe por AF foi o principal responsável pela diminuição da sua disponibilidade.

Como a disponibilidade de Fe é inversamente relacionada ao aumento do $\mathrm{pH}$ do solo (Shuman, 1986; Sims \& Patrick, 1978), a ausência de variação nos teores de Fe observada no presente estudo (Tabela 12) também pode ser atribuída à falta de variação ocorrida nos valores de $\mathrm{pH}$ do solo (Tabela 8). Desse modo, acredita-se que as modificações ocorridas nos teores de MO tiveram pouca influência nos teores de $\mathrm{Fe}$.

Como observado para o $\mathrm{Cu}$, a solução ácida Mehlich I também foi a que extraiu os menores teores de Fe em todas as profundidades (Tabela 12). No entanto, os teores mais elevados foram extraídos pelas soluções $\mathrm{HCl} 0,1 \mathrm{~mol} \mathrm{~L}^{-1}$ e Mehlich III, provavelmente porque a primeira é muita ácida $(\mathrm{pH} \cong 1,1)$ e a segunda, além de ser ácida $(\mathrm{pH} \cong 2,4)$ possui EDTA em sua constituição, que forma complexos muito estáveis com o Fe em condições ácidas (Norvell, 1991). A menor quantidade de Fe extraída pelo DTPA TEA pH 7,3 do que com o Mehlich III ocorre porque o quelato DTPA-Fe possui baixa estabilidade em meio neutro a alcalino (Tisdale et al., 1985). 
Tabela 12. Teores de Fe obtidos por diferentes extratores em um LATOSSOLO VERMELHO cultivado sob diferentes sistemas de preparo por 12 anos consecutivos, em diferentes profundidades (médias de três repetições).

\begin{tabular}{|c|c|c|c|c|c|}
\hline \multirow[t]{2}{*}{ Extrator } & \multicolumn{5}{|c|}{ Método de preparo } \\
\hline & SSD & SSC & $\mathbf{P M}$ & SSD/Preparo & Média \\
\hline & \multicolumn{5}{|c|}{$\mathrm{mg} \mathrm{kg}^{-1}$} \\
\hline & \multicolumn{5}{|c|}{$0,00-0,05 \mathrm{~m}$} \\
\hline Mehlich I & $19,7 \mathrm{~A}^{2}$ & $23,9 \mathrm{~A}$ & $23,5 \mathrm{~A}$ & $26,0 \mathrm{~A}$ & $23,3 d$ \\
\hline Mehlich III & $92,4 \mathrm{~A}$ & $83,2 \mathrm{~A}$ & $90,0 \mathrm{~A}$ & $87,4 \mathrm{~A}$ & $88,2 \mathrm{a}$ \\
\hline $\mathrm{HCl}$ & $77,8 \mathrm{~A}$ & $75,9 \mathrm{~A}$ & $77,1 \mathrm{~A}$ & $77,8 \mathrm{~A}$ & $77,1 \mathrm{~b}$ \\
\hline DTPA & $41,7 \mathrm{~A}$ & $37,6 \mathrm{~A}$ & $40,9 \mathrm{~A}$ & $46,6 \mathrm{~A}$ & $41,7 \mathrm{c}$ \\
\hline \multirow[t]{2}{*}{ C.V. } & $11,8 \%$ & & & & \\
\hline & \multicolumn{5}{|c|}{$0,05-0,10 \mathrm{~m}$} \\
\hline Mehlich I & $19,5 \mathrm{~A}$ & $23,8 \mathrm{~A}$ & $21,8 \mathrm{~A}$ & $21,3 \mathrm{~A}$ & $21,6 \mathrm{c}$ \\
\hline Mehlich III & $90,7 \mathrm{~A}$ & $89,3 \mathrm{~A}$ & $82,7 \mathrm{~A}$ & $90,6 \mathrm{~A}$ & 88,3 a \\
\hline $\mathrm{HCl}$ & $86,1 \mathrm{~A}$ & $78,0 \mathrm{~A}$ & $80,4 \mathrm{~A}$ & $75,9 \mathrm{~A}$ & 80,1 a \\
\hline DTPA & $41,5 \mathrm{~A}$ & $38,9 \mathrm{~A}$ & $40,7 \mathrm{~A}$ & $53,4 \mathrm{~A}$ & $43,1 \mathrm{~b}$ \\
\hline \multirow[t]{2}{*}{ C.V. } & $17,7 \%$ & & & & \\
\hline & \multicolumn{5}{|c|}{$0,10-0,20 \mathrm{~m}$} \\
\hline Mehlich I & $17,0 \mathrm{~A}$ & $19,8 \mathrm{~A}$ & $17,4 \mathrm{~A}$ & $18,4 \mathrm{~A}$ & $18,2 \mathrm{c}$ \\
\hline Mehlich III & $78,4 \mathrm{~A}$ & $76,0 \mathrm{~A}$ & $73,4 \mathrm{~A}$ & $78,4 \mathrm{~A}$ & $76,6 \mathrm{a}$ \\
\hline $\mathrm{HCl}$ & $81,4 \mathrm{~A}$ & $75,1 \mathrm{~A}$ & $78,0 \mathrm{~A}$ & $81,8 \mathrm{~A}$ & $79, \mathrm{I}$ a \\
\hline DTPA & $37,3 \mathrm{~A}$ & $36,2 \mathrm{~A}$ & $34,8 \mathrm{~A}$ & $38,9 \mathrm{~A}$ & $36,8 \mathrm{~b}$ \\
\hline \multirow[t]{2}{*}{ C.V. } & $12,7 \%$ & & & & \\
\hline & \multicolumn{5}{|c|}{$0,00-0,20 \mathrm{~m}^{3}$} \\
\hline Mehlich I & $18,3 \mathrm{~A}$ & $21,8 \mathrm{~A}$ & $20,4 \mathrm{~A}$ & $21,0 \mathrm{~A}$ & $20,3 \mathrm{c}$ \\
\hline Mehlich III & $85,0 \mathrm{~A}$ & $81,1 \mathrm{~A}$ & $79,9 \mathrm{~A}$ & $83,7 \mathrm{~A}$ & 82,4 a \\
\hline $\mathrm{HCl}$ & $81,7 \mathrm{~A}$ & $76,0 \mathrm{~A}$ & $78,4 \mathrm{~A}$ & $79,3 \mathrm{~A}$ & 78,9 a \\
\hline DTPA & $39,4 \mathrm{~A}$ & $37,2 \mathrm{~A}$ & $37,8 \mathrm{~A}$ & $44,4 \mathrm{~A}$ & $39,7 b$ \\
\hline C.V. & $11,5 \%$ & & & & \\
\hline
\end{tabular}

(1) SSD: sistema de semeadura direta; SSC: sistema de semeadura convencional - uma aração com arado de discos $(\cong 0,20 \mathrm{~m})$ e uma gradagem com grade niveladora $(\cong 0,10 \mathrm{~m})$, antes dos cultivos de verão e inverno a cada ano; PM: preparo mínimo - uma gradagem com grade aradora $(\cong 0,17 \mathrm{~m})$ e duas com grade niveladora $(\cong 0,10 \mathrm{~m})$, antes dos cultivos de verão e inverno de cada ano; SSD/Preparo: SSD com escarificação $(\cong 0,30 \mathrm{~m})$ a cada três anos (inverno). ${ }^{(2)}$ Letras maiúsculas comparam métodos de preparo e minúsculas comparam extratores dentro de cada profundidade, pelo teste de Tukey a $5 \% .{ }^{(3)}$ Os teores dessa camada são médias ponderadas dos teores das camadas de $0,00-0,05 ; 0,05-0,10 \mathrm{e} 0,10-0,20 \mathrm{~m}$.

A partir da extração seqüencial do Fe no solo, pode-se observar que sua grande maioria estava na forma de óxidos (Tabela 13), o que era esperado, uma vez que trata-se de um LATOSSOLO VERMELHO, com elevados teores de argila.

Transformando-se os teores totais de $\mathrm{Fe}^{3+}$ para percentagem de óxido de $\mathrm{Fe}$ $\left(\mathrm{Fe}_{2} \mathrm{O}_{3}\right)$, verificaram-se que os teores variaram de 14,7 a $16,4 \%$, nas camadas superficiais do solo sob SSC e SSD, respectivamente. Se forem considerados os critérios da EMBRAPA (1999), para valores obtidos por ataque sulfúrico (teor médio = 8 a 18\%), 
pode dizer que o solo apresenta teores médios de óxido de Fe. No entanto, espera-se que a quantidade de Fe obtida pela digestão das amostras de terra em microondas seja maior do que a obtida pelo ataque sulfúrico, uma vez que normalmente há dificuldade de digerir completamente o material pelo último método.

Tabela 13. Percentagem de Fe em diferentes frações e profundidades, em um LATOSSOLO VERMELHO, submetido a diferentes métodos de preparo do solo (médias de 12 repetições).

\begin{tabular}{|c|c|c|c|c|c|c|}
\hline \multirow{2}{*}{$\begin{array}{l}\text { Sistema de } \\
\text { preparo . }\end{array}$} & \multicolumn{4}{|c|}{ Frações } & \multirow{2}{*}{$\begin{array}{c}\text { Soma das } \\
\text { frações }\end{array}$} & \multirow[t]{2}{*}{ Total } \\
\hline & Trocável & Orgânica & Óxidos & Residual & & \\
\hline & & & & & $\mathrm{g} \mathrm{kg}$ & $\bar{z}$ \\
\hline \multirow{7}{*}{$\begin{array}{l}\text { SSD } \\
\text { SSD/prep. } \\
\text { PM } \\
\text { SSC } \\
\text { Média } \\
\text { C.V. }\end{array}$} & \multicolumn{6}{|c|}{$0,00-0,05 \mathrm{~m}$} \\
\hline & 0,00 & 0,02 & 89,66 & 10,32 & 54,9 & 54,3 \\
\hline & 0,00 & 0,03 & 89,56 & 10,41 & 53,2 & 55,4 \\
\hline & 0,00 & 0,03 & 91,45 & 8,52 & 53,1 & 51,6 \\
\hline & 0,00 & 0,02 & 90,46 & 9,53 & 53,8 & 57,5 \\
\hline & $0,00 \underline{C}^{2}$ & $0,03 \underline{\mathrm{C}}$ & $90,29 \mathrm{~A}$ & $9,79 \underline{B}$ & & \\
\hline & 3,8 & & & & & \\
\hline & \multicolumn{6}{|c|}{$0,05-0,10 \mathrm{~m}$} \\
\hline SSD & 0,00 & 0,02 & 90,81 & 9,17 & 53,5 & 56,2 \\
\hline SSD/prep. & 0,00 & 0,02 & 90,79 & 9,18 & 52,4 & 56,0 \\
\hline PM & 0,00 & 0,02 & 90,21 & 9,77 & 52,4 & 53,1 \\
\hline SSC & 0,00 & 0,02 & 91,35 & 8,64 & 57,0 & 54,9 \\
\hline Média & $0,00 \underline{\mathrm{C}}$ & $0,02 \underline{\mathrm{C}}$ & $90,87 \underline{\mathrm{A}}$ & $9,11 \underline{B}$ & & \\
\hline \multirow[t]{2}{*}{ C.V. } & 3,9 & & & & & \\
\hline & \multicolumn{6}{|c|}{$0,10-20 \mathrm{~m}$} \\
\hline SSD & $0,00 \mathrm{aC}$ & $0,02 \mathrm{aC}$ & $90,44 \mathrm{abA}$ & $9,55 \mathrm{abB}$ & 54,0 & 56,4 \\
\hline SSD/prep. & $0,00 \mathrm{aC}$ & $0,02 \mathrm{aC}$ & $89,35 \mathrm{bA}$ & $10,64 \mathrm{aB}$ & 54,3 & 54,8 \\
\hline $\mathbf{P M}$ & $0,00 \mathrm{aC}$ & $0,01 \mathrm{aC}$ & $89,80 \mathrm{abA}$ & $10,19 \mathrm{abB}$ & 53,5 & 56,9 \\
\hline SSC & $0,00 \mathrm{aC}$ & $0,02 \mathrm{aC}$ & $91,77 \mathrm{aA}$ & $8,21 \mathrm{bB}$ & 55,9 & 56,9 \\
\hline Média & 0,00 & 0,02 & 90,34 & 9,65 & & \\
\hline \multirow[t]{2}{*}{ C.V. } & 4,1 & & & & & \\
\hline & \multicolumn{6}{|c|}{$0,00-0,20 \mathrm{~m}^{3}$} \\
\hline SSD & $0,00 \mathrm{aC}$ & $0,02 \mathrm{aC}$ & $90,34 \mathrm{bA}$ & $9,65 \mathrm{aB}$ & 54,09 & 55,81 \\
\hline SSD/prep. & $0,00 \mathrm{aC}$ & $0,02 \mathrm{aC}$ & $89,76 \mathrm{bA}$ & $10,22 \mathrm{aB}$ & 53,56 & 55,23 \\
\hline $\mathbf{P M}$ & $0,00 \mathrm{aC}$ & $0,02 \mathrm{aC}$ & $90,31 \mathrm{bA}$ & $9,67 \mathrm{aB}$ & 53,09 & 54,62 \\
\hline SSC & $0,00 \mathrm{aC}$ & $0,02 \mathrm{aC}$ & $91,34 \mathrm{aA}$ & $8,65 \mathrm{bB}$ & 55,63 & 56,55 \\
\hline C.V. & 1,6 & & & & & \\
\hline
\end{tabular}

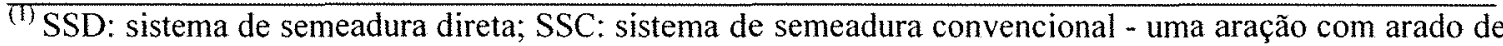
discos $(\cong 0,20 \mathrm{~m})$ e uma gradagem com grade niveladora $(\cong 0,10 \mathrm{~m})$, antes dos cultivos de verão e inverno a cada ano; PM: preparo mínimo - uma gradagem com grade aradora $(\cong 0,17 \mathrm{~m})$ e duas com grade niveladora $(\cong 0,10 \mathrm{~m})$, antes dos cultivos de verão e inverno de cada ano; SSD/prep.: SSD com escarificação $(\cong 0,30 \mathrm{~m})$ a cada três anos (inverno). ${ }^{(2)}$ Letras maiúsculas sublinhadas comparam frações dentro de profundidades; minúsculas comparam sistemas de preparos dentro de cada fração; e maiúsculas comparam frações dentro de métodos de preparo pelo teste de Tukey a $5 \%$. Os dados originais apresentados foram transformados em arco seno $(\mathrm{X} / 100)^{1 / 2}$, para as análises estatísticas. ${ }^{(3)}$ Os teores dessa camada são médias ponderadas dos teores das camadas de 0,00-0,05; 0,05-0,10 e 0,10-0,20 m. 
As percentagens de Fe nas diferentes formas geralmente não foram modificadas pelos métodos de preparo (Tabela 13). Como a disponibilidade de Fe é inversamente relacionada ao pH do solo (Shuman, 1986; Sims \& Patrick, 1978), a falta de variação ocorrida nos valores de $\mathrm{pH}$ (Tabela 8) pode ser a principal explicação para a ausência de variação nos teores de Fe das diferentes frações.

Da mesma forma ao que foi observado para o $\mathrm{Cu}$, não foi detectado $\mathrm{Fe}$ na fração trocável $\left(\mathrm{Sr}\left(\mathrm{NO}_{3}\right)_{2} 0,1 \mathrm{~mol} \mathrm{~L}^{-1}\right)$. Acredita-se que os valores de $\mathrm{pH}$ da camada superficial de todos os tratamentos tenham sido altos o suficiente para afetar negativamente a disponibilidade de Fe, uma vez que Shuman (1986) observou que o aumento do $\mathrm{pH}$ diminuiu o $\mathrm{Fe}$ trocável e elevou os teores de Fe na forma orgânica. Sims \& Patrick (1978) obtiveram altos teores de Fe no solo em pH (água) 4,5, mas os teores foram drasticamente reduzidos em $\mathrm{pH} 6,0$.

Existem grandes evidências, entretanto, que o Fe pode ser absorvido pela soja mesmo estando em pequena quantidade no solo. Durante situações de deficiência, a soja produz e libera na rizosfera muitos ácidos orgânicos, capazes de quelatizar e reduzir o $\mathrm{Fe}^{3+}$ para $\mathrm{Fe}^{2+}$, o qual é disponível às plantas (Laurie \& Manthey, 1994).

\subsubsection{Zinco no solo}

$\mathrm{Na}$ média dos quatro extratores, o teor de $\mathrm{Zn}$ da camada superficial decresceu no solo sob SSC, comparado aos demais métodos de preparo (Tabela 14). Existem diversos relatos na literatura de maiores teores de $\mathrm{Zn}$ na camada superficial de solos sob SSD em relação aos solos sob SSC, em condições norte-americanas (Edwards et al., 1992; Follett \& Peterson, 1988; Franzluebbers \& Hons, 1996; Motta et al., 2002; Rhoton, 2000; Shuman \& McCracken, 1999b). A elevação dos teores de Zn nos solos sob SSD, de maneira geral, ocorre apenas na camada superficial. $\mathrm{O}$ acúmulo de resíduos, a aplicação superficial de fertilizantes, aliado à baixa mobilidade do $\mathrm{Zn}$ no solo e à ausência de revolvimento são os fatores responsáveis por esse aumento (Motta et al., 2002). 
Tabela 14. Teores de $\mathrm{Zn}$ obtidos por diferentes extratores em um LATOSSOLO VERMELHO cultivado sob diferentes sistemas de preparo por 12 anos consecutivos, em diferentes profundidades (médias de três repetições).

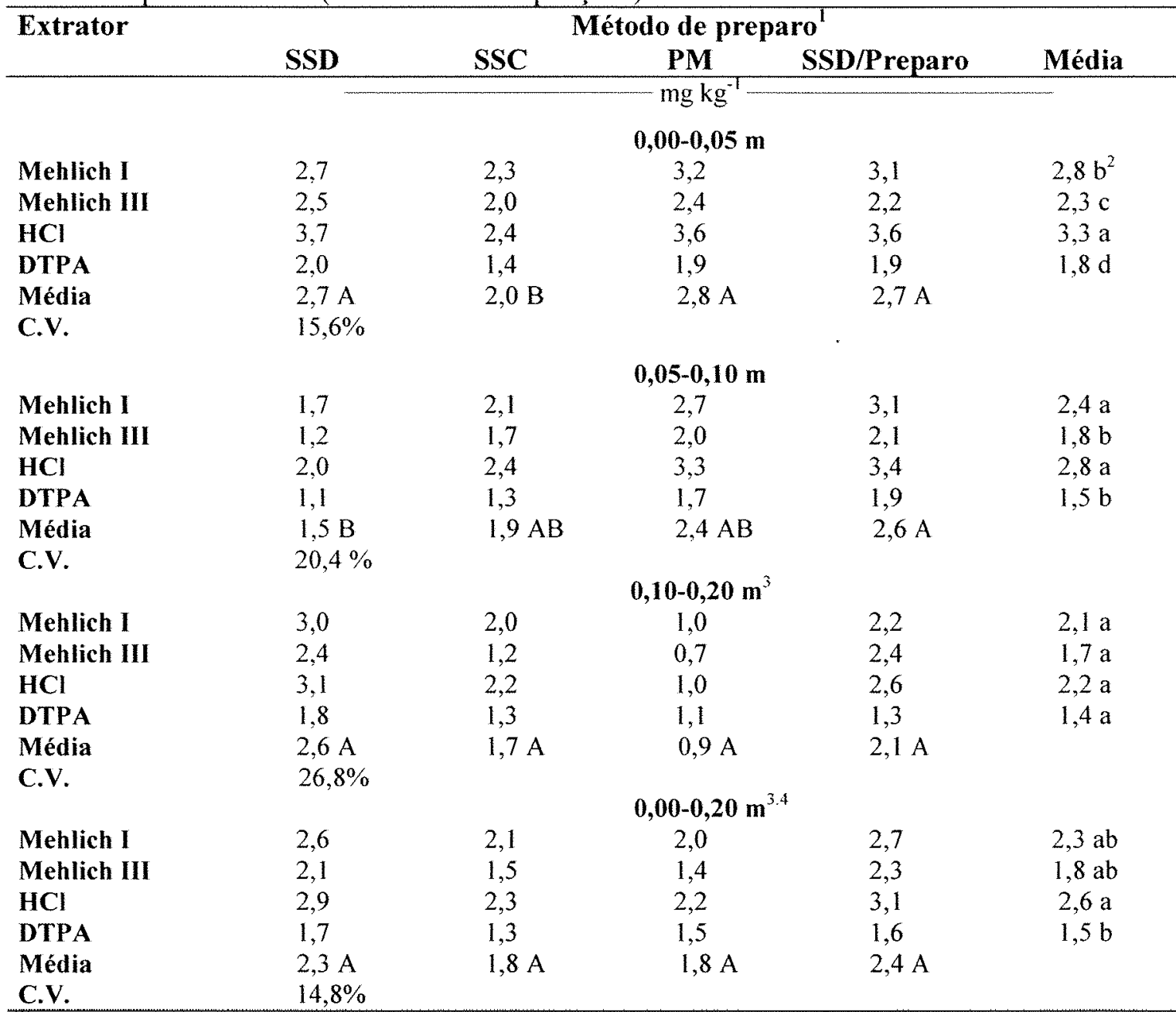

(1) SSD: sistema de semeadura direta; SSC: sistema de semeadura convencional - uma aração com arado de discos $(\cong 0,20 \mathrm{~m})$ e uma gradagem com grade niveladora $(\cong 0,10 \mathrm{~m})$, antes dos cultivos de verão e inverno a cada ano; PM: preparo mínimo - uma gradagem com grade aradora $(\cong 0,17 \mathrm{~m})$ e duas com grade niveladora $(\cong 0,10$ $\mathrm{m}$ ), antes dos cultivos de verão e inverno de cada ano; SSD/Preparo: SSD com escarificação $(\cong 0,30 \mathrm{~m})$ a cada três anos (inverno). ${ }^{(2)}$ Letras minúsculas comparam médias de extratores e as maiúsculas comparam médias de métodos de preparo dentro de cada profundidade, pelo teste de Tukey a $5 \% .{ }^{3}$ Dados transformados em $(\mathrm{X}+1)^{1 / 2}$. ${ }^{(4)}$ Os teores dessa camada são médias ponderadas das camadas de $0,00-0,05 ; 0,05-0,10$ e $0,10-0,20 \mathrm{~m}$.

A adubação nitrogenada em altas doses pode diminuir os valores de $\mathrm{pH}$ e aumentar os teores de $\mathrm{Zn}$ dos solos sob SSD (Edwards et al., 1992). Em solos não fertilizados, o aumento dos teores de $\mathrm{Zn}$ ocorre devido à elevação dos teores de $\mathrm{MO}$ (Franzluebbers \& Hons, 1996). Rhoton (2000) observou que os teores de Zn, extraídos com Mehlich I, estavam diretamente correlacionados à MO. Resultados semelhantes 
foram observados por Motta et al. (2002) em um Ultissolo argiloso norte-americano e por Castro et al. (1992) em latossolos paulistas sob SSD, utilizando-se DTPA. No presente trabalho, não houve boas correlações entre os teores de $\mathrm{Zn}$ e de $\mathrm{MO}$ e valores de $\mathrm{pH}$ do solo, possivelmente devido à baixa amplitude dos dados.

As maiores quantidades de $\mathrm{Zn}$ geralmente foram obtidas com a solução de $\mathrm{HCl}$ $0,1 \mathrm{~mol} \mathrm{~L}^{-1}$ em relação ao DTPA TEA pH 7,3, mostrando o efeito do $\mathrm{pH}$ da solução extratora na extração de Zn. Esperavam-se altas quantidades extraídas pelo extrator DTPA em relação ao Mehlich III $(\mathrm{pH} \cong 2,4)$, uma vez que o quelato DTPA-Zn é muito estável em meio neutro a alcalino, e o complexo EDTA-Zn tem baixa estabilidade em condições ácidas (Tisdale et al., 1985). Além disso, a concentração do DTPA (0,005 mol $\left.\mathrm{L}^{-1}\right)$ na solução extratora é superior à do EDTA na solução Mehlich III $\left(0,001 \mathrm{~mol} \mathrm{~L}^{-1}\right)$. Por outro lado, as soluções ácidas têm capacidade de abaixar o pH e solubilizar o Zn, o que não ocorre com o DTPA de reação alcalina (Abreu \& Raij, 1996; Galrão, 1995). Assim, a acidez da solução extratora prevaleceu na solubilização do Zn, comparada à ação quelante do DTPA.

Com exceção dos teores de $\mathrm{Zn}$ da camada de $0,05-0,10 \mathrm{~m}$, as percentagens de $\mathrm{Zn}$ nas diferentes formas (trocável, orgânica, óxidos de $\mathrm{Fe} / \mathrm{Mn} / \mathrm{Al}$, residual) não foram modificadas pelos métodos de preparo (Tabela 15). Nessa camada, as percentagens de $\mathrm{Zn}$ na forma orgânica foram maiores nos solos sob SSD/preparo e PM, comparado ao solo sob SSC. No entanto, não foi encontrada nenhuma explicação para o fato. Se as variações nos teores de $\mathrm{Zn}$ fossem devidas às modificações nos teores de $\mathrm{P}$ e $\mathrm{MO}$ (Tabela 8), causadas pelos métodos de preparo, elas deveriam ter ocorrido na camada superficial, o que não foi verificado (Tabela 15).

Como observado para $\mathrm{Cu}$ e $\mathrm{Fe}$, os teores de $\mathrm{Zn}$ trocáveis $\left(\mathrm{Sr}\left(\mathrm{NO}_{3}\right)_{2}\right)$ também não foram detectados por meio de espectroscopia de absorção atômica e de plasma em nenhum dos tratamentos, indicando que o elemento deve estar em baixíssimos níveis no solo. Nascimento et al. (2002b) também não encontraram teores trocáveis de $\mathrm{Zn}$, extraídos com $\mathrm{Mg}\left(\mathrm{NO}_{3}\right)_{2}$ 1,0 mol L $\mathrm{L}^{-1}$, em dois latossolos ácidos ( $\mathrm{pH}_{\text {água }}=4,4$ a 4,6) de Minas Gerais, sem adição de fertilizantes. Em condições chinesas, Cong-Tu \& Chen 
(2001) observaram que apenas $0,4 \%$ do teor total de $\mathrm{Zn}$ nativo de um Ferrossolo $\left(\mathrm{pH}_{\text {água }}=4,6\right)$ estava na forma trocável $\left(\mathrm{Mg}\left(\mathrm{NO}_{3}\right)_{2} 0,05 \mathrm{~mol} \mathrm{~L}^{-1}\right)$.

Tabela 15. Percentagem de $\mathrm{Zn}$ em diferentes frações e profundidades, em um LATOSSOLO VERMELHO, submetido a diferentes métodos de preparo do solo (médias de 12 repetições).

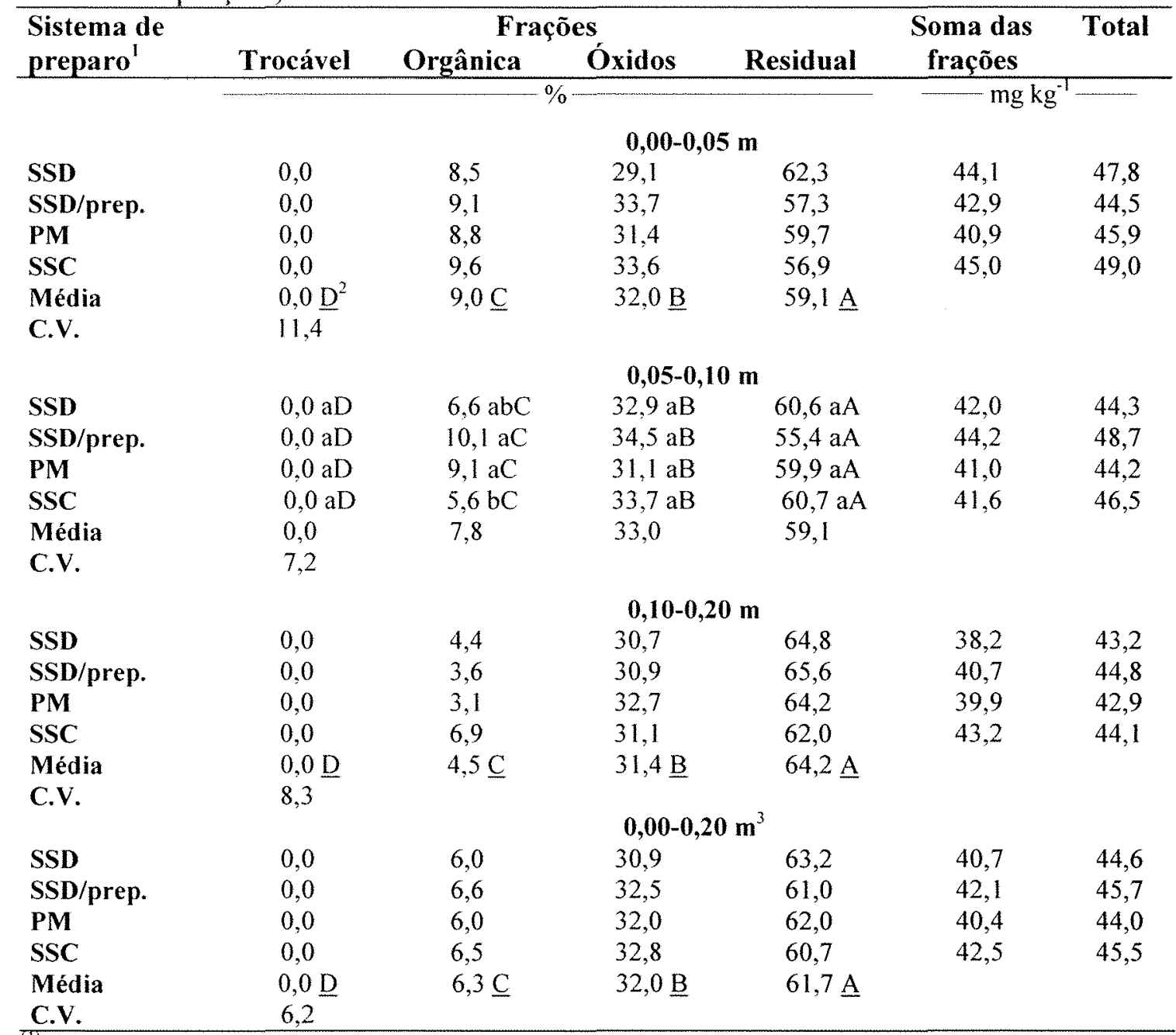

${ }^{(1)}$ SSD: sistema de semeadura direta; SSC: sistema de semeadura convencional - uma aração com arado de discos $(\cong 0,20 \mathrm{~m})$ e uma gradagem com grade niveladora $(\cong 0,10 \mathrm{~m})$, antes dos cultivos de verão e inverno a cada ano; PM: preparo mínimo - uma gradagem com grade aradora $(\cong 0,17 \mathrm{~m})$ e duas com grade niveladora $(\cong 0,10 \mathrm{~m})$, antes dos cultivos de verão e inverno de cada ano; SSD/prep.: SSD com escarificação $(\cong 0,30$ m) a cada três anos (inverno). ${ }^{(2)}$ Letras maiúsculas sublinhadas comparam frações dentro de profundidades; minúsculas comparam sistemas de preparos dentro de cada fração; e maiúsculas comparam frações dentro de métodos de preparo, pelo teste de Tukey a $5 \%$. Os dados originais apresentados foram transformados em arco seno $(\mathrm{X} / 100)^{1 / 2}$, para as análises estatísticas ${ }^{(3)}$ Os teores dessa camada são médias ponderadas dos teores das camadas de $0,00-0,05 ; 0,05-0,10$ e $0,10-0,20 \mathrm{~m}$. 
Acredita-se que os valores de $\mathrm{pH}$ de todos os tratamentos tenham influenciado negativamente a disponibilidade de $\mathrm{Zn}$. O aumento do $\mathrm{pH}$ diminui as formas trocáveis de Zn e eleva os teores de Zn na fração orgânica (Nascimento et al., 2002b; Shuman, 1986; Sims, 1986), principalmente nos solos arenosos. Dados de diversos autores levantados por Stevenson (1994) e Ninfant'eva et al. (2001) indicam que as constantes de estabilidade do $\mathrm{Zn}$ com os $\mathrm{AF}$ e $\mathrm{AH}$ aumenta com a elevação do $\mathrm{pH}$, porque o número de sítios de ligação para os metais nos grupos da MO são aumentados (Evangelou \& Marsi, 2001; Sims \& Patrick, 1978).

Nos solos argilosos, com o aumento do $\mathrm{pH}$, o $\mathrm{Zn}$ tende a se ligar principalmente aos óxidos de Fe e Mn em complexos de esfera interna (Ma \& Uren, 1997; Sims \& Patrick, 1978). Sims \& Patrick (1978) observaram altos teores de Zn na forma trocável, quando o pH (água) foi 4,5, e baixos teores em pH 6,0. Nos estudos realizados por Sims (1986) em solos arenosos, a maior parte do $\mathrm{Zn}$ estava na fração trocável até pH (água) 5,2, mas acima deste valor, estava complexado organicamente e ligado aos óxidos de $\mathrm{Fe}$.

A maior parte do $\mathrm{Zn}$ foi encontrada na forma residual (Tabela 15) $(55,4 \mathrm{a}$ $65,6 \%$ ). Em locais não fertilizados, as percentagens de $\mathrm{Zn}$ residual variaram de 75 a $87 \%$ nos estudos de Ma \& Uren (1997), e de 71 a 98\% nos trabalhos de Nascimento et al. (2002b), em latossolos de Minas Gerais. Resultados semelhantes foram obtidos por Cong-Tu \& Chen (2001) em um Ferrossolo chinês, não adubado.

Nos solos não fertilizados, a maioria do $\mathrm{Zn}$ encontrada na fração residual encontra-se na forma de silicatos (Ma \& Uren, 1997), em ligações altamente estáveis e, consequentemente, indisponível às plantas (Nascimento et al., 2002b). Por sua vez, quando o $\mathrm{Zn}$ é recém adicionado ao solo, a maior parte encontra-se em formas disponíveis (solúvel em água + trocável) (Ma \& Uren, 1997), que podem inicialmente ser associadas à MO, após o aumento de pH (Nascimento et al., 2002b). No entanto, após alguns anos, o $\mathrm{Zn}$ associa-se aos óxidos de $\mathrm{Fe}$ e $\mathrm{Al}$, em formas pouco disponiveis às plantas (Ma \& Uren, 1997). 


\subsubsection{Manganês no solo}

Os teores de Mn da camada superficial do solo cultivado sob SSD, extraídos com todas as soluções extratoras, foram maiores do que os do solo sob SSC (Tabela 16). Nas camadas de 0,05-0,10 e 0,00-0,20 m, na média dos extratores, os teores de Mn do solo sob SSD também foram superiores aos do solo sob SSC, mas não houve variação na camada de 0,10-0,20 m. Resultados semelhantes, na camada superficial, foram obtidos por Castro et al. (1992) em solos do Estado de São Paulo, e por diversos autores em solos norte-americanos (Edwards et al., 1992; Follett \& Peterson, 1988; Franzluebbers \& Hons, 1996; Motta et al., 2002; Shuman \& McCracken, 1999b).

No presente estudo, possivelmente os valores de $\mathrm{pH}_{\mathrm{CaCl}}(5,4$ a 6,0$)$ tenham influenciado negativamente a disponibilidade de $\mathrm{Mn}$ às plantas, independentemente dos tratamentos. Em solos arenosos norte-americanos, a maior parte do Mn estava na fração trocável até pH (água) 5,2, mas acima desse valor, estava complexado organicamente e ligados aos óxidos de Fe (Sims, 1986).

Os teores de $\mathrm{Mn}$ na camada superficial foram diretamente correlacionados com os teores de MO (Figura 4). Os coeficientes de correlação linear entre os teores de MO e os teores de Mn da camada de 0,00-0,05 m, extraídos por $\mathrm{HCl} 0,1 \mathrm{~mol} \mathrm{~L}^{-1}$, DTPA, Mehlich I e III foram 0,84, 0,87, 0,86, 0,58, respectivamente (três primeiros significativos a $1 \%$ e o último, a 5\%). Edwards et al. (1992) e Motta et al. (2002) também obtiveram correlações diretas entre os teores de MO e os teores de $\mathrm{Mn}$, extraídos por Mehlich I de solos norte-americanos. Em solos brasileiros, Castro et al. (1992) também observaram correlações diretas entre a MO e os teores de $\mathrm{Mn}$ e $\mathrm{Zn}$, extraídos por DTPA. Assim, era de se esperar que o aumento dos teores de MO no SSD (Tabela 8) elevasse os teores de Mn no solo (Tabela 16). 
Tabela 16. Teores de Mn obtidos por diferentes extratores em um LATOSSOLO VERMELHO cultivado sob diferentes métodos de preparo por 12 anos consecutivos, em diferentes profundidade (médias de três repetições).

\begin{tabular}{|c|c|c|c|c|c|}
\hline \multirow[t]{2}{*}{ Extrator } & \multicolumn{5}{|c|}{ Método de preparo' } \\
\hline & SSD & SSC & PM & SSD/Preparo & \multirow[t]{2}{*}{ Média } \\
\hline & & & $\mathrm{mg} \mathrm{kg}^{-1}$ & & \\
\hline & \multicolumn{4}{|c|}{$0,00-0,05 \mathrm{~m}$} & \\
\hline Mehlich I & $27,9 \mathrm{Aa}^{2}$ & $20,8 \mathrm{Ca}$ & $24,0 \mathrm{Ba}$ & $27,3 \mathrm{Aa}$ & 25,0 \\
\hline Mehlich III & $15,0 \mathrm{Ab}$ & $8,7 \mathrm{Bc}$ & $10,3 \mathrm{Bc}$ & $11,0 \mathrm{Bb}$ & 11,2 \\
\hline $\mathrm{HCl}$ & $29,2 \mathrm{Aa}$ & $16,8 \mathrm{Db}$ & $20,9 \mathrm{Cb}$ & $24,5 \mathrm{Ba}$ & 22,9 \\
\hline DTPA & $11,0 \mathrm{Ac}$ & $5,2 \mathrm{Cd}$ & $6,7 \mathrm{BCd}$ & $9,5 \mathrm{ABb}$ & 8,1 \\
\hline Média & 20,8 & 12,9 & 15,5 & 18,1 & \\
\hline \multirow{2}{*}{ C.V. } & $8,0 \%$ & & & & \\
\hline & \multicolumn{4}{|c|}{$0,05-0,10 \mathrm{~m}$} & \\
\hline Mehlich I & 24,2 & 20,0 & 22,9 & 24,2 & $22,8 \underline{\mathrm{a}}^{3}$ \\
\hline Mehlich III & 10,7 & 8,8 & 9,8 & 11,7 & $10,2 \underline{c}$ \\
\hline $\mathrm{HCl}$ & 22,6 & 16,3 & 20,3 & 20,4 & $19,9 \bar{b}$ \\
\hline DTPA & 6,5 & 5,2 & 6,0 & 7,1 & $6,2 \underline{\mathrm{d}}$ \\
\hline Média & $16,0 \mathrm{~A}$ & $12,6 \underline{B}$ & $14,8 \underline{\mathrm{A}}$ & $15,8 \underline{\mathrm{A}}$ & \\
\hline \multirow[t]{2}{*}{ C.V. } & $11,4 \%$ & & & & \\
\hline & \multicolumn{4}{|c|}{$0,10-0,20 \mathrm{~m}$} & \\
\hline Mehlich I & 19,2 & 19,3 & 17,3 & 19,1 & $18,7 \underline{\mathrm{a}}$ \\
\hline Mehlich III & 7,0 & 7,9 & 6,1 & 8,3 & $7,3 \underline{\mathrm{c}}$ \\
\hline $\mathrm{HCl}$ & 15,2 & 14,7 & 13,9 & 15,8 & $14, \overline{9} \underline{b}$ \\
\hline DTPA & 3,3 & 4,3 & 3,9 & 3,2 & $3,7 \mathrm{~d}$ \\
\hline Média & $11,2 \underline{\mathrm{A}}$ & $11,6 \underline{\mathrm{A}}$ & $10,2 \underline{\mathrm{A}}$ & $11,6 \underline{\mathrm{A}}$ & \\
\hline \multirow[t]{2}{*}{ C.V. } & $14,0 \%$ & & & & \\
\hline & \multicolumn{4}{|c|}{$0,00-0,20 \mathrm{~m}^{4}$} & \\
\hline Mehlich I & 22,6 & 19,8 & 20,4 & 22,4 & $21,3 \underline{a}$ \\
\hline Mehlich III & 9,9 & 8,3 & 8,1 & 9,8 & $9,0 \underline{\mathrm{c}}$ \\
\hline $\mathrm{HCl}$ & 20,1 & 15,6 & 17,3 & 19,1 & $18,1 \underline{b}$ \\
\hline DTPA & 6,0 & 4,8 & 5,1 & 5,7 & $5,4 \underline{\mathrm{d}}$ \\
\hline Média & $14,8 \underline{\mathrm{A}}$ & $12,1 \underline{\mathrm{B}}$ & $12,7 \underline{\mathrm{B}}$ & $14,3 \mathrm{~A}$ & \\
\hline C.V. & $9,2 \%$ & & & & \\
\hline \multicolumn{6}{|c|}{$\begin{array}{l}\text { (1) SSD: sistema de semeadura direta; SSC: sistema de semeadura convencional - uma aração com arado de } \\
\text { discos }(\cong 0,20 \mathrm{~m}) \text { e uma gradagem com grade niveladora }(\cong 0,10 \mathrm{~m}) \text {, antes dos cultivos de verão e inverno a } \\
\text { cada ano; PM: preparo mínimo - uma gradagem com grade aradora }(\cong 0,17 \mathrm{~m}) \text { e duas com grade niveladora } \\
(\cong 0,10 \mathrm{~m}) \text {, antes dos cultivos de verão e inverno de cada ano; SSD/Preparo: SSD com escarificação }(\cong 0,30 \\
\mathrm{m}) \text { a cada três anos (inverno). }{ }^{(2)} \text { Letras minúsculas comparam extratores dentro de métodos de preparo e as } \\
\text { maiúsculas comparam métodos de preparo dentro de cada extrator e }{ }^{(3)} \text { Letras minúsculas sublinhadas } \\
\text { comparam extratores e as maiúsculas comparam métodos de preparo, pelo teste de Tukey a } 5 \%{ }^{(4)} \text { Os teores } \\
\text { dessa camada são médias ponderadas dos teores das camadas de } 0,00-0,05 ; 0,05-0,10 \text { e } 0,10-0,20 \mathrm{~m} \text {. }\end{array}$} \\
\hline
\end{tabular}




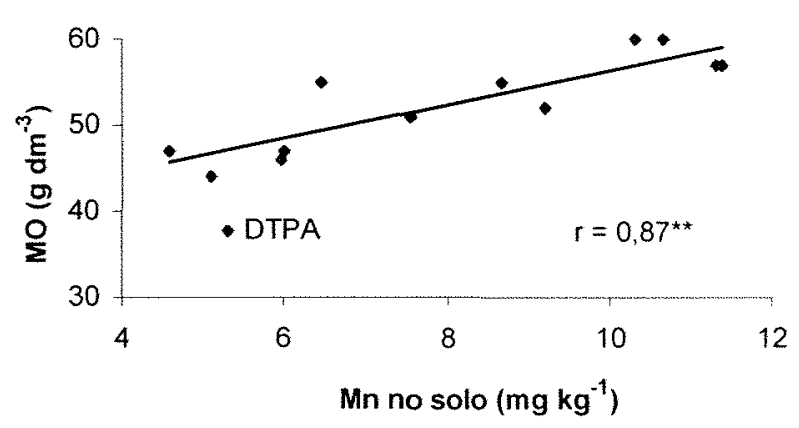

Figura 4 - Relação linear entre os teores de matéria orgânica (MO) e os teores de Mn da camada de 0,00$0,05 \mathrm{~m}$, extraídos por DTPA. ${ }^{* *}$ significativo a $1 \%$.

Independentemente do método de cultivo, os teores de $\mathrm{Mn}$ das camadas superficiais geralmente são maiores do que os teores das camadas inferiores, devido à reciclagem do nutriente e às adubações (Borkert et al., 2001). No caso dos solos sob SSD, a importância da reciclagem e das adubações é maior, porque provavelmente parte do Mn absorvido pelas raízes das plantas seja das camadas inferiores dos solos, devido aos menores valores de $\mathrm{pH}$ (Pauletti, 1998).

Uma parcela do Mn absorvido das camadas mais profundas, acumula-se na superfície dos solos sob SSD, por meio da deposição de resíduos. Por sua vez, o revolvimento dos solos em SSC aumenta as condições de aeração e acelera a decomposição dos restos vegetais, além de provocar a diluição do $\mathrm{Mn}$ associado à $\mathrm{MO}$ e daquele adicionado na camada superficial, via adubação, com as camadas mais profundas. Esses fatos explicam porque os solos cultivados sob SSD apresentaram maior quantidade de Mn "trocável" do que aqueles cultivados sob SSC.

Em todas as profundidades, as soluções ácidas (Mehlich I: pH 1,2; III: pH 2,4; HCl: pH 1,1) extraíram maiores quantidades de Mn do que a solução DTPA TEA pH 7,3 (Tabela 16), mostrando que o $\mathrm{Mn}$ foi sensível às variações do $\mathrm{pH}$ das soluções extratoras. Resultados semelhantes foram obtidos por Moreira et al. (2000) em um LATOSSOLO VERMELHO com nove anos sob SSD.

Esperavam-se maiores teores extraídos pelo DTPA TEA pH 7,3, do que com o

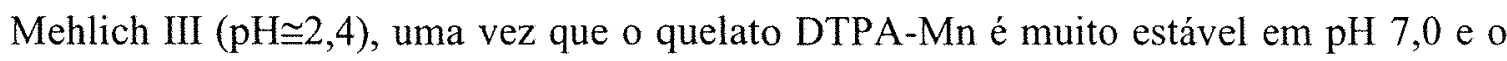
complexo EDTA-Mn apresenta alta estabilidade apenas em condições moderadamente ácidas a alcalinas (Norvell, 1991; Tisdale et al., 1985). Além disso, a concentração do 
DTPA $\left(0,005 \mathrm{~mol} \mathrm{~L}^{-1}\right)$ na solução extratora é superior à do EDTA na solução Mehlich III $\left(0,001 \mathrm{~mol} \mathrm{~L}^{-1}\right)$. Por outro lado, as soluções ácidas têm capacidade de abaixar o pH e solubilizar o Mn, o que não ocorre com o DTPA de reação alcalina (Abreu \& Raij, 1996; Galrão, 1995). Assim, a acidez da solução extratora prevaleceu na solubilização do Mn sobre a capacidade de quelação do DTPA.

A partir da extração seqüencial, observou-se que independentemente dos métodos de preparo, a maior quantidade de Mn estava ligada aos óxidos, seguida da fração residual e orgânica (Tabela 17), o que era esperado, devido aos elevados teores de argila do solo (Shuman, 1985; Sims, 1986). Nos solos argilosos, a maior quantidade de Mn geralmente está adsorvida aos óxidos (Shuman, 1985), e nos arenosos, complexada pela MO (Sims, 1986; Zhang et al., 1997a,b).

As percentagens de $\mathrm{Mn}$ na fração orgânica da camada superficial foram modificadas com os métodos de preparo, sendo as maiores quantidades observadas nos solos cultivados sob SSD e SSD/escarificação em relação ao solo sob SSC. Em outro solo, cultivado há oito anos sob diferentes métodos de preparo, Shuman \& Hargrove (1985) observaram que o SSD aparentou diminuir os teores de Mn da fração trocável e aumentá-los na orgânica. No entanto, essa observação se restringiu apenas à camada de 0,00-0,02 m.

Os maiores teores de Mn na fração orgânica dos solos com menor intensidade de preparo (SSD e SSD/escarificação) ocorreram devido à falta de revolvimento do solo, a qual permite que o Mn absorvido pelas plantas das camadas inferiores e o Mn aplicado via adubações possa ser adsorvido aos grupos funcionais da $\mathrm{MO}$ e acumulado na superfície. No caso do SSC, o revolvimento do solo provoca a diluição do $\mathrm{Mn}$ da fração orgânica da camada superficial com as inferiores.

Em condições de pH elevado, geralmente a quantidade de Mn adsorvido à MO é maior. Nessa situação, normalmente diminui-se as formas trocáveis de $\mathrm{Mn}$, e eleva-se a quantidade nas formas orgânica e de óxidos (Bibak, 1994; Shuman, 1986), porque há maior ionização dos grupos $\mathrm{COOH}$ presentes nos $\mathrm{AH}$ e $\mathrm{AF}$ e, consequentemente, aumenta sua habilidade em se ligar aos íons metálicos (Evangelou \& Marsi, 2001; Stevenson, 1994). Além disso, aumenta-se a oxidação química (Borkert et al., 2001) e a 
atividade dos microorganismos que oxidam o $\mathrm{Mn}^{2+}$ em complexos estáveis com a $\mathrm{MO}$ (Tisdale et al., 1985). Nos estudos de McBride (1982), realizados com RPE, a estabilidade dos complexos do Mn com os ácidos monocarboxílicos e policarboxílicos aumentou com a elevação do pH.

Tabela 17. Percentagem de Mn em diferentes frações e profundidades, em um LATOSSOLO VERMELHO, submetido a diferentes métodos de preparo do solo (médias de 12 repetições).

\begin{tabular}{|c|c|c|c|c|c|c|}
\hline \multirow{2}{*}{$\begin{array}{l}\text { Sistema de } \\
\text { preparo }\end{array}$} & \multicolumn{4}{|c|}{ Frações } & \multirow{2}{*}{$\begin{array}{l}\text { Soma das } \\
\text { frações }\end{array}$} & \multirow[t]{2}{*}{ Total } \\
\hline & Trocável & Orgânica & Óxidos & Residual & & \\
\hline & \multicolumn{4}{|c|}{$\%$} & $\mathrm{mg} \mathrm{k}$ & 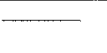 \\
\hline & \multicolumn{6}{|c|}{$0,00-0,05 \mathrm{~m}$} \\
\hline $\mathrm{SSD}^{1}$ & $1,6 \mathrm{aD}^{2}$ & $19,2 \mathrm{aC}$ & $45,5 \mathrm{aA}$ & $33,7 \mathrm{aB}$ & 114,8 & 111,1 \\
\hline SSD/prep. & $2,3 \mathrm{aD}$ & $15,9 \mathrm{aC}$ & 47,3 aA & $34,6 \mathrm{aB}$ & 108,4 & 110,4 \\
\hline PM & $1,9 \mathrm{aD}$ & $15,3 \mathrm{abC}$ & $49,2 \mathrm{aA}$ & $33,6 \mathrm{aB}$ & 107,1 & 104,2 \\
\hline SSC & $2,0 \mathrm{aD}$ & $11,8 \mathrm{bC}$ & 48,9 aA & $37,3 \mathrm{aB}$ & 105,2 & 104,9 \\
\hline Média & 2,0 & 11,8 & 48,9 & 37,8 & & \\
\hline \multirow[t]{2}{*}{ C.V. } & 5.2 & & & & & \\
\hline & \multicolumn{6}{|c|}{$0,05-0,10 \mathrm{~m}$} \\
\hline SSD & 1,5 & 14,7 & 49,6 & 34,2 & 103,8 & 106,9 \\
\hline SSD/prep. & 2,1 & 14,1 & 49,2 & 34,7 & 106,1 & 109,9 \\
\hline $\mathbf{P M}$ & 1,6 & 14,5 & 49,7 & 34,1 & 105,5 & 102,9 \\
\hline SSC & 1,6 & 11,2 & 51,2 & 36,0 & 100,7 & 103,1 \\
\hline Média & $1,7 \underline{\mathrm{D}}$ & $13,6 \underline{\mathrm{C}}$ & $50,0 \underline{\mathrm{A}}$ & $34,7 \underline{B}$ & & \\
\hline \multirow[t]{2}{*}{ C.V. } & 4,5 & & & & & \\
\hline & \multicolumn{6}{|c|}{$0,10-0,20 \mathrm{~m}$} \\
\hline SSD & 1,2 & 12,0 & 49,4 & 37,5 & 102,7 & 101,4 \\
\hline SSD/prep. & 1,3 & 11,2 & 51,2 & 36,3 & 101,7 & 107,1 \\
\hline PM & 1,2 & 11,1 & 51,4 & 36,4 & 103,8 & 109,6 \\
\hline SSC & 1,6 & 11,5 & 51,6 & 35,4 & 103,1 & 103,0 \\
\hline Média & $1,3 \underline{D}$ & $11,5 \underline{B}$ & $50,9 \underline{\mathrm{A}}$ & $36,4 \underline{B}$ & & \\
\hline \multirow[t]{2}{*}{ C.V. } & 5,0 & & & & & \\
\hline & \multicolumn{6}{|c|}{$0,00-0,20 \mathrm{~m}^{3}$} \\
\hline SSD & 1,35 & 14,45 & 48,49 & 35,71 & 105,99 & 105,22 \\
\hline SSD/prep. & 1,72 & 13,11 & 49,79 & 35,44 & 104,48 & 108,63 \\
\hline PM & 1,48 & 12,99 & 50,40 & 35,12 & 105,03 & 106,59 \\
\hline SSC & 1,66 & 11,51 & 50,82 & 36,00 & 103,02 & 103,50 \\
\hline Média & $1,55 \underline{\mathrm{A}}$ & $13,01 \underline{\mathrm{C}}$ & $49,86 \underline{\mathrm{A}}$ & $35,57 \underline{\mathrm{B}}$ & & \\
\hline C.V. & 4,2 & & & & & \\
\hline
\end{tabular}

(1) SSD: sistema de semeadura direta; SSC: sistema de semeadura convencional - uma aração com arado de discos $(\cong 0,20 \mathrm{~m})$ e uma gradagem com grade niveladora $(\cong 0,10 \mathrm{~m})$, antes dos cultivos de verão e inverno a cada ano; PM: preparo mínimo - uma gradagem com grade aradora $(\cong 0,17 \mathrm{~m})$ e duas com grade niveladora $(\cong 0,10 \mathrm{~m})$, antes dos cultivos de verão e inverno de cada ano; SSD/prep.: SSD com escarificação ( $\cong 0,30$ m) a cada três anos (inverno). ${ }^{(2)}$ Letras minúsculas comparam sistemas de preparos dentro de cada fração; maiúsculas comparam frações dentro de métodos de preparo; e maiúsculas sublinhadas comparam frações dentro de profundidades, pelo teste de Tukey a $5 \%$. Os dados originais apresentados foram transformados em arco seno $(\mathrm{X} / 100)^{1 / 2}$, para as análises estatísticas. ${ }^{(3)}$ Os teores dessa camada são médias ponderadas dos teores das camadas de $0,00-0,05 ; 0,05-0,10$ e $0,10-0,20 \mathrm{~m}$. 
Apesar de as evidências apontarem para o fato de que o Mn associado à fração orgânica dos solos sob SSD esteja ligado aos grupos funcionais da $\mathrm{MO}$, na forma de complexos estáveis, somente a partir dos resultados obtidos pela extração seqüencial, não é possível inferir sobre esse tipo de associação. $O$ extrator utilizado na extração do Mn da forma orgânica $(\mathrm{NaOCl})$, oxida praticamente 100\% da MO do solo (Chao, 1984), liberando para a solução todo o $\mathrm{Mn}$ associado à $\mathrm{MO}$, em diferentes formas (atração eletrostática, ligação covalente). Para determinar os tipos de associações do Mn com a MO, outras técnicas devem ser utilizadas, como a RPE. Deve ser ressaltado também que essa não é uma limitação do hipoclorito, uma vez que o mesmo é um dos extratores mais seletivos para extração de metais ligados à MO do solo (Bertoncini, 2002; Chao, 1984). 


\subsubsection{Avaliação dos micronutrientes do solo por Ressonância Paramagnética Eletrônica}

Os espectros de RPE das amostras de AH, extraídas das camadas superficiais dos solos sob SSD e SSC, são apresentados nas Figuras 5 e 6, respectivamente. Verificou-se que o processo de centrifugação das amostras de $\mathrm{AH}$, em alta rotação, foi altamente eficiente na eliminação do Fe.

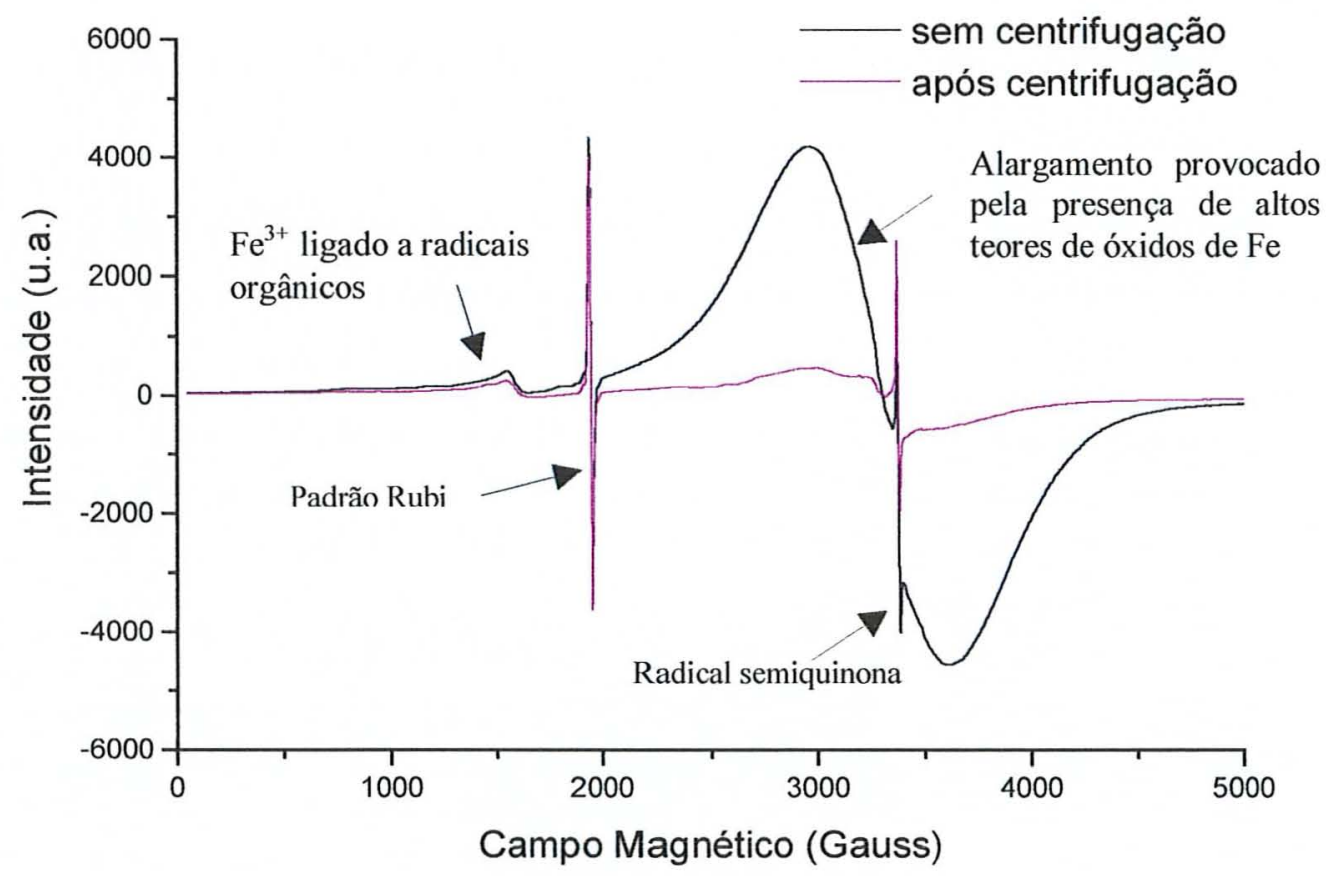

Figura 5 - Espectros de RPE em amostras sólidas de AH, extraído da camada de 0,00-0,05 m, do LATOSSOLO cultivado ha 12 anos sob SSD, antes e após a centrifugação a $12500 \mathrm{rpm}$ por 3 horas.

O Fe eliminado durante o processo de centrifugação encontra-se nas formas de óxido e hidróxido de $\mathrm{Fe}^{3+}$ (Novotny, 2002), sendo o principal responsável pelo alargamento do sinal em RPE (Ceretta et al., 1999) e, consequentemente, pela diminuição da intensidade dos sinais dos radicais semiquinonas e por perdas de informações sobre as interações dos metais com os grupos funcionais da MO. Assim, 
tratamentos para a eliminação dos óxidos de Fe são extremamente importantes para os trabalhos realizados com solos sob condições tropicais, os quais são geralmente intemperizados e com altos teores de óxidos.

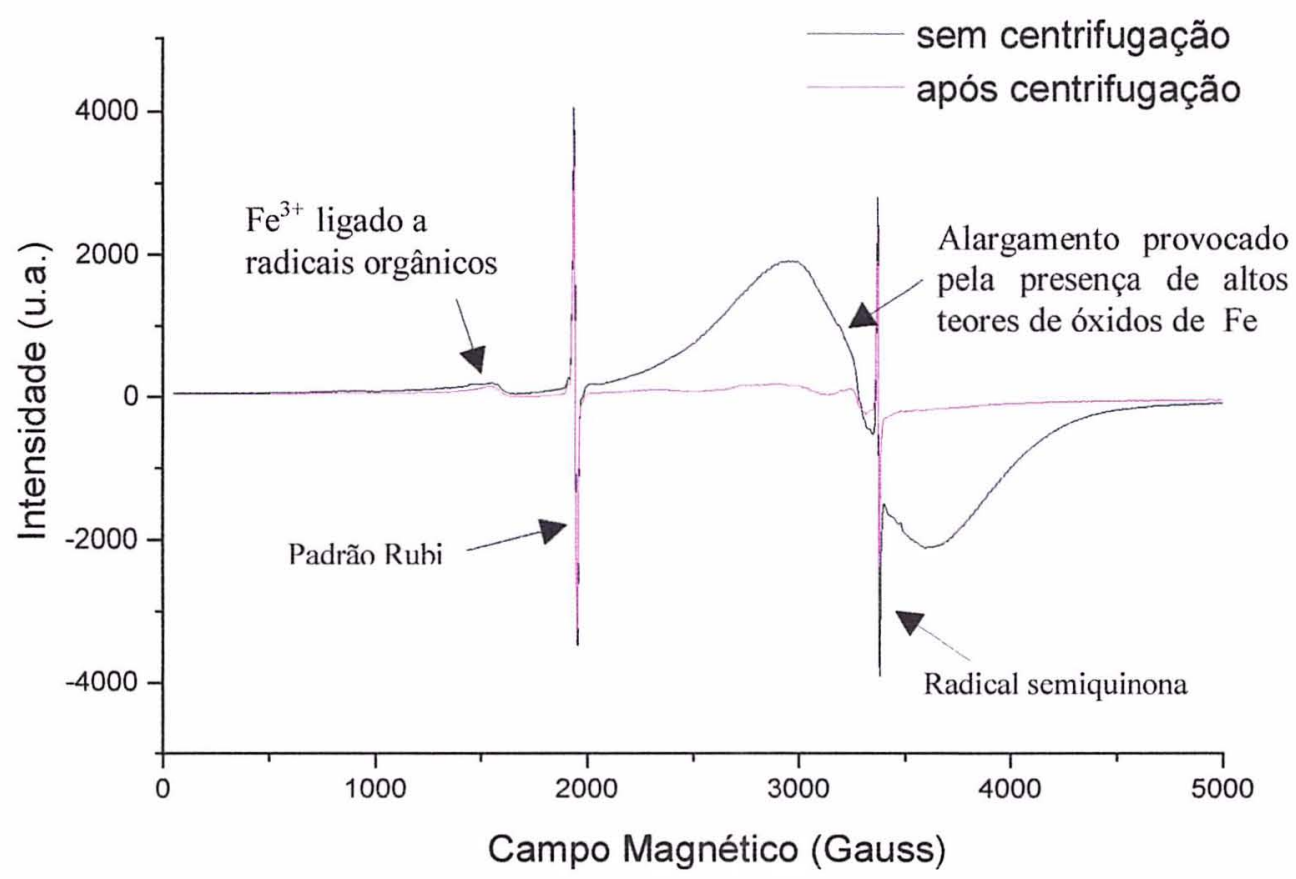

Figuras 6 - Espectros de RPE em amostras sólidas de AH, extraído da camada de 0,00-0,05 m, do LATOSSOLO cultivado ha 12 anos sob SSC, antes e após a centrifugação a $12500 \mathrm{rpm}$ por 3 horas.

A observação das linhas de RPE depende da existência de uma diferença de população de spins entre os estados fundamental e excitado dos elétrons, quando estão sob um campo magnético. Por sua vez, a intensidade da absorção depende da magnitude de diferença dessa população de spins. No momento em que as populações de spins dos dois estados se igualam, ocorre a saturação do sinal e os elétrons que estão no estado excitado, por terem absorvido energia, passam para um estado de menor energia (fundamental). Desse modo, é necessário um certo tempo (tempo de relaxação longitudinal), para transferência dessa energia à rede, a qual é detectada pelo espectrômetro de RPE (Senesi, 1990). 
A diminuição do tempo de relaxação longitudinal, causada por grande quantidade de $\mathrm{Fe}^{3+}$, decresce o tempo de relaxação transversal, que é inversamente proporcional à largura da linha de RPE (Novotny, 2002). Assim, com a diminuição desse tempo pode haver um forte alargamento de linha e os sinais de RPE de interesse podem não ser obtidos (Senesi, 1990). De acordo com o princípio de incerteza de Heisenberg, um sistema que existe por curto tempo, ou seja relaxação rápida, não possui sua energia definida (Saab, 1999).

O alargamento de linha dos espectros, causado pela diminuição do tempo de relaxação transversal, ocorre quando centros paramagnéticos $\left(\mathrm{Fe}^{3+}\right)$ estão próximos o suficiente para que ocorra interação dipolar entre eles (interação entre os momentos magnéticos dos elétrons) (Novotny, 2002). Assim, a ausência da observação dos picos do $\mathrm{Cu}^{2+} \mathrm{e} \mathrm{Mn}^{2+}$, antes da centrifugação das amostras de $\mathrm{AH}$, ocorreu devido ao alargamento do sinal provocado pela grande quantidade de $\mathrm{Fe}^{3+}$ (Ceretta et al., 1999).

Nos espectros de RPE aparece outro sinal de $\mathrm{Fe}^{3+}$, que geralmente possui $\mathrm{g}$ (momento angular orbital do elétron) de 4,3 e simetria rômbica (Novotny, 2002). Esse Fe, ligado aos radicais orgânicos, apresenta considerável resistência em se reduzir ou realizar reações de troca, pois é fortemente ligado e protegido, na forma de complexos de esfera interna com os $\mathrm{AH}$ (Saab, 1999). Prova disso é que os sinais do $\mathrm{Fe}^{3+}$, associado aos radicais orgânicos persistiram, mesmo após o tratamento por centrifugação.

A eliminação do Fe das amostras de $\mathrm{AH}$ aumentou a intensidade dos sinais de RPE para os radicais livres semiquinona, mas de qualquer forma, os sinais dos outros metais ainda não puderam ser obtidos. Provavelmente o $\mathrm{Mn}$ que estava adsorvido fracamente à MO tenha sido eliminado durante as etapas de extração e fracionamento das $\mathrm{SH}$, uma vez que a separação dos $\mathrm{AH}$ dos $\mathrm{AF}$ é feita através da precipitação do primeiro em condições ácidas ( $\mathrm{pH} 1,0$ a 1,5). Nesse meio extremamente ácido parte dos metais associados aos AH são liberados para os AF em solução. Em cada etapa de abaixamento do $\mathrm{pH}$, para precipitação dos $\mathrm{AH}$, a quantidade de metais adsorvida aos $\mathrm{AH}$ é diminuída, e a dos AF, aumentada.

Nas outras etapas de purificação dos $\mathrm{AH}$, como centrifugações, lavagens com água acidificada ( $\mathrm{pH}$ 2,0) e diálise (cinco dias), para eliminação de substâncias de baixo 
peso molecular e íons, os metais solúveis em água e os associados fracamente à MO (ligações eletrostáticas) vão sendo retirados, permanecendo nas amostras de $\mathrm{AH}$ apenas aqueles ligados em formas mais estáveis.

No presente estudo, apesar de a etapa de centrifugação ter sido necessária, devido aos altos teores de óxidos de Fe das amostras de $\mathrm{AH}$, a mesma foi crítica na eliminação do Mn das amostras, uma vez que foi realizada a partir das amostras de AH, que já haviam sido liofilizadas. Isso exigiu nova dissolução dos $\mathrm{AH} e$, consequentemente, nova precipitação desses em meio ácido ( $\mathrm{pH} 1$ a 1,5 ), lavagens e diálise, que são etapas que aumentam as perdas do Mn das amostras de $\mathrm{AH}$.

Acredita-se que o Mn que permaneceu nas amostras de AH foi aquele ligado em formas muito estáveis com a MO e, portanto, não poderia ser detectado por RPE. Senesi \& Sposito (1989) observaram que os sinais de RPE do $\mathrm{Mn}^{2+}$, em amostras de liteira, desapareceram após sucessivos tratamentos ácidos. McBride (1982) observaram perda de sinal do $\mathrm{Mn}$, devido ao grande alargamento de linha provocado por ligações muito estáveis (esfera interna) do $\mathrm{Mn}$ em complexos com ácidos monocarboxílicos e policarboxílicos (AH e AF). Martin-Neto et al. (1988) também não observaram sinais de Mn em solução, extraído do solo com DTPA, mas intensos sinais de Mn foram observados, quando o metal foi retirado do solo com água ou pela solução Mehlich I.

Nos estudos de McBride (1982), a estabilidade dos complexos do Mn com os ácidos monocarboxílicos e policarboxílicos aumentou com a elevação do $\mathrm{pH}$, pois à medida que houve aumento do $\mathrm{pH}$ ocorreu diminuição na intensidade dos sinais. Desse modo, imaginava-se que o Mn presente nas amostras de $\mathrm{AH}(\mathrm{pH} \mathrm{3,0)}$ estivesse associado fortemente à $\mathrm{MO}$ e, desse modo, não poderia ser detectado por RPE.

Para comprovar a hipótese mencionada acima, amostras de AH dos solos sob SSC e SSD foram redissolvidas, e o $\mathrm{pH}$ foi abaixado para aproximadamente 2,5. Nessas amostras sólidas, após liofilização, novamente não foram observados sinais de Mn por RPE (Figuras 7).

Acredita-se que o abaixamento do $\mathrm{pH}$ para 2,5 tenha liberado parte do Mn que estava fortemente retido aos grupos da MO para a solução. No entanto, durante os processos de precipitação, lavagem e diálise das amostras de $\mathrm{AH}$, esse Mn foi mais uma 
vez eliminado dos AH. Assim, o Mn que permaneceu nas amostras sólidas de AH estava associado à $\mathrm{MO}$ do solo na forma de complexos muito estáveis e, portanto, não poderia ser observado por RPE (Martin-Neto et al., 1988; McBride, 1982). Além disso, a quantidade de $\mathrm{Mn}$ das amostras de $\mathrm{AH}$ pH 2,5 era menor do que nas amostras de $\mathrm{AH} \mathrm{pH}$ 3,0 , devido às perdas provocadas por mais uma etapa de dissolução dos $\mathrm{AH}$. Essa hipótese será melhor discutida no Estudo 2, em que foram obtidos espectros em RPE de $\mathrm{AH}$ em solução, utilizando-se amostras de $\mathrm{AH}$ de solos que receberam aplicação de $\mathrm{Mn}$.

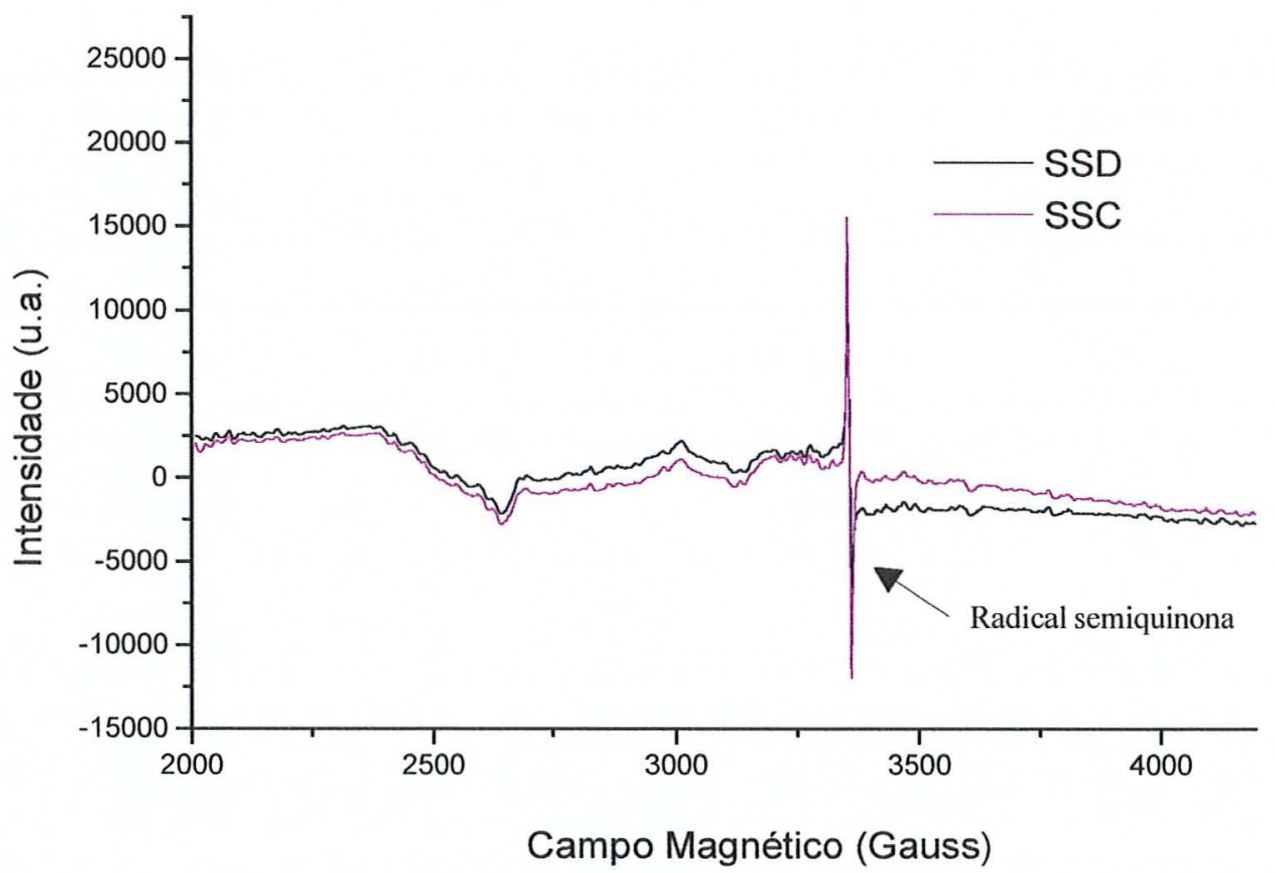

Figuras 7 - Espectros de RPE em amostras sólidas de $\mathrm{AH}$ a pH 2,5, extraído da camada de 0,00-0,05 m, do LATOSSOLO cultivado ha 12 anos sob SSD e SSC, após a centrifugação a 12500 rpm por 3 horas.

Para provar a existência de $\mathrm{Mn}$ nas amostras sólidas de $\mathrm{AH}(\mathrm{pH} 3,0)$, as mesmas foram digeridas por ataque nitro-perclórico, com posterior quantificação por espectrofotometria de absorção atômica. A presença de Mn nas amostras (Tabela 18), juntamente com a ausência de sinais de Mn nos espectros de RPE (Figuras 5 e 6), corrobora com a hipótese de que o Mn estava ligado aos $\mathrm{AH}$, na forma de complexos 
estáveis (ligações covalentes). Como discutido anteriormente, essa forma de Mn não pode ser detectada por RPE (Martin-Neto et al., 1988; McBride, 1982).

Devido à escassez de informações na literatura sobre teores de metais obtidos de amostras de $\mathrm{AH}$ do solo, após purificação e liofilização, há dificuldade de se fazer comparações desses teores com outros obtidos em situações semelhantes. Senesi et al. (1989) obtiveram em amostras de AH de solos norte-americanos, sem aplicação de lodo de esgoto, $46 \mathrm{mg} \mathrm{kg}^{-1}$ de $\mathrm{Mn} ; 2212 \mathrm{mg} \mathrm{kg}^{-1}$ de $\mathrm{Cu} ; 44 \mathrm{mg} \mathrm{kg}^{-1}$ de $\mathrm{Zn}$ e 7,3 $\mathrm{g} \mathrm{kg}^{-1}$ de Fe. Marzadori et al. (2000) quantificaram em amostras de AH, originadas de turfas na Itália, $15 \mathrm{mg} \mathrm{kg}^{-1}$ de $\mathrm{Mn} ; 38 \mathrm{mg} \mathrm{kg}^{-1}$ de $\mathrm{Cu} ; 141 \mathrm{mg} \mathrm{kg}^{-1}$ de $\mathrm{Zn} \mathrm{e} 664 \mathrm{mg} \mathrm{kg}^{-1}$ de Fe.

Tabela 18. Teores de $\mathrm{Cu}, \mathrm{Fe}, \mathrm{Mn}$ e $\mathrm{Zn}$ em amostras de $\mathrm{AH}$ lifiolizadas, extraídas das camadas superficiais de um LATOSSOLO VERMELHO, submetido a diferentes métodos de preparo.

\begin{tabular}{|c|c|c|c|c|}
\hline \multirow[t]{3}{*}{ Método de Preparo } & Mn & $\mathrm{Cu}$ & $\mathrm{Zn}$ & \multirow{2}{*}{$\begin{array}{c}\mathbf{F e} \\
\mathrm{g} \mathrm{kg}^{-1}\end{array}$} \\
\hline & & $\mathrm{mg} \mathrm{kg}^{-1}$ & & \\
\hline & \multicolumn{4}{|c|}{$0,00-0,05 \mathrm{~m}$} \\
\hline SSD & 8,4 & 136,0 & 61,7 & 14,5 \\
\hline SSC & 6,4 & 274,3 & 70,8 & 6,1 \\
\hline PM & 7,6 & 235,9 & 43,4 & 11,7 \\
\hline \multirow[t]{2}{*}{ SSD/prep. } & 8,4 & 154,9 & 32,2 & 16,2 \\
\hline & \multicolumn{4}{|c|}{$0,05-0,10 \mathrm{~m}$} \\
\hline SSD & 5,6 & $243,6^{\circ}$ & 55,0 & 7,0 \\
\hline SSC & 7,0 & 227,0 & 43,0 & 5,6 \\
\hline PM & 6,2 & 262,6 & 52,6 & 6,4 \\
\hline SSD/prep. & 5,8 & 330,7 & 35,8 & 10,9 \\
\hline
\end{tabular}

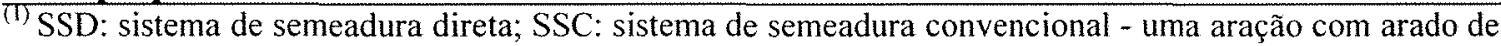
discos $(\cong 0,20 \mathrm{~m})$ e uma gradagem com grade niveladora $(\cong 0,10 \mathrm{~m})$, antes dos cultivos de verão e inverno a cada ano; PM: preparo mínimo - uma gradagem com grade aradora $(\cong 0,17 \mathrm{~m})$ e duas com grade niveladora $(\cong 0,10 \mathrm{~m})$, antes dos cultivos de verão e inverno de cada ano; SSD/prep.: SSD com escarificação $(\cong 0,30 \mathrm{~m})$ a cada três anos (inverno).

Os teores de Mn obtidos no presente estudo foram cerca de cinco vezes inferiores aos encontrados por Senesi et al. (1989) e, aproximadamente, metade dos encontrados por Marzadori et al. (2000). Apesar de esses autores terem utilizado basicamente os mesmos procedimentos na extração das $\mathrm{SH}(\mathrm{NaOH})$, adotado nesse estudo, não utilizaram da técnica de centrifugação em alta rotação para retirada do Fe adsorvido na 
forma de óxidos. Acredita-se que essa etapa foi crítica na eliminação do Mn das amostras, como discutido anteriormente.

Os teores de $\mathrm{Cu}$ obtidos no presente estudo foram muito inferiores aos de Senesi et al. (1989), possivelmente deve ter ocorrido perda do Cu no processo de centrifugação, como discutido para o Mn. Os teores de Fe das amostras de AH da camada superficial, independentemente do método de preparo, foram geralmente maiores do que os obtidos por Senesi et al. (1989), e os da camada de 0,05-0,10 m, normalmente inferiores. No entanto, podem ter sido suficientemente elevados para impedir a obtenção dos sinais de $\mathrm{Cu}$ nas amostras de $\mathrm{AH}$ (Figuras 5 e 6).Com algumas exceções, os teores de $\mathrm{Zn}$ foram maiores do que os encontrados por Senesi et al. (1989) e inferiores aos obtidos por Marzadori et al. (2000). 


\subsubsection{Concentração de nutrientes nas folhas e quantidade acumulada na parte aérea das plantas}

Com exceção do P, em que a concentração nas folhas de soja foi maior no SSD, comparado aos sistemas com maior revolvimento (SSC e PM), a concentração dos macronutrientes não variou com os métodos de preparo (Tabela 19). Maior concentração de P em plantas de milho cultivadas sob SSD do que nas cultivadas em SSC também foi observada por Muzilli (1983). De acordo com Phillips et al. (1980) e Muzilli (1985), os solos sob SSD apresentam maiores teores de umidade na camada superficial comparado aos solos cultivados sob SSC, o que favorece o aumento da taxa de difusão do $\mathrm{P}$ até as raízes das plantas. O aumento do $\mathrm{P}$ no solo sob SSD, comparado ao solo sob SSC (Tabelas 8 e 9) foi o principal responsável pela elevação da concentração de $\mathrm{P}$ nas folhas de soja.

Tabela 19. Concentração de macronutrientes nas folhas de soja, em função de métodos de preparo do solo (médias de três repetições).

\begin{tabular}{lcccccc}
\hline \multicolumn{1}{c}{ Preparo $^{1}$} & $\mathbf{N}$ & $\mathbf{P}$ & $\mathbf{K}$ & $\mathbf{C a}$ & $\mathbf{M g}$ & $\mathbf{S}$ \\
\cline { 2 - 7 } & $40,5 \mathrm{a}^{2}$ & $3,3 \mathrm{a}$ & $27,3 \mathrm{a}$ & $7,9 \mathrm{a}$ & $3,7 \mathrm{a}$ & $2,4 \mathrm{a}$ \\
SSD & $39,9 \mathrm{a}$ & $2,5 \mathrm{~b}$ & $29,9 \mathrm{a}$ & $8,6 \mathrm{a}$ & $3,6 \mathrm{a}$ & $2,4 \mathrm{a}$ \\
SSC & $36,6 \mathrm{a}$ & $2,4 \mathrm{~b}$ & $26,2 \mathrm{a}$ & $9,1 \mathrm{a}$ & $3,5 \mathrm{a}$ & $2,0 \mathrm{a}$ \\
PM & $42,4 \mathrm{a}$ & $3,0 \mathrm{ab}$ & $26,3 \mathrm{a}$ & $6,9 \mathrm{a}$ & $3,3 \mathrm{a}$ & $2,5 \mathrm{a}$ \\
SSD/prep. & & & &
\end{tabular}

(I) SSD: sistema de semeadura direta; SSC: sistema de semeadura convencional - uma aração com arado de discos $(\cong 0,20 \mathrm{~m})$ e uma gradagem com grade niveladora $(\cong 0,10 \mathrm{~m})$, antes dos cultivos de verão e inverno a cada ano; PM: preparo mínimo - uma gradagem com grade aradora $(\cong 0,17 \mathrm{~m})$ e duas com grade niveladora $(\cong 0,10 \mathrm{~m}$ ), antes dos cultivos de verão e inverno de cada ano; SSD/prep.: SSD com escarificação $(\cong 0,30 \mathrm{~m})$ a cada três anos (inverno). ${ }^{(2)}$ Valores seguidos da mesma letra, na coluna, não diferem entre si pelo teste de Friedman a $5 \%$.

$\mathrm{O}$ fato de os teores de $\mathrm{K}, \mathrm{Ca}$ e $\mathrm{Mg}$ no solo não terem sido modificados pelos métodos de preparo (Tabela 8) explica porque as concentrações desses elementos nas folhas de soja não variaram devido aos tratamentos (Tabela 19). Além disso, os teores desses nutrientes no solo, estavam dentro ou acima da faixa considerada adequada por Raij et al. (1997), independentemente dos métodos de preparo. Blevins et al. (1986) 
observaram que a absorção de Ca por plantas de milho não foi afetada pelos métodos de preparo. Contudo, no SSD houve menor absorção de $\mathrm{Mg}$, atribuída à alta absorção de $\mathrm{K}$. Nos estudos de Estes (1972) houve menor concentração de $\mathrm{Ca}, \mathrm{Mg}$ e $\mathrm{Al}$ nas folhas de milho no SSD, comparado ao SSC, que também foi relacionada à maior concentração foliar de K no SSD. Por sua vez, Centurion (1988) observou maior concentração de K nas folhas de milho, cultivado no SSD em relação ao SSC, mas não observou variações nas concentrações de $\mathrm{Ca}$ e $\mathrm{Mg}$ devido aos sistemas de cultivo.

Como ocorrido no presente trabalho, Lavado et al. (2001) e Centurion (1988), também não observaram modificações nas concentrações de $\mathrm{K}$ e $\mathrm{S}$ nas folhas de soja e de $\mathrm{N}$, Ca e Mg nas folhas de milho, respectivamente, devido aos métodos de preparo. Resultados semelhantes foram observados em soja e milho por Lal et al. (1990).

Vale ressaltar que as concentrações de $\mathrm{N}$ e $\mathrm{P}$ nas folhas de soja, cultivada nos sistemas com maior revolvimento (SSC e PM), e a concentração de S nas folhas das plantas cultivadas sob PM, estavam ligeiramente abaixo dos níveis sugeridos por Malavolta et al. (1997), como adequados. Os teores dos outros nutrientes estavam dentro da faixa de suficiência.

Apesar de a soja cultivada no SSD ter apresentado maior concentração foliar de P (Tabela 19), o acúmulo pelas plantas foi semelhante nos diferentes métodos de preparo (Tabela 20). Com exceção do $\mathrm{Ca}$, que foi maior no SSC, comparado ao SSD com escarificação, a quantidade acumulada dos macronutrientes não variou com os métodos de preparo, o que era esperado devido às pequenas diferenças na concentração foliar e na uniformidade de crescimento das plantas.

As concentrações dos micronutrientes nas folhas de soja não variaram com os métodos de preparo, em nenhum dos dois cultivos (Tabela 21). Resultados similares foram observados por Lavado et al. (2001). Nos estudos de Centurion (1988), as concentrações de $\mathrm{Fe}$ e $\mathrm{Zn}$ nas folhas de milho não foram modificadas pelos métodos de preparo. Resultados semelhantes foram observados por Estes (1972) quanto ao Mn. Por outro lado, Centurion (1988) observou que as concentrações de $\mathrm{Mn}$ e $\mathrm{Cu}$ nas folhas de milho apresentaram-se menores no SSD do que no SSC. Resultados similares foram observados por Estes (1972), quanto às concentrações de Zn. Shuman \& McCracken 
(1999a) observaram diminuição das concentrações de $\mathrm{Mn}$ e $\mathrm{Zn}$ em folhas de soja causada pela calagem, respectivamente, no SSD e no SSC.

Tabela 20. Quantidade de macronutrientes acumulada na parte aérea de plantas de soja em função de métodos de preparo do solo (médias de três repetições).

\begin{tabular}{lcccccc}
\hline \multicolumn{1}{c}{ Preparo $^{\mathrm{I}}$} & $\mathbf{N}$ & $\mathbf{P}$ & $\mathbf{K}$ & $\mathbf{C a}$ & $\mathbf{M g}$ & $\mathbf{S}$ \\
\cline { 2 - 7 } & & & & & \\
SSD & $4,9 \mathrm{a}^{3}$ & $0,5 \mathrm{a}$ & $5,4 \mathrm{a}$ & $1,6 \mathrm{ab}$ & $0,8 \mathrm{a}$ & $0,3 \mathrm{a}$ \\
SSC & $5,5 \mathrm{a}$ & $0,4 \mathrm{a}$ & $5,5 \mathrm{a}$ & $1,8 \mathrm{a}$ & $0,8 \mathrm{a}$ & $0,4 \mathrm{a}$ \\
PM & $5,7 \mathrm{a}$ & $0,5 \mathrm{a}$ & $6,0 \mathrm{a}$ & $1,8 \mathrm{ab}$ & $0,8 \mathrm{a}$ & $0,4 \mathrm{a}$ \\
SSD/prep. & $4,8 \mathrm{a}$ & $0,4 \mathrm{a}$ & $5,3 \mathrm{a}$ & $1,5 \mathrm{~b}$ & $0,7 \mathrm{a}$ & $0,3 \mathrm{a}$ \\
\hline
\end{tabular}

(7) SSD: sistema de semeadura direta; SSC: sistema de semeadura convencional - uma aração com arado de discos $(\cong 0,20 \mathrm{~m})$ e uma gradagem com grade niveladora $(\cong 0,10 \mathrm{~m})$, antes dos cultivos de verão e inverno a cada ano; PM: preparo mínimo - uma gradagem com grade aradora $(\cong 0,17 \mathrm{~m})$ e duas com grade niveladora $(\cong 0,10 \mathrm{~m})$, antes dos cultivos de verão e inverno de cada ano; SSD/prep.: SSD com escarificação $(\cong 0,30 \mathrm{~m})$ a cada três anos (inverno). ${ }^{(2)}$ Acúmulo de nutriente na matéria seca das plantas coletadas em um metro linear. ${ }^{(3)}$ Valores seguidos da mesma letra, na coluna, não diferem entre si pelo teste de Friedman a $5 \%$.

Tabela 21. Concentração de micronutrientes nas folhas de soja em função de métodos de preparo do solo, em 2000 e 2001 (médias de três repetições).

\begin{tabular}{cccccc}
\hline Preparo $^{1}$ & $\mathbf{B}$ & $\mathrm{Cu}$ & $\mathbf{F e}$ & $\mathrm{Mn}$ & $\mathbf{Z n}$ \\
\hline
\end{tabular}

\begin{tabular}{|c|c|c|c|c|c|}
\hline \multirow[b]{2}{*}{ SSD } & \multicolumn{5}{|c|}{2000} \\
\hline & nd & $9,7 \mathrm{a}^{2}$ & $95,0 \mathrm{a}$ & $18,0 \mathrm{a}$ & $23,3 \mathrm{a}$ \\
\hline SSC & nd & 9,7 a & $125,0 \mathrm{a}$ & $15,3 \mathrm{a}$ & $24,3 \mathrm{a}$ \\
\hline PM & nd & $9,7 \mathrm{a}$ & $119,0 \mathrm{a}$ & $18,3 \mathrm{a}$ & $30,0 \mathrm{a}$ \\
\hline \multirow[t]{2}{*}{ SSD/prep. } & nd & $12,3 \mathbf{a}$ & $91,0 \mathrm{a}$ & $17,3 \mathrm{a}$ & $21,3 \mathrm{a}$ \\
\hline & & & 2001 & & \\
\hline SSD & $34,7 \mathrm{a}$ & $8,3 \mathrm{a}$ & $122,0 \mathrm{a}$ & $23,0 \mathrm{a}$ & $20,0 \mathrm{a}$ \\
\hline SSC & $38,3 \mathrm{a}$ & $7,7 \mathrm{a}$ & $103,3 \mathrm{a}$ & $23,0 \mathrm{a}$ & $26,0 \mathrm{a}$ \\
\hline PM & $36,3 \mathrm{a}$ & $7,7 \mathrm{a}$ & 117,7 a & $22,0 \mathrm{a}$ & $23,3 \mathrm{a}$ \\
\hline SSD/prep. & $34,7 \mathrm{a}$ & 8,3 a & $92,0 \mathrm{a}$ & $24,7 \mathbf{a}$ & $25,0 \mathrm{a}$ \\
\hline
\end{tabular}

(I) SSD: sistema de semeadura direta; SSC: sistema de semeadura convencional - uma aração com arado de discos $(\cong 0,20 \mathrm{~m})$ e uma gradagem com grade niveladora $(\cong 0,10 \mathrm{~m})$, antes dos cultivos de verão e inverno a cada ano; PM: preparo mínimo - uma gradagem com grade aradora $(\cong 0,17 \mathrm{~m})$ e duas com grade niveladora $(\cong 0,10 \mathrm{~m})$, antes dos cultivos de verão e inverno de cada ano; SSD/prep.: SSD com escarificação $(\cong 0,30 \mathrm{~m})$ a cada três anos (inverno). ${ }^{(2)}$ Valores seguidos da mesma letra, na coluna, não diferem entre si pelo teste de Friedman a 5\%. nd: não determinado.

Nos dois cultivos (2000/2001 e 2001/2002), as concentrações de Cu estavam acima do nível crítico $\left(3,9 \mathrm{mg} \mathrm{kg}^{-1}\right)$ estabelecido por Galrão (1999) para solos sob 
cerrados e geralmente abaixo da faixa considerada adequada por Malavolta et al. (1997) para os micronutrientes, ou seja, 21-55, 10-30, 51-350, 21-100 e 21-50 mg kg ${ }^{-1}$ de B, $\mathrm{Cu}, \mathrm{Fe}, \mathrm{Mn}$ e $\mathrm{Zn}$, respectivamente. No entanto, os teores de $\mathrm{Cu}$ do solo, extraídos por DTPA (Tabela 10), estavam muito acima dos valores descritos por Raij et al. (1997), como adequados.

Em ambas as safras, observaram-se no período inicial de desenvolvimento da soja

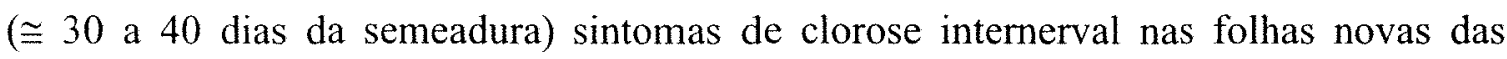
plantas cultivadas em todos os tratamentos, os quais são típicos de deficiência de Mn em soja (Borkert et al., 1994). No entanto, somente no primeiro cultivo, a concentração de Mn estava abaixo da faixa adequada $\left(20 \mathrm{mg} \mathrm{kg}^{-1}\right)$.

Devido aos maiores teores de Mn na camada superficial de solos cultivados sob SSD do que nos solos sob SSC (Tabela 16), poderia se esperar maior concentração de Mn nas plantas cultivadas sob SSD. Desse modo, pode-se dizer que os teores extraídos pelos extratores químicos não representaram adequadamente os teores disponíveis às plantas.

Como houve fortes correlações entre os teores de Mn e a MO do solo (Figura 4), maiores teores de Mn na fração orgânica dos solos sob SSD do que nos solos sob SSC (Tabela 17), além da observação de Mn ligado aos AH (Tabela 18), possivelmente de forma estável, sugere-se que esteja ocorrendo alguma forma de complexação do nutriente pela MO. Acredita-se que os valores de $\mathrm{pH} \mathrm{em} \mathrm{CaCl}_{2}$, de 5,4 a 6,0 (Tabela 8) tenham sido elevados o suficiente para influenciar negativamente a disponibilidade de Mn às plantas, uma vez que em condições de alto $\mathrm{pH}$ há maior adsorção do $\mathrm{Mn}$ aos grupos funcionais da MO (Tisdale et al., 1985).

Diferentemente ao observado no presente estudo, em condições norte-americanas e sul-africanas, a aplicação de elevadas doses de fertilizantes nitrogenados têm causado diminuição dos valores de $\mathrm{pH}$ e aumentado os teores de Mn da camada superficial dos solos sob SSD (Follett \& Peterson, 1988; Grove \& Blevins, 1988) e, consequentemente, a concentração foliar (Juo et al., 1995). No entanto, no presente estudo, os métodos de preparo não reduziram os valores de $\mathrm{pH}$ do solo. 
Em relação ao acúmulo de micronutrientes pelas plantas de soja, com exceção do $\mathrm{Fe}$, no primeiro cultivo, e do $\mathrm{B}$, no segundo, as quantidades acumuladas não variaram com os métodos de preparo (Tabela 22). As maiores quantidades de $\mathrm{Fe}$ foram observadas nos tratamentos com maior revolvimento (SSC e PM) do que nos com menor intensidade de preparo (SSD e SSD com escarificação). No caso do B, as maiores quantidades foram observadas no SSC, comparado ao SSD com escarificação.

Embora exista uma tendência de maiores quantidades acumuladas de alguns nutrientes nas plantas cultivadas no primeiro cultivo em relação ao segundo, esses valores não podem ser comparados, porque as coletas de plantas foram realizadas em estádios fisiológicos diferentes (safra 2000/2001: R2 a R3 e safra 2001/2002: R1 a R2).

Tabela 22. Quantidades de micronutrientes acumulada pelas plantas de soja, em função de métodos de preparo do solo, em 2000 e 2001 (médias de três repetições).

\begin{tabular}{lccccc}
\hline Preparo $^{1}$ & B & Cu & Fe & Mn & Zn \\
\hline & & & $\mathbf{m g}^{(2)}$ & & \\
& & & $\mathbf{2 0 0 0}$ & & \\
SSD & nd & $1,9 \mathrm{a}^{3}$ & $18,6 \mathrm{~b}$ & $3,5 \mathrm{a}$ & $4,2 \mathrm{a}$ \\
SSC & nd & $2,0 \mathrm{a}$ & $25,2 \mathrm{a}$ & $3,0 \mathrm{a}$ & $4,9 \mathrm{a}$ \\
PM & nd & $2,2 \mathrm{a}$ & $26,6 \mathrm{a}$ & $4,1 \mathrm{a}$ & $6,8 \mathrm{a}$ \\
SSD/Preparo & nd & $2,3 \mathrm{a}$ & $17,2 \mathrm{~b}$ & $3,3 \mathrm{a}$ & $4,4 \mathrm{a}$ \\
& & & $\mathbf{2 0 0 1}$ & & \\
SSD & $5,7 \mathrm{ab}$ & $1,5 \mathrm{a}$ & $22,5 \mathrm{a}$ & $3,2 \mathrm{a}$ & $2,3 \mathrm{a}$ \\
SSC & $7,1 \mathrm{a}$ & $1,5 \mathrm{a}$ & $31,8 \mathrm{a}$ & $3,8 \mathrm{a}$ & $3,9 \mathrm{a}$ \\
PM & $6,4 \mathrm{ab}$ & $1,5 \mathrm{a}$ & $25,7 \mathrm{a}$ & $3,7 \mathrm{a}$ & $3,8 \mathrm{a}$ \\
SSD/Preparo & $5,4 \mathrm{~b}$ & $1,2 \mathrm{a}$ & $27,5 \mathrm{a}$ & $3,5 \mathrm{a}$ & $3,0 \mathrm{a}$ \\
\hline
\end{tabular}

(1)SSD: sistema de semeadura direta; SSC: sistema de semeadura convencional - uma aração com arado de discos $(\cong 0,20 \mathrm{~m})$ e uma gradagem com grade niveladora $(\cong 0,10 \mathrm{~m})$, antes dos cultivos de verão e inverno a cada ano; PM: preparo mínimo - uma gradagem com grade aradora $(\cong 0,17 \mathrm{~m})$ e duas com grade niveladora $(\cong 0,10 \mathrm{~m})$, antes dos cultivos de verão e inverno de cada ano; SSD/prep.: SSD com escarificação $(\cong 0,30 \mathrm{~m})$ a cada três anos (inverno). ${ }^{(2)}$ Acúmulo de nutriente na matéria seca das plantas coletadas em um metro linear. ${ }^{(3)}$ Valores seguidos da mesma letra, na coluna, não diferem entre si pelo teste de Friedman a $5 \%$. nd: não determinado. 


\subsubsection{Estudo de correlação para micronutrientes}

Os coeficientes de correlação linear entre os teores de todos os micronutrientes no solo e os diferentes atributos da planta (concentração, quantidade acumulada, produção) geralmente foram baixos e, na maioria dos casos, não significativos (Tabelas 23 a 26).

Para o $\mathrm{Cu}$, as únicas correlações diretas foram entre os teores das camadas de 0,00-0,05 e 0,00-0,20 m, extraídos com Mehlich III, e a concentração foliar (Tabela 21). Por sua vez, as correlações entre os teores de $\mathrm{Cu}$ das camadas de $0,00-0,05,0,05-0,10 \mathrm{e}$ 0,00-0,20 m, extraídos com Mehlich I, com a concentração na folha diagnóstica foram negativas. Em outros estudos, a solução de Mehlich III também se mostrou adequada (Anjos \& Mattiazzo, 2001; Mulchi et al., 1992) e o Mehlich I, ineficiente (Abreu et al., 1996; Camargo et al., 1982; Galrão \& Sousa, 1985), inclusive em solo sob SSD (Shuman \& McCracken, 1999a).

Uma das causas da falta de correlação pode ser a pequena diferença entre os tratamentos, que resulta em baixa amplitude dos dados. No entanto, Kiehl et al. (2000) também não observaram correlações significativas entre a concentração de $\mathrm{Cu}$ em folhas de soja e o teor no solo, extraído com Mehlich I, III, HCl 0,1 mol L $\mathrm{L}^{-1}$ e DTPA, em um LATOSSOLO VERMELHO com nove anos sob SSD.

As correlações diretas entre os teores de Fe no solo, extraídos com diversos extratores, e os parâmetros vegetais foram baixas e geralmente não significativas (Tabela 24). Houve algumas correlações inversas entre as concentrações de $\mathrm{Fe}$ nas folhas e os teores de $\mathrm{Fe}$ do solo, indicando nesses casos, que o teor extraído por estes métodos não reflete a quantidade absorvida pelas plantas. Bataglia \& Raij (1989) também não observaram correlação entre $\mathrm{Fe}$ absorvido por plantas de sorgo e os teores no solo, extraídos com diversos extratores. Resultados similares foram observados por Mulchi et al. (1987), (1991) e 1992. Desse modo, nenhum dos extratores avaliados poderia ser recomendado para extração dos teores de Fe disponíveis. 
Tabela 23. Coeficientes de correlação linear (r) entre teores de $\mathrm{Cu}$ no solo a diferentes profundidades, extraídos por diversos extratores, e concentração de $\mathrm{Cu}$ na folha diagnóstica, quantidade de $\mathrm{Cu}$ acumulada na parte área, produção de grãos, pH e matéria orgânica do solo.

\begin{tabular}{|c|c|c|c|c|}
\hline Atributos & Mehlich I & Mehlich III & $\mathrm{HCl}$ & DTPA \\
\hline & \multicolumn{4}{|c|}{$0,00-0,05 \mathrm{~m}$} \\
\hline Conc. na folha diagnóstica & $-0,58 *$ & $0,58 *$ & $-0,22 \mathrm{~ns}$ & $0,45 \mathrm{~ns}$ \\
\hline Acumulado pela planta & $0,21 \mathrm{~ns}$ & $0,30 \mathrm{~ns}$ & $-0,14 \mathrm{~ns}$ & $-0,35 \mathrm{~ns}$ \\
\hline Produção de grãos & $-0,15 \mathrm{~ns}$ & $0,16 \mathrm{~ns}$ & $0,08 \mathrm{~ns}$ & $0,49 \mathrm{~ns}$ \\
\hline Matéria orgânica & $-0,57 \mathrm{~ns}$ & $0,30 \mathrm{~ns}$ & $-0,84 * *$ & $0,20 \mathrm{~ns}$ \\
\hline \multirow[t]{2}{*}{ PH } & $0,01 \mathrm{~ns}$ & $0,13 \mathrm{~ns}$ & $0,57 \mathrm{~ns}$ & $0,38 \mathrm{~ns}$ \\
\hline & \multicolumn{4}{|c|}{$0,05-0,10 \mathrm{~m}$} \\
\hline Conc. na folha diagnóstica & $-0,58 *$ & $0,27 \mathrm{~ns}$ & $0,00 \mathrm{~ns}$ & $0,05 \mathrm{~ns}$ \\
\hline Acumulado pela planta & $0,29 \mathrm{~ns}$ & $0,11 \mathrm{~ns}$ & $-0,23 \mathrm{~ns}$ & $0,22 \mathrm{~ns}$ \\
\hline Produção de grãos & $-0,34 \mathrm{~ns}$ & $0,11 \mathrm{~ns}$ & $0,07 \mathrm{~ns}$ & $-0,37 \mathrm{~ns}$ \\
\hline Matéria orgânica & $-0,10 \mathrm{~ns}$ & $0,36 \mathrm{~ns}$ & $0,07 \mathrm{~ns}$ & $-0,53 \mathrm{~ns}$ \\
\hline \multirow[t]{2}{*}{ PH } & $-0,01 \mathrm{~ns}$ & $0,30 \mathrm{~ns}$ & $0,14 \mathrm{~ns}$ & $-0,02 \mathrm{~ns}$ \\
\hline & \multicolumn{4}{|c|}{$0,10-0,20 \mathrm{~m}$} \\
\hline Conc. na folha diagnóstica & $-0,53 \mathrm{~ns}$ & $0,53 \mathrm{~ns}$ & $0,54 \mathrm{~ns}$ & $-0,23 \mathrm{~ns}$ \\
\hline Acumulado pela planta & $0,43 \mathrm{~ns}$ & $-0,18 \mathrm{~ns}$ & $-0,17 \mathrm{~ns}$ & $0,11 \mathrm{~ns}$ \\
\hline Produção de grãos & $-0,5 \mathrm{I} n \mathrm{~ns}$ & $0,16 \mathrm{~ns}$ & $0,18 \mathrm{~ns}$ & $0,17 \mathrm{~ns}$ \\
\hline Matéria orgânica & $-0,21 \mathrm{~ns}$ & $0,34 \mathrm{~ns}$ & $-0,46 \mathrm{~ns}$ & $-0,22 \mathrm{~ns}$ \\
\hline \multirow[t]{2}{*}{ PH } & $0,03 \mathrm{~ns}$ & $-0,43 \mathrm{~ns}$ & $0,51 \mathrm{~ns}$ & $-0,41 \mathrm{~ns}$ \\
\hline & \multicolumn{4}{|c|}{ 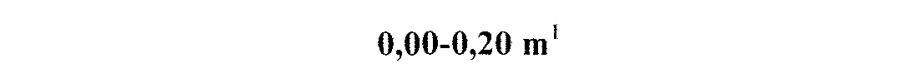 } \\
\hline Conc. na folha diagnóstica & $-0,62 *$ & $0,61 *$ & $0,24 \mathrm{~ns}$ & $-0,04 \mathrm{~ns}$ \\
\hline Acumulado pela planta & $0,39 \mathrm{~ns}$ & $0,13 \mathrm{~ns}$ & $-0,25 \mathrm{~ns}$ & $0,09 \mathrm{~ns}$ \\
\hline Produção de grãos & $-0,44 \mathrm{~ns}$ & $0,18 \mathrm{~ns}$ & $0,18 \mathrm{~ns}$ & $-0,17 \mathrm{~ns}$ \\
\hline Matéria orgânica & $-0,23 \mathrm{~ns}$ & $0,48 \mathrm{~ns}$ & $-0,44 \mathrm{~ns}$ & $0,32 \mathrm{~ns}$ \\
\hline PH & $-0,01 \mathrm{~ns}$ & $-0,07 \mathrm{~ns}$ & $0,69 *$ & $-0,55 \mathrm{~ns}$ \\
\hline
\end{tabular}

Para o $\mathrm{Zn}$, todas as correlações entre os teores no solo, extraídos com as diversas soluções, com os atributos avaliados não foram significativas (Tabela 25). Como discutido para o $\mathrm{Cu}$, possivelmente, uma das causas da falta de correlação pode ser a pequena diferença entre os tratamentos, que resulta em baixa amplitude dos dados. Nos estudos de Shuman \& McCracken (1999a) em solo sob SSD, utilizando-se o Mehlich I, verificou-se que o extrator não se mostrou adequado na avaliação da disponibilidade de $\mathrm{Zn}$. Os coeficientes de correlação entre os teores no solo e a concentração de $\mathrm{Zn}$ nas folhas de milho foram negativos. 
Tabela 24. Coeficientes de correlação linear (r) entre teores de Fe no solo a diferentes profundidades, extraídos por diversos extratores, e concentração de $\mathrm{Fe}$ na folha diagnóstica, quantidade de $\mathrm{Fe}$ acumulada na parte área, produção de grãos, pH e matéria orgânica do solo.

\begin{tabular}{|c|c|c|c|c|}
\hline Atributos & Mehlich I & Mehlich III & $\mathrm{HCl}$ & DTPA \\
\hline & \multicolumn{4}{|c|}{$0,00-0,05 \mathrm{~m}$} \\
\hline Conc. na folha diagnóstica & $-0,88 * *$ & $-0,54 \mathrm{~ns}$ & $-0,17 \mathrm{~ns}$ & $-0,70^{*}$ \\
\hline Acumulado pela planta & $-0,25 \mathrm{~ns}$ & $-0,38 \mathrm{~ns}$ & $0,00 \mathrm{~ns}$ & $0,14 \mathrm{~ns}$ \\
\hline Produção de grãos & $-0,49 \mathrm{~ns}$ & $-0,23 \mathrm{~ns}$ & $-0,04 \mathrm{~ns}$ & $-0,40 \mathrm{~ns}$ \\
\hline Matéria orgânica & $-0,20 \mathrm{~ns}$ & $-0,05 \mathrm{~ns}$ & $-0,07 \mathrm{~ns}$ & $0,12 \mathrm{~ns}$ \\
\hline \multirow[t]{2}{*}{ PH } & $-0,40 \mathrm{~ns}$ & $-0,12 \mathrm{~ns}$ & $0,24 \mathrm{~ns}$ & $-0,41 \mathrm{~ns}$ \\
\hline & \multicolumn{4}{|c|}{$0,05-0,10 \mathrm{~m}$} \\
\hline Conc. na folha diagnóstica & $-0,78 * *$ & $-0,51 \mathrm{~ns}$ & $0,32 \mathrm{~ns}$ & $-0,42 \mathrm{~ns}$ \\
\hline Acumulado pela planta & $0,02 \mathrm{~ns}$ & $0,34 \mathrm{~ns}$ & $-0,55 \mathrm{~ns}$ & $0,60 *$ \\
\hline Produção de grãos & $-0,41 \mathrm{~ns}$ & $0,49 \mathrm{~ns}$ & $0,38 \mathrm{~ns}$ & $-0,48 \mathrm{~ns}$ \\
\hline Matéria orgânica & $0,43 \mathrm{~ns}$ & $0,08 \mathrm{~ns}$ & $0,08 \mathrm{~ns}$ & $0,05 \mathrm{~ns}$ \\
\hline \multirow[t]{2}{*}{ PH } & $-0,29 \mathrm{~ns}$ & $-0,31 \mathrm{~ns}$ & $0,28 \mathrm{~ns}$ & $-0,43 \mathrm{~ns}$ \\
\hline & \multicolumn{4}{|c|}{$0,10-0,20 \mathrm{~m}$} \\
\hline Conc. na folha diagnóstica & $-0,76 * *$ & $-0,66 *$ & $0,17 \mathrm{~ns}$ & $-0,59 *$ \\
\hline Acumulado pela planta & $-0,05 \mathrm{~ns}$ & $0,14 \mathrm{~ns}$ & $-0,10 \mathrm{~ns}$ & $0,22 \mathrm{~ns}$ \\
\hline Produção de grãos & $0,30 \mathrm{~ns}$ & $-0,30 \mathrm{~ns}$ & $0,52 \mathrm{~ns}$ & $-0,61 *$ \\
\hline Matéria orgânica & $0,22 \mathrm{~ns}$ & $0,00 \mathrm{~ns}$ & $-0,53 \mathrm{~ns}$ & $0,00 \mathrm{~ns}$ \\
\hline \multirow[t]{2}{*}{$\mathbf{P H}$} & $0,03 \mathrm{~ns}$ & $-0,35 \mathrm{~ns}$ & $0,49 \mathrm{~ns}$ & $-0,19 \mathrm{~ns}$ \\
\hline & \multicolumn{4}{|c|}{$0,00-0,20 \mathrm{~m}^{1}$} \\
\hline Conc. na folha diagnóstica & $-0,87 * *$ & $-0,67 *$ & $0,18 \mathrm{~ns}$ & $-0,60 *$ \\
\hline Acumulado pela planta & $0,08 \mathrm{~ns}$ & $0,11 \mathrm{~ns}$ & $-0,27 \mathrm{~ns}$ & $0,39 \mathrm{~ns}$ \\
\hline Produção de grãos & $-0,42 \mathrm{~ns}$ & $-0,39 \mathrm{~ns}$ & $0,48 \mathrm{~ns}$ & $0,56 \mathrm{~ns}$ \\
\hline Matéria orgânica & $-0,06 \mathrm{~ns}$ & $0,25 \mathrm{~ns}$ & $-0,33 \mathrm{~ns}$ & $0,20 \mathrm{~ns}$ \\
\hline PH & $-0,22 \mathrm{~ns}$ & $-0,35 \mathrm{~ns}$ & $0,45 \mathrm{~ns}$ & $-0,36 \mathrm{~ns}$ \\
\hline
\end{tabular}

${ }^{(1)}$ Os teores dessa camada são médias ponderadas dos teores das camadas de $0,00-0,05 ; 0,05-0,10$ e 0,10 $0,20 \mathrm{~m} . \mathrm{ns}=$ não significativo; $*$ significativo a $5 \%$; * significativo a $1 \%$.

No caso do $\mathrm{Mn}$, as correlações entre os teores no solo e os atributos da planta (concentração na folha diagnóstica e acúmulo pela planta) também não foram significativas, na maioria dos casos (Tabela 26). Em algumas situações observaram-se coeficientes de correlação negativos entre os teores no solo, extraídos com $\mathrm{HCl} 0,1 \mathrm{~mol}$ $\mathrm{L}^{-1}$ e a concentração de Mn nas folhas e quantidade acumulada. Nos estudos de Shuman \& McCracken (1999a), os coeficientes de correlação entre os teores no solo, extraídos com Mehlich I, e a concentração de Mn nas folhas também foram negativos. 
Tabela 25. Coeficientes de correlação linear (r) entre teores de $\mathrm{Zn}$ no solo a diferentes profundidades, extraídos por diversos extratores, e concentração de $\mathrm{Zn}$ na folha diagnóstica, quantidade de $\mathrm{Zn}$ acumulada na parte área, produção de grãos, $\mathrm{pH}$ e matéria orgânica do solo.

\begin{tabular}{|c|c|c|c|c|}
\hline Atributos & Mehlich I & Mehlich III & $\mathrm{HCl}$ & DTPA \\
\hline & \multicolumn{4}{|c|}{$0,00-0,05 \mathrm{~m}$} \\
\hline Conc. na folha diagnóstica & $0,11 \mathrm{~ns}$ & $-0,34 \mathrm{~ns}$ & $-0,45 \mathrm{~ns}$ & $-0,35 \mathrm{~ns}$ \\
\hline Acumulado pela planta & $0,09 \mathrm{~ns}$ & $-0,33 \mathrm{~ns}$ & $-0,53 \mathrm{~ns}$ & $-0,43 \mathrm{~ns}$ \\
\hline Producão de grãos & $0,09 \mathrm{~ns}$ & $0,45 \mathrm{~ns}$ & $0,35 \mathrm{~ns}$ & $0,32 \mathrm{~ns}$ \\
\hline Matéria orgânica & $0,32 \mathrm{~ns}$ & $0,33 \mathrm{~ns}$ & $0,57 \mathrm{~ns}$ & $0,38 \mathrm{~ns}$ \\
\hline \multirow[t]{2}{*}{ PH } & $-0,07 \mathrm{~ns}$ & $0,47 \mathrm{~ns}$ & $0,28 \mathrm{~ns}$ & $0,49 \mathrm{~ns}$ \\
\hline & \multicolumn{4}{|c|}{$0,05-0,10 \mathrm{~m}$} \\
\hline Conc. na folha diagnóstica & $0,34 \mathrm{~ns}$ & 0,35 ns & $-0,04 \mathrm{~ns}$ & $0,28 \mathrm{~ns}$ \\
\hline Acumulado pela planta & $0,36 \mathrm{~ns}$ & $0,42 \mathrm{~ns}$ & $0,06 \mathrm{~ns}$ & $0,31 \mathrm{~ns}$ \\
\hline Produção de grãos & $-0,21 \mathrm{~ns}$ & $-0,09 \mathrm{~ns}$ & $0,13 \mathrm{~ns}$ & $-0,14 \mathrm{~ns}$ \\
\hline Matéria orgânica & $-0,05 \mathrm{~ns}$ & $-0,06 \mathrm{~ns}$ & $-0,01 \mathrm{~ns}$ & $-0,09 \mathrm{~ns}$ \\
\hline \multirow[t]{2}{*}{ PH } & $0,19 \mathrm{~ns}$ & $0,45 \mathrm{~ns}$ & $0,34 \mathrm{~ns}$ & $0,35 \mathrm{~ns}$ \\
\hline & \multicolumn{4}{|c|}{$0,10-0,20 \mathrm{~m}$} \\
\hline Conc. na folha diagnóstica & $-0,39 \mathrm{~ns}$ & $-0,34 \mathrm{~ns}$ & $-0,40 \mathrm{~ns}$ & $-0,25 \mathrm{~ns}$ \\
\hline Acumulado pela planta & $-0,47 \mathrm{~ns}$ & $-0,45 \mathrm{~ns}$ & $-0,51 \mathrm{~ns}$ & $-0,31 \mathrm{~ns}$ \\
\hline Produção de grãos & $0,39 \mathrm{~ns}$ & $0,32 \mathrm{~ns}$ & $0,38 \mathrm{~ns}$ & $0,21 \mathrm{~ns}$ \\
\hline Matéria orgânica & $0,27 \mathrm{~ns}$ & $0,17 \mathrm{~ns}$ & $0,31 \mathrm{~ns}$ & $0,26 \mathrm{~ns}$ \\
\hline \multirow[t]{2}{*}{ PH } & $-0,21 \mathrm{~ns}$ & $-0,32 \mathrm{~ns}$ & $-0,19 \mathrm{~ns}$ & $-0,07 \mathrm{~ns}$ \\
\hline & \multicolumn{4}{|c|}{$0,00-0,20 \mathrm{~m}^{1}$} \\
\hline Conc. na folha diagnóstica & $-0,32 \mathrm{~ns}$ & $-0,29 \mathrm{~ns}$ & $-0,42 \mathrm{~ns}$ & $-0,21 \mathrm{~ns}$ \\
\hline Acumulado pela planta & $-0,39 \mathrm{~ns}$ & $-0,38 \mathrm{~ns}$ & $-0,51 \mathrm{~ns}$ & $-0,26 \mathrm{~ns}$ \\
\hline Produção de grãos & $0,35 \mathrm{~ns}$ & $0,32 \mathrm{~ns}$ & $0,40 \mathrm{~ns}$ & $0,40 \mathrm{~ns}$ \\
\hline Matéria orgânica & $0,04 \mathrm{~ns}$ & $0,09 \mathrm{~ns}$ & $0,04 \mathrm{~ns}$ & $-0,19 \mathrm{~ns}$ \\
\hline PH & $0,00 \mathrm{~ns}$ & $0,03 \mathrm{~ns}$ & $0,03 \mathrm{~ns}$ & $0,27 \mathrm{~ns}$ \\
\hline
\end{tabular}

(1) Os teores dessa camada são médias ponderadas dos teores das camadas de $0,00-0,05 ; 0,05-0,10$ e 0,10 $0,20 \mathrm{~m} . \mathrm{ns}=$ não significativo.

Considerando-se que teores de Mn do solo (camada de 0,00-0,20 m), acima de $1,3 \mathrm{mg} \mathrm{dm}^{-3}$ (DTPA), são adequados para o SSC (Raij et al. (1997), os teores "trocáveis" de todas as camadas estavam acima dessa faixa (Tabela 16). No entanto, sintomas de deficiências de Mn foram observadas no campo, independentemente dos tratamentos. Além disso, houve fortes correlações entre os teores de Mn da camada superficial do solo, extraídos por todos os extratores químicos, e o teor de MO (Tabela 26). Esses resultados sugerem que os extratores utilizados no presente estudo não estão avaliando adequadamente a quantidade disponível às plantas.

Os coeficientes de correlação obtidos entre o teor de Mn ligado à fração orgânica com a concentração nas folhas e com o acúmulo de Mn pelas plantas foram inversos na 
camada de 0,10-0,20 m e baixos e não significativos nas camadas superficiais (Figura 8). Em experimento de casa de vegetação, Sims (1986) também obteve correlações inversas entre o Mn da fração orgânica e o Mn absorvido pelo trigo. Desse modo, sugere-se que os extratores não estão sendo eficientes porque estão extraindo o $\mathrm{Mn}$ ligado à $\mathrm{MO}$, o qual não é disponível às plantas.

Tabela 26. Coeficientes de correlação linear (r) entre teores de Mn no solo a diferentes profundidades, extraídos por diversos extratores, e concentração de Mn na folha diagnóstica, quantidade de $\mathrm{Mn}$ acumulada na parte área, produção de grãos, $\mathrm{pH}$ e matéria orgânica do solo.

\begin{tabular}{|c|c|c|c|c|}
\hline Atributos & Mehlich I & Mehlich III & $\mathrm{HCl}$ & DTPA \\
\hline & \multicolumn{4}{|c|}{$0,00-0,05 \mathrm{~m}$} \\
\hline Conc. na folha diagnóstica & $0,20 \mathrm{~ns}$ & $-0,29 \mathrm{~ns}$ & $-0,22 \mathrm{~ns}$ & $0,10 \mathrm{~ns}$ \\
\hline Acumulado pela planta & $-0,15 \mathrm{~ns}$ & $-0,57 \mathrm{~ns}$ & $-0,55 \mathrm{~ns}$ & $-0,27 \mathrm{~ns}$ \\
\hline Produção de grãos & $-0,01 \mathrm{~ns}$ & $0,39 \mathrm{~ns}$ & $0,32 \mathrm{~ns}$ & $0,04 \mathrm{~ns}$ \\
\hline Matéria orgânica & $0,86 * *$ & $0,58 *$ & $0,84 * *$ & $0,87 * *$ \\
\hline \multirow[t]{2}{*}{ PH } & $-0,55 \mathrm{~ns}$ & $-0,02 \mathrm{~ns}$ & $-0,17 \mathrm{~ns}$ & $-0,45 \mathrm{~ns}$ \\
\hline & \multicolumn{4}{|c|}{$0,05-0,10 \mathrm{~m}$} \\
\hline Conc. na folha diagnóstica & $-0,12 \mathrm{~ns}$ & $0,00 \mathrm{~ns}$ & $-0,46 \mathrm{~ns}$ & $-0,26 \mathrm{~ns}$ \\
\hline Acumulado pela planta & $-0,26 \mathrm{~ns}$ & $0,00 \mathrm{~ns}$ & $-0,66^{*}$ & $-0,22 \mathrm{~ns}$ \\
\hline Produção de grãos & $0,16 \mathrm{~ns}$ & $-0,02 \mathrm{~ns}$ & $0,40 \mathrm{~ns}$ & $0,20 \mathrm{~ns}$ \\
\hline Matéria orgânica & $0,19 \mathrm{~ns}$ & $-0,02 \mathrm{~ns}$ & $0,07 \mathrm{~ns}$ & $0,16 \mathrm{~ns}$ \\
\hline \multirow[t]{2}{*}{ PH } & $-0,42 \mathrm{~ns}$ & $-0,21 \mathrm{~ns}$ & $-0,04 \mathrm{~ns}$ & $-0,29 \mathrm{~ns}$ \\
\hline & \multicolumn{4}{|c|}{$0,10-0,20 \mathrm{~m}$} \\
\hline Conc. na folha diagnóstica & $-0,48 \mathrm{~ns}$ & $-0,14 \mathrm{~ns}$ & $-0,76 * *$ & $-0,28 \mathrm{~ns}$ \\
\hline Acumulado pela planta & $-0,41 \mathrm{~ns}$ & $0,05 \mathrm{~ns}$ & $-0,80 * *$ & $0,23 \mathrm{~ns}$ \\
\hline Produção de grãos & $0,19 \mathrm{~ns}$ & $-0,15 \mathrm{~ns}$ & $0,60 *$ & $-0,18 \mathrm{~ns}$ \\
\hline Matéria orgânica & $0,29 \mathrm{~ns}$ & $0,46 \mathrm{~ns}$ & $0,00 \mathrm{~ns}$ & $0,52 \mathrm{~ns}$ \\
\hline \multirow[t]{2}{*}{ PH } & $-0,55 \mathrm{~ns}$ & $-0,60 *$ & $-0,11 \mathrm{~ns}$ & $0,15 \mathrm{~ns}$ \\
\hline & \multicolumn{4}{|c|}{$0,00-0,20 \mathrm{~m}^{\mathrm{l}}$} \\
\hline Conc. na folha diagnóstica & $-0,20 \mathrm{~ns}$ & $-0,25 \mathrm{~ns}$ & $-0,55 \mathrm{~ns}$ & $-0,17 \mathrm{~ns}$ \\
\hline Acumulado pela planta & $-0,37 \mathrm{~ns}$ & $-0,30 \mathrm{~ns}$ & $-0,78 * *$ & $-0,21 \mathrm{~ns}$ \\
\hline Produção de grãos & $0,15 \mathrm{~ns}$ & $0,12 \mathrm{~ns}$ & $0,52 \mathrm{~ns}$ & $0,01 \mathrm{~ns}$ \\
\hline Matéria orgânica & $0,67 *$ & $0,66^{*}$ & $0,33 \mathrm{~ns}$ & $0,54 \mathrm{~ns}$ \\
\hline PH & $-0,70 *$ & $-0,49 \mathrm{~ns}$ & $-0,16 \mathrm{~ns}$ & $-0,21 \mathrm{~ns}$ \\
\hline
\end{tabular}

${ }^{(1)}$ Os teores dessa camada são médias ponderadas dos teores das camadas de 0,00-0,05;0,05-0,10 e 0,10-

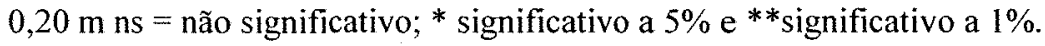

Uma outra causa da ineficiência dos extratores pode ser também a pequena amplitude entre os teores no solo e na planta. Desse modo, foi conduzido outro estudo (estudo 2), utilizando-se solos com maior variação nos teores de Mn, o qual será discutido posteriormente. 

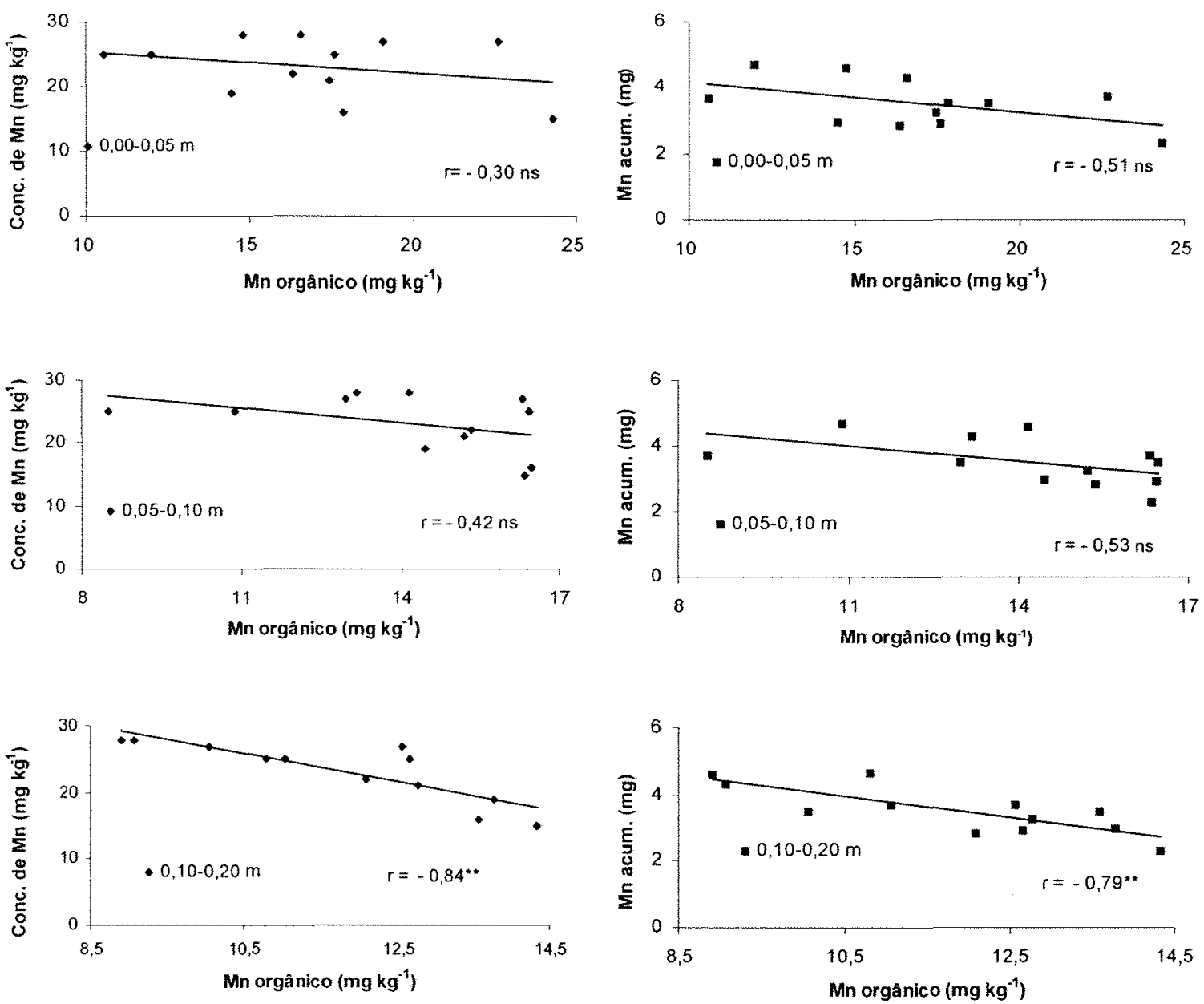

Figura 7 - Coeficientes de correlação entre o teor de Mn ligado à fração orgânica com a concentração de Mn nas folhas e com a quantidade de Mn acumulada na parte aérea da soja. ${ }^{* *}$ significativo a $1 \%$, ns=não significativo.

Os coeficientes de correlação obtidos entre os teores de Mn trocáveis das camadas superficiais, extraídos com $\mathrm{Sr}\left(\mathrm{NO}_{3}\right)_{2}$, e a concentração de Mn nas folhas e o acumulado na parte aérea foram positivos e altamente significativos (Figura 9). Essa informação indica a possibilidade de o $\mathrm{Sr}\left(\mathrm{NO}_{3}\right)_{2}$ ser incluído nos estudos futuros de avaliação de extratores para o Mn. 

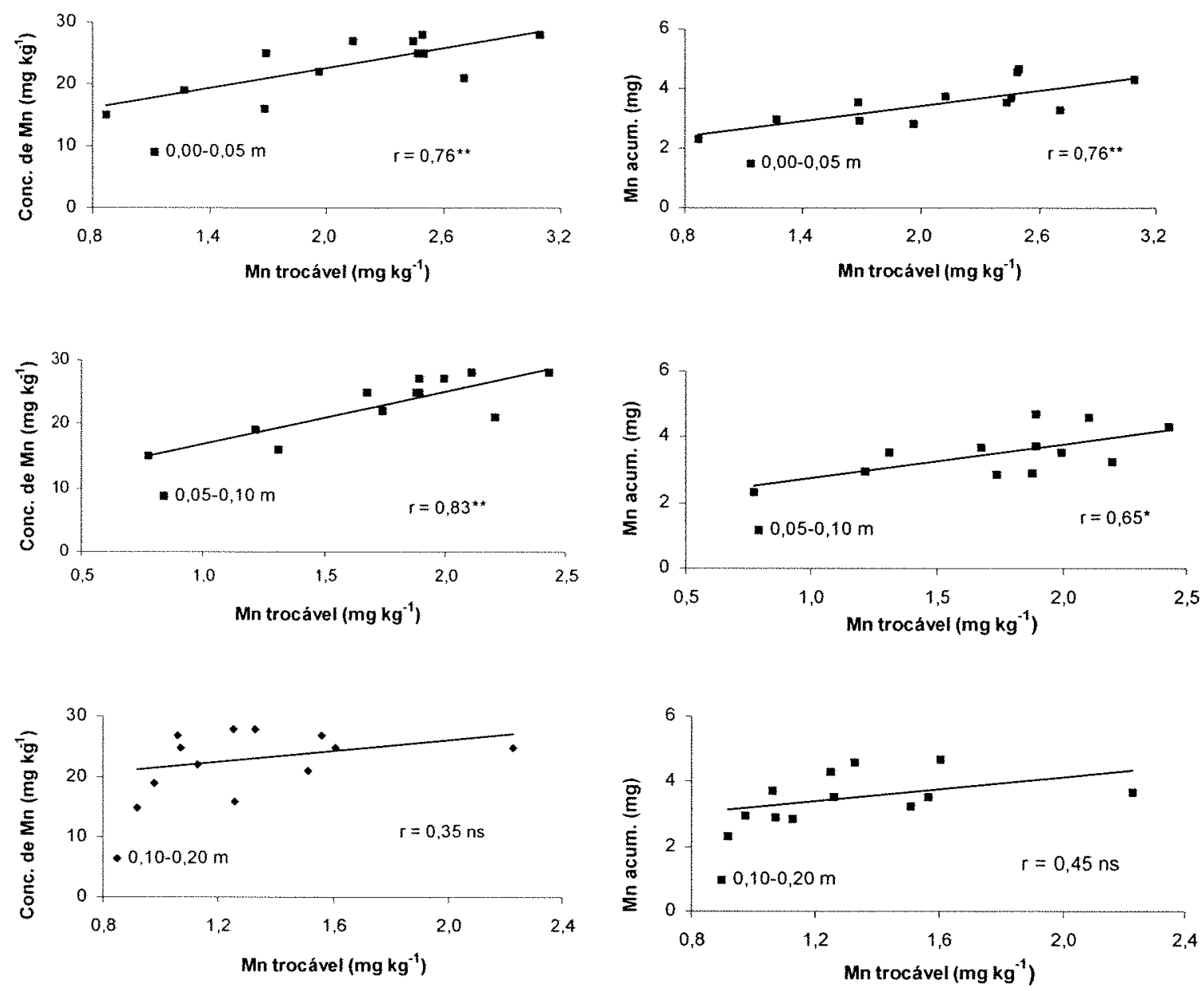

Figura 9 - Coeficientes de correlação entre o teor de $\mathrm{Mn}$ trocável, extraído com $\operatorname{Sr}\left(\mathrm{NO}_{3}\right)_{2}$, com a concentração de $\mathrm{Mn}$ nas folhas e com a quantidade de Mn acumulada na parte aérea da soja. ${ }^{*} \mathrm{e}$ ** significativos a $5 \%$ e a $1 \%$, ns=não significativo. 


\subsubsection{Produtividade de grãos de soja}

As produtividades de soja não variaram com os métodos de preparo em nenhum dos cultivos (Tabela 27). Por outro lado, maiores rendimentos de grãos no SSD em relação ao SSC foram encontrados por outros autores (Edwards et al., 1988; Estes 1972; Sidiras et al., 1983). Maiores produtividades de grãos foram observadas no SSC em situações específicas, como nos trabalhos de Dick et al. (1991), Griffith et al. (1988) e Phillips et al. (1980), em solos orgânicos mal drenados dos EUA. Nessa situação, a presença dos restos culturais na superfície aumenta a disponibilidade de água, diminui a temperatura do solo e prejudica a germinação das sementes, além de favorecer a perda de nitrato por desnitrificação devido ao aumento das condições redutoras do solo (Phillips et al., 1980).

Apesar de o SSD não ter aumentado a produtividade da soja (Tabela 27), a utilização desse sistema é justificada por vários fatores. Dentre eles, os mais importantes são diminuição da erosão, uma vez que a manutenção da palha na superfície diminui o impacto das gotas de chuva. Além disso, o aumento da MO melhora a estrutura física e aumenta a infiltração de água no solo (Bruce et al., 1995) e, desse modo, diminui-se o escorrimento superficial de água e as perdas de nutrientes (Castro et al., 1986; Dedecek et al., 1986; Vieira et al., 1978). Esses fatores, aliado à menor utilização de implementos agrícolas, diminuem os custos de produção das culturas sob SSD.

Tabela 27. Produtividade de grãos de soja em função de métodos de preparo do solo (médias de três repetições).

\begin{tabular}{|c|c|c|}
\hline \multirow[t]{2}{*}{ Método de Preparo } & \multicolumn{2}{|c|}{ Produtividade } \\
\hline & safra $2000 / 2001$ & safra $2001 / 2002$ \\
\hline & & \\
\hline SSD & $3872 a^{2}$ & $3207 a$ \\
\hline SSC & $3939 a$ & $3094 \mathrm{a}$ \\
\hline PM & $3855 a$ & $3214 a$ \\
\hline SSD/prep. & $3828 \mathrm{a}$ & $2907 \mathrm{a}$ \\
\hline
\end{tabular}

SSD: sistema de semeadura direta; SSC: sistema de semeadura convencional - uma aração com arado de discos $(\cong 0,20 \mathrm{~m})$ e uma gradagem com grade niveladora $(\cong 0,10 \mathrm{~m})$, antes dos cultivos de verão e inverno a cada ano; PM: preparo mínimo - uma gradagem com grade aradora $(\cong 0,17 \mathrm{~m})$ e duas com grade niveladora $(\cong 0,10 \mathrm{~m})$, antes dos cultivos de verão e inverno de cada ano; SSD/prep.: SSD com escarificação $(\cong 0,30 \mathrm{~m})$ a cada três anos (inverno). ${ }^{(2)}$ Valores seguidos da mesma letra, na coluna, não diferem entre si pelo teste de Friedman a $5 \%$. 


\subsubsection{Conclusões do Estudo 1}

Os teores de Mn trocáveis (DTPA TEA pH 7,3, HCl 0,1 mol L ${ }^{-1}$, Mehlich I e III) da camada de 0,00-0,05 $\mathrm{m}$ do solo cultivado sob semeadura direta e a percentagem de Mn na fração orgânica, dessa mesma profundidade, nos solos com menor revolvimento (semeadura direta e semeadura direta/preparo) foram maiores do que no solo sob SSC.

Os resultados do fracionamento químico do $\mathrm{Mn}$ nos diferentes sistemas de cultivo e das análises por ressonância paramagnética eletrônica sugerem que as ligações estáveis entre o Mn e a MO são responsáveis pelos maiores teores de Mn no solo sob SSD e o aparecimento de sintomas de deficiências de Mn nas plantas de soja. 


\subsection{Estudo 2}

\subsubsection{Extração seqüencial de micronutrientes nas amostras originais}

Os resultados referentes à extração seqüencial do $\mathrm{Mn}$ dos nove locais selecionados para o estudo 2 encontram-se na Tabela 28. Observou-se que os solos mais argilosos (locais I, IV, VII e IX) geralmente apresentaram maiores teores totais de Mn, em relação aos mais arenosos (Tabelas 7 e 28). Resultados similares foram observados por Nascimento et al. (2002a) e Valadares \& Camargo (1983), em solos do Estado de Minas Gerais e São Paulo, respectivamente. Os teores nativos totais obtidos por Nascimento et al. (2002a) variaram de 49 a $1160 \mathrm{mg} \mathrm{kg}^{-1}$, sendo os maiores teores encontrados nos latossolos originados de rochas máficas, e os menores, nos derivados de granitos e gnaisses. Por sua vez, a faixa de teores encontrada por Valadares \& Camargo (1983) foi de 14 a $2395 \mathrm{mg} \mathrm{kg}^{-1}$ nos solos derivados de sedimentos arenosos e latossolos, respectivamente.

Tabela 28. Teores de Mn na camada de 0,00-0,10 m de profundidade, em diferentes frações do solo, nos locais com e sem deficiência de Mn (médias de três repetições).

\begin{tabular}{|c|c|c|c|c|c|c|}
\hline \multirow{2}{*}{$\begin{array}{l}\text { Locais/ } \\
\text { Def. de } M n^{1}\end{array}$} & \multicolumn{4}{|c|}{ Frações } & \multirow{2}{*}{$\begin{array}{c}\text { Soma das } \\
\text { frações }\end{array}$} & \multirow[t]{2}{*}{ Total } \\
\hline & Trocável & Orgânica & Óxidos & Residual & & \\
\hline & & & & & & \\
\hline I- Com Def. & $0,9(2,6)^{2}$ & $8,4(23,1)$ & $13,4(36,8)$ & $13,6(37,5)$ & 36,3 & 42,4 \\
\hline II- Com Def. & $0,9(0,4)$ & $12,7(5,3)$ & $69,9(29,1)$ & $156,4(65,2)$ & 239,8 & 228,3 \\
\hline III- Sem Def. & $2,2(3,5)$ & $10,1(15,9)$ & $43,5(68,9)$ & $7,4(11,6)$ & 63,2 & 44,8 \\
\hline IV-Sem Def. & $0,9(0,9)$ & $28,9(29,3)$ & $38,4(39,0)$ & $30,4(30,8)$ & 98,5 & 85,3 \\
\hline V-Com Def. & $0,7(2,6)$ & $4,5(18,1)$ & $6,9(27,7)$ & $12,9(51,6)$ & 24,9 & 28,2 \\
\hline VI-Com Def. & $0,7(4,2)$ & $0,7(4,7)$ & $7,2(45,8)$ & $7,1(45,3)$ & 15,7 & 16,6 \\
\hline VII-Sem Def. & $1,5(2,3)$ & $4,9(7,5)$ & $38,1(58,3)$ & $20,9(31,9)$ & 65,3 & 67,8 \\
\hline VIII- Com Def. & $0,3(0,4)$ & $6,8(10,8)$ & $21,1(33,6)$ & $34,7(55,2)$ & 62,9 & 64,3 \\
\hline IX-Com Def. & $0,9(0,7)$ & $20,1(16,9)$ & $49,9(41,9)$ & $48,3(40,5)$ & 119,2 & 102,3 \\
\hline
\end{tabular}

(1)Local I: Faz. Santa Rosa; Locais II e III: Faz. Novo Horizonte; Local IV: Campo Experimental da Fundação ABC; Locais V e VI: Faz. Capão da Onça; Local VII: Faz. Curralinho; Local VIII: Faz. Boa Vista e Local IX: Faz. São Daniel. Com Def.: local com constatação de deficiência de Mn em soja; Sem Def.: local onde não é constatada deficiência. Os locais I, II, III e VIII estão localizados no município de Tibagi; os locais V e VI, em Ponta Grossa, PR; e os locais IV, VII e IX, em Castro, PR. ${ }^{(2)}$ Valores entre parênteses referem-se à percentagem do teor em relação à soma das frações. 
Os teores totais de $\mathrm{Mn}$, extraídos das amostras de terra dos locais $\mathrm{V}\left(28,2 \mathrm{mg} \mathrm{kg}^{-1}\right)$ e VI (16,6 $\left.\mathrm{mg} \mathrm{kg}^{-1}\right)$ estão próximos dos menores valores encontrados por Valadares \& Camargo (1983). Desse modo, deficiências de Mn nesses locais (V e VI) podem ser devidas à baixa disponibilidade de Mn no solo, causada pela baixa fertilidade natural em Mn.

Acredita-se que após inúmeros cultivos em solos com baixos teores totais de Mn, as plantas têm maior probabilidade de apresentarem deficiências do que àquelas cultivadas em solos com altos teores iniciais, devido ao esgotamento natural dos solos. Deste modo, outro problema de alguns solos sob SSD da Região Centro-Sul do Paraná, principalmente os arenosos, é a baixa fertilidade natural em Mn, que associada à calagem superficial e ao aumento do teor de $\mathrm{MO}$ causado pelo SSD, potencializam a possibilidade de ocorrência de deficiências. Deve ser ressaltado também que essa região apresenta alguns solos com teores naturalmente elevados de $\mathrm{MO}$ (solos de várzeas drenados e alguns solos situados em condições de relevo plano e elevado), independentemente do sistema de cultivo, devido sua condição morfoclimática. Desse modo, alguns solos podem apresentar alta capacidade de adsorção de micronutrientes, independentemente do sistema de cultivo.

Esperava-se distinção entre as frações de Mn na forma orgânica entre os locais com deficiências (I, II, V, VI, VIII e IX) e sem deficiências (III, IV e VII), com maiores teores nos solos dos locais que já apresentaram deficiências de Mn em soja. A expectativa foi baseada principalmente no fato de que tem sido encontrado por vários autores maiores teores de MO dos solos sob SSD, comparado aos solos sob SSC (Bayer et al., 2002a; Bayer et al., 2002b; Motta et al., 2002; Paiva et al., 1997; Rhoton, 2000) e fortes correlações entre os teores de Mn e a MO (Castro et al., 1992; Motta et al., 2002). Além disso, em alguns solos sob SSD, com teores considerados adequados para o SSC, tem sido observadas deficiências de Mn em soja (Pauletti, 1998).

A extração seqüencial dos teores de Mn das amostras de terra, no entanto, pouco contribuiu para explicar a hipótese de que as deficiências nas plantas de soja, cultivadas nos solos sob SSD, são provocadas pela complexação do Mn pela MO (Tabela 28), devido à interposição de resultados. Os teores de Mn da fração orgânica dos locais com 
deficiências de $\mathrm{Mn}$ variaram de 4,7\% $\left(0,7 \mathrm{mg} \mathrm{kg}^{-1}\right)$ a 23,1\% $\left(8,4 \mathrm{mg} \mathrm{kg}^{-1}\right)$ do total da soma das frações, e nos locais sem deficiência, de $7,5 \%\left(4,9 \mathrm{mg} \mathrm{kg}^{-1}\right)$ a $29,3 \%$ $\left(28,9 \mathrm{mg} \mathrm{kg}^{-1}\right)$.

O fato é que a quantidade de $\mathrm{Mn}$ presente em cada forma no solo depende também de outros fatores, como clima, material de origem e textura do solo (Shuman, 1985; Sims, 1986), dentre outros. No presente estudo, os teores de Mn na fração orgânica correlacionaram-se inversamente com os teores de argila $(\mathrm{r}=-0,76)$ e diretamente com os teores de areia $(r=0,80)(\mathrm{p}<0,05)$. Por sua vez, os coeficientes de correlação obtidos entre os teores de $\mathrm{Mn}$ da fração óxidos com teor de argila e areia foram baixos e não significativos $(\mathrm{p}>0,10)$, sendo de $-0,44$ e 0,46 , respectivamente. Nos estudos de Sims (1986) e Sims \& Patrick (1978), a maior quantidade de Mn estava na fração orgânica nos solos arenosos, e adsorvida aos óxidos, nos solos argilosos.

Os resultados obtidos no presente trabalho sugerem que a textura dos solos foi a principal responsável pela variação dos teores de Mn na fração orgânica. No entanto, a textura dos solos depende do material origem, sendo que solos originados de minerais máficos ferromagnesianos, com altos teores de $\mathrm{Fe}, \mathrm{Mg}, \mathrm{Mn}$, normalmente apresentam altos teores de argila. Por sua vez, solos originados de materiais com baixos conteúdos de minerais máficos (granitos e gnaisses) são geralmente arenosos e com menores teores de Mn (Porta-Casanellas et al., 1999). Assim, o aumento do teor de Mn na fração orgânica de solos arenosos depende principalmente de adubações e do aumento do conteúdo de MO, e nos argilosos, do teor total do nutriente no material de origem.

Outros fatores importantes no controle da disponibilidade de Mn são os valores de pH (Bibak, 1994; Shuman, 1986) e de potencial redox. Com a elevação do $\mathrm{pH}$ acelera-se a ionização dos grupos $\mathrm{COOH}$ presentes nos $\mathrm{AH}$ e $\mathrm{AF}$ e, consequentemente, sua tendência em se ligar aos íons metálicos (Evangelou \& Marsi, 2001; Stevenson, 1994). O aumento do pH também induz a oxidação química (Borkert et al., 2001) e biológica (Tisdale et al., 1985) do $\mathrm{Mn}^{2+}$ a um estado de maior valência e, desse modo, de menor disponibilidade às plantas. Sims \& Patrick (1978) observaram que o aumento das condições redutoras em solos norte-americanos, bem como a diminuição do $\mathrm{pH}$, 
aumentaram a solubilização do Mn precipitado e ocluso nos óxidos e hidróxidos, elevando-se os teores de Mn nas frações trocável e orgânica.

No presente estudo, os coeficientes de correlação obtidos entre os valores de $\mathrm{pH}$ e os teores de Mn das formas trocável, orgânica e óxido foram não significativos $(\mathrm{p}>0,05)$, sendo de $-0,45,0,47$ e 0,01 , respectivamente. Isso provavelmente ocorreu devido à baixa amplitude nos valores de $\mathrm{pH}_{\mathrm{CaCl}}(4,8$ a 5,8$)$ (Tabela 5) e ao pequeno número de dados. Os coeficientes de correlação entre os teores de Mn da fração trocável com os teores de MO dos solos também não foram significativos.

No caso específico do Local VII, o menor valor de $\mathrm{pH}_{\mathrm{CaCl} 2}(4,8)$ observado explica o fato de as plantas cultivadas nesse solo não apresentarem deficiências de $\mathrm{Mn}$, mesmo possuindo apenas $1,4 \mathrm{mg} \mathrm{kg}^{-1}$ (DTPA TEA pH 7,3) na camada de 0,00-0,10 m (Tabela 5) (o nível crítico para a camada de 0,00-0,20 m é $1,3 \mathrm{mg} \mathrm{kg}^{-1}$ ). Em solos arenosos norte-americanos, a maior parte do $\mathrm{Mn}$ estava na fração trocável até pH (água) 5,2 , mas acima desse valor, estava complexado organicamente e ligados aos óxidos de Fe (Sims, 1986).

Apesar de não se conhecer interpretações para níveis de $\mathrm{Mn}$, extraídos com $\mathrm{Sr}\left(\mathrm{NO}_{3}\right)_{2}$, baseada em classes de teores, houve certa distinção entre as frações de Mn na forma trocável entre os locais com deficiências (I, II, V, VI, VIII e IX) e sem deficiências (III, IV e VII), com menores teores nos solos dos locais que já apresentaram deficiências de Mn em soja. Os teores trocáveis de Mn dos solos dos locais em que foi constatado deficiências variou de 0,3 a $0,9 \mathrm{mg} \mathrm{kg}^{-1}$, e nos solos sem constatação de deficiência de 0,9 a $2,2 \mathrm{mg} \mathrm{kg}^{-1}$. No entanto, esse valor não deve ser observado isoladamente, uma vez que os teores trocáveis de Mn na camada de 0,00-0,05 m dos solos do estudo 1, variaram de 1,8 (SSD) a $2,5 \mathrm{mg} \mathrm{kg}^{-1}$ (SSD/preparo) e, mesmo assim, as deficiências ocorreram.

Com relação ao $\mathrm{Cu}$ e $\mathrm{Zn}$, os teores trocáveis da maioria dos solos não foram detectados por meio de espectroscopia de absorção atômica e de plasma, indicando que esses nutrientes devem estar em baixíssimas concentrações nos solos (Tabela 29). Não se pode descartar a hipótese de que o extrator utilizado $\left(\mathrm{Sr}\left(\mathrm{NO}_{3}\right)_{2}\right)$ tenha sido ineficiente na extração do $\mathrm{Cu}$ e $\mathrm{Zn}$ trocáveis, mas é mais provável que os teores prontamente 
disponíveis às plantas sejam baixos no solo, devido aos valores de $\mathrm{pH}_{\mathrm{CaCl} 2}(4,8$ a 5,8$)$ (Tabela 5).

Tabela 29. Teores de Cu e Zn na camada de 0,00-0,10 m de profundidade, em diferentes frações do solo, nos locais com e sem deficiência de Mn (médias de três repetições).

\begin{tabular}{|c|c|c|c|c|c|c|}
\hline \multirow{2}{*}{$\begin{array}{l}\text { Locais/ } \\
\text { Def. de Mn1 }\end{array}$} & \multicolumn{4}{|c|}{ Frações } & \multirow{2}{*}{$\begin{array}{c}\text { Soma das } \\
\text { frações }\end{array}$} & \multirow[t]{2}{*}{ Total } \\
\hline & Trocável & Orgânica & Óxidos & Residual & & \\
\hline & \multicolumn{6}{|c|}{$-\mathrm{mg} \mathrm{kg}^{-1}$} \\
\hline & & & Cobr & & & \\
\hline I-Com Def. & 0,0 & $2,9(43,3)^{2}$ & $1,4(21,5)$ & $2,3(35,2)$ & 6,7 & 7,5 \\
\hline II- Com Def. & 0,0 & $5,2(13,1)$ & $20,3(51,2)$ & $14,2(35,7)$ & 39,7 & 41,8 \\
\hline III-Sem Def. & 0,0 & $1,5(13,2)$ & $3,7(32,6)$ & $6,1(54,2)$ & 11,3 & 10,2 \\
\hline IV-Sem Def. & 0,0 & $2,3(18,0)$ & $4,7(37,0)$ & $5,7(45,0)$ & 12,7 & 12,8 \\
\hline V-Com Def. & 0,0 & $1,7(34,6)$ & $1,2(24,0)$ & $2,0(41,4)$ & 4,8 & 4,3 \\
\hline VI- Com Def. & 0,0 & $0,4(10,3)$ & $1,2(28,6)$ & $2,6(61,1)$ & 4,2 & 3,6 \\
\hline VII-Sem Def. & 0,0 & $4,8(13,5)$ & $15,0(42,6)$ & $15,5(43,9)$ & 35,3 & 35,5 \\
\hline VIII-Com Def. & 0,0 & $3,5(8,0)$ & $12,0(27,5)$ & $28,0(64,5)$ & 43,4 & 33,5 \\
\hline \multirow[t]{2}{*}{ IX-Com Def. } & 0,0 & $3,3(10,3)$ & $12,0(37,3)$ & $16,8(52,4)$ & 32,1 & 28,0 \\
\hline & \multicolumn{6}{|c|}{ Zinco } \\
\hline I- Com Def. & 0,0 & $2,8(18,8)$ & $5,2(35,2)$ & $6,8(46,0)$ & 14,8 & 15,5 \\
\hline II-Com Def. & 0,0 & $1,3(3,4)$ & $17,3(44,9)$ & $19,9(51,8)$ & 38,5 & 36,1 \\
\hline III-Sem Def. & 0,0 & $2,4(11,8)$ & $7,6(36,9)$ & $10,6(51,4)$ & 20,6 & 19,5 \\
\hline IV-Sem Def. & 0,0 & $2,5(12,2)$ & $7,3(35,3)$ & $10,9(52,5)$ & 20,7 & 24,5 \\
\hline V-Com Def. & 0,0 & $1,0(10,2)$ & $3,6(37,9)$ & $5,5(59,1)$ & 9,4 & 8,6 \\
\hline VI- Com Def. & 0,0 & $0,5(5,1)$ & $2,6(27,5)$ & $6,3(67,4)$ & 9,4 & 7,5 \\
\hline VII-Sem Def. & $2,0(4,7)$ & $6,9(15,9)$ & $11,5(26,5)$ & $22,9(53,0)$ & 43,3 & 41,6 \\
\hline VIII- Com Def. & 0,0 & $14,1(20,9)$ & $10,1(15,1)$ & $43,1(64,0)$ & 67,4 & 55,0 \\
\hline IX-Com Def. & 0,0 & $11,4(13,1)$ & $25,4(29,0)$ & $57,2(65,5)$ & 87,4 & 69,5 \\
\hline
\end{tabular}

(I) Local I: Faz. Santa Rosa; Locais II e III: Faz. Novo Horizonte; Local IV: Campo Experimental da Fundação ABC; Locais V e VI: Faz. Capão da Onça; Local VII: Faz. Curralinho; Local VIII: Faz. Boa Vista e Local IX: Faz. São Daniel. Com Def.: local com constatação de deficiência de Mn em soja; Sem Def.: local onde não é constatada defíciência. Os locais I, II, III e VIII estão localizados no município de Tibagi; os locais V e VI, em Ponta Grossa, PR; e os locais IV, VII e IX, em Castro, PR. ${ }^{(2)}$ Valores entre parênteses referem-se à percentagem dos teores em relação à soma das frações.

Em condições controladas, Al-Sewailem et al. (1999) utilizaram partículas de areia cobertas com óxidos de $\mathrm{Fe}$ e verificaram que a maior adsorção do $\mathrm{Cu}$ aos óxidos ocorreu entre pH (água) 5,0 e 6,5. Sims \& Patrick (1978) observaram altos teores de Zn na forma trocável, quando o pH (água) foi 4,5, e baixos teores em pH 6,0. Nos estudos realizados por Sims (1986), em solos arenosos, a maior parte do Zn estava na fração trocável até 
pH (água) 5,2, mas acima deste valor, estava complexado organicamente e ligado aos óxidos de Fe.

No caso do $\mathrm{Cu}$, McLaren \& Crawford (1973) observaram que os teores solúveis + trocáveis $\left(\mathrm{CaCl}_{2} 0,05 \mathrm{~mol} \mathrm{~L}^{-1}\right)$ de 16 solos norte-americanos, variaram de 0,1 a $0,2 \%$ do teor total. De acordo com Stevenson (1994), grande parte desse Cu trocável pode estar em formas quelatadas, o que dificulta sua extração com o sal utilizado no estudo $\left(\mathrm{Sr}_{(}\left(\mathrm{NO}_{3}\right)_{2} \quad 0,1 \mathrm{~mol} \mathrm{~L}^{-1}\right)$. No caso do $\mathrm{Zn}$, Nascimento et al. (2002b) também não encontraram teores trocáveis, extraídos com $\mathrm{Mg}\left(\mathrm{NO}_{3}\right)_{2} \quad 1,0 \mathrm{~mol} \mathrm{~L}^{-1}$, em dois latossolos ácidos $\left(\mathrm{pH}_{\text {agua }}=4,4\right.$ a 4,6) de Minas Gerais, sem adição de fertilizantes. Em condições chinesas, Cong-Tu \& Chen (2001) observaram que apenas $0,4 \%$ do teor total de $\mathrm{Zn}$ nativo de um Ferrossolo $\left(\mathrm{pH}_{\text {agua }}=4,6\right)$ estava na forma trocável $\left(\mathrm{Mg}\left(\mathrm{NO}_{3}\right)_{2} 0,05 \mathrm{~mol} \mathrm{~L}^{-1}\right)$.

Os teores de $\mathrm{Cu}$ e $\mathrm{Zn}$ totais encontrados no presente estudo (3,6-41,8 e 7,5-69,5 $\mathrm{mg} \mathrm{kg}{ }^{-1}$, respectivamente para $\mathrm{Cu}$ e $\mathrm{Zn}$ ) encontra-se geralmente dentro da faixa obtida na maioria dos solos (2-100 e 10-300 $\mathrm{mg} \mathrm{kg}^{-1}$, respectivamente para Cu e $\mathrm{Zn}$ ) (Abreu et al., 2001). Esses valores provavelmente estejam relacionados ao material de origem desses solos, pois, geralmente são encontrados maiores teores em solos originários de rochas máficas e menores teores naqueles derivados de granitos e gnaisses (Nascimento et al., 2002b). Como ocorreu para o Mn, as amostras dos locais $\mathrm{V}$ e VI foram as que apresentaram os menores teores de $\mathrm{Cu}$ e $\mathrm{Zn}$ totais, indicando mais uma vez a baixa fertilidade natural desses solos. 


\subsubsection{Teores e formas de Mn no solo, em função de doses de Mn no solo}

Na Tabela 30 são apresentados os teores de Mn dos quatro locais selecionados para obtenção das curvas de resposta (I, II, III e IV), extraídos da camada de 0,00-0,10 $\mathrm{m}$, com os diferentes extratores ( $\mathrm{HCl}$, Mehlich I e III e DTPA). A quantificação dos teores de Mn foi realizada após três meses da aplicação das doses de Mn no solo.

Tabela 30. Teores de Mn na camada de 0,00-0,10 m, obtidos por diferentes extratores, em função de extratores, dentro de cada dose de $\mathrm{Mn}$ aplicada, em quatro locais (médias de quatro repetições).

\begin{tabular}{|c|c|c|c|c|c|c|c|}
\hline \multirow[t]{2}{*}{ Extrator } & \multicolumn{7}{|c|}{ Doses de Mn $\left(\mathrm{kg} \mathrm{ha}^{-1}\right)$} \\
\hline & 0 & 1,5 & 3,0 & 6,0 & 12,0 & 24,0 & 48,0 \\
\hline & & & & $\mathrm{mg} \mathrm{kg}^{-1}$ & & & \\
\hline & \multicolumn{7}{|c|}{ Local I' } \\
\hline $\mathrm{HCl}$ & $8,4 \mathrm{a}^{2}$ & $12,3 \mathrm{a}$ & $11,8 \mathrm{a}$ & $12,2 \mathrm{a}$ & $15,4 \mathrm{a}$ & $31,5 \mathrm{a}$ & $37,3 \mathrm{a}$ \\
\hline Mehlich I & $7,0 \mathrm{a}$ & $9,6 \mathrm{a}$ & $8,9 \mathrm{a}$ & $10,1 \mathrm{a}$ & $12,1 \mathrm{a}$ & $20,6 \mathrm{~b}$ & $23,7 \mathrm{~b}$ \\
\hline Mehlich III & $4,2 a b$ & $7,2 \mathrm{ab}$ & $7,0 \mathrm{ab}$ & $8,3 \mathrm{a}$ & $11,1 \mathrm{a}$ & $26,5 \mathrm{ab}$ & $34,3 \mathrm{a}$ \\
\hline DTPA & $0,6 \mathrm{~b}$ & $1,2 \mathrm{~b}$ & $1,0 \mathrm{~b}$ & $1,1 \mathrm{~b}$ & $1,5 \mathrm{~b}$ & $3,1 \mathrm{c}$ & $3,2 \mathrm{c}$ \\
\hline \multirow[t]{2}{*}{ C.V. } & $27,4 \%$ & & & & & & \\
\hline & \multicolumn{7}{|c|}{ Local II } \\
\hline $\mathrm{HCl}$ & $16,1 \mathrm{a}$ & $19,0 \mathrm{a}$ & $19,7 \mathbf{a}$ & $18,9 \mathrm{a}$ & $21,7 \mathrm{a}$ & $28,6 \mathrm{a}$ & $41,8 \mathrm{a}$ \\
\hline Mehlich I & $11,3 \mathrm{ab}$ & $12,8 \mathrm{ab}$ & $12,9 \mathrm{ab}$ & $13,5 \mathrm{ab}$ & $15,7 \mathrm{ab}$ & $17,1 \mathrm{~b}$ & $24,3 \mathrm{~b}$ \\
\hline Mehlich III & $6,1 \mathrm{bc}$ & $7,2 \mathrm{bc}$ & $8,2 \mathrm{bc}$ & $9,0 \mathrm{bc}$ & $12,0 \mathrm{~b}$ & $16,2 \mathrm{~b}$ & $36,5 \mathrm{a}$ \\
\hline DTPA & $1,8 \mathrm{c}$ & $1,6 \mathrm{c}$ & $1,8 \mathrm{c}$ & $1,6 \mathrm{c}$ & $1,7 \mathrm{c}$ & $2,9 \mathrm{c}$ & $4,7 \mathrm{c}$ \\
\hline \multirow[t]{2}{*}{ C.V. } & $32,5 \%$ & & & & & & \\
\hline & \multicolumn{7}{|c|}{ Local III } \\
\hline $\mathrm{HCl}$ & $15,5 \mathrm{a}$ & $14,6 \mathrm{a}$ & $15,2 \mathrm{a}$ & $17,4 \mathrm{a}$ & $18,6 \mathrm{a}$ & 21,3 a & $29,1 \mathrm{a}$ \\
\hline Mehlich I & $14,6 \mathrm{a}$ & $14,5 \mathrm{a}$ & $14,5 \mathrm{a}$ & $16,4 \mathrm{a}$ & $17,2 \mathrm{a}$ & $18,2 \mathrm{ab}$ & $23,7 \mathrm{~b}$ \\
\hline Mehlich III & $7,8 \mathrm{~b}$ & $8,1 \mathrm{~b}$ & $8,8 \mathrm{~b}$ & $11,1 \mathrm{~b}$ & $12,5 \mathrm{~b}$ & $16,8 \mathrm{~b}$ & $28,1 \mathrm{a}$ \\
\hline DTPA & $5,0 \mathrm{~b}$ & $4,8 \mathrm{~b}$ & $4,7 \mathrm{c}$ & $5,6 \mathrm{c}$ & $5,9 \mathrm{c}$ & $8,1 \mathrm{c}$ & $12,1 \mathrm{c}$ \\
\hline \multirow[t]{2}{*}{ C.V. } & $14,4 \%$ & & & & & & \\
\hline & \multicolumn{7}{|c|}{ Local IV } \\
\hline $\mathrm{HCl}$ & $30,1 \mathrm{a}$ & $29,8 \mathrm{a}$ & $29,2 \mathrm{a}$ & $30,8 \mathrm{a}$ & $45,6 \mathrm{a}$ & 35,1 a & $49,8 \mathrm{a}$ \\
\hline Mehlich I & $14,8 \mathrm{~b}$ & $14,3 \mathrm{~b}$ & $15,2 \mathrm{~b}$ & $15,1 \mathrm{~b}$ & $17,8 \mathrm{~b}$ & $17,7 \mathrm{~b}$ & $19,9 \mathrm{c}$ \\
\hline Mehlich III & $10,3 \mathrm{bc}$ & $11,2 \mathrm{bc}$ & $10,0 \mathrm{bc}$ & $12,0 \mathrm{bc}$ & $19,8 \mathrm{~b}$ & $16,2 \mathrm{~b}$ & $28,3 \mathrm{~b}$ \\
\hline DTPA & $6,8 \mathrm{c}$ & $6,4 \mathrm{c}$ & $6,4 \mathrm{c}$ & $6,8 \mathrm{c}$ & $9,8 \mathrm{c}$ & $8,8 \mathrm{c}$ & $12,1 \mathrm{~d}$ \\
\hline C.V. & $18,9 \%$ & & & & & & \\
\hline
\end{tabular}

(I) Local I: Fazenda Santa Rosa; Locais II e III: Fazenda Novo Horizonte; Local IV: Campo Experimental da Fundação ABC. Locais I e II: já apresentaram deficiências de Mn em soja; Locais III e IV: sem registros de deficiências de Mn. Os locais I, III, IV estão localizados no município de Tibagi, e o Local IV, em Castro, PR. ${ }^{(2)}$ Valores seguidos da mesma letra, na coluna, não diferem entre si, pelo teste de Tukey a $5 \%$. 
Em todas as situações, as soluções ácidas $\mathrm{HCl} 0,1 \mathrm{~mol} \mathrm{~L}^{-1}(\mathrm{pH} \cong 1,1)$ e Mehlich I $(\mathrm{pH} \cong 1,2)$ extraíram maiores quantidades de $\mathrm{Mn}$ do que a solução DTPA TEA pH 7,3, sugerindo que o $\mathrm{Mn}$ foi sensível às variações do $\mathrm{pH}$ das soluções extratoras. As soluções ácidas têm capacidade de abaixar o $\mathrm{pH}$ e solubilizar o $\mathrm{Mn}$, o que não ocorre com o DTPA de reação alcalina (Abreu \& Raij, 1996; Galrão, 1995). No entanto, sabe-se que em condições moderadamente ácidas a alcalinas, o DTPA pode quelatizar o Mn da solução, formando complexos (DTPA-Mn) de alta estabilidade (Norvell, 1991). De qualquer forma, a acidez das soluções extratoras ( $\mathrm{HCl}$ e Mehlich I) foi mais importante na solubilização do Mn do que a capacidade do DTPA em quelatizar o Mn do solo.

O extrator Mehlich III $(\mathrm{pH} \cong 2,4)$ extraiu maiores quantidades de $\mathrm{Mn}$ do que o Mehlich I, nas parcelas que receberam a maior dose de Mn de todos os locais. Apesar de o EDTA, presente no Mehlich III, ser mais eficiente na complexação do Mn em condições alcalinas do que em condições ácidas (Norvell, 1991), nesse caso, sua

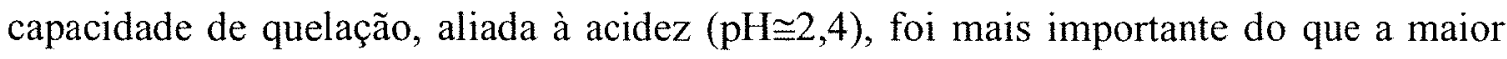

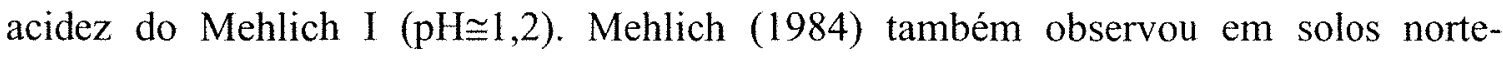
americanos que o Mehlich III extraiu maiores quantidades de Mn do que o Mehlich II, o qual não possuía EDTA em sua composição.

Em muitos casos, o Mehlich III ( $\mathrm{pH} \cong 2,4)$ extraiu maiores teores do que o DTPA TEA pH 7,3, o que não era esperado, uma vez que o quelato DTPA-Mn tem alta estabilidade em condições de elevado $\mathrm{pH}$ e o complexo EDTA-Mn é mais estável em condições moderadamente ácidas a alcalinas (Norvell, 1991;Tisdale et al., 1985). Além disso, a concentração do DTPA $\left(0,005 \mathrm{~mol} \mathrm{~L}^{-1}\right)$ na solução extratora é superior à do EDTA na solução Mehlich III $\left(0,001 \mathrm{~mol} \mathrm{~L}^{-1}\right)$. Por outro lado, as soluções ácidas têm capacidade de abaixar o pH e solubilizar o $\mathrm{Mn}$, o que não ocorre com o DTPA de reação alcalina (Abreu \& Raij, 1996; Galrão, 1995). Assim, a acidez da solução extratora prevaleceu na solubilização do Mn sobre a capacidade de quelação do DTPA.

Com exceção dos teores de Mn, extraídos por DTPA, nas amostras de terra dos locais I e II, os teores de Mn aumentaram com as doses (Figura 10), o que era esperado devido às elevadas quantidades aplicadas. Miyazawa et al. (1996a) e Silva (2000) 
também observaram aumento dos teores de $\mathrm{Mn}$, com aplicação do nutriente no solo. No entanto, nos estudos de Miyazawa et al. (1996a), após o sétimo mês de avaliação, os teores de $\mathrm{Mn}$ dos tratamentos que receberam as menores doses (abaixo de $100 \mathrm{ug} \mathrm{g}^{-1}$ ) foram reduzidos para teor igual ao do tratamento testemunha.

No estudo mencionado anteriormente, as diminuições dos teores de Mn foram atribuídas apenas às reações de oxidação e redução, as quais o Mn participa como carreador de elétrons (Borkert et al., 2001), descartando-se a possibilidade de formação de compostos estáveis do Mn com a MO, que pode ser mais importante em solos sob SSD, principalmente em condições de pH elevado (Sims, 1986; Tisdale et al., 1985). Após 14 semanas da aplicação de $\mathrm{Mn}$, na forma de $\mathrm{MnSO}_{4} \cdot \mathrm{H}_{2} \mathrm{O}$, em 10 solos norteamericanos, com pH acima de 6,4 (pasta de saturação), apenas 14\% do Mn aplicado foi recuperado com DTPA TEA pH 7,3 (Follett \& Lindsay, 1971). No entanto, no solo em que o pH era 5,4 , a recuperação foi de $62 \%$.

A partir da extração seqüencial do Mn das amostras de terra do Local I, realizada após três meses da aplicação do nutriente no solo (doses 0,12 e $48 \mathrm{~kg} \mathrm{ha}^{-1}$ ), verificaramse que os teores de $\mathrm{Mn}$ trocáveis, extraídos com $\operatorname{Sr}\left(\mathrm{NO}_{3}\right)_{2}$, aumentaram com as doses aplicadas (Figura 11). Os teores de Mn na forma trocável aumentaram de $0,6 \mathrm{mg} \mathrm{kg}^{-1}$ na testemunha, para 2,5 $\mathrm{mg} \mathrm{kg}^{-1}$, com a aplicação da maior dose (Figura 11, Tabela 31). Apesar de esse aumento na fração trocável ter sido mais de quatro vezes maior do que o teor original, o mesmo foi pequeno quando comparado com o aumento ocorrido na fração orgânica.

Na fração orgânica, os teores de Mn variaram de $5,4 \mathrm{mg} \mathrm{kg}^{-1}$ na testemunha, para $35,1 \mathrm{mg} \mathrm{kg}^{-1}$, com a aplicação da maior dose . Nas parcelas sem aplicação de $\mathrm{Mn}, 44,2 \%$ do Mn (soma das frações) estava na forma residual e apenas 15,5\% na forma orgânica (Tabela 31). Com a aplicação de $48 \mathrm{~kg} \mathrm{ha}^{-1}$ de $\mathrm{Mn}$, a quantidade de $\mathrm{Mn}$ na forma orgânica passou para $51,9 \%$ do $\mathrm{Mn}$ total, e apenas $20 \%$ ficou na forma residual, demonstrando que a maior parte do $\mathrm{Mn}$ ficou retido na $\mathrm{MO}$. 

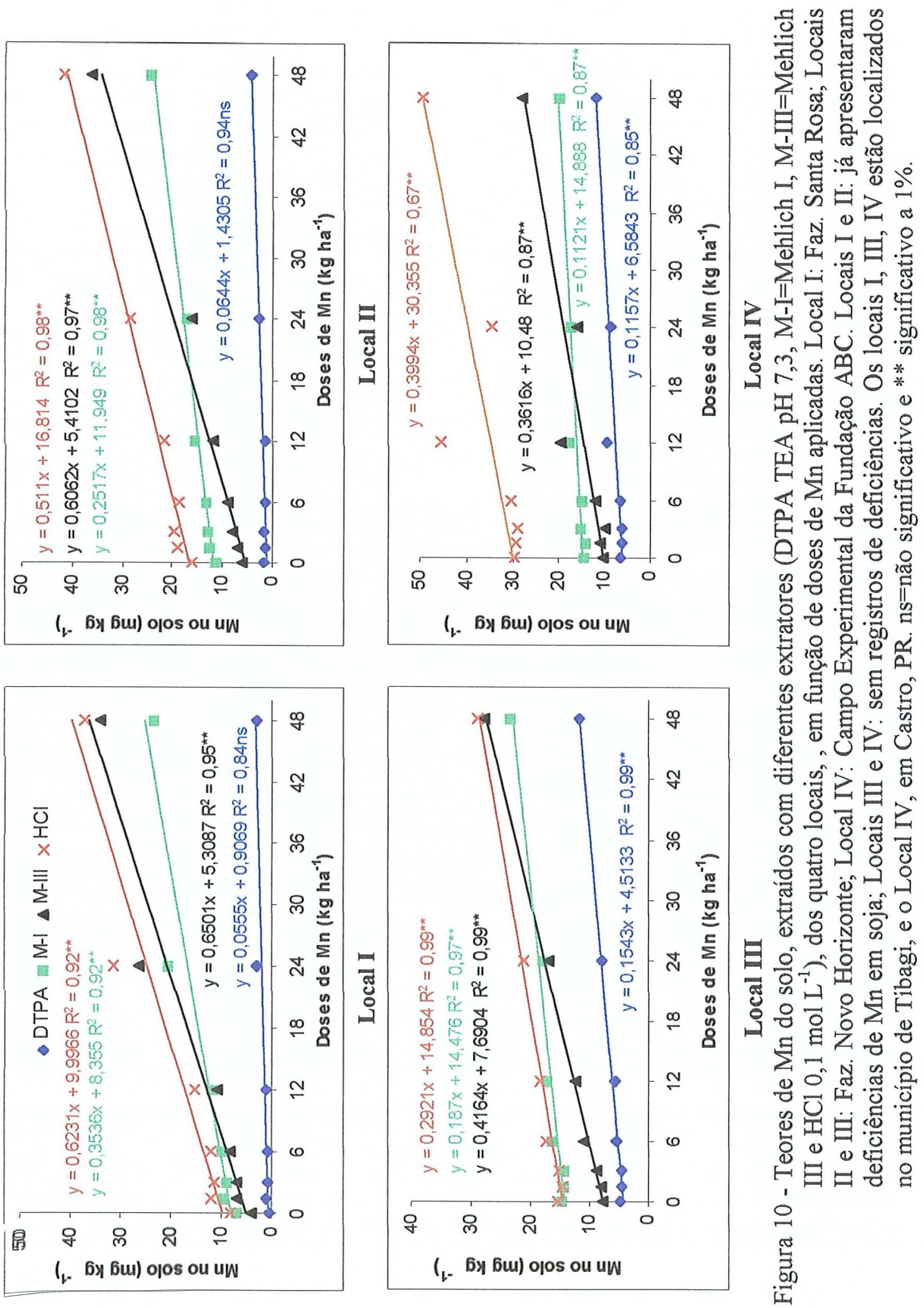

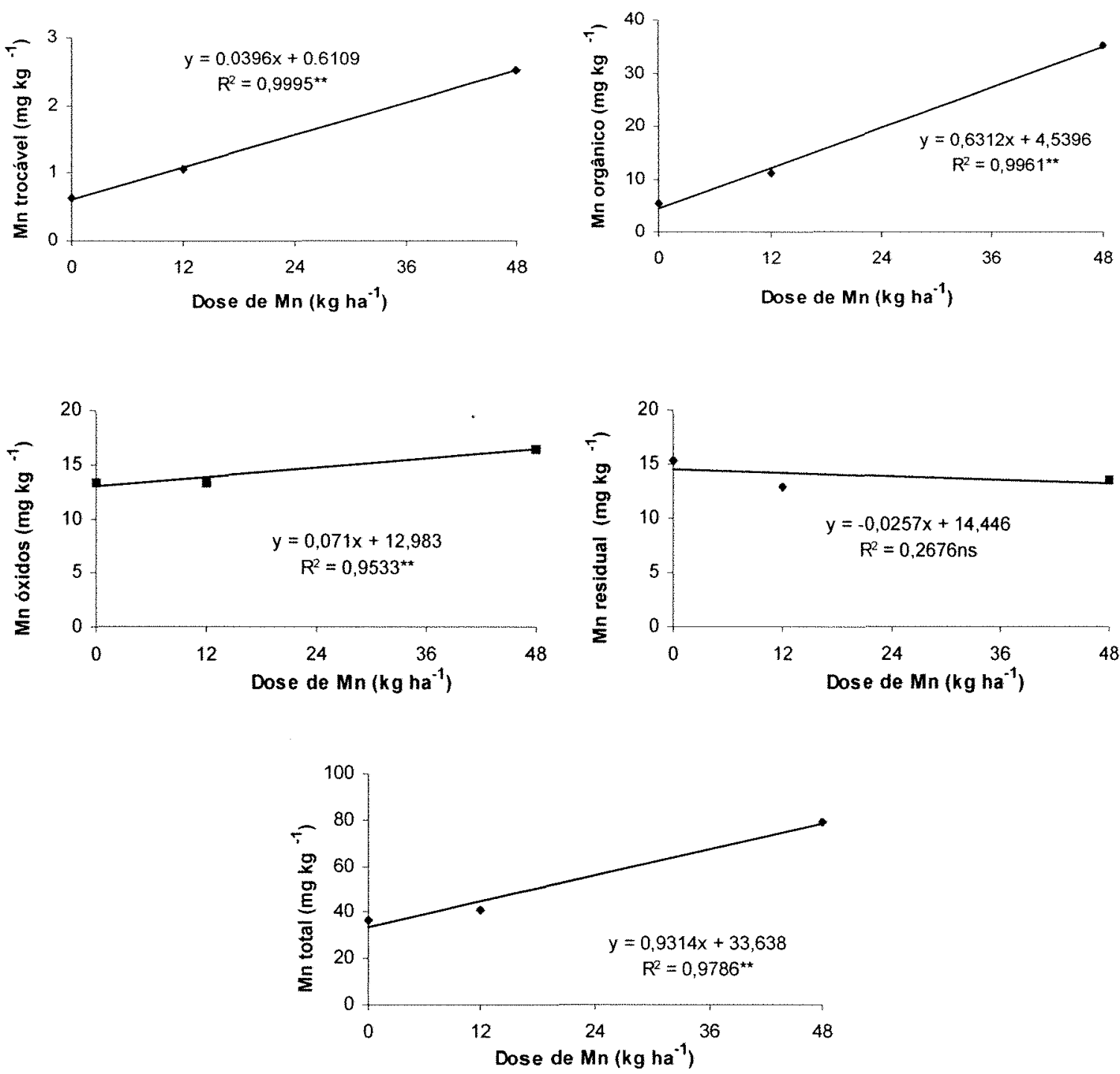

Figura 11 - Formas de Mn extraídas do CAMBISSOLO HÚMICO do Local I (Faz. Santa Rosa), em função de doses de Mn aplicadas. Os dados originais apresentados foram transformados $\mathrm{em}^{1 / 2}$ para as análises estatísticas. ${ }^{* *}$ significativo a $1 \%$.

$\mathrm{O} \mathrm{Mn}$ que foi retido pela $\mathrm{MO}$ do solo pode estar associado aos grupos funcionais da mesma, na forma de complexos de esfera externa e interna. No caso dos complexos de esfera externa, o Mn é adsorvido apenas por atração eletrostática (Lakatos et al., 1977), permanecendo solvatado às moléculas de água, $\left[\mathrm{Mn}\left(\mathrm{H}_{2} \mathrm{O}\right)_{6}\right]^{2+}$ (Novotny, 2002). Esse tipo de interação é relativamente fraca e o metal complexado pode ser facilmente trocado por outros cátions não específicos (Evangelou \& Marsi, 2001) e encontra-se disponível às plantas (Canellas et al., 1999). 
Tabela 31. Teores de Mn em diferentes formas, na camada de 0,00-0,10 $\mathrm{m}$ de profundidade, em função de doses de Mn aplicadas no Local I (Faz. Santa Rosa) (médias de 12 repetições).

\begin{tabular}{|c|c|c|c|c|c|c|}
\hline \multirow[t]{2}{*}{ Dose } & \multicolumn{4}{|c|}{ Frações } & \multirow{2}{*}{$\begin{array}{c}\text { Soma das } \\
\text { frações }\end{array}$} & \multirow[t]{2}{*}{ Total } \\
\hline & Trocável & Orgânica & Óxidos & Residual & & \\
\hline $\mathrm{kg} \mathrm{ha}^{-1}$ & & & $-\mathrm{mg} \mathrm{kg}$ & & & \\
\hline 0 & $0,6\left(1,8^{*}\right) C^{1}$ & $5,4(15,5) \mathrm{B}$ & $13,3(38,4) \mathrm{A}$ & $15,3(44,2) \mathrm{A}$ & 34,6 & 36,5 \\
\hline 12 & $1,1(2,6) \mathrm{B}$ & $11,0(28,7) \mathrm{A}$ & $13,4(34,9) \mathrm{A}$ & $13,0(33,9) \mathrm{A}$ & 38,4 & 41,0 \\
\hline 48 & $2,5(3,7) \mathrm{C}$ & $35,1(51,9) \mathrm{A}$ & $16,5(24,4) \mathrm{B}$ & $13,5(20,0) \mathrm{B}$ & 67,6 & 79,3 \\
\hline C.V. & $6,9 \%$ & & & & & \\
\hline
\end{tabular}

*Valores dentro dos parênteses referem-se às percentagens dos teores em relação à soma das frações. Os dados originais apresentados foram transformados em $x^{1 / 2}$ para as análises estatísticas ${ }^{(1)}$ Letras maiúsculas comparam, na linha, teores de Mn nas diferentes frações, dentro de cada dose, pelo teste de Tukey a 5\%.

Quando as moléculas de água, que solvatam o cátion, são trocadas pelos grupamentos funcionais da MO, e o cátion passa a se coordenar diretamente aos grupos funcionais, por meio de ligações covalentes, é formado um complexo chamado esfera interna (Canellas et al., 1999). Nesses complexos, forma-se um quelato em que o ligante precisa ter no mínimo dois doadores de elétrons, capazes de se ligar ao mesmo íon metálico, formando-se um anel (Evangelou \& Marsi, 2001). Os principais grupos funcionais envolvidos seriam o carboxílico, as hidroxilas fenólicas e alcoólica, a carbonila e a metoxila (Schnitzer \& Khan, $1978^{4}$, citados por Novotny, 2002), mas o mais importante é o carboxílico (Evangelou \& Marsi, 2001).

$\mathrm{O} \mathrm{Mn}^{2+}$ adsorvido pela $\mathrm{MO}$ em baixos valores de $\mathrm{pH}$, provavelmente está presente nos solos na forma de complexos de esfera externa, enquanto grande parte pode estar como complexo de esfera interna, com o aumento do $\mathrm{pH}$ e temperatura (McBride, 1982; Senesi, 1990). Com a elevação do $\mathrm{pH}$ aumenta-se a ionização dos grupos $\mathrm{COOH}$ presentes nos AH e AF (Evangelou \& Marsi, 2001) e, consequentemente, sua tendência em se ligar ao Mn (Bibak, 1994; Stevenson, 1994). Nos solos com altos valores de pH, a atividade dos microorganismos que oxidam o $\mathrm{Mn}^{2+} \mathrm{em}$ complexos estáveis com a $\mathrm{MO}$ também é elevada (Tisdale et al., 1985).

Devido aos altos teores de MO dos solos sob SSD, às fortes correlações entre os teores de Mn e a MO e às deficiências de Mn em soja nos solos sob SSD, com teores considerados adequados para o SSC, provavelmente parte do Mn extraído desses solos 
pode estar associado aos grupos funcionais da $\mathrm{MO}$ em formas muito estáveis e indisponíveis às plantas.

Conforme discutido no estudo 1 , apesar de as evidências apontarem para o fato de que o Mn de alguns solos sob SSD estar associado à MO de forma indisponível às plantas, somente a partir dos dados obtidos pela extração seqüencial, não é possível inferir sobre o tipo de complexo MO-metal. O extrator utilizado para extração do Mn da forma orgânica $(\mathrm{NaClO})$, oxida praticamente 100\% da MO do solo (Chao, 1984), liberando para a solução todo o $\mathrm{Mn}$ associado à $\mathrm{MO}$, em diferentes formas (atração eletrostática, ligação covalente). Para determinar as formas de ligações do Mn com a MO, outras técnicas devem ser utilizadas, como a RPE.

${ }^{4}$ SCHNITZER, M.; KHAN, S.U. Soil Organic Matter. Amsterdam: Elsevier, 1978. 319p. 


\subsubsection{Avaliação dos micronutrientes do solo por Ressonância Paramagnética Eletrônica}

Com observado no estudo 1 , o processo de centrifugação das amostras de $\mathrm{AH}$, em alta rotação, foi altamente eficiente na eliminação do Fe. Nas Figuras 12 e 13 são mostrados, respectivamente, os espectros de RPE obtidos das amostras de AH, extraídas dos solos dos locais I e III, antes e após as centrifugações. O Fe eliminado durante o processo de centrifugação, está nas formas de óxido e hidróxido (Novotny, 2002), sendo o principal responsável pelo alargamento do sinal em RPE (Ceretta et al., 1999).

Conforme discutido no estudo 1, o alargamento da linha de RPE acontece devido a presença do íon $\mathrm{Fe}^{3+}$ em alta quantidade, o qual diminui os tempos de relaxação dos spins dos elétrons, causando a saturação do sinal e, consequentemente, perda de informações. Assim, a ausência da observação dos sinais do $\mathrm{Cu}^{2+}$ e $\mathrm{Mn}^{2+}$, antes da centrifugação das amostras de $\mathrm{AH}$, ocorreu devido ao alargamento das linhas provocado pelo $\mathrm{Fe}^{3+}$ (Ceretta et al., 1999).

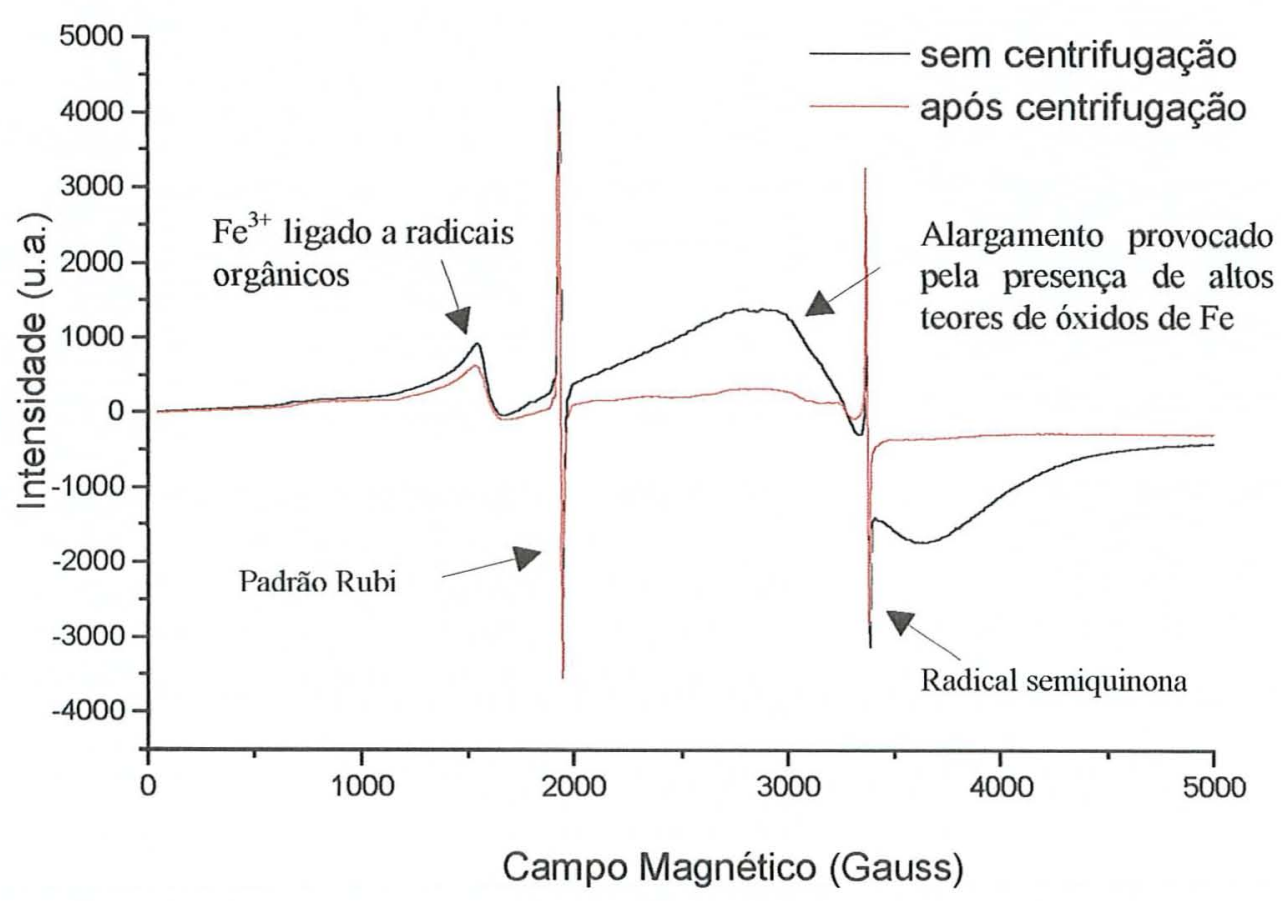

Figura 12 - Espectro de RPE de amostras sólidas de AH, extraído da camada de 0,00-0,10 m, do Local I, antes e após a centrifugação de 12500 rpm por 3 horas. 


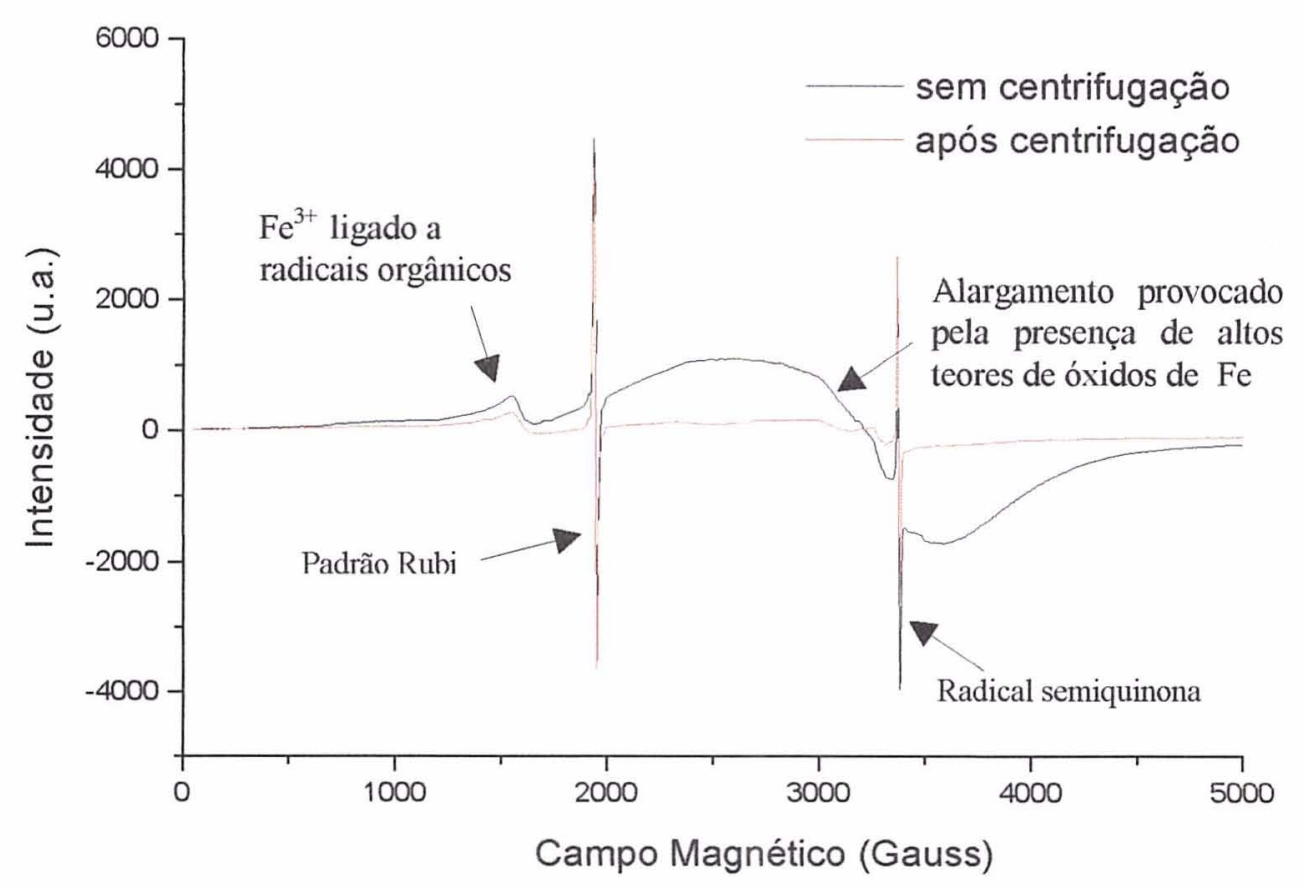

Figura 13 - Espectro de RPE de amostras sólidas de AH, extraído da camada de 0,00-0,10 m, do Local III, antes e após a centrifugação de 12500 rpm por 3 horas.

Assim como nas amostras de AH do estudo 1, nos espectros de RPE apareceu outro sinal de $\mathrm{Fe}^{3+}$, que geralmente possui fator $\mathrm{g}$ de 4,3 e simetria rômbica (Novotny, 2002). Esse $\mathrm{Fe}$, ligado aos radicais orgânicos, apresenta considerável resistência em se reduzir ou realizar reações de troca, pois é fortemente ligado e protegido, na forma de complexos de esfera interna com os AH (Saab, 1999). Prova disso é que os sinais do $\mathrm{Fe}^{3+}$, associado aos radicais orgânicos, persistiram após o tratamento por centrifugação.

A eliminação do $\mathrm{Fe}$ das amostras de $\mathrm{AH}$, por centrifugações em alta rotação, aumentou a intensidade dos sinais de RPE para os radicais livres semiquinona, mas de qualquer forma, os sinais dos outros metais ( $\mathrm{Cu}$ e $\mathrm{Mn}$ ) ainda não puderam ser obtidos (Figuras 12 e 13). A RPE é uma técnica muito sensível e sob condições favoráveis o limite de detecção para centros paramagnéticos (substâncias que possuem elétrons com spins desemparelhados) encontra-se no intervalo de $10^{11}$ a $10^{12}$ spins $\mathrm{g}^{-1}$, ou seja, parte por bilhão (Novotny, 2002). No entanto, mesmo após a eliminação de parte do $\mathrm{Fe}$, a 
quantidade remanescente deve ter sido suficiente para interferir nos sinais dos outros metais.

Conforme discutido para estudo 1 , os processos de extração e purificação dos $\mathrm{AH}$, juntamente com a centrifugação para eliminação dos óxidos de $\mathrm{Fe}$, possivelmente tenham eliminado grande parte dos metais e diminuído sua quantidade adsorvida à MO. Senesi \& Sposito (1989) observaram que os sinais de RPE do $\mathrm{Mn}^{2+}$, em amostras de liteira, desapareceram após sucessivos tratamentos ácidos das amostras.

Durante o processo de extração e fracionamento das SH do solo, a separação dos AH e AF é feita através da precipitação dos primeiros em condições ácidas (pH 1,0 a 1,5). Esse abaixamento do $\mathrm{pH}$ provoca a liberação dos metais associados aos AH para os AF em solução. Desse modo, em cada etapa de abaixamento do pH, para precipitação dos $\mathrm{AH}$, a quantidade de metais adsorvida aos $\mathrm{AH}$ é diminuída, e a dos AF, aumentada. Acredita-se que tanto os metais associados fracamente aos $\mathrm{AH}$, como parte daqueles ligados de forma covalente possam ser liberados, devido às condições extremamente ácidas do meio.

Nas outras etapas de purificação dos AH, como centrifugações, lavagens com água acidificada ( $\mathrm{pH} 2,0$ ) e diálise (cinco dias), para eliminação de substâncias de baixo peso molecular e íons, os metais solúveis em água e os associados fracamente à MO (ligações eletrostáticas) vão sendo retirados, permanecendo nas amostras de AH apenas aqueles ligados em formas mais estáveis. Além disso, como discutido no estudo 1, a etapa de centrifugação para eliminação do Fe foi crítica para a perda dos outros metais, uma vez que a mesma representou mais uma etapa de dissolução dos $\mathrm{AH}$ e precipitação desses em meio ácido.

$\mathrm{O}$ Mn associado à $\mathrm{MO}$ na forma de ligações muito estáveis não pode ser observado por RPE, uma vez que o íon $\mathrm{Mn}^{2+}$ apresenta uma interação fina ou separação de campo zero grande, que alarga o sinal e a linha de ressonância desaparece (MartinNeto et al., 1988). McBride (1982) observou perda de sinal do Mn em RPE, devido ao grande alargamento de linha provocado por ligações muito estáveis (esfera interna) do Mn em complexos com ácidos monocarboxílicos e policarboxílicos (AH e AF). MartinNeto et al. (1988) também não observaram sinais de Mn em solução, extraído do solo 
com DTPA TEA pH 7,3, mas intensos sinais de Mn foram observados, quando o metal foi retirado do solo com água ou pela solução Mehlich I.

A ausência de sinais de Mn nos espectros de RPE das amostras de AH dos locais I e III (Figuras 12 e 13), juntamente com a quantificação do metal nas amostras de AH (30,2 e $13 \mathrm{mg} \mathrm{kg}^{-1}$, respectivamente nos locais I e III) (Tabela 32), confirma a hipótese de que o Mn estava presente nas amostras de $\mathrm{AH}$, na forma de complexos muito estáveis (ligações covalentes). Como discutido anteriormente, essa forma de Mn não pode ser detectada por RPE (Martin-Neto et al., 1988; McBride, 1982).

Tabela 32. Teores de $\mathrm{Cu}, \mathrm{Fe}, \mathrm{Mn}$ e $\mathrm{Zn}$ em amostras de $\mathrm{AH}$ lifiolizadas, extraídas das camada de 0,00-0,10 $\mathrm{m}$ de profundidade, de locais com e sem deficiência de $\mathrm{Mn}$.

\begin{tabular}{|c|c|c|c|c|}
\hline Locais/Def. de $\mathrm{Mn}^{1}$ & $\mathbf{M n}$ & $\mathrm{Cu}$ & $\mathrm{Zn}$ & $\mathrm{Fe}$ \\
\hline & & $\mathrm{mg} \mathrm{kg}{ }^{-1}$ & & $\mathrm{~g} \mathrm{~kg}^{-}$ \\
\hline Local I/com def. & 30,2 & 95,0 & 59,8 & 43,4 \\
\hline Local I/com def.* & 43,8 & 286,8 & 23,5 & 25,0 \\
\hline Local II/com def. & 25,8 & 136,8 & 40,3 & 25,8 \\
\hline Local II/com def.* & 28,4 & 138,9 & 38,6 & 31,7 \\
\hline Local III/sem def. & 13,0 & 124,0 & 44,6 & 15,2 \\
\hline Local IV/sem def. & 8,2 & 454,6 & 50,2 & 10,5 \\
\hline Local V/com def. & 16,8 & 62,0 & 56,4 & 23,8 \\
\hline Local VI/com def. & 23,0 & 67,4 & 35,0 & 36,9 \\
\hline Local VII/sem def. & 15,0 & 244,3 & 36,5 & 24,1 \\
\hline Local VIII/com def. & 23,6 & 98,0 & 61,9 & 30,7 \\
\hline Local IX/com def. & 37,6 & 115,4 & 29,5 & 53,0 \\
\hline
\end{tabular}

(1)Local I: Faz. Santa Rosa; Locais II e III: Faz. Novo Horizonte; Local IV: Campo Experimental da Fundação ABC; Locais V e VI: Faz. Capão da Onça; Local VII: Faz. Curralinho; Local VIII: Faz. Boa Vista e Local IX: Faz. São Daniel. Com Def.: local com constatação de deficiência de Mn em soja; Sem Def:: local onde não é constatada deficiência. Os locais I, II, III e VIII estão localizados no município de Tibagi; os locais V e VI, em Ponta Grossa, PR; e os locais IV, VII e IX, em Castro, PR. * Aplicação de 48 $\mathrm{kg} \mathrm{ha}^{-1}$ de Mn em relação à testemunha.

Como discutido no estudo 1 , devido à escassez de informações na literatura sobre teores de metais obtidos de amostras de $\mathrm{AH}$ do solo, após purificação e liofilização, há dificuldade de se fazer comparações desses teores com outros obtidos em situações semelhantes. Senesi et al. (1989) obtiveram em amostras de AH de solos norteamericanos, sem aplicação de lodo de esgoto, $46 \mathrm{mg} \mathrm{kg}^{-1}$ de $\mathrm{Mn} ; 2.212 \mathrm{mg} \mathrm{kg}^{-1}$ de Cu; $44 \mathrm{mg} \mathrm{kg}^{-1}$ de $\mathrm{Zn} \mathrm{e} 7.300 \mathrm{mg} \mathrm{kg}^{-1}$ de Fe. Marzadori et al. (2000) quantificaram em 
amostras de $\mathrm{AH}$, originadas de turfas na Itália, $15 \mathrm{mg} \mathrm{kg}^{-1}$ de $\mathrm{Mn} ; 38 \mathrm{mg} \mathrm{kg}^{-1}$ de Cu; 141 $\mathrm{mg} \mathrm{kg}{ }^{-1}$ de $\mathrm{Zne} 664 \mathrm{mg} \mathrm{kg}^{-1}$ de Fe.

Os teores de Mn obtidos no presente estudo foram geralmente inferiores aos de Senesi et al. (1989). Por sua vez, nos solos com deficiências de $\mathrm{Mn}$, os teores foram superiores aos encontrados por Marzadori et al. (2000), em amostras de AH de turfas. Apesar de esses autores terem utilizado basicamente o mesmo procedimento de extração das $\mathrm{SH}(\mathrm{NaOH})$, adotado nesse estudo, não utilizaram a técnica de centrifugação em alta rotação para retirada do $\mathrm{Fe}$, na forma de óxidos. Como já discutido, a maior purificação dos $\mathrm{AH}$ no presente estudo, possivelmente tenha facilitado a perda de parte do Mn que estava adsorvido à $\mathrm{MO}$ e aos óxidos de $\mathrm{Fe}$. No entanto, deve ser considerado que os $\mathrm{AH}$ foram originados em situações diferentes.

Vale destacar que os teores de $\mathrm{Mn}$ nas amostras de $\mathrm{AH}$ dos locais que apresentam deficiências de $\mathrm{Mn}$ foram superiores $\left(16,8 \mathrm{a} 37,6 \mathrm{mg} \mathrm{kg}^{-1}\right)$ aos dos locais sem constatação de deficiência (8,2 a 15,0 $\mathrm{mg} \mathrm{kg}^{-1}$ ) (Tabela 32). As quantidades de Mn nos $\mathrm{AH}$ das parcelas que receberam $48 \mathrm{~kg} \mathrm{ha}^{-1}$ (locais I e II) foram superiores às encontradas na testemunha. Essas constatações evidenciam o fato de que nos locais que as plantas apresentam-se deficientes em Mn, existe maior quantidade do elemento complexado pelos grupos da MO (carboxílicos e fenólicos), na forma de complexos estáveis.

Os teores de $\mathrm{Cu}$ obtidos no presente estudo foram muito inferiores aos de Senesi et al. (1989). Possivelmente deve ter ocorrido perda do $\mathrm{Cu}$ no processo de centrifugação, como discutido para o $\mathrm{Mn}$. Por outro lado, os teores de $\mathrm{Cu}$ obtidos nesse estudo, foram superiores aos encontrados por Marzadori et al. (2000), em amostras de AH de turfas. A obtenção dos sinais de $\mathrm{Cu}$ nas amostras de $\mathrm{AH}$ provavelmente foi impedida pelos altos teores de $\mathrm{Fe}$ das amostras, que mesmo após a eliminação de óxidos e hidróxidos por centrifugação, foram muito superiores aos obtidos por Senesi et al. (1989) e Marzadori et al. (2000). Por outro lado, os teores de $\mathrm{Zn}$ foram semelhantes aos encontrados por Senesi et al. (1989), mas inferiores aos obtidos por Marzadori et al. (2000), em amostras de AH de turfas. 
Como era previsto que os procedimentos utilizados para a extração e purificação dos $\mathrm{AH}$ também pudessem eliminar o Mn, adicionaram-se ao estudo, amostras de $\mathrm{AH}$ dos locais I e II, utilizando-se as parcelas que receberam $48 \mathrm{~kg} \mathrm{ha}^{-1}$ de $\mathrm{Mn}$. Mesmo nesses casos, não foram obtidos sinais em RPE para o Mn (Figura 14). Como discutido anteriormente, o Mn que foi liberado para a solução durante os processos de separação dos $\mathrm{AH}$ dos $\mathrm{AF}$, pelo abaixamento do $\mathrm{pH}$, provavelmente foi perdido durante as lavagens e diálise do material.

Como havia sido quantificado $\mathrm{Mn}$ nas amostras de $\mathrm{AH}$, extraídas dos solos dos locais I e II (Tabela 32), o qual não pôde ser detectado por RPE (Figura 14), imaginavase que o Mn presente nessas amostras estava associado de forma muito forte aos grupos funcionais da MO. Para comprovar essa hipótese, obtiveram-se espectros de RPE da amostra de AH do Local I em solução. A amostra de AH foi dissolvida em água, a pH natural $(3,0)$, para verificar ou não a presença de $\mathrm{Mn}$ solúvel $\left[\left(\mathrm{Mn}\left(\mathrm{H}_{2} \mathrm{O}\right)_{6}\right]^{2+}\right.$. Outra amostra de AH foi submetida aos mesmos procedimentos, mas abaixando-se o $\mathrm{pH}$ da solução para 2,4 .

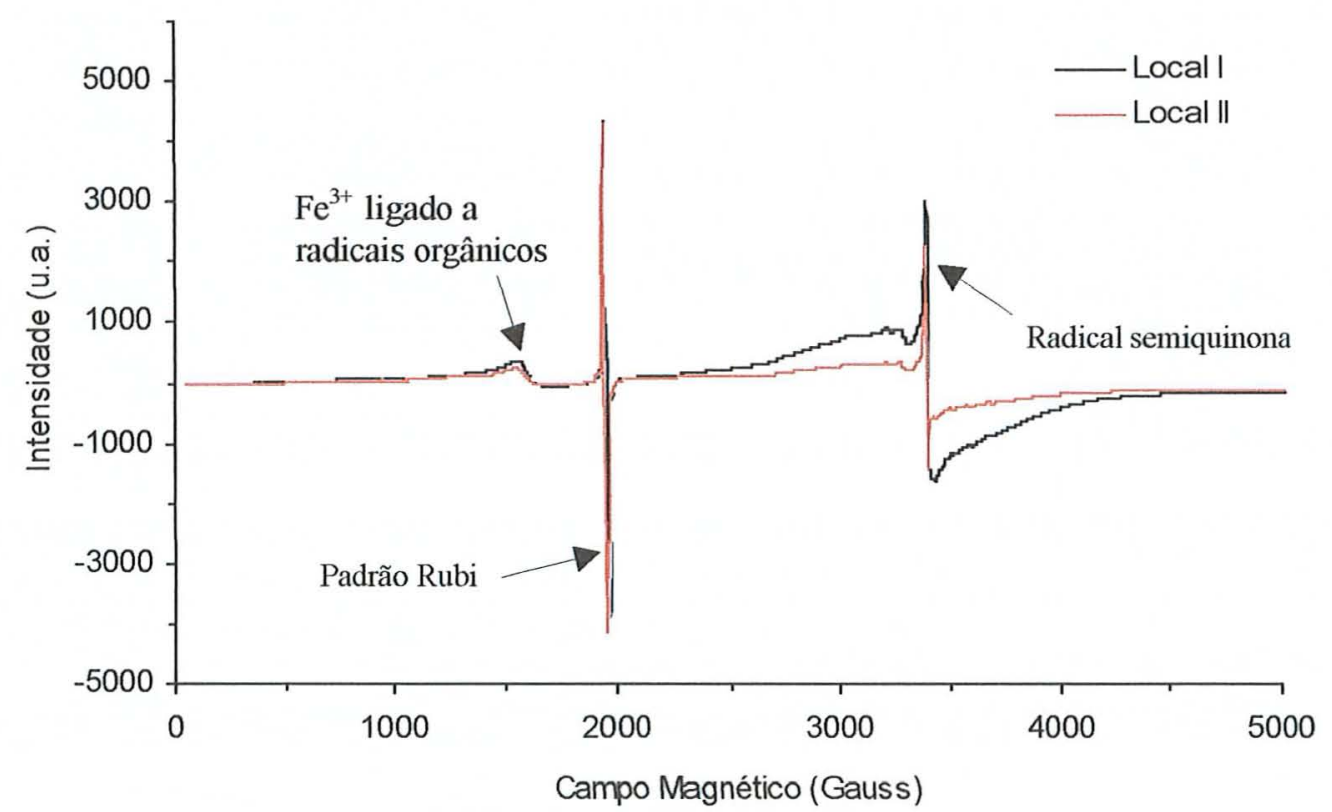

Figura 14 - Espectro de RPE das amostras sólidas de AH, extraído da camada de 0,00-0,10 m, dos locais I e II, após a centrifugação de 12500 rpm por 3 horas. 
$\mathrm{O}$ abaixamento do $\mathrm{pH}(2,4)$ liberou o $\mathrm{Mn}$ retido nos $\mathrm{AH}$, o qual foi visualizado por RPE, na forma de seis linhas, com interação hiperfina (A) de 90,8 Gauss (Figura 15). Desse modo, confirmaram-se as hipóteses de que o $\mathrm{Mn}$ presente nas amostras de $\mathrm{AH}$ estava associado aos grupos funcionais da MO na forma de complexos de esfera interna, e que não havia Mn solúvel (solvatado), uma vez que não foram obtidos sinais a pH 3,0 (sem adição de ácido). Provavelmente o grupo da MO envolvido na complexação do $\mathrm{Mn}$ seja o carboxílico, uma vez que o mesmo é o responsável pela complexação do metal em condições ácidas, devido seu baixo valor de pKa (Manunza et al., 1995).

A deteç̧ão do Mn por RPE em solução (pH 2,4) só foi possível porque sob condições extremamente ácidas, o Mn que estava fortemente retido aos grupos da MO, foi liberado. Sabe-se que em condições de pH elevado, a complexação dos metais pelos grupos dos AH é muito forte, uma vez que muitas cargas negativas são geradas a partir da dissociação dos grupos COOH (Evangelou \& Marsi, 2001). Esses resultados sugerem que grande parte do Mn aplicado em solos sob SSD, com altos teores de MO, pode ser adsorvido pelos grupos funcionais da $\mathrm{MO}$. 


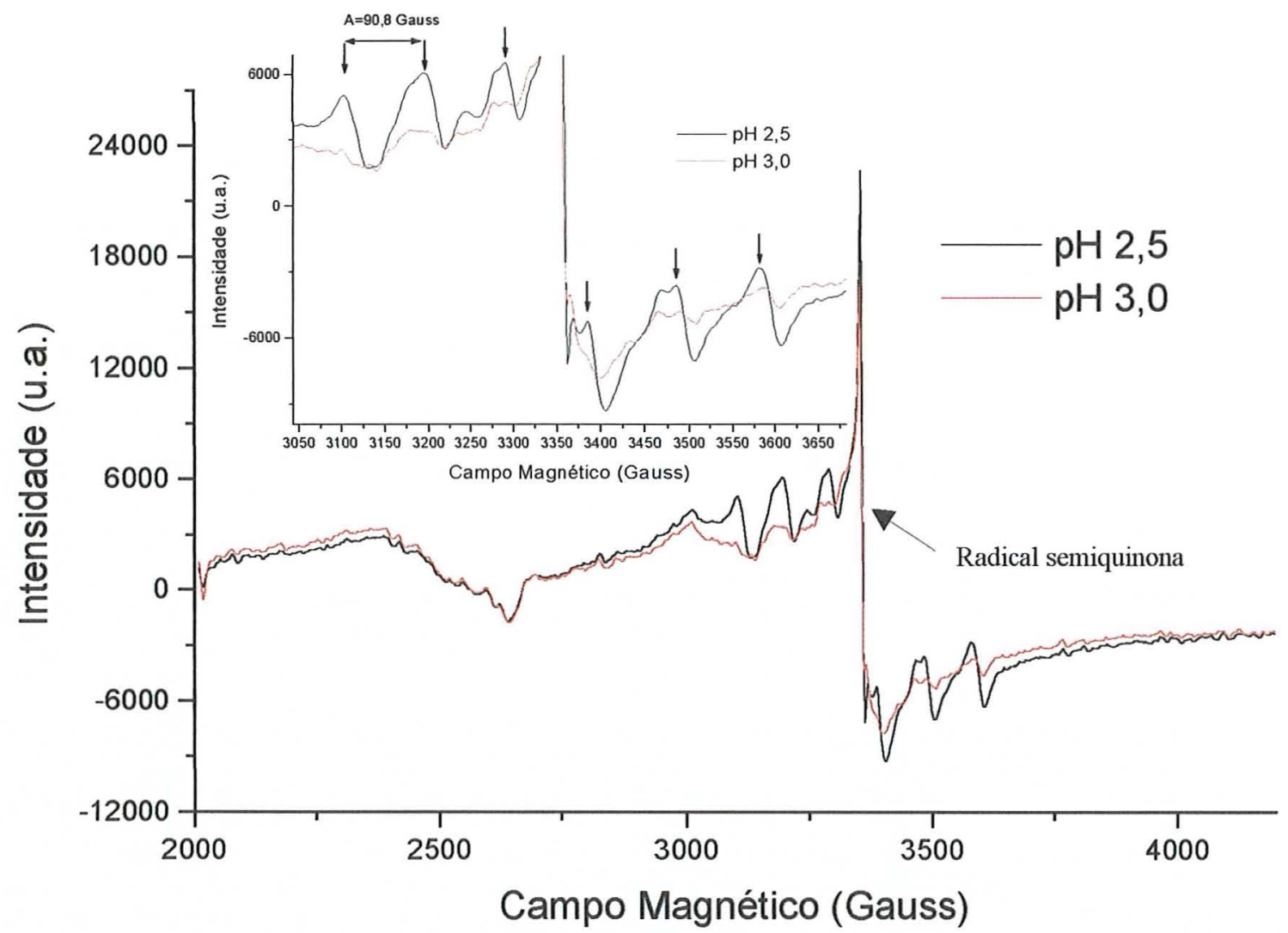

Figura 15 - Espectro de RPE do $\mathrm{AH}$ em solução (50 mg de $\mathrm{AH} / \mathrm{mL}$ de água), extraído da camada de $0,00-0,10 \mathrm{~m}$ do solo do Local I, a pH natural $(3,0)$ e pH 2,5 . 


\subsubsection{Concentração e acúmulo de Mn na parte aérea das plantas, em função da aplicação de doses de Mn no solo}

A concentração e a quantidade de Mn acumulada pelas plantas de soja variaram muito pouco com as doses (Figura 16), havendo uma pequena elevação somente nos locais I e III. Em solos sob cerrado, Silva (2000) também não obteve aumento da concentração de Mn nas folhas de soja com a aplicação de $4 \mathrm{~kg} \mathrm{ha}^{-1}$ de $\mathrm{Mn}$, nas formas de sulfato e oxi-sulfato, em experimentos de casa de vegetação e campo.
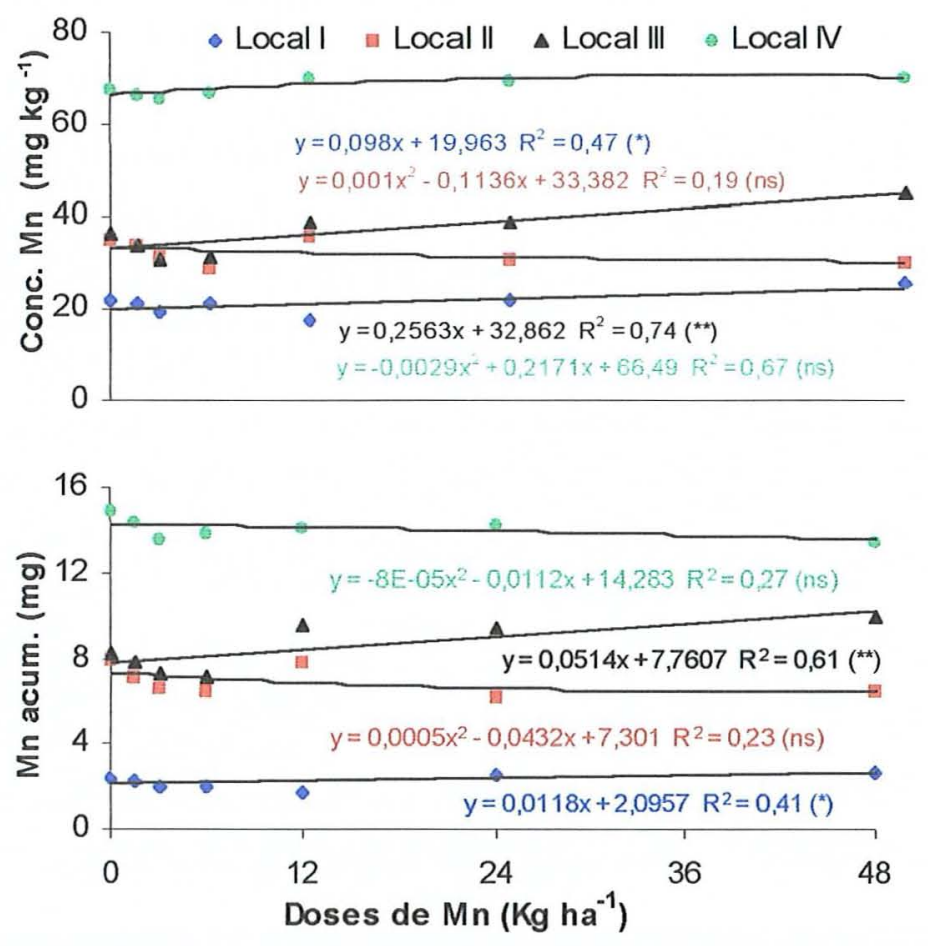

Figura 16 - Concentração e acúmulo de Mn na parte aérea das plantas de soja, nos quatro locais, em função de doses de Mn aplicadas (médias de quatro repetições). Local I: Faz. Santa Rosa; Locais II e III: Faz. Novo Horizonte; Local IV: Campo Experimental da Fundação ABC. Locais I e II: já apresentaram deficiências de Mn em soja; Locais III e IV: sem registros de deficiências. Os locais I, III, IV estão localizados no município de Tibagi, e o Local IV, em Castro, PR. ns=não significativo, ** e * significativo a 1 e $5 \%$.

Houve grande diferença entre o acúmulo de Mn do Local I com relação aos demais, devido principalmente a sua menor produção de matéria seca. Além disso, as plantas cultivadas nesse local apresentaram menor concentração de Mn na parte aérea, 
comparada aos outros locais. A menor produção de matéria seca do Local 1 em relação aos demais ocorreu devido ao atraso da semeadura e germinação da soja, causado por um veranico em Tibagi, PR (19/10 a 09/11/2001).

Apesar de a semeadura do Local IV ter sido realizada na mesma época do que a do Local I, suas melhores condições de fertilidade e de umidade do solo, favoreceram o desenvolvimento da planta, não atrasando o ciclo da cultura em relação aos locais II e III. Assim, na época da coleta das amostras, as plantas dos locais II, III e IV encontravam-se no início do florescimento (R2) e as plantas do Local I, ainda estavam no estádio imediatamente anterior ao estádio reprodutivo, R1.

Esperava-se que as elevadas doses de Mn aplicadas pudessem aumentar a concentração e a quantidade de Mn acumulada na parte aérea das plantas. Como esses parâmetros praticamente não variaram com as doses aplicadas, acredita-se que grande parte do nutriente foi complexado pela $\mathrm{MO}$, como discutido anteriormente. Parte do $\mathrm{Mn}$ também foi adsorvido pelos óxidos de $\mathrm{Fe} / \mathrm{Mn} / \mathrm{Al}$ do solo, como mostrado na Figura 11.

Provavelmente as deficiências de Mn em soja cultivada sob SSD, ocorridas em solos com teores considerados adequados, acontecem porque grande parte do $\mathrm{Mn}$ do solo, extraído pelos diversos extratores, não está disponível às plantas, mas associado à MO. Prova disso é que vem sendo observadas correlações diretas entre os teores de Mn do solo e a MO (Castro et al., 1992; Edwards et al., 1992; Motta et al., 2002) e correlações inversas entre o $\mathrm{Mn}$ da fração orgânica e o $\mathrm{Mn}$ absorvido pelas plantas (Sims, 1986) (Figura 8). No estudo 2, as correlações entre a concentração e quantidade acumulada na parte aérea com os teores de Mn nas formas trocáveis e orgânica foram baixas e não significativas $(\mathrm{p}>0,05)$, devido ao pequeno número de dados $(12$ parcelas $=$ 3 doses $\times 4$ blocos). No entanto, a constatação de que os teores de Mn do solo geralmente aumentaram com as doses aplicadas (Figura 10) e que grande parte do $\mathrm{Mn}$ aplicado foi retido pela MO (Figura 11) sugere que os teores extraídos por esses extratores pode não ser o disponível às plantas. 


\subsubsection{Estudo de correlação para manganês}

Os coeficientes de correlação linear (r) entre teores de $\mathrm{Mn}$ no solo, extraídos pelos diversos extratores, e a concentração e quantidade de Mn acumulada na parte aérea, nos quatro locais estudados geralmente foram baixos, havendo valores de $r$ significativos apenas nos locais I e III (Tabela 33). No Local I, com exceção do Mehlich I, os coeficientes de correlação entre a concentração de Mn na parte aérea e os teores no solo foram significativos. No caso do Local III, com exceção do valor de $r$ entre os teores extraídos com Mehlich I e a quantidade acumulada na parte aérea, os valores de $\mathrm{r}$ foram significativos.

Tabela 33. Coeficientes de correlação linear (r) entre teores de Mn no solo, extraídos por diversos extratores, e concentração de Mn e quantidade de Mn acumulada na parte aérea, nos quatro locais estudados.

\begin{tabular}{|c|c|c|c|c|}
\hline Atributos & DTPA & Mehlich I & Mehlich III & $\mathrm{HCl}$ \\
\hline & \multicolumn{4}{|c|}{ Local $\mathbf{I}^{1}$} \\
\hline Concentração na parte aérea & $0,42 *$ & $0,35 \mathrm{~ns}$ & $0,39 *$ & $0,41 *$ \\
\hline \multirow[t]{2}{*}{ Acumulado na parte aérea } & $0,36 \mathrm{~ns}$ & $0,26 \mathrm{~ns}$ & $0,32 \mathrm{~ns}$ & $0,33 \mathrm{~ns}$ \\
\hline & \multicolumn{4}{|c|}{ Local II } \\
\hline Concentração na parte aérea & $-0,19 \mathrm{~ns}$ & $-0,15 \mathrm{~ns}$ & $-0,19 \mathrm{~ns}$ & $-0,21 \mathrm{~ns}$ \\
\hline \multirow[t]{2}{*}{ Acumulado na parte aérea } & $-0,16 \mathrm{~ns}$ & $-0,07 \mathrm{~ns}$ & $-0,15 \mathrm{~ns}$ & $-0,18 \mathrm{~ns}$ \\
\hline & \multicolumn{4}{|c|}{ Local III } \\
\hline Concentração na parte aérea & $0,45^{*}$ & $0,45 *$ & $0,50 *$ & $0,45^{*}$ \\
\hline \multirow[t]{2}{*}{ Acumulado na parte aérea } & $0,44 *$ & $0,34 \mathrm{~ns}$ & $0,45 *$ & $0,37 *$ \\
\hline & \multicolumn{4}{|c|}{ Local IV } \\
\hline Concentração na parte aérea & $0,17 \mathrm{~ns}$ & $0,21 \mathrm{~ns}$ & $0,16 \mathrm{~ns}$ & $0,23 \mathrm{~ns}$ \\
\hline Acumulado na parte aérea & 0,09 ns & $0,10 \mathrm{~ns}$ & $0,01 \mathrm{~ns}$ & $0,01 \mathrm{~ns}$ \\
\hline
\end{tabular}

Os baixos coeficientes de correlação obtidos entre os teores de Mn no solo e a concentração e a quantidade acumulada na parte aérea eram esperados, uma vez que os atributos da planta praticamente não variaram com as doses aplicadas em cada local. Como haviam diferenças entre os locais na concentração e na quantidade acumulada de Mn e nos teores de Mn no solo, procederam-se estudos de correlação utilizando-se as variáveis de todos os locais em conjunto. Nesse caso, a amplitude entre os atributos da 
planta foi aumentada e maiores valores de $\mathrm{r}$ foram obtidos entre os teores de $\mathrm{Mn}$ no solo, extraídos com DTPA, e a concentração e quantidade acumulada pelas plantas (Figuras 17 e 18).

Resultados similares quanto à eficiência do DTPA foram observados por outros autores em solos que receberam aplicação de lodo de esgoto, em condições norteamericanas (Brown et al., 1997; Mulchi et al., 1987 e 1991), e em alguns estudos desenvolvidos no Estado de São Paulo, em solos sem aplicação de lodo (Camargo et al., 1982; Rosolem et al., 1992).

Em experimento desenvolvido em condições de casa de vegetação, com aplicação de doses de Mn, Abreu et al. (1996) obtiveram maior coeficiente de determinação $\left(R^{2}=0,76\right)$ entre o Mn absorvido pela soja e o Mn extraído do solo por DTPA, comparado ao Mehlich $1\left(\mathrm{R}^{2}=0,67\right)$. Em outro trabalho, realizado por Borkert et al. (1984), a solução de $\mathrm{HCl}$ foi a menos eficiente na avaliação da disponibilidade de $\mathrm{Mn}$ entre os diversos extratores avaliados $\left(\mathrm{SrCl}_{2} 1 \mathrm{~mol} \mathrm{~L}^{-1}\right.$; NH4OAc $1 \mathrm{~mol} \mathrm{~L}^{-1} \mathrm{pH} 7,0 ; \mathrm{Mg}\left(\mathrm{NO}_{3}\right)_{2} 0,5 \mathrm{~mol} \mathrm{~L}^{-1}$ e $\left.\mathrm{HCl} 0,1 \mathrm{~mol} \mathrm{~L}^{-1}\right)$. 


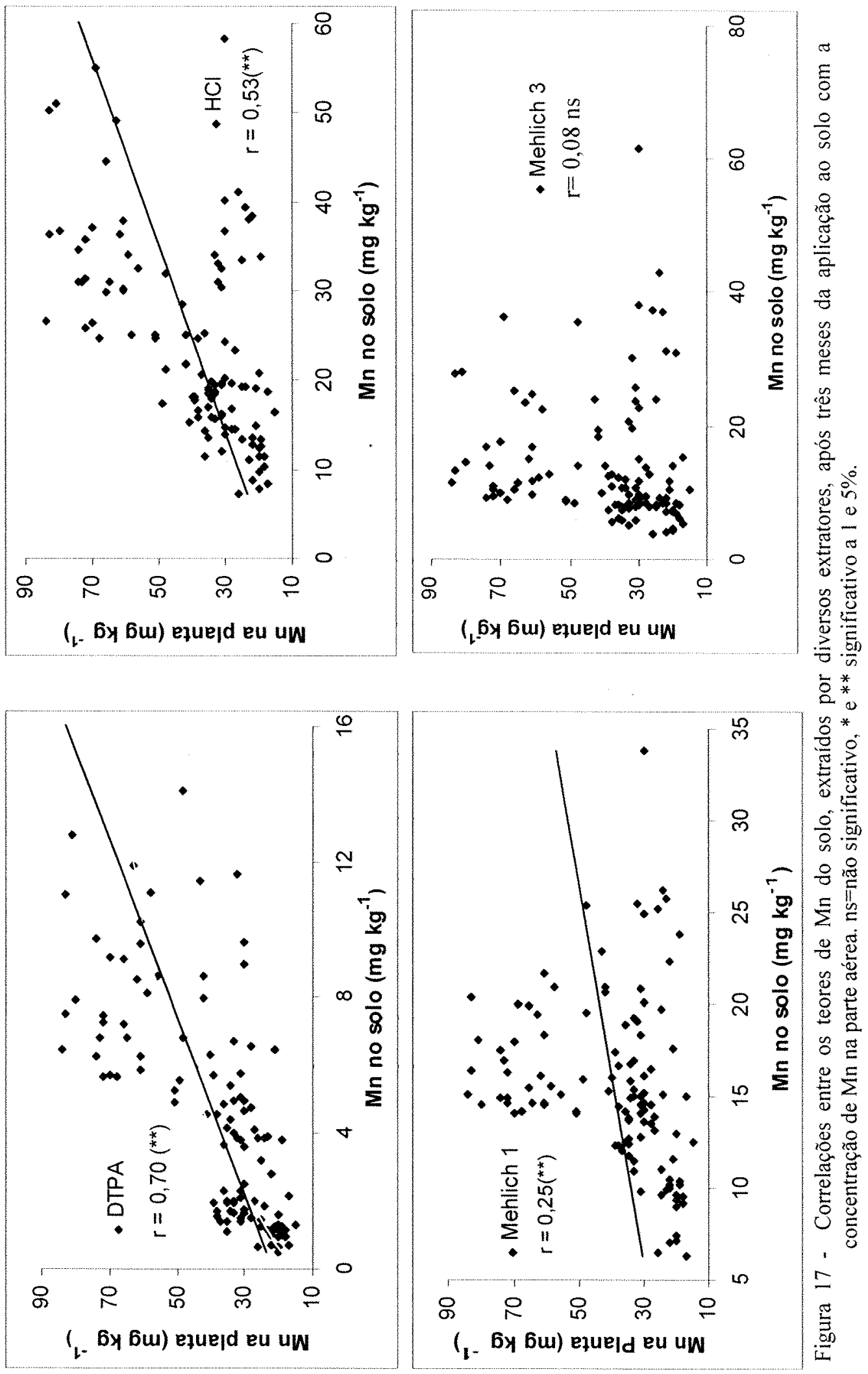



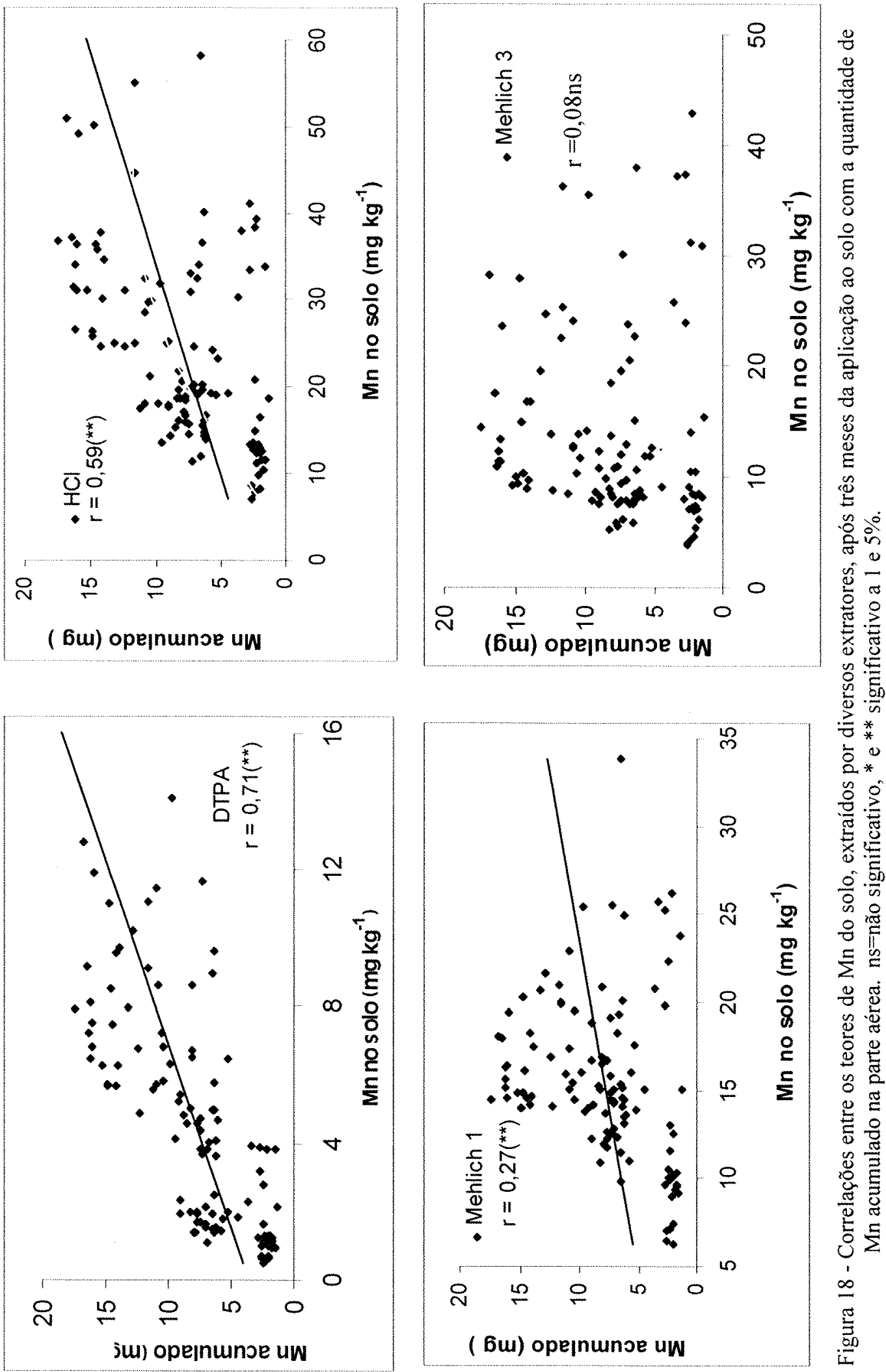


\subsubsection{Produtividade de soja, em função da aplicação de doses de Mn no solo}

As produtividades de soja dos quatro locais selecionados para o cultivo (I, II, III, IV) são apresentadas na Figura 19. Tanto nos locais em que haviam sido constatadas deficiências de Mn (I e II), como nos locais sem constatações de deficiências de Mn em soja (III e IV), as produtividades de soja não variaram com as doses. A complexação de grande parte do Mn aplicado pela MO e o aumento do Mn na forma de óxidos no solo (Figura 11), podem explicar a ausência de resposta na produtividade de soja observada no presente trabalho (Figura 19) e por outros autores (Pauletti, 1998; Silva, 2000) em solos sob SSD, deficientes no nutriente.

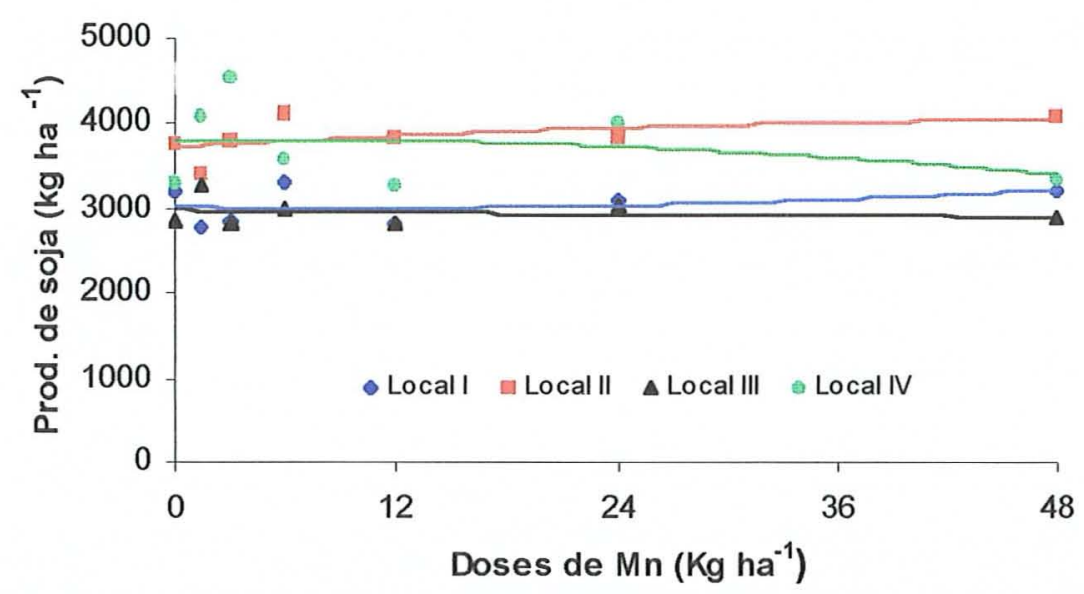

Figura 19 - Produtividade de soja em quatro locais, em função de doses de Mn (médias de quatro repetições). Local I: Fazenda Santa Rosa; Locais II e III: Fazenda Novo Horizonte; Local IV: Campo Experimental da Fundação ABC. Locais I e II: com constatações de deficiências de Mn em soja; Locais III e IV: sem registros de deficiências. Os locais I, III, IV estão localizados no município de Tibagi, e o Local IV, em Castro, PR.

Como as produtividades de soja não variaram com doses de até $48 \mathrm{~kg} \mathrm{ha}^{-1}$ de $\mathrm{Mn}$, mesmo nos locais deficientes em Mn, pode ser que as doses aplicadas não tenham sido suficientes, devido à complexação de grande parte do nutriente pela MO. Assim, novos estudos devem ser conduzidos em condições de campo em solos sob SSD com altos teores de MO, utilizando-se doses mais elevadas. Provavelmente as doses atualmente recomendadas (14-17 kg ha ${ }^{-1}$ a lanço, e 3-4 $\mathrm{kg} \mathrm{ha}^{-1}$, no sulco de semeadura) (Borkert et al., 2001) sejam baixas para esses solos. 
A aplicação de $\mathrm{Mn}$, na forma de quelatos sintéticos, em solos sob SSD com altos teores de $\mathrm{MO}$, poderia evitar a formação de complexos estáveis de Mn com a MO, deixando o Mn disponível às plantas (Lopes, 1999) e, desse modo, aumentar a produtividade das culturas. Assim, recomendam-se estudos nesse sentido, buscando-se avaliar conjuntamente a eficiência agronômica e o custo/benefício, uma vez que os quelatos geralmente apresentam custos elevados.

Apesar de alguns trabalhos anteriores na Região Centro Sul do Paraná mostrarem que aplicação foliar não teve efeito na produção de soja (Pauletti, 1998), recomenda-se a realização de outros estudos com a utilização de diferentes doses e fontes, uma vez que na aplicação via solo ocorre grandes perdas do nutriente, devido sua adsorção pela MO.

Como o SSD aumenta os teores de MO da camada superficial, a qual possui alta capacidade de adsorção de metais, principalmente em condições de $\mathrm{pH}$ elevado, altas doses de calcário devem ser evitadas nesses solos. Nesse sentido, a calagem não deve ser realizada em locais com $\mathrm{V} \%$ das camadas de $0,00-0,05$ e $0,00-0,20$ m maior que $65 \%$ (Caires et al., 2000) e 45\% (Sá, 1995a), respectivamente e/ou nos locais com pH $\mathrm{CaCl}_{2}$ da camada de 0,00-0,05 m acima de 5,6 (Caires et al., 2000). 


\subsubsection{Conclusões do Estudo 2}

Com base nos resultados obtidos pela extração seqüencial e pela ressonância paramagnética eletrônica conclui-se que grande parte do Mn aplicado nos solos sob semeadura direta é retido na fração orgânica em formas estáveis, não disponíveis às plantas.

Os teores de Mn trocáveis extraídos pelos diversos extratores (DTPA TEA pH 7,3, $\mathrm{HCl} 0,1 \mathrm{~mol} \mathrm{~L}^{-1}$, Mehlich I e III) geralmente não representaram a quantidade disponível às plantas. De todos extratores, o DTPA foi o extrator mais adequado na avaliação da disponibilidade de $\mathrm{Mn}$ à soja. 


\section{CONCLUSÕES}

A camada de 0,00-0,05 $\mathrm{cm}$ do solo sob sistema de semeadura direta (SSD) apresentou maior quantidade de $\mathrm{Mn}$ trocável e orgânico do que nos solos cultivados convencionalmente. No entanto, os estudos de extração seqüencial e ressonância paramagnética eletrônica (RPE) mostraram evidências de que nos solos sob SSD, o nutriente encontra-se ligado fortemente aos grupos da $\mathrm{MO}$ e, portanto, indisponível às plantas.

Os estudos de fracionamento químico do Mn e de RPE mostraram fortes evidências de que a ausência de resposta ao Mn aplicado nos solos sob SSD é devido à complexação do nutriente pela MO do solo, possivelmente, na forma de complexos de esfera interna.

A contradição verificada em condições de campo entre os elevados teores de $\mathrm{Mn}$ revelados pela análise de terra e as deficiências deste elemento apresentadas pela soja ocorre porque a maioria dos extratores químicos não estão discriminando o $\mathrm{Mn}$ complexado pela MO do Mn disponível. O DTPA foi extrator mais adequado na avaliação da disponibilidade de Mn à soja. 


\section{REFERÊNCIAS BIBLIOGRÁFICAS}

ABREU, C.A.; ABREU, M.F.; ANDRADE J.C.; RAIJ, B. van. Restrictions in the use of correlation coefficients in comparing methods for the determination of the micronutrients in soils. Communications in Soil Science and Plant Analysis, v.29, n.1114, p.1961-1972, 1998.

ABREU, C.A.; ABREU, M.F.; BERTON, R.S. Análise química de solo para metais pesados. Tópicos em Ciência do Solo, v.2, p.645-692, 2002.

ABREU, C.A; FERREIRA, M.E.; BORKERT, C.M. Disponibilidade e avaliação de elementos catiônicos: zinco e cobre. In: FERREIRA, M.E.; CRUZ, M.C.P.; RAIJ, B. van; ABREU, C.A. (Ed.). Micronutrientes elementos tóxicos na agricultura. Jaboticabal: CNPq/FAPESP/POTAFOS, 2001. cap.6, p. 125-151.

ABREU, C.A; LOPES, A.S.; RAIJ, B.van. Análise de micronutrientes em solos brasileiros: situação atual e perspectiva (compact disc). In: CONGRESSO BRASILEIRO DE CIÊNCIA DO SOLO, 26., Rio de Janeiro, 1997. Informação, globalização, uso do solo; Palestra. Rio de Janeiro: SBCS, 1997.

ABREU, C.A; NOVAIS, R.F.; RAIJ, B. van; RIBEIRO, A.C. Comparação de métodos químicos para avaliar a disponibilidade do manganês em solos. Revista Brasileira de Ciência do Solo, v.18, p.81-90, 1994a.

ABREU, C.A; NOVAIS, R.F.; RAIJ, B. van; RIBEIRO, A.C. Influência da reação do solo na extração de manganês por diferentes extratores químicos. Revista Brasileira de Ciência do Solo, v.18, p.91-99, 1994b. 
ABREU, C.A.; RAIJ, B. van. Efeito da reação do solo no zinco extraído pelas soluções de DTPA e Mehlich-1. Bragantia, v.55, p.357-363, 1996.

ABREU, C.A; RAIJ, B. van; ABREU, M.F.; SANTOS, W.R.; ANDRADE, J.C. Efficiency of multinutrient extractants for the determination of available copper in soils. Communications in Soil Science and Plant Analysis, v.27, n.3-4, p.763-771, 1996.

ABREU, C.A.; RAIJ, B. van.; TANAKA, R.T. Fontes de manganês para a soja e seus efeito na análise do solo. Revista Brasileira de Ciência do Solo, v.20, p.91-97, 1996.

AHNSTROM, Z.S., PARKER, D.R. Development and assessment of a sequential extraction procedure for the fractionation of soil cadmium. Soil Science Society American Journal, v.63, p.1650-1658, 1999.

ALEXANDROVA, L.N. The use of sodium pyrophosphate for isolating free humic substances and their organic mineral compounds form soil. Soviet Soil Science, v.2, p.190-197, 1960.

AL-SEWAILEM, M.S.; KHALED, E.M.; MASHHADY, A.S. Retention of copper by desert sands coated with ferric hydroxides. Geoderma, v.89, p.249-258, 1999.

ALVA, A.K. Micronutrients status of Florida soils under citrus production. Communications in Soil Science and Plant Analysis, v.23, n.1720, p.2493-2510, 1992.

AMARAL SOBRINHO, N.M.B.; COSTA, L.M.; DIAS, L.E.; BARROS, N.F. Aplicação de resíduo siderúrgico em Latossolo: Efeitos na correção do solo e na disponibilidade de nutrientes e metais pesados, Revista Brasileira de Ciência do Solo, v.17, n.2, p.299-304, 1993.

AMARAL SOBRINHO, N.M.B.; GOMES, M.F.; VELLOSO, A.C.X.; OLIVEIRA, C. Fracionamento de zinco e chumbo em solos tratados com fertilizantes e corretivos. Revista Brasileira de Ciência do Solo, v.21, n.1, p.17-21, 1997. 
ANJOS, A.R.M. dos; MATTIAZZO, M.E. Extratores para Cd, Cu, Cr, Mn, Ni, Pb e Zn e em Latossolos tratados com biossólido e cultivados com milho. Scientia Agrícola, v. 58, n.2, p. $337-344,2001$.

ARRIECHI, E.; RAMIREZ, R. Soil test for available zinc in acid soils of Venezuela. Communications in Soil Science and Plant Analysis, v.28, p.1471-1480, 1997.

BASTA, N.T.; TABATABAI, M.A. Effects of cropping systems on adsorption of metals by soils: 1. Single-metal adsorption. Soil Science, v.153, n.2, p.108-114, 1992.

BATAGLIA, O.C.; RAIJ, B. van. Eficiência de extratores de micronutrientes na análise de solo. Revista Brasileira de Ciência do Solo, v.13, n.2, p.205-212, 1989.

BATAGLIA, O.C.; RAIJ, B. van. Soluções extratoras na avaliação da fitodisponibilidade do zinco em solos. Revista Brasileira de Ciência do Solo, v.18, p.457-461, 1994.

BAYER, C.; DICK, D.P.; RIBEIRO, G.M.; SCHEUERMANN, K.K. Carbon stocks in organic matter fractions as affected by land use and soil management, with emphasis on no-tillage effect. Ciência Rural, v.32, n.3, p.401-406, 2002a.

BAYER, C.; MARTIN-NETO, L.; MIELNICZUKC, J.; CERETTA, C.A. Effect of notill cropping systems on soil organic matter in a sandy clay loam Acrisol from Southern Brazil by electron spin resonance and nuclear magnetic resonance. Soil and Tillage Research, v.53, n.2, p.95-104, 2000.

BAYER, C.; MARTIN-NETO, L.; MIELNICZUKC, J.; CERETTA, C.A. Fracionamento da matéria orgânica e sua avaliação qualitativa por EPR num solo submetido por 10 anos a diferentes sistemas de cultura em plantio direto. In: SIMPÓSIO NACIONAL DE INSTRUMENTAÇÃO AGROPECUÁRIA, I., São Carlos, 1996. Resumos. São Carlos: EMBRAPA-CNPDIA, 1996. p.115-121.

BAYER, C.; MARTIN-NETO, L.; MIELNICZUKC, J.; ERNANI, P.R.. Stocks and humification degree of organic matter fractions as affected by no-tillage on a subtropical soil. Plant and Soil, v.238, p.133-140, 2002 b. 
BAYER, C.; MARTIN-NETO, L.; MIELNICZUKC, J.; ERNANI, P.R.. Tillage and cropping system effects on soil humic acid characteristic as determined by electron spin resonance and fluorescence spectroscopies. Geoderma, v.105, p.81-92, 2002c.

BERTONCINI, E.I. Comportamento de $\mathrm{Cd}, \mathrm{Cr}, \mathrm{Cu}, \mathrm{Ni}$ e $\mathrm{Zn}$ em latosssolos sucessivamente tratados com biossólido: extração seqüencial, fitodisponibilidade e caracterização de substâncias húmicas. Piracicaba, 2002. 195p. Tese (Doutorado)Escola Superior de Agricultura "Luiz de Queiroz", Universidade de São Paulo.

BIBAK, A. Cobalt, copper, and manganese adsorption by aluminium and iron oxides and humic acid. Communications in Soil Science and Plant Analysis, v. 25, n. 19/20, p.3229-3239, 1994.

BLEVINS, R.L.; GROVE, J.H.; KITUR, B.K. Nutrition uptake of corn grown using moldboard plow or no-tillage soil management. Communications in Soil Science and Plant Analysis, v. 17, n.4, p.401-417, 1986.

BORKERT, C.M.; LANTMANN, A.F; PALHANO, J.B.; SFREDO, G.J. Determinação química do manganês absorvível pela soja. In: SEMINÁRIO NACIONAL DE PESQUISA DA SOJA, 3., Campinas, 1984. Anais. Londrina: EMBRAPA/CNPSo, 1984. p. 879-887.

BORKERT, C.M.; PAVAN, M.A.; BATAGLIA, O.C. Disponibilidade e avaliação de elementos catiônicos: ferro e manganês. In: FERREIRA, M.E.; CRUZ, M.C.P.; RAIJ, B. van; ABREU, C.A. (Ed.) Micronutrientes elementos tóxicos na agricultura. Jaboticabal: CNPq/FAPESP/POTAFOS, 2001. cap.7, p. 151-186.

BORKERT, C.M.; YORINORI, J.T; FERREIRA, B.S.C. et al. Seja o doutor da sua Soja.Piracicaba: POTAFOS, 1994, 16p. (Informações Agronômicas, 66).

BOWMAN, R.A.; HALVORSON, A.D. Soil Chemical after nine years of differential N fertilization in a no-till dryland wheat-corn-fallow rotation. Soil Science, v.163, n.2, p.241-247, 1998. 
BROWN, S.; ANGLE, J.S.; CHANEY, R.L. Correction of limed biosolid induced manganese deficiency on a long-term field experiment. Journal of Environmental Quality, v.26, n.5, p.1375-1384, 1997.

BRUCE, R.R.; LANGDALE, G.W.; WEST, L.T; MILLER, W.P. Surface soil degradation and soil productivity restoration and maintenance. Soil Science Society American Journal, v.59, p.654-660, 1995.

BUZETTI, S. Estudo da eficiência de extratores químicos de zinco, no solo, para o milho. Revista Brasileira de Ciência do Solo, v.16, p.367-372, 1992.

CAIRES, E.F.; BANZATTO, D.A.; FONSECA, A.F. Calagem na superfície em sistema de plantio direto. Revista Brasileira de Ciência do Solo, v.24, p.161-170, 2000.

CAIRES, E.F.; FONSECA, A.F.; MENDES, J.; CHUEIRI, W.A.; MADRUGA, E. F. Produção de milho, trigo e soja em função das alterações das características químicas do solo pela aplicação de calcário e gesso na superfície, em sistema de plantio direto. Revista Brasileira de Ciência do Solo, v.23, n.2, p.315-327, 1999.

CAMARGO, O.A.; VALADARES, J.M.A.S.; DECHEN, A.R. Efeitos do pH e da incubação na extração do manganês, zinco, cobre e ferro do solo. Revista Brasileira de Ciência do Solo, v.6, p.83-88, 1982.

CAMERON, R.S.; THORNTON, B.K.; SWIFT, R.S.; POSNER, A.M. Molecular weigth and shape of humic acid from sedimentation and diffusion measurements on fraction extracts. Journal of Soil Science, v.23, p.394-408, 1972.

CANELLAS, L.P.; SANTOS, G.A.; AMARAL SOBRINHO, N.M.B. Reações da matéria orgânica. In: SANTOS, G.A.; CAMARGO, F.A.O. (Ed.). Fundamentos da matéria orgânica do solo: ecossistemas tropicais e subtropicais. Porto Alegre: Genesis, 1999. cap.5, p.69-90.

CASTRO, O.M. Comportamento físico e químico de um Latossolo Roxo em função do seu preparo na cultura do milho (Zea Mays L.). Piracicaba, 1995. 174p. Tese (Doutorado) - Escola Superior de Agricultura "Luiz de Queiroz", Universidade de São Paulo. 
CASTRO, O.M. de; LOMBARDI NETO, F.; QUAGGIO, J.A.; MARIA, I.C.; VIEIRA, S.R; DECHEN, S.C.F. Perdas por erosão de nutrientes vegetais na sucessão soja/trigo em diferentes sistemas de manejo. Revista Brasileira de Ciência do Solo, v.10, n.3, p.293-297, 1986.

CASTRO, O.M.; CAMARGO, O.A.; CANTARELLA, H.; VIEIRA, S.R; DECHEN, S.C.F. Teores de zinco, cobre, manganês e ferro em dois Latossolos sob plantio direto e convencional. Bragantia, v.51, n.1, p.77-84, 1992.

CENTURION, J.F. Efeito de métodos de preparo nas propriedades químicas e físicas de um solo argiloso sob cerrado e na cultura do milho implantada. Piracicaba, 1988. 125p. Tese (Doutorado)-Escola Superior de Agricultura "Luiz de Queiroz", Universidade de São Paulo.

CERETTA, C.A; BAYER, C.; DICK, D.P.; MARTIN-NETO, L.; COLNAGO, L.A. Métodos espectroscópicos. In: SANTOS, G.A.; CAMARGO, F.A.O. (Ed.). Fundamentos da matéria orgânica do solo: ecossistemas tropicais e subtropicais. Porto Alegre: Genesis, 1999. cap.14, p.293-336.

CHANG, A.C.; PAGE, A.L.; WARNEKE, J.E.; GRGUREVIC, E. Sequential extraction on soil heavy metals following a sludge application. Journal of Environmental Quality, v.13, p.33-38, 1984.

CHAO, T.T. Use of partial dissolutin techniques in geochemical exploration. Journal of Geochemical Exploration, v.20, p.101-135, 1984.

CONG TU, C.Z.; CHEN, H. Distribution of copper and zinc fractions in red soil as influenced by fertilizer application. Communications in Soil Science and Plant Analysis, v.32, n.5/6, p.661-673, 2001.

COUTO, C.; NOVAIS, R.F.; TEIXEIRA, J.L. BARROS, N.F.; NEVES, J.C.L. Níveis críticos de zinco no solo e na planta para o crescimento de milho em amostras de solos com diferentes valores do fator capacidade. Revista Brasileira de Ciência do Solo, v.16, p.79-87, 1992. 
CROZIER, C.R.; NADERMAN, G.C.; TUCKER, M.R; SUGG, R.E. Nutrient and pH stratification with convencional and no-till management. Communication in Soil Science and Plant Analysis, v. 30, n.1/2, p.65-74, 1999.

DAVIS, J.G.; GAINES, T.P; PARKER, M.B. Comparison of soil zinc extractants for detection of applied zinc and prediction of leaf zinc concentration. Communications in Soil Science and Plant Analysis, v.26, p.2969-2981, 1995.

DEDECEK, R.A.; RESK, D.V.S.; FREITAS JÚNIOR, E. Perdas de solo, água e nutrientes por erosão em Latossolo Vermelho Escuro dos cerrados em diferentes cultivos sob chuva natural. Revista Brasileira de Ciência do Solo, v.10, n.3, p.265$272,1986$.

DICK, W.A.; McCOX, E.L.; EDWARDS, W.M.; LAL, R. Continuos application of notillage to Ohio soil. Agronomy Journal, v.83, n.1, p.63-73, 1991.

EDWARDS, J.H.; THURLOW, D.L. EASON, J.T. Influence of tillage and crop rotation on yields of corn, soybean, and wheat. Agronomy Journal, v.80, n.1, p.76-80, 1988.

EDWARDS, J.H.; WOOD, C.W.; THURLOW, D.L.; RUF, M.E. Tillage and crop rotation on fertility status of a Hapludult soil. Soil Science Society American Journal, v.56, n.5, p.1577-1582, 1992.

EMPRESA BRASILEIRA DE PESQUISA AGROPECUÁRIA. Cultura da soja nos cerrados (compact disc). Planaltina: EMBRAPAICPAC,1997/1998.

EMPRESA BRASILEIRA DE PESQUISA AGROPECUÁRIA. Serviço nacional de levantamento e conservação de solos. Manual de métodos de análise de solo. método 2-6: análise química: fósforo assimilável. Rio de Janeiro, 1979.271p.

EMPRESA BRASILEIRA DE PESQUISA AGROPECUÁRIA. Sistema brasileiro de classificação de solos. Rio de Janeiro: EMBRAPAICNPS, 1999. 412p.

ESTES, O.G. Elemental composition of maize grown under no-till and conventional tillage. Agronomy Journal, v.64, n.6, p.733-735, 1972. 
EVANGELOU, V.P.; MARSI, M. Composition and metal ion complexation behavour of humic factions derived from corn tissue. Plant and Soil, v.229, p.13-24, 2001.

FAUST, M.B.; CHRISTIANS, N.E. AB-DTPA and Mehlich III soil tests unable to predict copper available to creeping bentgrass. Communication in Soil Science and Plant Analysis, v.30, n.17/18, p.2475-2484, 1999.

FERNÁNDEZ, O.,I.; FACAL, M. GONZÁLEZ, M.; REY, F. Conductimetric analysis of the interaction of $\mathrm{Cu}$ (II) ions and a humic-like natural polyelectrolyte (Laurel, Laurus nobilis) misture. Analytica chimica Acta, v.401; p.251-255, 1999.

FOLLETT, R.F.; LINDSAY, W.L. Changes in DTPA-extractable Zinc, iron, manganese, and coper in soils followiing fertilization. Soil Science Society American Journal, v.35, p.600-602, 1971.

FOLLETT, R.F.; PETERSON, G.A. Surface soil nutrient distribution as affected by wheat- fallow tillage systems. Soil Science Society American Journal, v.52, n.1, p.141-147, 1988.

FONTES, R.L.F. Pesquisa com micronutrientes em solos e plantas. Difusão dos resultados no Brasil (compact disc). In: CONGRESSO BRASILEIRO DE CIÊNCIA DO SOLO, 26., Rio de Janeiro, 1997. Informação, globalização, uso do solo; Palestra. Rio de Janeiro: SBCS, 1997.

FRANCHINI, J.C.; PAVAN, M.A.; MIYAZAWA, M.; TORRES, E.; SARAVA, O.F. Pontencial de utilização de resíduos vegetais (compact disc). In: REUNIÂO BRASILEIRA DE MANEJO E CONSERVAÇÃO DO SOLO E DA ÁGUA, 14., Cuiabá, 2002. Os descaminhos do uso da água na agricultura brasileira; Palestra. Cuiabá: SBCS/UFMT, 2002

FRANZLUEBBERS, A.J.; HONS, F.M. Soil-profile distribution of primary and secondary plant-available nutrients under conventional and no-tillage. Soil and Tillage Research, v.39, p.229-239, 1996. 
GALRÃO, E.Z. Métodos de aplicação de cobre e avaliação da disponibilidade para a soja num Latossolo Vermelho-Amarelo franco-argilo-arenoso fase cerrado. Revista Brasileira de Ciência do Solo, v.23, n.2, p.265-272, 1999.

GALRÃO, E.Z. Níveis críticos de Zn para o milho cultivado em Latossolo VermelhoAmarelho, fase cerrado. Revista Brasileira de Ciência do Solo, v.19, p.255-260, 1995.

GALRÃO, E.Z.; SOUSA, D.M.G. Resposta do trigo à aplicação de cobre em solo orgânico. Revista Brasileira de Ciência do Solo, p.149-153, 1985.

GIBSON, M.J. FARMER, J.G. Multi-step sequential chemical extraction of heavy metals from urbanus soils. Environment Pollution (Series B), v.11, p.117-135, 1986.

GIMENEZ, S.M.N.; CHAVES, J.C.D.; PAVAN, M.A.; CRUCES, I.I. Toxicidade de cobre em mudas de cafeeiro. Revista Brasileira de Ciência do Solo, v.16, p.361$366,1992$.

GRIFFITH, D.R.; KLADIVKO, E.J., MANNERING, J.V.; WEST, T.D.; PARSONS, S.D. Long term tillage and rotation effects on corn growth and high and low organic matter, poorly drained soil. Agronomy Journal, v.80, n.4, p.599-605, 1988.

GROVE, J.H.; BLEVINS, R.L. Correcting soil acidification in continuous corn (Zea Mays L.). Communication in Soil Science and Plant Analysis, v.19, n.7/12, p.1331-1342, 1988.

GUERRA, J.G.M.; SANTOS, G.A. Métodos químicos e físicos. In: SANTOS, G.A.; CAMARGO, F.A.O. (Ed.). Fundamentos da matéria orgânica do solo: ecossistemas tropicais e subtropicais. Porto Alegre: Genesis, 1999. p.267-292.

HARGROVE, W.L.; REID, J.T.; TOUCHTON, J.T.; GALLAHER, R.N. Influence of tillage practices on the fertility status of an acid soil double-cropped to wheat and soybeans. Agronomy Journal, v.74, n.4, p.674-687, 1982. 
HAVLIN, J.L.; KISSEL, D.E.; MADDUX, L.D.; CLAASSEN, M.M.; LONG, J. H. Crop rotation and tillage effects on soil organic carbon and nitrogen. Soil Science Society American Journal, v.54, n.2, p.448-452, 1990.

HUNGRIA, M.; ANDRADE, D. de S.; BALOTA, E.L.; COLOZZI-FILHO, A. Importância do sistema de semeadura direta na população microbiana do solo. Londrina: EMBRAPA-CNPS, 1997. 9p. (Comunicado Técnico, 7).

JUO, A.S.R.; DABIRI, A.; FRANZLUEBBERS, A.J. Acidification of kaolinitic alfisol under cropping with nitrogen fertilization in West Africa. Plant and Soil, v. 171, p.245-253, 1995.

KIEHL, J.C.; MOREIRA, S.G., PROCHNOW, L.I.; PAULETTI, V. Disponibilidade de $\mathrm{Cu}$, Fe e $\mathrm{Zn}$ em sistema de semeadura direta (compact disc). In: FERTBIO, 2000., Santa Maria, 2000. Biodinâmica do solo: Trabalhos. Santa Maria: SBCS/SBM, 2000.

KING, L.D. Retention of metals by several soils of the Southeastern United States. Journal Environment quality, v.17, n.2, p.239-246, 1988.

KING, L.D.; HAJJAR, L.M. The residual effect of sewage sludge on heavy metal content of tobacco and peanut. Journal of Environmental Quality, v.19, n.4, p.738748,1990 .

KITUR, B.K.; PHILLIPS, S.R.; OLSON, K.R.; EBELHAR, S.A. Tillage effects on selected chemical properties of Grantsburg silt loam. Communication in Soil Science and Plant Analysis, v.25, n.3/4, p.225-246, 1994.

LAKATOS, B.; TIBAI, T.; MEISEL, J. EPR espectra of humic acids and their metal complexes. Geoderma, v.19, p.319-338, 1977.

LAL, R. No-tillage effects on soil properties under different crops in Western Nigeria. Soil Science Society American Journal, v.40, n.5, p.762-768, 1976. 
LAL, R.; LOGAN, T.J.; FAUSEY, N.R. Long term tillage effects on Molic Ochraqualf in Northwest Ohio. III Soil nutrient profile. Soil and Tillage Research, v.15, n.4, p.371-382, 1990.

LANTMANN, A.F.; MEURER, E.J. Estudo da eficiência de extratores para avaliação do zinco disponível para o milho. Revista Brasileira de Ciência do Solo, v.6, p.131$135,1982$.

LAURIE, S.H.; MANTHEY, J.A. The chemistry and role of metal ion chelation in plant uptake processes. In: MANTHEY, J.A.; CROWLEY, D.E.; LUSTER, D.G. (Ed.). Biochemistry of metal micronutrients in the rizosphere. Boca Raton: Lewis, 1994. cap. 12, p.165-198.

LAVADO, S.R.; PORCELlI, C.A.; ALVAREZ, R. Nutrient and heavy metal concentration and distribuition in corn, soybean and wheat as affected by different tillage systems in the Angentine Pampas. Soil and Tillage Research, v.62, p.55-60, 2001.

LINDSAY, W.L.; NORVELL, W.A. Development of a DTPA soil test for zinc, iron, manganese, and copper. Soil Science Society American Journal, v. 42, n.3, p421$428,1978$.

LOBARTINI, J.C.; ORIOLI, G.A. Las substancias húmicas y la nutrición vegetal. Revista de la Facultad de Agronomia, La Plata, v.101, n.2, p.201-209, 1996.

LOPES, A.S. Micronutrientes: filosofias de aplicação e efíciência agronômica. São Paulo: ANDA, 1999. 70 p. (ANDA. Boletim Técnico, 8).

MA, L.Q.; RAO, G.N. Chemical fractionation of cadmium, copper, nickel, and zinc in contaminated soil. Journal Environment quality, v.26, p.259-264, 1997.

MA, L.Q.; UREN, N.C. Application of a new fractionation scheme for heavy metals in soils. Communication in Soil Science and Plant Analysis, v.26, n.19-20, p.33913303, 1995. 
MA, L.Q.; UREN, N.C. The fate and transformations of zinc added to soils. Australian Journal Soil Research, v.35, p.725-738, 1997.

MA, L.Q.; UREN, N.C. Transformations of heavy metals added to soil application of a new sequencial extraction procedure. Geoderma, v.84, p.157-168, 1998.

MALAVOLTA, E.; VITTI, G.C.; OLIVEIRA, S.A. Avaliação do Estado Nutricional das Plantas: princípios e aplicações. Piracicaba-SP: POTAFOS, 1997. 319p.

MANUNZA, B.; DEIANA, S.; MADDAU, V.; GESSA, C.; SEEBER, R. Stability constants of metal-humate complexes: titration data analyzed by bimodal gaussian distribution. Soil Science Society American Journal, v.59, p.1570-1574, 1995.

MARTINI, J.A.; KOCHHANN, R.A.; SIQUEIRA, O.J. BORKERT, C.M. Response of soybeans to liming as related to soil acidity, $\mathrm{Al}, \mathrm{Mn}$, toxicidies, and $\mathrm{P}$ in oxisols of Brazil. Soil Science Society American Journal, v.32, p.616-620, 1974.

MARTIN-NETO, L.; ANDRIULO, A.E.; TRACHETTA, D.G. Effects of cultivation on ESR spectra of organic matter from soil size fractions of molisol. Soil Science, v.157, n.6, p.365-372, 1994.

MARTIN-NETO, L.; BISCEGLI, C.I.; COLNAGO, L.A. Ressonância paramagnética nuclear: aplicações em solo. In: ESCUELA LATINO-AMERICANA DE FÍSICA DE SUELOS, 1., São Carlos, 1988. Anais. São Carlos: EMBRAPA/CNPDIA, 1988. 1v.

MARTIN-NETO, L.; BONAMANGA, T.J.; COLNAGO, L.A.; PANEPUCCI, H.C.; VIEIRA, E. MIYAZAWA, M. Efeitos de diferentes manejos do solo sobre substâncias húmicas: avaliação com ressonância magnética nuclear. In: CONGRESSO BRASILEIRO DE CIÊNCIA DO SOLO, 25., Viçosa-MG, 1995. Resumos. Viçosa:SBCS, 1995. p.1810-1812.

MARTIN-NETO, L.; NASCIMENTO, O.R.; TALAMONI, J.; POPPI, N.R. EPR of micronutrients-humic substances complexes extracted from a brazilian soil. Soil Science, v.151, n.5, p.369-377, 1991. 
MARTIN-NETO, L.; RAMÓN ROSELL, SPOSITO, G. Correlation of spectroscopic indications of humification with mean annual rainfall along a temperature grassland climosequence. Geoderma, v.81, p.305-311, 1998.

MARZADORI, C.; FRANCIOSO, O.; CIAVATTA, C.; GESSA, C. Activity and stability of jack bean urease in the presence of peat humic acids obtained using different extractants. Biology and Fertility of Soils, v.32, n.415-420, 2000.

McBRIDE, M.B. Electron Spin Resonance investigation of $\mathrm{Mn}^{2+}$ complexation in natural and synthetic organics. Soil Science Society American Journal, v.46, p.1137-1143, 1982.

McDANIEL, P.A.; BUOL, S.W. Manganese distributions in acid soils of the North Carolina Piedmont. Soil Science Society American Journal, v.55, p.152-158, 1991.

McLAREN, R.G.; CRAWFORD, D.V. Studies on soil copper. I. The fractionation of cooper in soils. Journal of Soil Science, v.24, p. 172-181, 1973.

MEHLICH, A. Mehlich-3 soil test extractant: a modification of Mehlich-2 extractant. Communications in Soil Science and Plant Analysis, v.15, p.1409-1416, 1984.

MILLER, W.P.; MARTENS, D.C.; ZELAZNY, L.W. Effect of sequence in extraction of trace metals from soil. Soil Science Society American Journal, v.50, p.598-601, 1986.

MIYAZAWA, M.; PAVAN, M.A.; MACHADO, P.L.O.A.; OLIVEIRA, E.D.; YAMASCHITA, M. Manganese dynamic in acid soils and uptake by maize seedlings. Communications in Soil Science and Plant Analysis, v. 27, p.2347-2359, 1996a.

MIYAZAWA, M.; PAVAN, M.A.; SANTOS, J.C.F. Effects of addition of crop residues on the leaching of $\mathrm{Ca}$ and $\mathrm{Mg}$ in Oxysols. In: INTERNATIONAL SYMPOSIUM ON PLANT-SOIL INTERACTIONS AT LOW pH 4., Belo Horizonte, 1996. Resumos. Belo Horizonte: SBCS/EMBRAPA-CPAC, 1996b. p.8. 
MOREIRA, S.G.; KIEHL, J.C.; PROCHNOW, L.I.; PAULETTI, V. Disponibilidade de manganês em sistema de semeadura direta (compact disc). In: FERTBIO, 2000., Santa Maria, 2000. Biodinâmica do solo: Trabalhos. Santa Maria: SBCS/SBM, 2000 .

MOREIRA, S.G. Calagem em sistema de semeadura direta e efeitos sobre a acidez do solo, disponibilidade de nutrientes e produção de soja. Piracicaba, 1999. 87p. Dissertação (Mestrado)- Escola Superior de Agricultura "Luiz de Queiroz", Universidade de. São Paulo.

MOREIRA, S.G.; KIEHL, J.C.; PROCHNOW, L.I.; PAULETTI, V. Calagem em sistema de semeadura direta e efeitos sobre a acidez do solo, disponibilidade de nutrientes e produtividade de milho e soja. Revista Brasileira de Ciência do Solo, v. 25, p. $71-81,2001$.

MOTTA, A.C.; PREVEDELLO, B.M.S. Micronutrientes: fatores que afetam a disponibilidade e respostas das culturas. In: SÁ, J.C.M. (Coord.) Curso sobre o Manejo do Solo no Sistema de Plantio Direto. Castro-PR: Fundação ABC, 1995. p.302-327.

MOTTA, A.C.; REEVES, D.W.; TOUCHTON; J.T. Tillage intensity effects on chemical indicators of soil quality in two coastal plain soils. Communications in Soil Science and Plant Analysis, v.33, n.5/6, p.913-932, 2002.

MULCHI, C.L.; ADAMU, C.A.; BELL, P.F.; CHANEY, R.L. Residual heavy metal concentrations in sludgeamended coastal plain soils. I. Comparison of extractants. Communications in Soil Science and Plant Analysis, v.22, n.910, p.919-941, 1991.

MULCHI, C.L.; ADAMU, C.A.; BELL, P.F.; CHANEY, R.L. Residual heavy metal concentrations in sludge amended coastal plain soils II. Predicting metal concentrations in tobacco from soil test information. Communications in Soil Science and Plant Analysis, v.23, n.910, p.1053-1069, 1992. 
MULCHI, C.L.; BELL, P.F.; ADAMU, C.; CHANEY,R. Long term availability of metals in sludge amended acid soils. Journal of Plant Nutrition, v.10, n.916, p.1149-1161, 1987.

MURAOKA, T.; NEPTUNE, A.M.L.; NASCIMENTO FILHO, V.F. Avaliação da disponibilidade de zinco e manganês do solo para o feijoeiro. II Manganês. Revista Brasileira de Ciência do Solo, v.7, p.177-182, 1983a.

MURAOKA, T.; NEPTUNE, A.M.L.; NASCIMENTO FILHO, V.F. Avaliação da disponibilidade de zinco e manganês do solo para o feijoeiro. I. Zinco. Revista Brasileira de Ciência do Solo, v.7, p.167-176, 1983b.

MUZILLI, O. Influência do sistema de plantio direto, comparado ao convencional, sobre a fertilidade da camada arável do solo. Revista Brasileira de Ciência do Solo, v.7, n.1, p. $95-102,1983$.

MUZILLI, O. A Fertilidade do solo em plantio direto. In: FANCELLI, L.A.; TORRADO, P.V.; MACHADO, J. Atualização em Plantio Direto. Campinas-SP: Fundação Cargill, 1985. cap.7, p.147-159.

NASCIMENTO, C.W.A.; FONTES, R.L.F.; NEVES, J.C.L. Dessorção, extração e fracionamento de Manganês em latossolos. Revista Brasileira de Ciência do Solo, v.26, n.3, p.589-597, 2002a.

NASCIMENTO, C.W.A.; FONTES, R.L.F.; NEVES, J.C.L.; MELÍCIO, A.C.F.D. Fracionamento, dessorção e extração química de zinco em latossolos. Revista Brasileira de Ciência do Solo, v.26, n.3, p.599-606, 2002 b.

NIFANT'EVA, T.I.; BURBA, P.; FEDEROVA, O.; SHKINEV, V.M.; SPIVAKOV, B.Ya. Ultrafiltration and determination of $\mathrm{Zn}-$ and $-\mathrm{Cu}$ humic substances complexes stability constants. Talanta, v.53, p.1127-1131, 2001.

NORVELL, W.A. Comparison of chelating agents as extractants for metals in diverse soil materials. Soil Science Society American Journal, v.48, n.3, p.1285-1292, 1984. 
NORVELL, W.A. Reactions of metal chelates in soils and nutrient solutions. In: MORTVEDT, J. J.; COX, F.R.; SHUMAN, L.M.; WELCH, R.M (Ed.). Micronutrients in agriculture. Madison: Soil Science Society of America, 1991. p.187-228.

NOVOTNY, E.H. Estudos espectroscópicos e cromatográficos de substâncias húmicas do solo sob diferentes sistemas de preparo. São Carlos, 2002. 215p. Tese (Doutorado) - Instituto de Química de São Carlos, Universidade de São Paulo.

O'CONNOR, G.A. Use e misuse of DTPA soil test. Journal Environment quality, v.17, n.4, p.715-718, 1998.

OLIVEIRA, E.L. de; PAVAN, M.A. Control of acidity in no-tillage system soybean production. Soil and Tillage Research, v.38, n.1/2, p.47-57, 1996.

OLIVEIRA, F.C.; MATTIAZZO, M.E. Metais pesados em Latossolo tratado com lodo de esgoto e em plantas de cana-de-açúcar. Scientia Agrícola, v.58, n.3, p.581-593, 2001 .

PAIVA, P.L.R.; FURTINE NETO, A.E.; VALE, F.R.; FAQUIN, V. Efeito do manejo do solo sobre os teores de matéria orgânica, nitrogênio mineral, fósforo e base trocáveis. Ciência Agrotecnologia, v.21, p.35-43, 1997.

PAULA, M.B. de; CARVALHO, J.G. de; NOGUEIRA, F.D.; MESQUITA, H. A. Curva de resposta e avaliação de extratores para zinco disponível em solos hidromórficos e aluviais sob arroz inundado. Revista Brasileira de Ciência do Solo, v.15, p.49-55, 1991.

PAULETTI, V. Disponibilidade e resposta de culturas a micronutrientes em solos arenosos. In: FRIES, M.R. (Coord.). Plantio direto em solos arenosos: alternativas de manejo para a sustentabilidade agropecuária. Santa Maria:CCR-UFSM, 1998, p. $82-103$.

PAVANASASIVAM, V. Manganese studies in some soils with a high organic matter content. Plant and Soil, v.38, p.245-255, 1973. 
PHILLIPS, E.R.; BLEVINS, R.L.; THOMAS, G.W.; FRYE, W.W.; PHILLIPS, S.H. No-tillage agriculture. Science, v.208, n.4448, p.1108-1113, 1980.

PICCOLO, A. The supramolecular structure of humic substances. Soil Science, v.166, n.11, p.810-832, 2001.

PORTA-CASANELLAS, J.; REGUERÍN, L.A.R.; DELABURU, C.R Edafología para la agricultura y el medio ambiente. Madrid: Ediciones Mundi-Prensa, 1999. 849p.

PRESTON, C.M. Aplication of NMR to soil organic matter analysis: history and prospects. Soil Science, v.161, p.144-166, 1996.

RAIJ, B.van. Bioavailable tests: alternatives to standard soil extractions. Communications in Soil Science and Plant Analysis, v.29, n.1114, p.1553-1570, 1998.

RAIJ, B. van; CANTARELlA, H.; QUAGGIO, J.A.; FURLANI, A.M.C. Recomendações de calagem e adubação para o Estado de São Paulo. Campinas: IAC \& Fundação IAC, 1997, 285p.

RAIJ, B. van; QUAGGIO, J.A; CANTARELLA, H.; FERREIRA, M.E.; LOPES, A.S.; BATAGLIA, O.C. Análise Química do Solo para fins de Fertilidade. Campina: Fundação Cargill, 1987. 170p.

RASHID, A.; RAFIQUE, E.; BUGHIO, N.; YASIN, M. Micronutrient deficiencies in rainfed calcareous soils of Pakistan. IV. Zinc nutrition of sorghum. Communications in Soil Science and Plant Analysis, v.28, n.68, p.455-467, 1997.

RHOTON, F.E. Influence of time on soil response to no-till practices. Soil Science Society American Journal, v.64, p.700-709, 2000.

RIBEIRO, A.C.; TUCUNANGO SARABIA, W.A. Avaliação de extratores para zinco e boro disponíveis em latossolos do Triângulo Mineiro. Revista Brasileira de Ciência do Solo, v.8, p.85-89, 1984. 
ROSOLEM, C.A.; BESSA, M.A.; AMARAL, P.G.; PEREIRA, H.F.M. Manganês no solo, sua avaliação e toxidez de manganês em soja. Pesquisa Agropecuária Brasileira, v.27, n.2, p.277-285, 1992.

SÁ, J.C.M. Manejo da fertilidade do solo no plantio direto. Castro: Fundação ABC, 1993. 96p.

SÁ, J.C.M. Calagem em solos sob plantio direto da Região dos Campos Gerais, Centro Sul do Paraná. In: SÁ, J.C.M.(Coord.) Curso sobre o Manejo do Solo no Sistema de Plantio Direto. Castro: Fundação ABC, 1995a. p.73-107.

SÁ, J.C.M. Fósforo: frações, formas de ocorrência e distribuição no perfil do solo. In: SÁ, J.C.M (Coord.) Curso sobre o manejo do solo no sistema de plantio direto. Castro: Fundação ABC, 1995b. p.229-243.

SAAB, S.;C. Caracterização da matéria orgânica em gleissolos por espectroscopias de EPR, RMN, IV e UV-visível. São Carlos, 1999, 111 p. Tese (Doutorado)- Instituto de Química de São Carlos, Universidade de São Paulo.

SANTOS, H.P.; SIQUEIRA, O.J.W. Plantio direto e rotação de culturas para a cevada: Efeitos sobre a fertilidade do solo. Revista Brasileira de Ciência do Solo, v.20, n.1, p.163-169, 1996.

SANZONOWICZ, C. Deficiência de manganês em solos do cerrado. Piracicaba: POTAFOS, 1995. 7p. (POTAFOS: Informações Agronômicas, 71).

SAVIOZZI, A.; LEVI-MINZI, R.; RIFFALDI, R.; VANNI, G. Laboratory studies on the application of wheat straw and pig slurry to soil and the resulting environmental implications. Agriculture Ecosystems Environment, v.61, p.35-43, 1997.

SCHMISEK, M.E; CIHACEK, L.J.; SWENSON, L.J. Relationships between the Mehlich III soil test extraction procedure and standard soil test methods in North Dakota. Communications in Soil Science and Plant Analysis, v.29, n.1114, p.1719$1729,1998$. 
SCHNITZER, M. Organic matter characterization. In: PAGE, A.L. (Ed.). Methods of soil analysis. Madison: ASA;SSSA, 1982. cap.30, p.581-594.

SCHNITZER, M.; CHOSH, K. Characteristics of water-soluble fulvic acid-copper and fulvic acid-iron complexes. Soil Science, v.134, n.6, p.354-363, 1982.

SELLES, F.; KOCHANN, R.A.; DENARDIN, J.E.; ZENTNER, R.P.; FAGANELLO,

A. Distribution of phosphorus fractions in a Brazilian Oxisol under different tillage systems. Soil and Tillage Research, v.44, p.23-34, 1997.

SENESI, N. Application of electron spin resonance (ESR) spectroscopy in soil chemistry. Soil Advances in Science, v.14, p.77-123, 1990.

SENESI, N.; SPOSITO, G. Residual copper (II) complexes in purified soil and sewage sludge fulvic acids: Electron spin resonance study. Soil Science Society American Journal, v.48, p.1247-1253, 1984.

SENESI, N.; SPOSITO, G. Characterization and stability of transition metal complexos of chestnut (Castanea sativa L.) leaf litter. Journal of Soil Science, v.40, p.461-472, 1989.

SENESI, N.; LOFFREDO, E. The chemistry of soil organic matter. In: SPARKS, D.L. (Ed.) Soil physical chemistry. Boca Raton: CRC Press, 1999. cap. 6, p.242-270.

SENESI, N.; BOCIAN, D.F.; SPOSITO, G. Electron spin resonance investigation of copper (II) complexation by fulvic acid extracted from sewage sludge. Soil Science Society American Journal, v.49, p.119-126, 1985a.

SENESI, N.; BOCIAN, D.F.; SPOSITO, G. Electron spin resonance investigation of copper (II) complexation by soil fulvic acid. Soil Science Society American Journal, v.49, p.114-119, 1985b.

SENESI, N.; SPOSITO, G.; HOLTZCLAW, K.M.; BRADFORD, G.R. Chemical properties of metal-humic acid fractions of a sewage sludge-amended aridisol. Journal Environmental Quality, v.18, p.186-194, 1989. 
SHANG.C; BATES, T.E. Comparison of zinc soil tests adjusted for soil and fertilizer phosphorus. Fertilizer Research, v.11, n.3, p.209-220, 1987.

SHUMAN, L.M. Fractionation method for soil micronutrients. Soil Science, v.140, n.1, p.11-16, 1985.

SHUMAN, L.M. Effect of liming on the distribution of manganese, copper, iron, and zinc among soil fractions. Soil Science Society American Journal, v.50, p.1236$1240,1986$.

SHUMAN, L.M. Effect of organic matter on the distribution of manganese, copper, iron, and zinc in soil fractions. Soil Science, v.146, n.3, p.192-198, 1988.

SHUMAN, L.M. Chemical forms of micronutrients in soil. In: MORTVEDT, J. J.; COX, F.R.; SHUMAN, L.M.; WELCH, R.M (Ed.). Micronutrients in agriculture. Madison: Soil Science Society of America, 1991.p.114-144.

SHUMAN, L.M.; HARGROVE, W.L. Effect of tillage on distribution of manganese, copper, iron and zinc in soil fractions. Soil Science Society American Journal, v.49, n.5, p.117-1121, 1985.

SHUMAN, L.M.; McCRACKEN, D.V. Tillage, and poultry litter effects on plant concentrations of zinc, manganese, and copper. Journal of Plant Nutrition, v.22, n.3, p.609-620, 1999a.

SHUMAN, L.M.; McCRACKEN, D.V. Tillage, and poultry litter effects on soil zinc, manganese, and copper. Communication in Soil Science and Plant Analysis, v.30, n.9/10, p.1267-1277, 1999b.

SIDIRAS, N.; DERPSCH, R.; MONDARDO, A. Influência de diferentes métodos de preparo do solo na variação da umidade e rendimento da soja, em Latossolo Roxo distrófico (Oxisol). Revista Brasileira de Ciência do Solo, v.7, n.1, p.103-106, 1983.

SIDIRAS, N.; PAVAN, M.A. Influência do sistema de manejo do solo no seu nível de fertilidade. Revista Brasileira de Ciência do Solo, v.9, n.2, p.249-254, 1985. 
SILVA, M.M. Fontes e modos de aplicação de manganês na nutrição, produção e qualidade da soja, cultivada em solo de cerrado. Piracicaba, 2000. 174p. Tese (Doutorado)- Escola Superior de Agricultura "Luiz de Queiroz", Universidade de São Paulo.

SIMS, J.L.; PATRICK, J.W.H. The distribution of micronutrient cations in soil under conditions of varying redox potential and $\mathrm{pH}$. Soil Science Society American Journal, v42, p.258-262, 1978.

SIMS, J.T. A comparison of Mehlich I and Mehlich III extractants as predictors of manganese, copper and zinc availability in four Delaware soils. Communications in Soil Science and Plant Analysis, v.16, n. 10, p.1039-1052, 1985.

SIMS, J.T. Soil pH effects on the distribution and plant availability of manganese, copper, and zinc organic matter in soil fractions. Soil Science Society American Journal, v.50, p.367-373, 1986.

SINGER, L.S. Synthetic ruby as a secondary standard for the measurement of intensities in Electron Paramagnetic Resonance. Journal Applied Physics, v.30, p.1463-1464, 1959.

STEVENSON, F.J. Humus chemistry: Genesis, composition, reactions. New York: John Wiley, 1994. 496p.

SWIFT, R.S. Organic matter characterization. In: SPARKS, D. (Ed.). Methods of Soil Analysis. Madison: SSSA, 1996. cap. 3, p. 1011-1069.

TANAKA, R.T.; MASCARENHAS, H.A.A.; BULISANI, E.A. Manganese deficiency in soybean induced by excess lime. Better Crops International, v.9, n.2, p.7, 1993.

TESSIER, A.; CAMPBELL, P.G.C.; BISSON, M. Sequencial extraction procedure for especiation of particulate trace metais. Analysis Chemical, v.51, p.844-851, 1979.

TISDALE, S.L.; NELSON, W.L.; BEATON, J.D. Soil Fertility and Fertilizers. New York: Macmillan, 1985.754p. 
VALADARES, J.M.A.S.; CAMARGO, O.A. Manganês em solos do Estado de São Paulo. Revista Brasileira de Ciência do Solo, v.7, p.123-130, 1983.

VIEIRA, M.J.; COGO, N.P.; CASSOL, E.A. Perdas por erosão, em diferentes sistemas de preparo do solo, para a cultura da soja (Glycine max (L) merr.) em condições de chuva simulada. Revista Brasileira de Ciência do Solo, v.2, n.3, p.209-214, 1978.

VOCASEK, F.F.; FRIEDERIC, K.S. Soil micronutrient extraction by Mehlich 3 compared to $\mathrm{CaCl}_{2}$-DTPA. Communications in Soil Science and Plant Analysis, v.25, n.910, p.1583-1593, 1994.

VOSS, M.; SIDIRAS, N. Nodulação da soja em plantio direto em comparação com o plantio convencional. Pesquisa Agropecuária Brasileira, v.20, n.2, p.775-782, 1985.

WALWORTH, J.L.; GAVLAK, R.G.; PANCIERA, M.T. Mehlich 3 extractant for determination of available $\mathrm{B}, \mathrm{Cu}, \mathrm{Fe}, \mathrm{Mn}$, and $\mathrm{Zn}$ in cryic Alaskan soils. Canadian Journal of Soil Science, v.72, n. 4, p.517-526, 1992.

WANG, P.; QU, E.; LI, Z.; SUMAN, L.M. Fractions and availability of nickel in Loessial soil amended with sewage or sewage sludge. Journal Environment quality, v.26, p. 795-801, 1997.

WARMAN, P.R. The response of fluecured tobacco and fertility status of a sandy loam soil to $\mathrm{Mg}, \mathrm{P}$, and $\mathrm{Zn}$ fertilization. Communications in Soil Science and Plant Analysis, v.23, n.1720, p.2283-2294, 1992.

WEAR, J.L., SOMMER, A.L. Acid-extractable zinc of soils in relation to the occurrence of zinc deficiency symptoms of corn: a method analysis. Soil Science Society American, v.12, p.143-144. 1948.

ZALIDIS, G.; BARBAYIARINIS, N.; MATSI, T. Forms and distribution of heavy metals in soils of the axios Delta of Northern Greece. Communication in Soil Science and Plant Analysis, v.30, n.5/6, p.817-827, 1999. 
ZHANG, M.; ALVA, A.K.; LI,Y.C.; CALVERT, D.V. Chemical association of Cu, Mn, and $\mathrm{Pb}$ in selected sandy citrus soils. Soil Science, v.162, n.3, p.181-188, 1997a.

ZHANG, M.; ALVA, A.K.; LI,Y.C.; CALVERT, D.V. Fractionation of iron, manganese, aluminum, and phosphorus in selected sandy soil under citrus production. Soil Science Society American Journal, v.61, p.794-801, 1997 b. 
APÊNDICE 
Tabela 1. Teores de $\mathrm{Cu}$ em diferentes frações e profundidades, em um LATOSSOLO VERMELHO, submetido a diferentes métodos de preparo (médias de três repetições).

\begin{tabular}{|c|c|c|c|c|c|c|}
\hline \multirow{2}{*}{$\begin{array}{l}\text { Sistema de } \\
\text { preparo }\end{array}$} & \multicolumn{4}{|c|}{ Frações } & \multirow{2}{*}{$\begin{array}{c}\text { Soma das } \\
\text { frações }\end{array}$} & \multirow[t]{2}{*}{ Total } \\
\hline & Trocável & Orgânica & Óxidos & Residual & & \\
\hline & \multicolumn{6}{|c|}{$\mathrm{mg} \mathrm{kg}^{-1}$} \\
\hline & \multicolumn{6}{|c|}{$0,00-0,05 m$} \\
\hline SSD $^{1}$ & 0 & 1,92 & 5,95 & 19,50 & 27,4 & 28,5 \\
\hline SSD/prep & 0 & 2,01 & 6,12 & 19,40 & 27,5 & 28,9 \\
\hline $\mathbf{P M}$ & 0 & 2,08 & 6,05 & 19,15 & 27,3 & 27,3 \\
\hline SSC & 0 & 1,68 & 6,34 & 18,83 & 27,0 & 27,2 \\
\hline \multicolumn{7}{|c|}{$0,05-0,10 \mathrm{~m}$} \\
\hline SSD & 0 & 1,38 & 6,54 & 19,33 & 27,2 & 28,7 \\
\hline SSD/prep & 0 & 1,66 & 6,56 & 19,33 & 27,6 & 28,3 \\
\hline PM & 0 & 1,74 & 6,15 & 19,25 & 27,1 & 27,9 \\
\hline SSC & 0 & 1,76 & 6,53 & 18,75 & 27,0 & 28,9 \\
\hline \multicolumn{7}{|c|}{$0,10-0,20 \mathrm{~m}$} \\
\hline SSD & 0 & 1,16 & 6,30 & 19,33 & 26,8 & 29,3 \\
\hline SSD/prep & 0 & 1,23 & 6,55 & 19,75 & 27,5 & 29,9 \\
\hline PM & 0 & 1,41 & 6,38 & 19,84 & 27,6 & 28,1 \\
\hline SSC & 0 & 1,56 & 6,32 & 19,44 & 27,3 & 27,3 \\
\hline
\end{tabular}

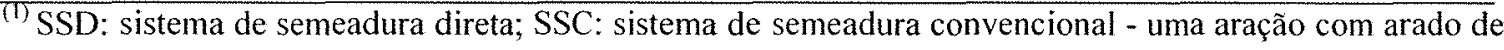
discos $(\cong 0,20 \mathrm{~m})$ e uma gradagem com grade niveladora $(\cong 0,10 \mathrm{~m})$, antes dos cultivos de verão e inverno a cada ano; PM: preparo mínimo - uma gradagem com grade aradora $(\cong 0,17 \mathrm{~m})$ e duas com grade niveladora $(\cong 0,10 \mathrm{~m})$, antes dos cultivos de verão e inverno de cada ano; SSD/prep.: SSD com escarificação $(\cong 0,30 \mathrm{~m})$ a cada três anos (inverno). 
Tabela 2. Teores de Fe em diferentes frações e profundidades, em um LATOSSOLO VERMELHO, submetido a diferentes métodos de preparo (médias de três repetições).

\begin{tabular}{|c|c|c|c|c|c|c|}
\hline \multirow{2}{*}{$\begin{array}{l}\text { Sistema de } \\
\text { preparo }\end{array}$} & \multicolumn{4}{|c|}{ Frações } & \multirow{2}{*}{$\begin{array}{c}\text { Soma das } \\
\text { frações }\end{array}$} & \multirow[t]{2}{*}{ Total } \\
\hline & Trocável & Orgânica & Óxidos & Residual & & \\
\hline & \multicolumn{2}{|c|}{ mg kg ${ }^{-1}$} & $\ldots$ & $\mathrm{kg}^{-1}-\ldots$ & -- & \\
\hline & \multicolumn{6}{|c|}{$0,00-0,05 \mathrm{~m}$} \\
\hline SSD $^{1}$ & 0 & 11,65 & 49,20 & 5,65 & 54,9 & 54,3 \\
\hline SSD/prep & 0 & 15,71 & 47,67 & 5,55 & 53,2 & 55,4 \\
\hline PM & 0 & 14,81 & 48,52 & 4,52 & 53,1 & 51,6 \\
\hline SSC & 0 & 9,73 & 48,69 & 5,12 & 53,8 & 57,5 \\
\hline & \multicolumn{6}{|c|}{$0,05-0,10 \mathrm{~m}$} \\
\hline SSD & 0 & 9,0 I & 48,60 & 4,92 & 53,5 & 56,2 \\
\hline SSD/prep & 0 & 11,86 & 47,58 & 4,81 & 52,4 & 56,0 \\
\hline $\mathbf{P M}$ & 0 & 11,92 & 47,28 & 5,10 & 52,4 & 51,6 \\
\hline SSC & 0 & 9,93 & 52,05 & 4,93 & 57,0 & 54,9 \\
\hline \multicolumn{7}{|c|}{$0,10-0,20 \mathrm{~m}$} \\
\hline SSD & 0 & 8,83 & 48,83 & 5,14 & 54,0 & 56,4 \\
\hline SSD/prep & 0 & 8,83 & 48,51 & 5,77 & 54,3 & 54,8 \\
\hline PM & 0 & 7,89 & 48,01 & 5,44 & 53,5 & 56,9 \\
\hline SSC & 0 & 9,47 & 51,29 & 4,56 & 55,9 & 56,9 \\
\hline
\end{tabular}

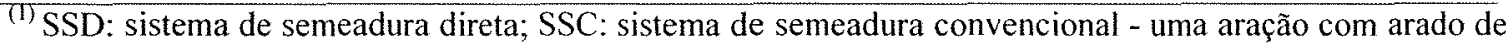
discos $(\cong 0,20 \mathrm{~m})$ e uma gradagem com grade niveladora $(\cong 0,10 \mathrm{~m})$, antes dos cultivos de verão e inverno a cada ano; PM: preparo mínimo - uma gradagem com grade aradora $(\cong 0,17 \mathrm{~m})$ e duas com grade niveladora $(\cong 0,10 \mathrm{~m})$, antes dos cultivos de verão e inverno de cada ano; SSD/prep.: SSD com escarificação ( $\cong 0,30 \mathrm{~m})$ a cada três anos (inverno). 
Tabela 3. Teores de Mn em diferentes frações e profundidades, em um LATOSSOLO VERMELHO, submetido a diferentes métodos de preparo (médias de três repetições).

\begin{tabular}{|c|c|c|c|c|c|c|}
\hline \multirow{2}{*}{$\begin{array}{l}\text { Sistema de } \\
\text { preparo }\end{array}$} & \multicolumn{4}{|c|}{ Frações } & \multirow{2}{*}{$\begin{array}{c}\text { Soma das } \\
\text { frações }\end{array}$} & \multirow[t]{2}{*}{ Total } \\
\hline & Trocável & Orgânica & Óxidos & Residual & & \\
\hline & \multicolumn{6}{|c|}{$\mathrm{mg} \mathrm{kg}^{-1}$} \\
\hline & \multicolumn{6}{|c|}{$0,00-0,05 \mathrm{~m}$} \\
\hline SSD $^{\prime}$ & 1,81 & 22,02 & 52,23 & 38,69 & 114,8 & 111,1 \\
\hline SSD/prep & 2,49 & 17,21 & 51,22 & 37,52 & 108,4 & 110,4 \\
\hline PM & 2,04 & 16,31 & 52,58 & 36,12 & 107,1 & 104,2 \\
\hline \multirow[t]{2}{*}{ SSC } & 2,07 & 12,32 & 51,45 & 39,40 & 105,2 & 104,9 \\
\hline & \multicolumn{6}{|c|}{$0,05-0,10 \mathrm{~m}$} \\
\hline SSD & 1,55 & 15,21 & 51,53 & 35,54 & 103,8 & 106,9 \\
\hline SSD/prep & 2,17 & 14,94 & 52,20 & 36,75 & 106,1 & 109,9 \\
\hline PM & 1,72 & 15,33 & 52,51 & 35,98 & 105,5 & 102,9 \\
\hline \multirow[t]{2}{*}{ SSC } & 1,59 & 11,28 & 51,61 & 36,23 & 100,7 & 103,1 \\
\hline & \multicolumn{6}{|c|}{$0,10-0,20 \mathrm{~m}$} \\
\hline SSD & 1,18 & 12,31 & 50,77 & 38,42 & 102,7 & 101,4 \\
\hline SSD/prep & 1,28 & 11,50 & 51,93 & 36,99 & 101,7 & 107,1 \\
\hline PM & 1,24 & 11,52 & 53,28 & 37,71 & 103,8 & 109,6 \\
\hline SSC & 1,60 & 11,88 & 53,14 & 36,46 & 103,0 & 103,0 \\
\hline
\end{tabular}

${ }^{(1)}$ SSD: sistema de semeadura direta; SSC: sistema de semeadura convencional - uma aração com arado de discos $(\cong 0,20 \mathrm{~m})$ e uma gradagem com grade niveladora $(\cong 0,10 \mathrm{~m})$, antes dos cultivos de verão e inverno a cada ano; PM: preparo mínimo - uma gradagem com grade aradora $(\cong 0,17 \mathrm{~m})$ e duas com grade niveladora $(\cong 0,10 \mathrm{~m})$, antes dos cultivos de verão e inverno de cada ano; SSD/prep.: SSD com

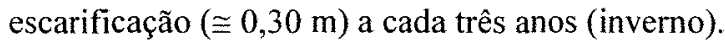


Tabela 4. Teores de $\mathrm{Zn}$ em diferentes frações e profundidades, em um LATOSSOLO VERMELHO, submetido a diferentes métodos de preparo (médias de três repetições).

\begin{tabular}{|c|c|c|c|c|c|c|}
\hline \multirow{2}{*}{$\begin{array}{l}\text { Sistema de } \\
\text { preparo }\end{array}$} & \multicolumn{4}{|c|}{ Frações } & \multirow{2}{*}{$\begin{array}{c}\text { Soma das } \\
\text { frações }\end{array}$} & \multirow[t]{2}{*}{ Total } \\
\hline & Trocável & Orgânica & Óxidos & Residual & & \\
\hline & \multicolumn{6}{|c|}{$\mathrm{mg} \mathrm{kg}^{-1}$} \\
\hline & \multicolumn{6}{|c|}{$0,00-0,05 \mathrm{~m}$} \\
\hline SSD $^{1}$ & 0 & 3,80 & 12,89 & 27,44 & 44,1 & 47,8 \\
\hline SSD/prep & 0 & 3,90 & 14,40 & 24,60 & 42,9 & 44,5 \\
\hline PM & 0 & 3,59 & 12,89 & 24,44 & 40,9 & 45,9 \\
\hline SSC & 0 & 4,16 & 15,46 & 25,36 & 45,0 & 49,0 \\
\hline \multicolumn{7}{|c|}{$0,05-0,10 \mathrm{~m}$} \\
\hline SSD & 0 & 2,78 & 13,74 & 25,49 & 42,0 & 44,3 \\
\hline SSD/prep & 0 & 4,53 & 15,21 & 24,42 & 44,2 & 48,7 \\
\hline $\mathbf{P M}$ & 0 & 3,73 & 12,74 & 24,50 & 41,0 & 44,2 \\
\hline SSC & 0 & 2,31 & 14,03 & 25,25 & 41,6 & 46,5 \\
\hline \multicolumn{7}{|c|}{$0,10-0,20 \mathrm{~m}$} \\
\hline SSD & 0 & 1,69 & 11,73 & 24,81 & 38,2 & 43,2 \\
\hline SSD/prep & 0 & 1,44 & 12,73 & 26,55 & 40,7 & 44,8 \\
\hline PM & 0 & 1,21 & 13,08 & 25,60 & 39,9 & 42,9 \\
\hline SSC & 0 & 3,00 & 13,50 & 26,66 & 43,2 & 44,1 \\
\hline
\end{tabular}

(I) SSD: sistema de semeadura direta; SSC: sistema de semeadura convencional - uma aração com arado de discos $(\cong 0,20 \mathrm{~m})$ e uma gradagem com grade niveladora $(\cong 0,10 \mathrm{~m})$, antes dos cultivos de verão e inverno a cada ano; PM: preparo mínimo - uma gradagem com grade aradora $(\cong 0,17 \mathrm{~m})$ e duas com grade niveladora $(\cong 0,10 \mathrm{~m})$, antes dos cultivos de verão e inverno de cada ano; SSD/prep.: SSD com escarificação $(\cong 0,30 \mathrm{~m})$ a cada três anos (inverno). 